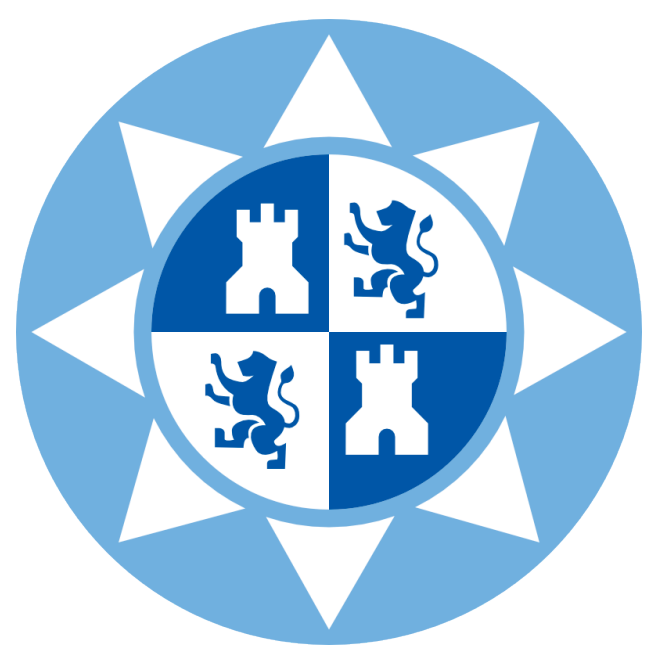

Universidad Politécnica de Cartagena

Departamento de Electrónica, Tecnología de Computadoras y Proyectos

\title{
Computing tools applied to the analysis of performance and sustainability of photovoltaic systems
}

Lucía Serrano Luján 



\title{
UNIVERSIDAD POLITÉCNICA DE CARTAGENA
}

Departamento de Electrónica, Tecnología de Computadores y Proyectos

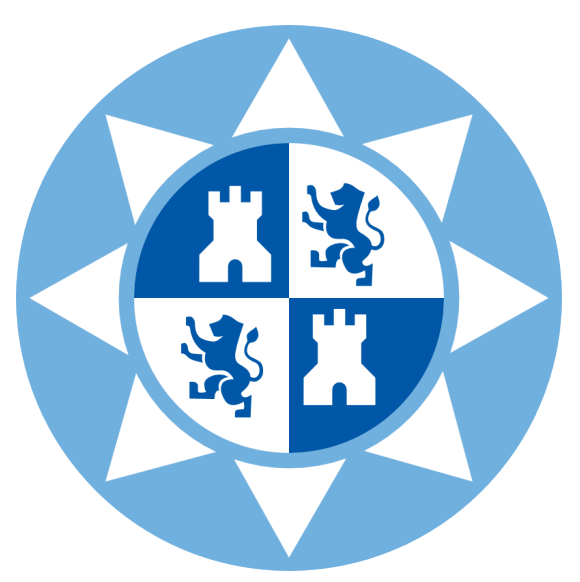

Computing tools applied to the analysis of performance and sustainability of photovoltaic systems

\section{Lucía Serrano Luján}

\author{
Dirigida por: \\ Dr. Antonio Urbina Yeregui \\ Dra. Judith A. Cherni
}





\section{CONFORMIDAD DE DEPÓSITO DE TESIS DOCTORAL POR LA COMISIÓN ACADÉMICA DEL PROGRAMA}

D/Da. ----Antonio Urbina Yeregui------------------, Presidente/a de la Comisión Académica del Programa-Energías Renovables y Eficiencia Energética

\section{INFORMA: 。}

Que la Tesis Doctoral titulada, "-Computing tools applied to the analysis of performance and sustainability of photovoltaic systems--", ha sido realizada, dentro del mencionado programa de doctorado, por D/Da .-Lucía Serrano Luján-----,

bajo la dirección y supervisión del Dr/ Dra.-Antonio Urbina Yeregui --.

En reunión de la Comisión Académica de fecha -25-10-2013-, visto que en la misma se acreditan los indicios de calidad correspondientes y la autorización del Director de la misma, se acordó dar la conformidad, con la finalidad de que sea autorizado su depósito por la Comisión de Doctorado.

La Rama de conocimiento por la que esta tesis ha sido desarrollada es:

Ciencias

Ciencias Sociales y Jurídicas

Ingeniería y Arquitectura

En Cartagena, a 25 de octubre de 2013

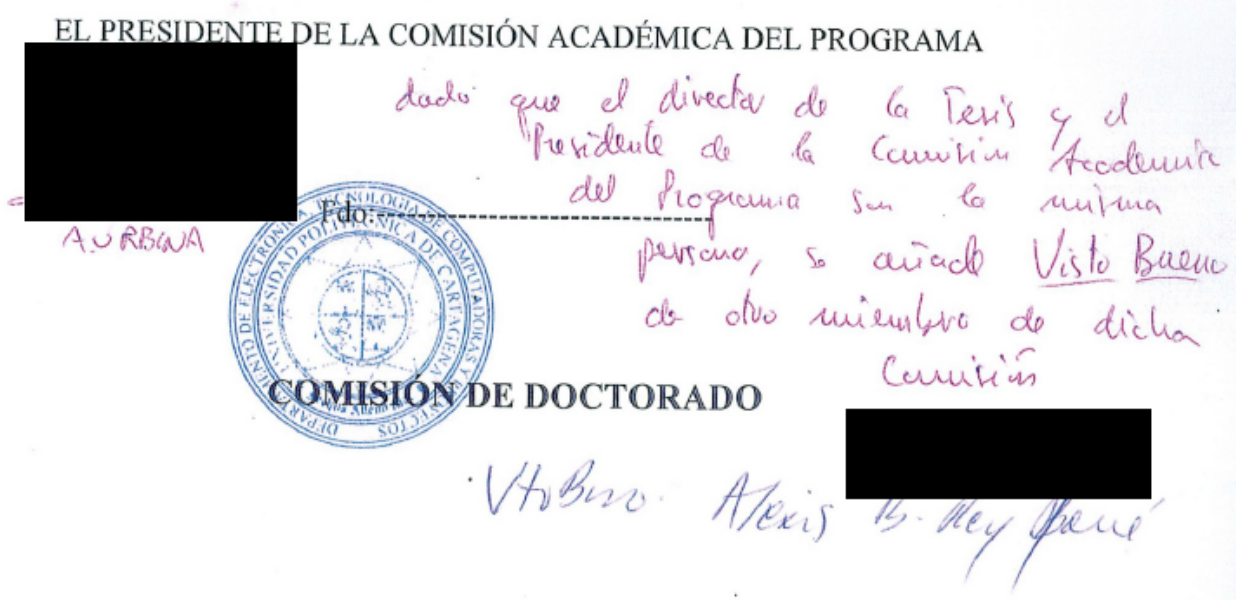



Universidad

Politécnica

de Cartagena

\section{CONFORMIDAD DE SOLICITUD DEAUTORIZACIÓN DE DEPÓSITO DE} TESIS DOCTORAL POR EL/LA DIRECTOR/A DE LA TESIS

JUDITH A. CHERNI y ANTONIO URBINA YEREGUI, Directores de la Tesis doctoral "COMPUTING TOOLS APPLIED TO THE ANALISYS OF PERFORMANCE AND SUSTAINABILITY OF PHOTOVOLTAIC SYSTEMS"

\section{INFORMA:}

Que la referida Tesis Doctoral, ha sido realizada por D/D ${ }^{a}$. LUCÍA SERRANO LUJÁN, dentro del programa de doctorado en Energías Renovables y Eficiencia Energética, dando mi conformidad para que sea presentada ante la Comisión de Doctorado para ser autorizado su depósito.

La rama de conocimiento en la que esta tesis ha sido desarrollada es:

Ciencias

Ciencias Sociales y Jurídicas

$\checkmark$ Ingeniería y Arquitectura

En Cartagena, a 25 de Octubre de 2013

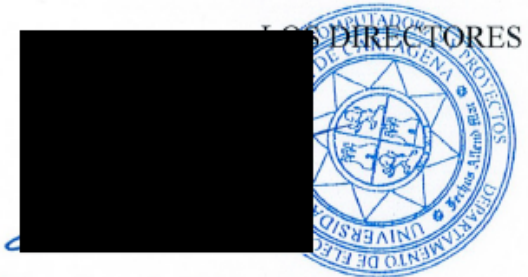

Fdo.: Antonio Urbina Yeregui

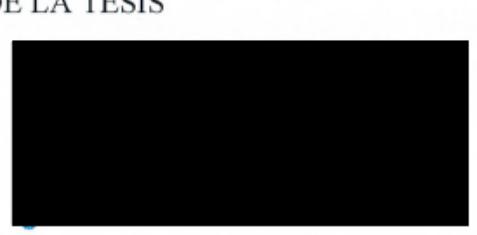

Fdo. Judith A. Cherni

\section{COMISIÓN DE DOCTORADO}





\section{Acknowledgements}

First of all, I would like to express my deepest gratitude to my advisor Dr Antonio Urbina who guided me and gave me his unconditional support throughout this research adventure. I would like to extend my thanks to my co-supervisor Dr Judith A. Cherni for her warm reception at Imperial College, who was resourceful and very helpful.

Special thanks go to my close friends and old workmates Dr Nieves Espinosa and Dr Rafael García-Valverde, who were very patient with their new colleague at work when I started, and helped me in many challenging and hard situations, being my compass when I felt lost. You both are inspiring.

I would like to thank Dr Jose Manuel Cadenas as well, from the University of Murcia, who patiently contributed to the third chapter of this thesis.

Of course I have to thank my current workmates at the University of Cartagena: Jose, Chocky, Juanmi, Javi, Gino, Juan Gabriel, Mamen and Paco, thank you for your company. And my colleagues at the University of Murcia: Juani, Astrid, Jojo, Miguel Ángel, Manu, $\mathrm{M}^{\mathrm{a}}$ Carmen, Teddy and Fran, thank you for the very fun and sweet coffees.

I cannot forget the lovable people that made my days a bit easier, such as Rodrigo, Maruja, Carmen, Pilar, Puri, Léter, Jose Luis, Antonio, Josefa, Lolica, Alfonso, Raúl... and all the people who at one time to another gave me energy.

Finally, of course, I wish to thank my family, Ana $\mathrm{M}^{\mathrm{a}}$, Paco and Ana. Thank you for always being there, and also thank to my brother-in-law, Dr Matthew Livesey, who helped me with my English in the redaction of this scientific work. 



\section{Abstract}

This $\mathrm{PhD}$ dissertation focuses on the evaluation of the environmental impact of different photovoltaic technologies, with special focus on the benefits of replacing conventional fossil fuels with clean electricity production from photovoltaic systems. Emissions of $\mathrm{CO}_{2}$ are highlighted as the main reason of climate change. Human life style (transport, industry, etc.) has to be changed in order to follow the IEA directives. Sustainable energy has an important role to reduce the use of fossil fuels as energy source. Growing economies depend strongly on fossil fuels, and therefore, changing its energy policy are key to slow down global warming. The study follows a detailed methodology based on "Life Cycle Analysis" in combination with technical approaches to monitor working PV facilities and therefore provides quantitative results in term of avoided emissions and the potential for climate change mitigation of PV in different context, ranging from building integration of grid-connected systems to electrification of rural livelihoods.

Electricity production is responsible for $32 \%$ of total global fossil fuel consumption. In order to mitigate climate change, several countries have already established protocols aimed at the reduction of green-house-gases emissions (Kyoto protocol) and promoted the increase of renewable energy contribution into the energy mix. Development of renewable energies has been continuously growing despite the economic crisis in recent years. Wind and photovoltaic technologies excel in progress and are considered as a reliable future sustainable source of electricity. This thesis is a contribution to the improvement of performance and long term sustainability of photovoltaic systems provided by the use of computing tools and several methodologies which have been applied to different case studies, ranging from the monitoring and experimental evaluation of a photovoltaic grid connected system to the electrification of a rural livelihood.

Standardised Life Cycle Assessment (LCA) methodology is applied during this dissertation to measure the environmental impact of a $222 \mathrm{kWp}$ CdTe grid-connected photovoltaic generator located at University of Murcia. Environmental benefits of building integration (in the roof of a parking lot) were identified. Constant monitoring of the system allowed us to get real information about its performance. The Energy Pay Back Time of the system was found to be 2.06 years and 1.69 when a recycling scenario is assumed. Having a $\mathrm{CO}_{2}$ emission factor is $6.33 \mathrm{gCO}_{2} / \mathrm{kWh}$ and $5.38 \mathrm{gCO}_{2} / \mathrm{kWh}$ respectively.

LCA is also applied to measure avoided emissions of $1 \mathrm{~kW}_{\mathrm{p}}$ of three photovoltaic technologies: thin-film (CdTe), c-Silicon and Organic polymeric technologies, modelling sixteen different combinations of geographical locations where the modules could be manufactured and/or installed, respectively. The optimum geographical 
combination, manufacturer-installer relationship, that is, a geographical "allocation" that provides the higher avoided $\mathrm{CO}_{2}$ emissions per $\mathrm{kWp}$ of installed $\mathrm{PV}$ capacity is proposed: Brazil-South Africa, Colombia-South Africa. Brazil-Australia, ColombiaAustralia, etc.

Finally, in order to decide which energy technology can supply electricity to isolated rural areas in developing countries, an existing multi-criteria decision software (SUREDSS) which takes into account the impacts on environmental, financial, human, nature and physical assets has been employed. The global environmental impact of photovoltaic technology was added to this software, therefore extending the information provided to the decision maker. The software was applied to a case study in Cuba, and the results showed that the considered photovoltaic technologies are the best energy alternative that maximizes the benefits on the five capitals or assets of the rural community, being better solution than diesel generator.

This $\mathrm{PhD}$ dissertation draws on the importance of PV technologies in our society as solution to slow down the greenhouse gas effect. It provides quantitative assessment by evaluating its environmental impacts and the benefits of replacing fossil fuel consumption by clean electricity from the solar resource. The results are based in real case studies and collection of experimental data which allowed us to calculate the performance of the systems and its potential for climate change mitigation. 


\section{Contents}

CHAPTER 1 INTRODUCTION AND MOTIVATION .............................................

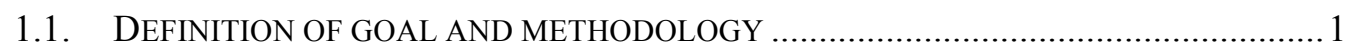

1.2. Motivation: ClimATE CHANGE AND WORLD ENERGY DEMAND .......................... 3

1.3. Photovoltaic Technology for Climate Change Mitigation .................... 8

1.4. DECISION-MAKING ON SUSTAINABLE ENERGIES ............................................... 19

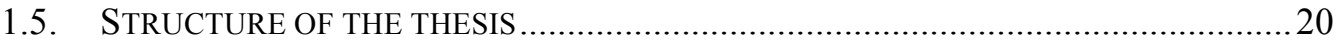

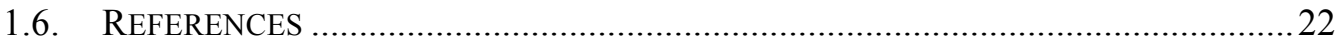

CHAPTER 2 METHODOLOGY AND DATA COLLECTION …................25

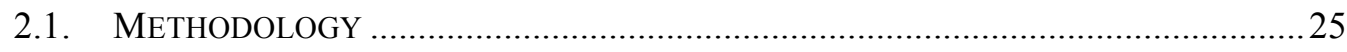

2.2. DESCRIPTION OF THE PV GENERATOR: $222 \mathrm{KWP}$ CDTE PARKING INTEGRATED GRID-

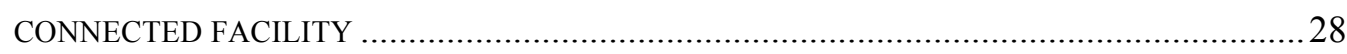

2.3. DATA COLLECTION. MONITORING ENVIRONMENTAL AND SYSTEM PARAMETERS. 35

2.3.1 Data Acquisition System.............................................................. 36

2.3.2 Permanent Data Storage ............................................................... 41

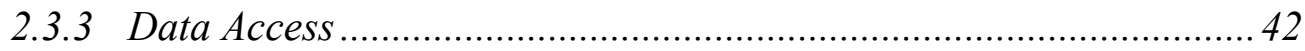

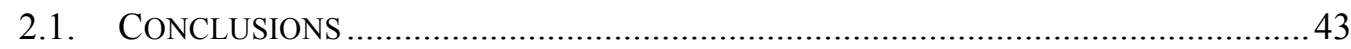

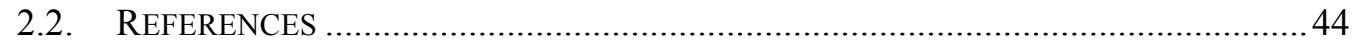

\section{CHAPTER 3 COMPUTATIONAL INTELLIGENCE APPLIED TO}

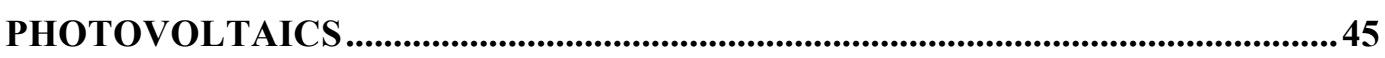

3.1 INTRODUCTION. LEARNING-COMPUTING ALGORITHMS AS A SOLUTION TO RENEWABLES

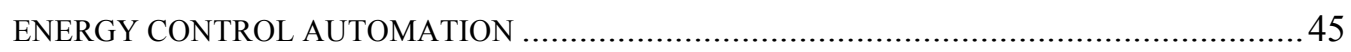

3.2 DATA-MINING TO FIND PHOTOVOLTAIC PARAMETERS RELATIONS ......................48

3.3 ApPlying Computational Learning TeChniQues. Methodology ............57

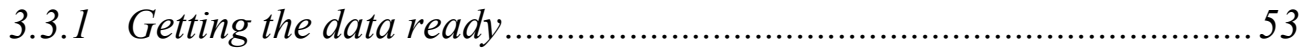

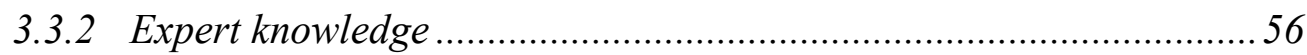

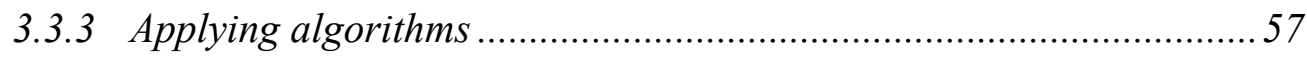

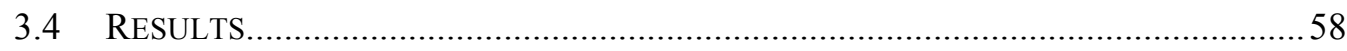




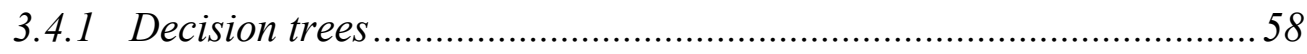

3.4.2 Managing without environmental information ...............................60 60

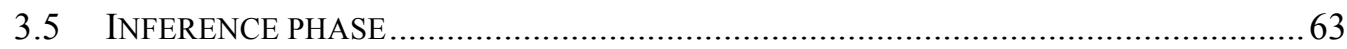

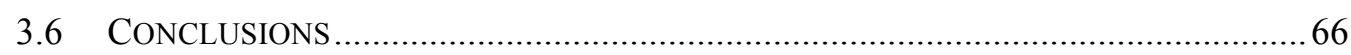

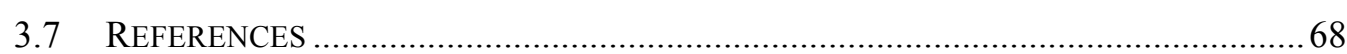

\section{CHAPTER 4 LIFE CYCLE ASSESSMENT APPLIED TO PHOTOVOLTAICS 71}

4.1 INTRODUCTION. ABOUt LIFE CYCLE ASSESSMENT (LCA) ................................... 71

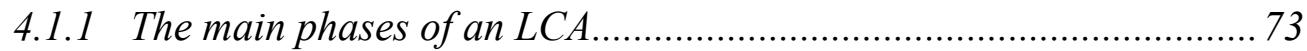

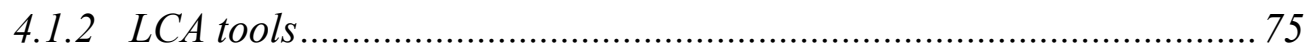

4.2 LIFE CYCLE ASSESSMENT APPLIED TO PHOTOVOLTAIC TECHNOLOGIES .............78

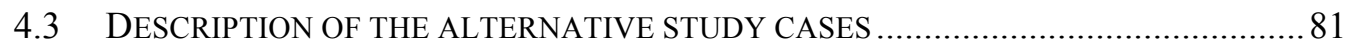

4.3.1 Case 1 (PV\&PK): 222kWp CdTe parking integrated grid-connected facility 82

4.3.2 Case 2 (PK_ONLY): Same-size parking without PV.... 84

4.3.3 Case 3 (PV_ONLY): 222kWp ground-mounted CdTe grid-connected facility 85

4.4 LIFE-CYCLE ASSESSMENT APPLIED TO THE PARKING-INTEGRATED PHOTOVOLTAIC

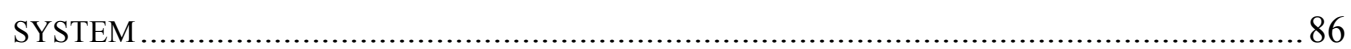

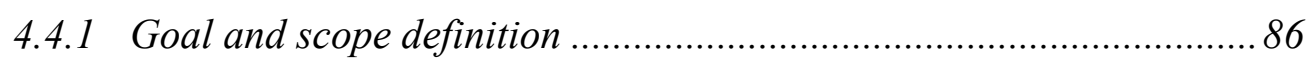

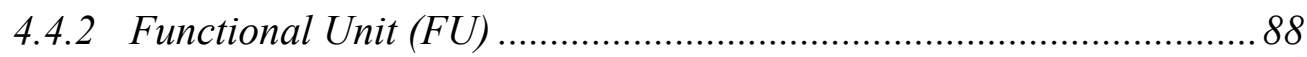

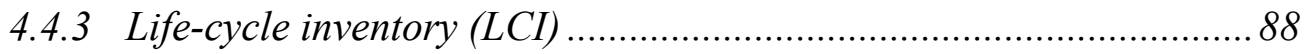

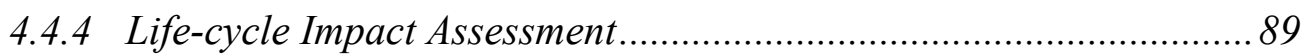

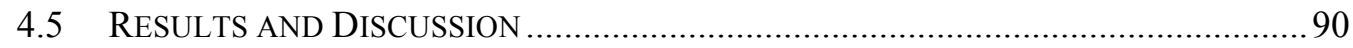

3.5.1 Material, energy and emissions inventory ....................................91

3.5.2 Life-cycle impact assessment (LCIA) ..............................................93

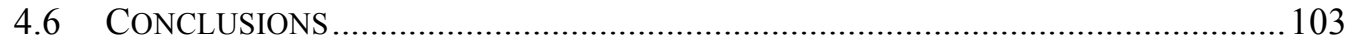

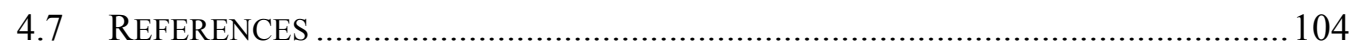

CHAPTER 5 GEOGRAPHICAL DEPENDENCE OF PHOTOVOLTAIC

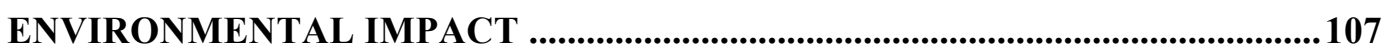


5.1 INTRODUCTION. GEOGRAPHICAL DEPENDENCE OF THE ENVIRONMENTAL IMPACT OF A PHOTOVOLTAIC GENERATOR.

5.2 HighLIGHTING GEOGRAPHICAL DEPENDENCE: LCA APPLIED TO 1KWP PV

TECHNOLOGIES. 109

5.2.1 Appling LCA methodology with a global approach 110

5.2.2 Results: EPBT, ERF and avoided emissions 114

5.3 CONCLUSIONS 128

5.4 REFERENCES 129

\section{CHAPTER 6 BEYOND TECHNICAL SUSTAINABILITY: A GLOBAL APPROACH} TO PV SYSTEMS . 131

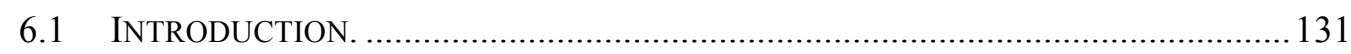

6.2 DECISION SOFTWARE TOOLS THAT ASSIST ELECTRIFICATION............................133

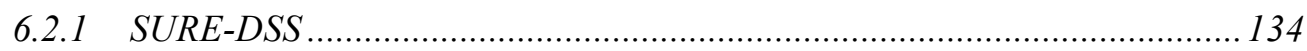

6.2.2 Information technology for rural areas: the SURE-DSS .......................... 135

6.2.3 Adding global environmental impact to SURE ........................................ 138

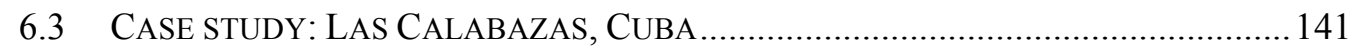

6.3.1 Data collection and analysis of community baseline ................................ 141

6.3.2 Results: providing solar electricity to the community ............................... 144

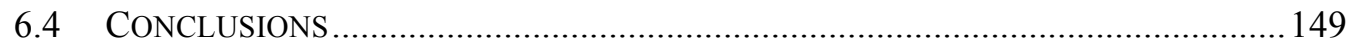

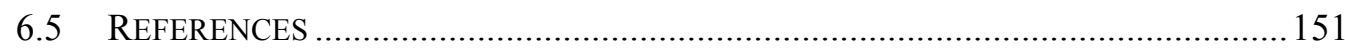

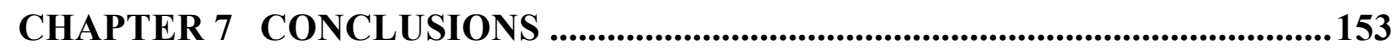

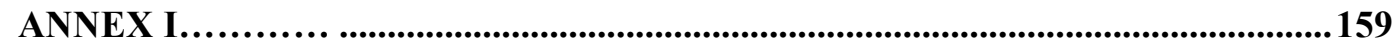

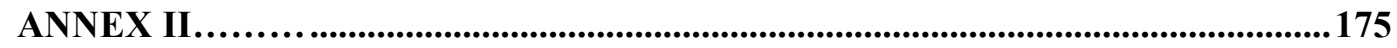





\section{LIST OF FIGURES}

FIGURE 1.1 WORLD TOTAL PRIMARY ENERGY SUPPLY FROM 1971 TO 2011 BY REGION (Mtoe)

FIGURE 1.2 INFLUENCE OF SELECTED COUNTRIES AND COUNTRY GROUPS ON GLOBAL CHANGES IN $\mathrm{CO}_{2}$ EMISSIONS FROM 1971 TO 2008. ROW: REST OF WORLD. 4 FIGURE 1.3 SHARES OF WORLD PRIMARY ENERGY CONSUMPTION (\%) 5 FIGURE 1.4 CORRELATION BETWEEN THE UNITED NATIONS' HUMAN DEVELOPMENT INDEX (HDI) AND ANNUAL PER-CAPITA ELECTRICITY CONSUMPTION 7 FIGURE 1.5 RENEWABLES SHARE OF POWER GENERATION BY REGION PERCENTAGE FIGURE 1.6 HISTORICAL PV MARKET VS. PRODUCTION BY REGION (\%) 10 FIGURE 1.7 NET GENERATION CAPACITY ADDED IN THE EU 27 2000-2012 (GW) 11 FIGURE 1.8 CRYSTALLINE SILICON MODULES INSTALLED AT UNIVERSITY OF MURCIA

FIGURE 1.9 PV MODULES PRODUCTION CAPACITY UNTIL 2017 (MW; \%) 13 FIGURE 1.10 EVOLUTION OF GLOBAL PV CUMULATIVE INSTALLED CAPACITY 2000-2012 (MW) PHOTOVOLTAIC EVOLUTION 14 FIGURE 1.11 SOLAR CELL TECHNOLOGY EFFICIENCIES

FIGURE 1.12. COST-EFFICIENCY ANALYSIS FOR FIRST-GENERATION (1), SECONDGENERATION (2) AND THIRD-GENERATION (3) OF PHOTOVOLTAIC TECHNOLOGIES.

FIGURE 1.13. NON C-SI PV PRODUCTION CAPACITY UNTIL 2017 (MW) 18 FIGURE 2.1 222KWP CDTE PARKING INTEGRATED GRID-CONNECTED FACILITY 28 FIGURE 2.2. GROUPS OF PV MODULES FORMING THE PV GENERATOR, GROUP ORGANIZATION AND INVERTER IDENTIFICATION................................................30 FIGURE 2.3. ELECTRICAL SCHEME OF $222 \mathrm{kWp}$ CdTe PV GENERATOR ............................34 FIGURE 2.4. RELATIONS BETWEEN DATA ACQUISITION SYSTEM, PERMANENT DATA

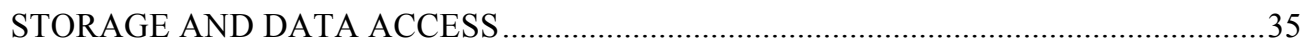

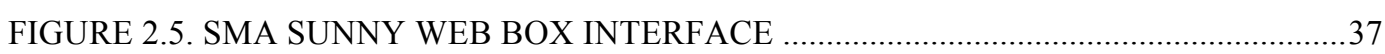
FIGURE 2.6. XML FORMAT OF PACKAGES SENT BY INVERTER AND SENSORS ...........40 FIGURE 3.1 RELATION BETWEEN PR OF THE WHOLE PV INSTALLATION AND PR OF FOUR GROUP OF MODULES.

FIGURE 3.2 FRECUENCY OF PERFORMANCE RATIOS OBTAINED FOR EACH INVERTER 51 FIGURE 3.3 POWER OUTPUT OF THREE INVERTERS AND THE TOTAL POWER OUTPUT OF THE PV SYSTEM DURING TEN HOURS. A SHADOW AFFECTS INVERTER I.2.1 IN THE MORNING 
FIGURE 3.4 RELATION BETWEEN INPUT AND OUTPUT POWER INDICATES A POSSIBLE ERROR IN THE INVERTER OR A SHADOW AFFECTING THIS GROUP OF MODULES. INVERTER I.2.1 HAS SMALLER PERFORMANCE.

FIGURE 3.5 DECISION TREE OBTAINED IN C4.5 LEARNING METHOD, READING 30550 INSTANCES OF PV GENERATOR INFORMATION

FIGURE 3.6 DECISION TREE OBTAINED IN C4.5 LEARNING METHOD, READING 30550 INSTANCES OF PV GENERATOR, WITHOUT ENVIRONMENTAL SENSOR INFORMATION

FIGURE 3.7 PERFORMANCE RATIO OF THE WHOLE PV GENERATOR AND OUTPUT POWER OF THE GROUP OF MODULES CONNECTED TO INVERTER I.1.2 DURINT DAYS WITH SPECIAL ATHMOSPHERIC CONDITIONS: STAND-STORM, RAIN AND SUNNY DAY.

FIGURE 3.8 RESULT OF CLASIFICATION DURING VARYING WEATHER

66 FIGURE 4.1 INPUTS AND OUTPUTS DURING LIFE CYCLE OF A PRODUCT. THE BLOCKS ILLUSTRATE THE MAIN STEPS OF LIFE CYCLE ASSESSMENT. 72 FIGURE 4.2 LCA FRAMEWORK DEFINED BY ISO 14044 73

FIGURE 4.3 PARKING ASSEMBLY ON SIMAPRO SOFTWARE: SPECIFING SUBASSEMBLIES OF WHICH THE PARKING IS MADE UP. THE VARIABLE "PK" LET US COMPARE SEVERAL CASES OF ASSEMBLIES, WITH OR WITHOUT SOME SUBASSEMBLIES.76 FIGURE 4.4 SPECIFING WITH SIMAPRO A SUBASSEMBLY. THE MATERIALS AND PROCESSES ARE REFERRED TO ECOINVENT DATABASE.

FIGURE 4.5 COMPARING GREEN HOUSE GAS EMISSIONS BETWEEN DIFFERENT ASSEMBLY CONFIGURATIONS

FIGURE 4.6 EMBEDDED ENERGY (MJ/KWHEL) AND GLOBAL WARMING POTENTIAL (GCO2/KWHEL) FOR SEVERAL ALTERNATIVE ENERGY TECHNOLOGIES

FIGURE 4.7. BUILDING PROCESS OF 222KWP CDTE PARKING FACILITIES: (A) EARTHWORKS, (B) MASTIC ASPHALT, (C) METALIC STRUCTURE ASSEMBLY AND (D) STRUCTURE-INTEGRATED CDTE MODULES PLACEMENT AND FINAL WIRING AND GRID CONNECTION. THE SYSTEM ALSO INCLUDES INFORMATIVE PANNELS ABOUT THE FACILITY FOR TEACHING PURPOSES.

FIGURE 4.8 LIFE-CYCLE STAGES OF THE PARKING CONSTRUCTION, WHERE THE DEFINED SYSTEM BOUNDARIES ARE CIRCLED BY DASHED LINE: RAW MATERIALS EXTRACTION, MANUFACTURING PROCESSES, PARKING ASSEMBLY, USE PHASE AND DECOMMISSION PHASE.

FIGURE 4.9 CED PER FUNCTIONAL UNIT FOR THE FOLLOWING INPUT MATERIALS AND PROCESSES IN GJ EPE UNITS, FOR THE THREE CONFIGURATIONS (PV\&PK, PV_ONLY AND PK_ONLY): METALLIC STRUCTURE, BOS, PV MODULES, EARTHWORKS, TRANSPORT AND OTHER PROCESSES AS EXPLAINED IN THE TEXT. FIGURE 4.10 GENERATED POWER OF THE PHOTOVOLTAIC INSTALLATION ALONG A DAY COVERING THE FOUR SEASONS AND DIFFERENT ENVIRONMENTAL CONDITIONS: 
(A) 30TH APRIL THE GENERATED ENERGY WAS 1,197.89 KWH, (B) 15TH AUGUST 1,316.42 KWH. IN AUTUMN (C), 15TH OCTOBER, 855.33 KWH AND FINALLY (D) 21ST DECEMBER WAS 247.50 KWH

FIGURE 4.11 (A) COMPARISON BETWEEN THE THREE SCENARIOS AND THE ENVIROMENTAL IMPACT BECAUSE OF THE PRODUCTION OF THE SAME AMOUNT OF ENERGY THAN PV\&PK USING RECIPE METHOD. (B) COMPARISON BETWEEN THREE SCENARIOS (PV\&PK, PV_ONLY AND PK_ONLY) USING RECIPE METHOD, WHERE THE COLUMNS HAVE BEEN NORMALIZED TO THE MAXIMUM VALUE IN EACH CASE.

FIGURE 4.12 COMPARISON OF ENVIRONMENTAL METHODOLOGIES AND THE INFLUENCE THEY HAVE IN THE FINAL OUTPUT OF THE ENVIRONMENTAL IMPACT CALCULATION.

FIGURE 5.1 DEPENDENCE OF THE AVOIDED EMISSIONS ON THE INSTALLATION PLACE FOR $1 \mathrm{kWp}$ THROUGHOUT THE LIFETIME (LF) OF THREE DIFFERENT PV TECHNOLOGIES: C-SI, CDTE AND OPV, ASSUMING THEIR MANUFACTURING HAS TAKEN PLACE IN CHINA

FIGURE 5.2 DEPENDENCE OF THE AVOIDED CO2 EMISSIONS ON THE INSTALLATION LOCATION OF $1 \mathrm{kWp}$ SI-PV, WHEN THE MANUFACTURE HAS TAKEN PLACE IN CHINA, AUSTRALIA, BRAZIL OR INDIA.

FIGURE 5.3 RELATION BETWEEN THE AMOUNTS OF AVOIDED CO $\mathrm{CO}_{2} \mathrm{BY} 1 \mathrm{~kW}_{\mathrm{P}}$ OF C-SI MANUFACTURED IN CHINA DURING ITS OPERATIONAL LIFETIME (IN tons $/ \mathrm{kW}_{\mathrm{P}}$, INDICATED IN SMALL WHITE NUMBERS AT THE LEVEL CURVES) AND THE PLACE WHERE IT IS INSTALLED, SHOWING THE BALANCE BETWEEN IRRADIATION AND $\mathrm{CO}_{2}$ EMISSIONS PER kWh FROM ELECTRICITY GENERATION.

FIGURE 5.4 THE NUMBER IN THE ARROWS INDICATES THE AVOIDED $\mathrm{CO}_{2}$ EMISSIONS $^{-}$ (TONS PER KW $\mathrm{W}_{\mathrm{P}}$ OF INSTALLED PV CAPACITY THROUGHOUT LIFETIME OF THE PV SYSTEM) FOR A GIVEN COMBINATION OF LOCATIONS: ORIGIN OF ARROW IS THE MANUFACTURING PLACE AND END OF ARROW IS THE INSTALLATION OF THE FACILITY.

FIGURE 5.5 TONS OF EMITTED $\mathrm{CO}_{2}$ DUE TO THE MANUFACTURING OF C-SI AND THINFILM SOLAR CELLS IN 2011. FOR EACH COUNTRY, THE GLOBAL MARKET SHARE OF TECHNOLOGY HAS BEEN ASSUMED.

FIGURE 5.6 EMISSIONS OF $\mathrm{CO}_{2}$ BY COUNTRY IN MEGATONS, SUPPOSING ALL PV CAPACITY WOULD HAVE BEEN MADE OF THE SAME PV TECHNOLOGY: C-SI OR THIN-FILM OR OPV (FOLLOWING VALUES OF THE MARKET IN 2011). 126 FIGURE 5.7 TONS OF AVOIDED $\mathrm{CO}_{2}$ EMISSIONS OF EACH COUNTRY, DUE TO ALL INSTALLED PV MODULES IN 2011, DURING ITS FIRST YEAR.

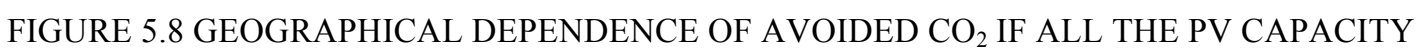
WOULD HAVE BEEN INSTALLED IN THE SAME COUNTRY AND WOULD HAVE BEEN RUNNING FOR ONE YEAR. . 
FIGURE 6.1 WINDOWS THAT ILLUSTRATE THE USER INTERFACE OF SURE SOFTWARE.

FIGURE 6.2 ENERGY OPTIONS, AS PER SURE-DSS, FOR LAS CALABAZAS, CUBA 146 FIGURE 6.3 IMPACT OF MODELLED ENERGY TECHNOLOGIES, INCLUDING THREE PHOTOVOLTAIC TYPES, ON THE LIVELIHOODS ASSETS OF LAS CALABAZAS, CUBA 147

FIGURE 6.4 GLOBAL IMPACTS RESULTS ON PHOTOVOLTAIC TECHNOLOGIES AND ITS GEOGRAPHICAL DEPENDENCE. 


\section{LIST OF TABLES}

TABLE 2.1 ORGANIZATION AND TECHNICAL SPECIFICATIONS OF THE GROUPS OF MODULES

TABLE 2.2. TECHNICAL SPECIFICATIONS OF THE PV MODULES USED AT THE PV-PARKING FACILITY

TABLE 2.3. TECHNICAL SPECIFICATIONS OF THE INVERTERS USED AT THE PV-PARKING FACILITY

TABLE 2.4. PARAMETERS SENT BY SMA SMC7000HV INVERTERS. NAME (TAG) AND DESCRIPTION.

TABLE 2.5. PARAMETERS SENT BY SUNNY SENSOR BOX. NAME (TAG) AND DESCRIPTION.

38

TABLE 3.1 PARAMETERS ADDED TO EACH REGISTER IN DATABASE 55

TABLE 3.2 POSSIBLE STATES OF THE GROUP OF PV MODULES CONSIDERED 56

TABLE 3.3 AVERAGE ACCURACY AND ROOT MEAN SQUARED ERROR OF LEARNING METHODS

TABLE 3.4 DISAGREEMENTS FOUND IN DECISION TREES. EQUIVALENT BRANCH WITH AND WITHOUT IRRADIATION ATTRIBUTE

TABLE 4.1 LISTING OF DIFFERENT RENEWABLE ENERGY TECHNOLOGIES AND THEIR EPBT (IN YEARS), MEASURED IN MJ/KWHEL

TABLE 4.2 MATERIAL AND ENERGY INVENTORY OF THE PARKING FOR THE THREE CONFIGURATIONS: PV\&PK, PV_ONLY AND PK_ONLY

TABLE 4.3 MONTHLY PERFORMANCE RATIO ESTIMATED FROM MORE THAN 2 YEARS OF MEASURED DATA AT THE FACILITY (SAMPLED EVERY 5 MIN), MONTHLY MEASURED IRRADIATION FOR $7^{\circ}$ TILTED SURFACE (GBA $7^{\circ}$ ), ESTIMATION OF IRRADIATION FOR $30^{\circ}$ TILTED SURFACE (GBA $7^{\circ}$ ) AND ESTIMATION OF GENERATED ENERGY OF PV_ONLY

TABLE 4.4 EPBT, ERF AND EMBODIED CO2 FOR PARKING WITH AND WITHOUT PV, AND PV GROUND-MOUNTED. VALUES FOR THE COMPLETE FACILITY ARE SHOWN IN THE CENTRAL COLUMNS OF THE TABLE. VALUES FOR 1KWP FUNCTIONAL UNIT ARE SHOWN IN THE TWO FINAL COLUMNS ON THE RIGHT HAND SIDE OF THE TABLE.

TABLE 5.1 TECHNICAL SPECIFICATION OF THE PV MODULES CONSIDERED AS REPRESENTATIVE OF THE CORRESPONDING TECHNOLOGIES.

TABLE 5.2 ENERGY PAY BACK TIME AND ENERGY RETURN FACTOR OF 1KWP OF PV, ORDERED FROM HIGHEST EPBT TO LOWEST FOR THE COUNTRIES UNDER CONSIDERATION. 
TABLE 5.3 MWP PV INSTALLED WORLDWIDE IN 2011, IRRADIATION, KG CO2 PER KWH FROM ELECTRICITY GENERATION AND CO2 FROM ELECTRICITY GENERATION OF EACH COUNTRY CONSIDERED IN THE STUDY. NOTE THAT THE VALUES IN LAST COLUMN ( $\mathrm{kg} \mathrm{CO}_{2}$ RELATED TO ENERGY MIX) ONLY APPEAR IN MANUFACTURING COUNTRIES.

$121-123$

TABLE 5.4 MANUFACTURING COUNTRIES IN 2011 AND ITS MANUFACTURED CAPACITY.

124

TABLE 6.1 CURRENT AND PROJECTED TECHNICAL, FINANCIAL AND LIFE-CYCLE INDICATORS FOR CRISTALLINE SILICON, THIN-FILM AND ORGANIC BULK HETEROJUNCTION PHOTOVOLTAIC TECHNOLOGIES. SOURCES 140

TABLE 6.2 INPUT-PARAMETERS IN PHOTOVOLTAIC GLOBAL IMPACT INTERFACE, FUNCTIONALITY ADDED TO SURE-DSS SOFTWARE

TABLE 6.3 SUPPLY OPTIONS CONSIDERED IN SURE BY DEFAULT AND ITS TECHNICAL PARAMETERS 


\section{LIST OF ACRONYMS}

\begin{tabular}{|c|c|}
\hline $\mathrm{AC}$ & Alternating Current \\
\hline BIPV & Building Integrated Photovoltiacs \\
\hline CdTe & Cadmium telluride \\
\hline CED & Cumulative Energy Demand \\
\hline $\mathrm{CF}$ & Capacity Factor \\
\hline CIS & Copper indium gallium selenide \\
\hline DC & Direct Current \\
\hline EPBT & Energy Pay-back Time \\
\hline $\mathrm{EPE}$ & Equivalent Primary Energy \\
\hline EPIA & European Photovoltaic Industry Association \\
\hline ERF & Energy Return Factor \\
\hline $\mathrm{EU}$ & European Union \\
\hline FU & Functional Unit \\
\hline GaAs & Gallium arsenide \\
\hline GaInP & Gallium indium phosphide \\
\hline GHG & Greenhouse Gas \\
\hline GB & gigabit \\
\hline GJ & gigajoule $\left(1\right.$ joule $\left.\times 10^{9}\right)$ \\
\hline GW & gigawatt $\left(1\right.$ Watt $\left.\times 10^{9}\right)$ \\
\hline $\mathrm{GWh}$ & gigawatt-hour \\
\hline IEA & International Energy Agency \\
\hline IPCC & Intergovernmental Panel on Climate Change \\
\hline ISO & International Organization for Standardisation \\
\hline $\mathrm{kW}$ & kilowatt (1 Watt x 10 $\left.0^{3}\right)$ \\
\hline
\end{tabular}




\begin{tabular}{|c|c|}
\hline kWel & kilowatt electrical capacity \\
\hline $\mathrm{kWh}$ & kilowatt-hour \\
\hline $\mathrm{kWp}$ & kilowatt-peak \\
\hline LCA & Life Cycle Analysis \\
\hline LCI & Life Cycle Inventory \\
\hline LCIA & Life Cycle Impact Assessment \\
\hline $\mathrm{LT}$ & Lifetime \\
\hline MPP & Maximum Power Point \\
\hline MW & megawatt $\left(1\right.$ Watt $\left.\times 10^{6}\right)$ \\
\hline MWh & megawatt-hour \\
\hline OPV & Organic solar cells \\
\hline PHP & Hypertext Preprocessor \\
\hline PV & Photovoltaics \\
\hline PVG & Photovoltaic generator \\
\hline PVGIS & Photovoltaic Geographical Information System \\
\hline PK & Parking \\
\hline PR & Performance Ratio \\
\hline PVC & Polyvinylchloride \\
\hline SSB & Sunny Sensor Box \\
\hline STC & Standard Test Conditions for PV devices \\
\hline SWB & Sunny Web Box \\
\hline TB & terabit \\
\hline $\mathrm{TJ}$ & terajoule \\
\hline TW & terawatt $\left(1\right.$ Watt $\left.\times 10^{12}\right)$ \\
\hline UMU & University of Murcia \\
\hline UPCT & Technical University of Cartagena \\
\hline XML & Extensible Markup Language \\
\hline
\end{tabular}




\title{
Chapter 1
}

\section{INTRODUCTION AND}

\author{
Motivation
}

\begin{abstract}
Synopsis Electricity production is responsible for 32\% of total global fossil fuel consumption. In order to mitigate climate change, all countries should establish political and economical regulations with a global approach, including international agreements in the framework of multinational organizations, such as the International Energy Agency. Development of renewable energies has been continuously growing despite the economic crisis in recent years. Wind and photovoltaic technologies excel in progress and are considered as a reliable future sustainable source of electricity. Growing economies depend strongly on fossil fuels, and therefore, changing its energy policy including more renewable technologies in their energy mix are key to slow down global warming. This thesis proposes several computer-based tools which improves the technical performance of photovoltaic systems and additionally calculates the environmental impact of these systems and therefore provides additional information to the decision makers.
\end{abstract}

\subsection{Definition of goal and methodology}

The main objective of this thesis is to demonstrate that the deployment of current photovoltaic technology can be optimised by the use of computer-based tools in order to improve its technical performance and to extend the lifetime of the systems. Additionally, the environmental impact of the systems is calculated and the quantitative information is provided to the decision makers, including information about the socio-economic context in which the systems will be deployed. This thesis is therefore a contribution to the solution of current environmental problems related to climate change; the objective of reducing the environmental impacts of electricity production is achieved by the improvement 
of sustainability of photovoltaic systems from a multidisciplinary environmental, technical and socioeconomical point of view. Several tools based in computing science have been used to analyse the performance of PV systems, to calculate its environmental impacts and to provide this information to the decision makers. The thesis combines the collection of data from different sources, and applies a multidisciplinary methodology which varies depending on the case studies under consideration; those case studies have been chosen in order to illustrate the different approaches, which nevertheless have the use of computing tools to improve the performance and sustainability of photovoltaic systems as the common method throughout the whole thesis.

During the development of this dissertation different sources of information were consulted: data provided by a detailed literature review, data measured by our own data acquisition system which was implemented on PV systems constructed and monitored at the university, data obtained by access to public databases, and finally, socio-economic field data collection obtained by a survey carried out in Cuba. The collection of this information have been applied to several casestudies: the analysis of the performance of a CdTe, $222 \mathrm{kWp}$, and its global environmental impact, the application of learning computing techniques to detect failures on this system, a quantitative global environmental impact calculation for several PV technologies, including the geographical dependence, and a practical case study of rural electrification in Cuba, in which a special software tool called SURE was applied.

A detailed description of each technique and each case study, including methodology, is provided in the corresponding chapter. The thesis is organized as explained at the end of this chapter. 


\subsection{Motivation: Climate Change and world energy demand.}

Climate change mitigation is one of the most important challenges that need to be addressed in the coming years. Europe is aware of this challenge and has signed several agreements and committed itself to very demanding targets to be accomplished by 2020 (European Commision 2012), which in relation to climate change and energy can be summarized in a reduction of $20 \%$ of greenhouse gases emissions, $20 \%$ of total consumed energy should be produced from renewables, and a $20 \%$ increase in energy efficiency should be achieved. In Figure 1.3 we can see the share of different sources of energy and its evolution during the past 47 years.

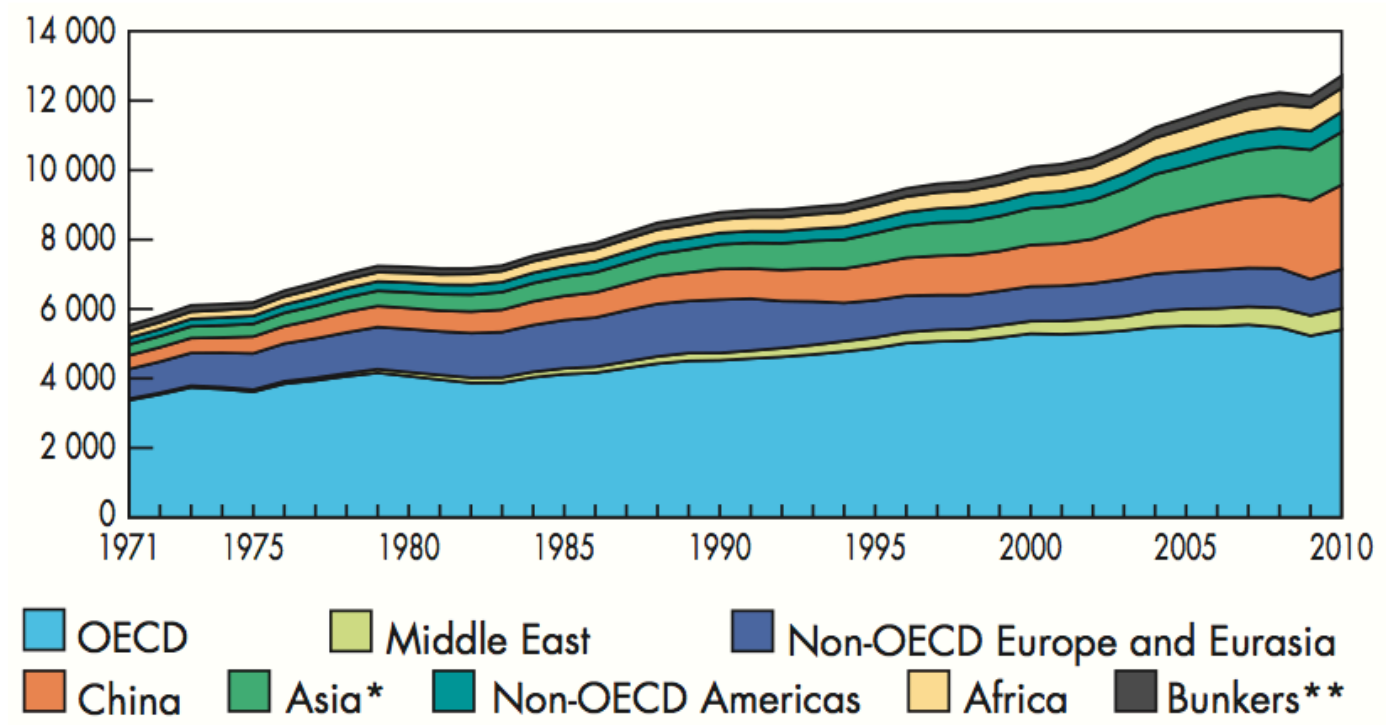

FIGURE 1.1 WORLD TOTAL PRIMARY ENERGY SUPPLY FROM 1971 TO 2011 BY REGION (Mtoe) (*Asia excludes China. **Includes international aviation and international marine bunkers.)

Electricity production is responsible for $32 \%$ of total global fossil fuel use, accounting for 10.9 Gtoe or $41 \%$ of energy-related $\mathrm{CO}_{2}$ emissions (IEA 2009). 
The world energy consumption was 10 terawatts TW per year in 2010 and by 2050 it is projected to be about 30 TW. The world will need about 20 TW of non$\mathrm{CO}_{2}$ energy to stabilize $\mathrm{CO}_{2}$ in the atmosphere by mid-century (Razykov T. M. 2011).

China and India alone contributed approximately to $90 \%$ of the increase of global energy consumption in 2012 (BP Global 2013), additionally these countries are growing in oil consumption due to an increase in transport. Emerging economies are responsible of most of the net growth in world total primary energy consumption from 1971 to 2008, causing an important amount of $\mathrm{CO}_{2}$ emissions, as Figure 1.2 and Figure 1.1 show.

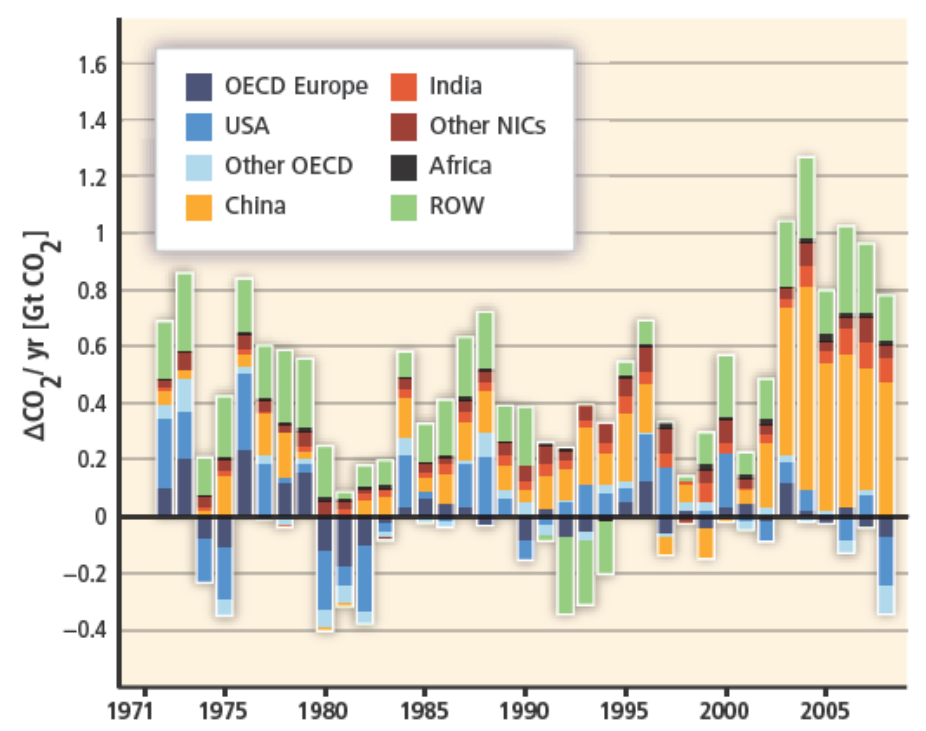

FIGURE 1.2 INFLUENCE OF SELECTED COUNTRIES AND COUNTRY GROUPS ON GLOBAL CHANGES IN $\mathrm{CO}_{2}$ EMISSIONS FROM 1971 TO 2008 ROW: REST OF WORLD. (OTTMAR EDENHOFER ET AL. 2011) 


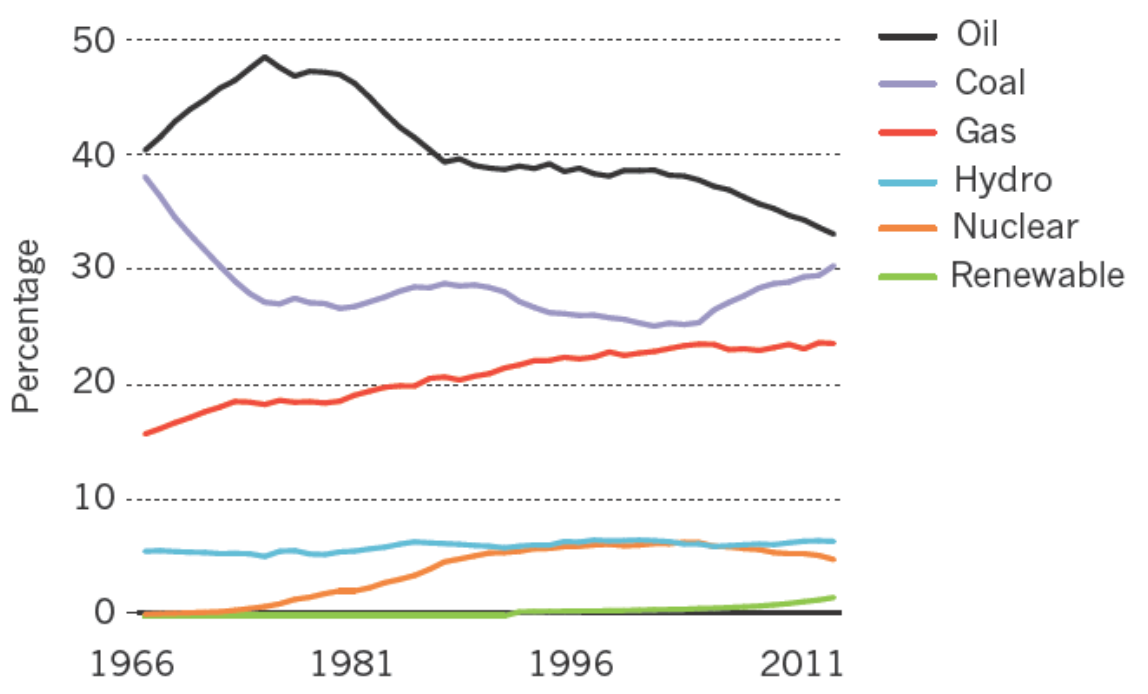

FIGURE 1.3 SHARES OF WORLD PRIMARY ENERGY CONSUMPTION (\%) (CHU AND MAJUMDAR 2012)

As we can see, share of coal is growing due increased consumption in developing economies, where life quality is progressing, and this progress is linked to a growth of energy consumption.

The rapid development of our societies, the conservation of scarce resources, and at the same time protecting the environment, is a huge challenge that we have to face today. It is necessary to pay attention to the needs and aspirations of population, with special attention to rural population, which suffers higher levels of poverty, and to ensure solutions that do not damage the environment. The solutions should be integrated into cultural and social life, then $<<$ balancing the need for continuing development with the need to conserve scarce resources and protect the environment is one of the most serious challenges facing society today $>>$, (Mulugetta et al. 2002).

At the same time, social and cultural lives are also affected by the energy consumption of the population, or in many cases by the "availability" of energy to be consumed by population. A very low access to energy, and in particular a very low access to electricity has a negative impact on the quality of life. One way to 
quantify this assumption is to compare data which measures the development of a society and the energy consumption by the population. The United Nations Development Program proposed a "index" which is a function of several parameters and enables a classification of countries according to its "level" of development ${ }^{1}$. (Khalid Malik et al. 2013)

Figure 1.4 shows the relation between the Human Development Index (HDI) and annual per-capita electricity consumption for 60 countries comprising $90 \%$ of the world's population. Line drawn in $4000 \mathrm{kWh}$ per year per person marks the point where the relation between HDI and electricity consumption is optimal. Developed countries waste more energy than necessary to have a high HDI, so the used energy could be optimized in order to take care of the environment and to deal with global warming and climate change.

\footnotetext{
${ }^{1}$ Human Index Development is the geometric mean of three normalized indices: $H D I=\sqrt{L E I \cdot E I \cdot I I}$, where LEI refers to Life Expectancy Index that is $L E I=\frac{\text { LifeExpectancy-20 }}{82.3-20}$, Education Index (IE) is equal to $E I=\frac{\sqrt{\text { MeanYearsSchooling } / 13.2^{\text {ExpectedYearsSchooling } / 20.6}}}{82.3-20}$, and finally, Income Index (II) that is calculated as $I I=\frac{\ln (\text { GrossNationalIncome })-\ln (100)}{\ln (107,721)-\ln (100)}$
} 


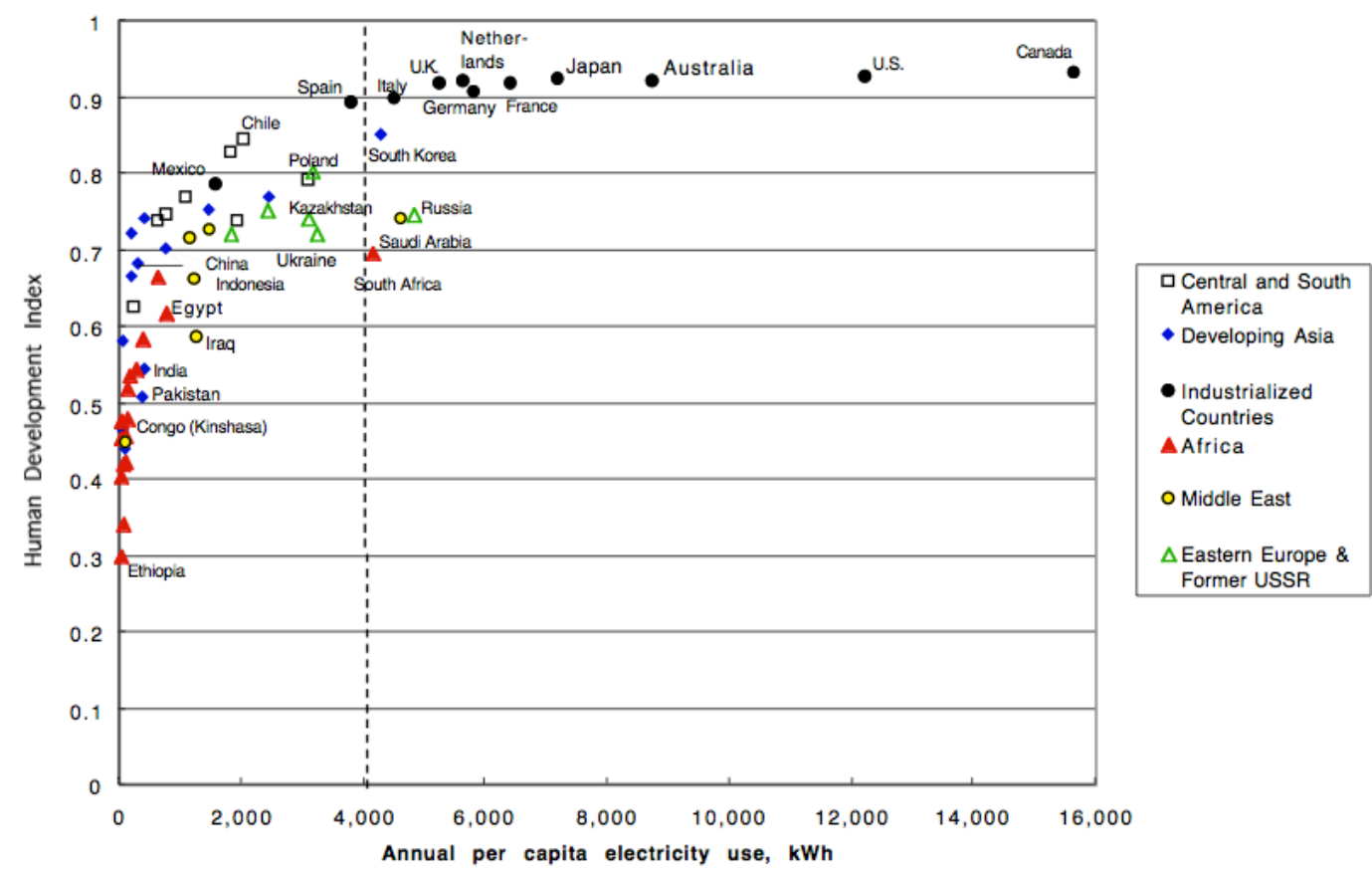

FIGURE 1.4 CORRELATION BETWEEN THE UNITED NATIONS' HUMAN DEVELOPMENT INDEX (HDI) AND ANNUAL PER-CAPITA ELECTRICITY CONSUMPTION (ALAN D. PASTERNAK 2000)

In developing countries and emerging economies, the use of renewable energies is a crucial key element to stop the use of fossil fuels when energy demand is continuously growing and is expected to grow even more in the near future.

Sustainable energies are those energy technologies whose environmental impact during its performance is nearby null. The notion of "sustainability" has numerous definitions; sustainability means therefore much more than mere "climate change mitigation". A way to improve citizens quality of life without compromising natural environment is strongly required, furthermore, considering Van de Kerk (Van de Kerk and Manuel 2008), <<climate change might affect our future $>>$. The use of sustainable energies is one of the solutions to avoid greenhouse gas emissions, which have been identified as one of the main causes for climate change. (Ottmar Edenhofer et al. 2011) 


\subsection{Photovoltaic Technology for Climate Change Mitigation}

Photovoltaic technologies have been highlighted as an ideal source of energy due to its non-polluting performance in the way it produces electricity by harvesting the energy available from the Sun, which is a free source of energy, once the facility has been built. $<<$ Access to clean, affordable and reliable energy has been a cornerstone of the world's increasing prosperity and economic growth since the beginning of the industrial revolution. Our use of energy in the twenty-first century must also be sustainable. Solar and water-based energy generation, and engineering of microbes to produce biofuels are a few examples of the alternatives. $>>$ (Chu and Majumdar 2012)

European Commission policy drivers established reducing greenhouse gas emissions as a priority, and points out that delays in climate change mitigation would raise societal costs significantly, $<<$ the photovoltaic industry will continue to be an ever more important part of Europe's energy sector $>$. It is expected renewable energy will be able to favourably compete with conventional energy sources. (International Energy Agency 2013b)

In order to fulfil European commitments, photovoltaic technology should be one of the main sources of sustainable energy supply. In 2010 there is a global cumulative installed capacity of $39.5 \mathrm{GW}_{\mathrm{p}}$, of which $29.2 \mathrm{GW}_{\mathrm{p}}$ have been installed in Europe. Figure 1.5 shows how solar PV generation capacity has grown worldwide. The trend forecasted by the European Photovoltaic Industry Association (EPIA) ranges between $64 \mathrm{GW}_{\mathrm{p}}$ and $120 \mathrm{GW}_{\mathrm{p}}$ depending on the considered scenario (moderate vs. policy-driven), but in both cases it seems insufficient to reach the European 2020 targets and much less to fulfil the world energy electricity demand sketched above unless there is a paradigm change (EPIA European Photovoltaic Industry Association 2012) 


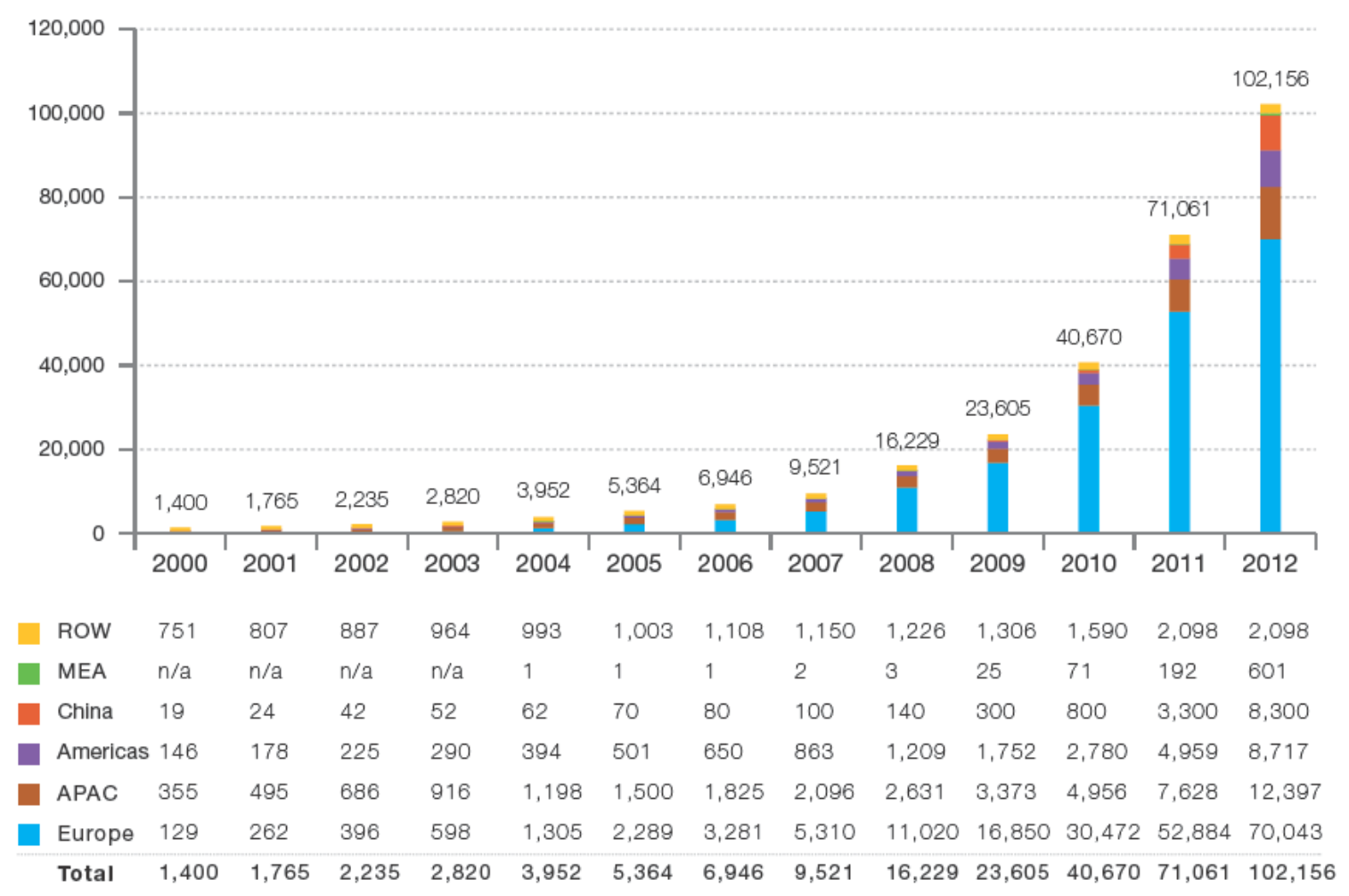

FIGURE 1.5 RENEWABLES SHARE OF POWER GENERATION BY REGION PERCENTAGE (EPIA EUROPEAN PHOTOVOLTAIC INDUSTRY ASSOCIATION 2013)

Solar PV was the fastest-growing power technology worldwide from 2000 to 2012; nevertheless international coordination of deployment will be a key element in making PV growth sustainable (Adam Brown, Simon Müller, and Zuzana Dobrotková 2011). Emerging economies are stepping up efforts in clean energy, but global policy development is mixed. These countries with economic growth depend strongly on coal and this dependence represents a fundamental threat to low-carbon future. China and India are the two giants in this situation. (International Energy Agency 2013) 


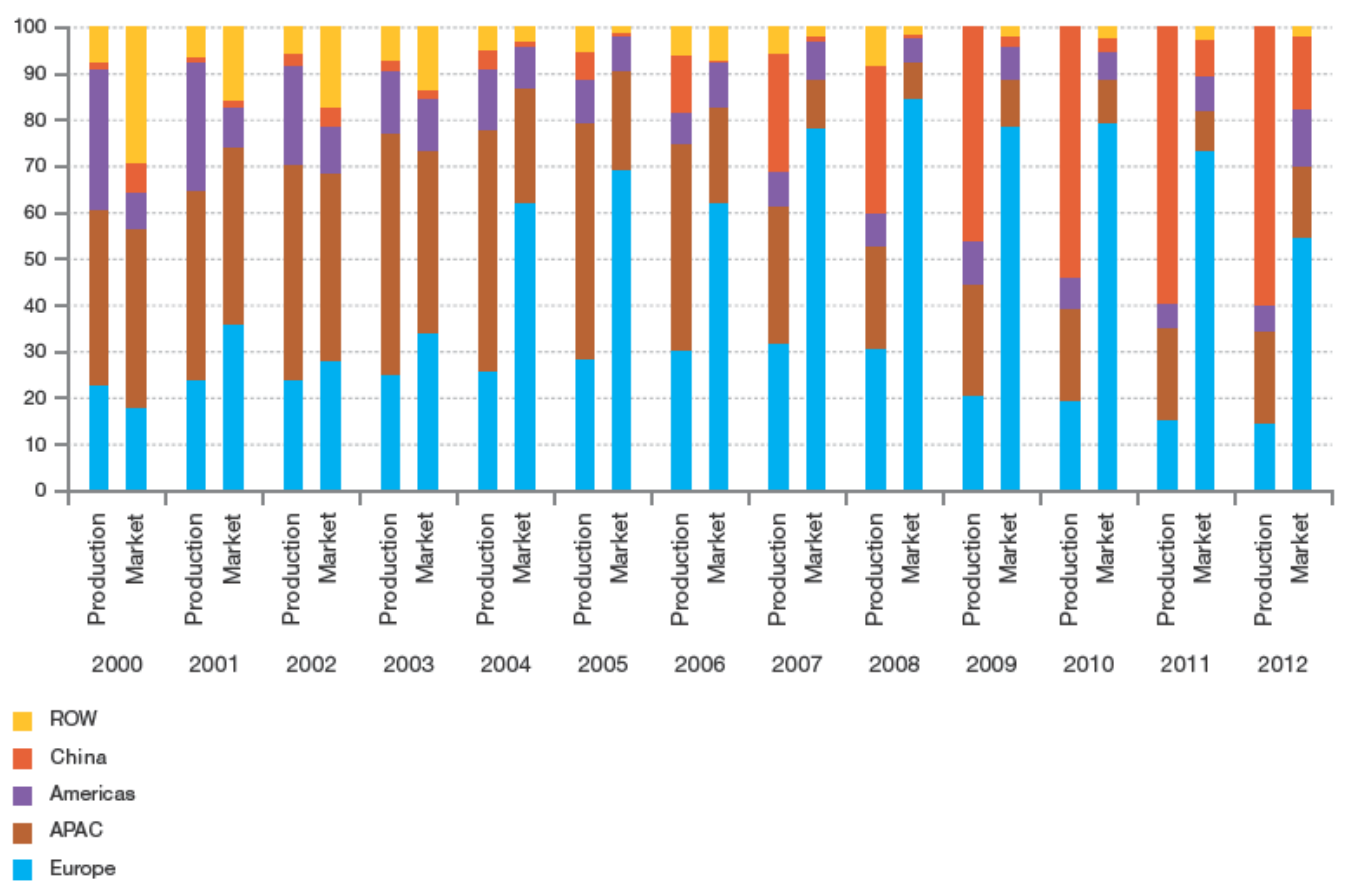

FIGURE 1.6 HISTORICAL PV MARKET VS. PRODUCTION BY REGION (\%) (EPIA EUROPEAN PHOTOVOLTAIC INDUSTRY ASSOCIATION 2013)

The evolution of the global PV module supply and market share since 2000 is shown in Figure 1.6. From 2004 Europe became the main importer from Asian countries. Currently, European industry represents about $13 \%$ of the global market and $24 \%$ of its own market. China covers its own growing market with $320 \%$ more production that it needs. During the past three years, module production capacity was $150-230 \%$ higher than annual global installations in China, although China is becoming one of the fastest growing PV markets for installation of new capacity. (EPIA European Photovoltaic Industry Association 2013) 


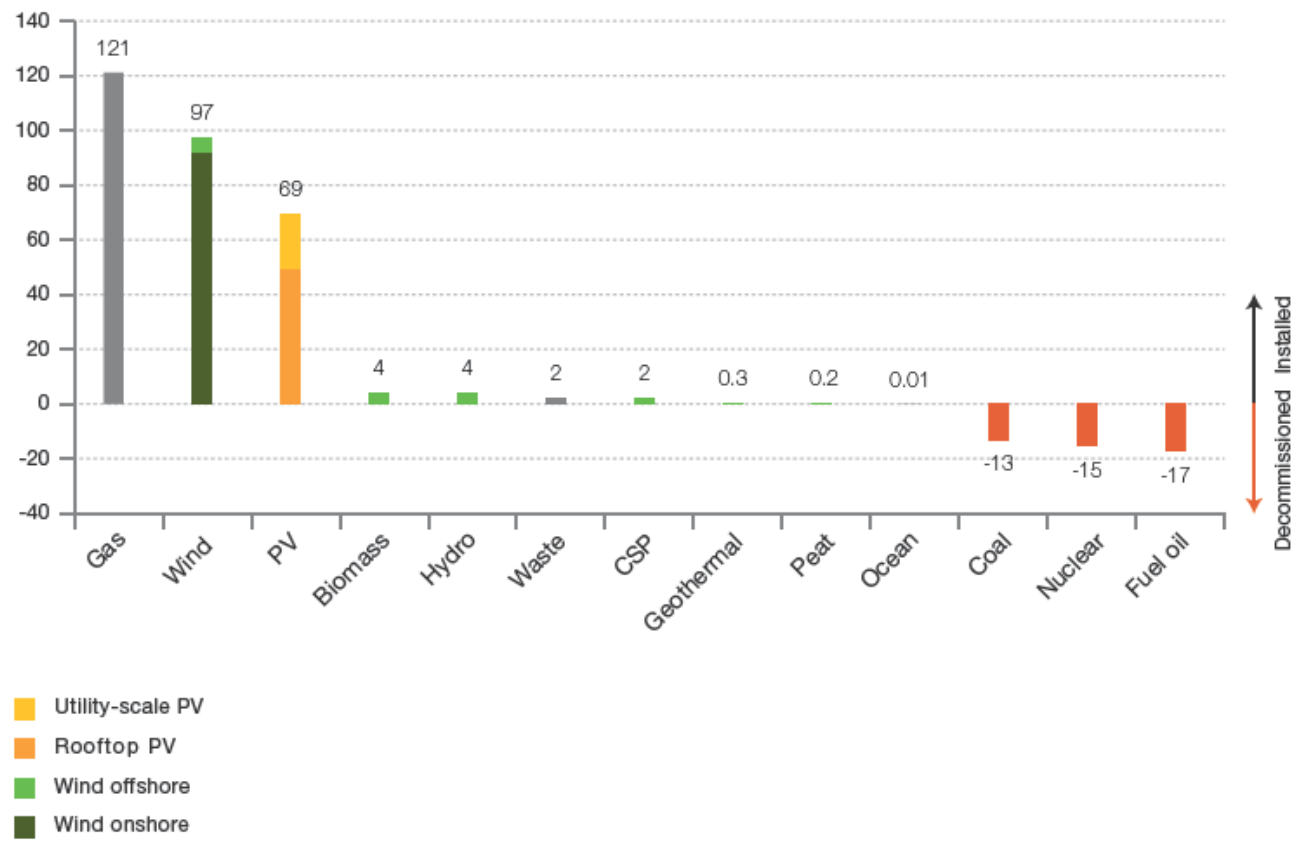

FIGURE 1.7 NET GENERATION CAPACITY ADDED IN THE EU 27 2000-2012 (GW) (EPIA EUROPEAN PHOTOVOLTAIC INDUSTRY ASSOCIATION 2013)

Despite economic, policy and industry turbulence, the growth of renewable power technologies continued steadily in 2012 . Solar PV capacity grew by an estimated 42\% compared with 2011 cumulative levels. (International Energy Agency 2013)

\section{Photovoltaic technologies}

Photovoltaic technology development covers different types of materials. Crystalline Silicon (c-Si) is the predominant technology (Figure 1.8). 


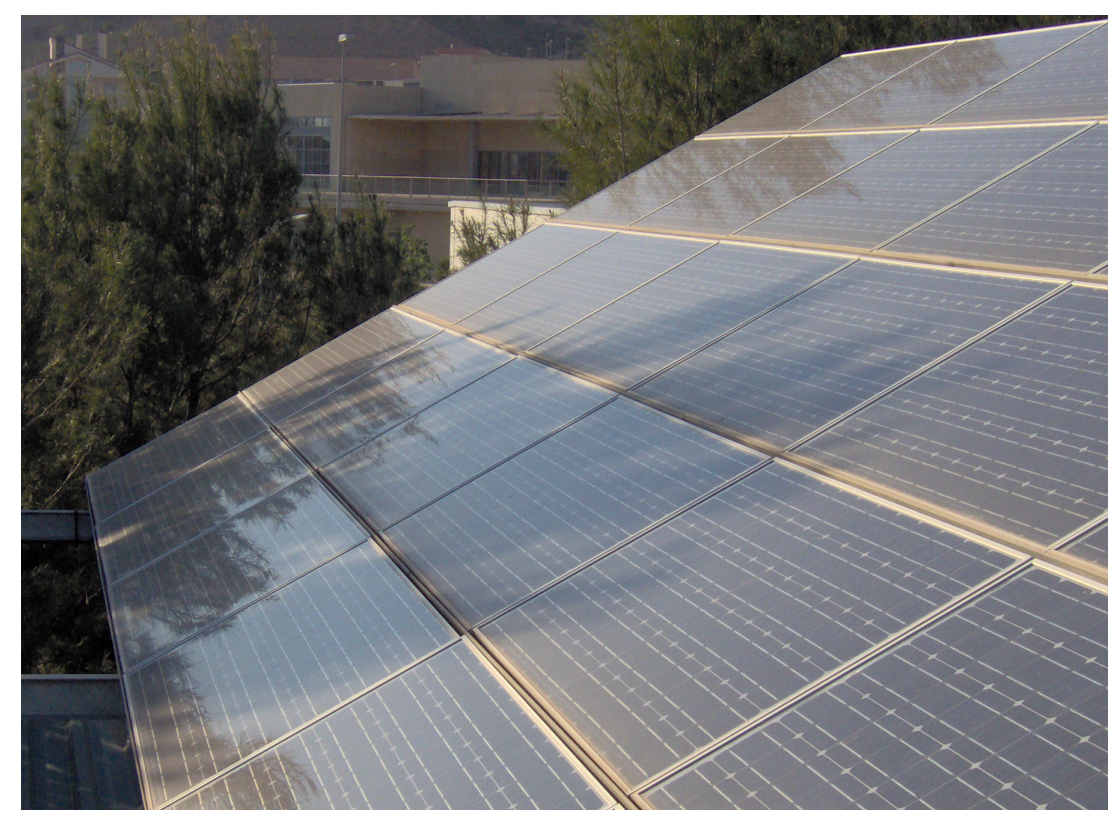

FIGURE 1.8 CRYSTALLINE SILICON MODULES INSTALLED AT UNIVERSITY OF MURCIA

Thin film technologies are characterized by lower use of material and less energy requirements during manufacture. This kind of PV covers several types, lead byCadmiun Telluride (CdTe), amorphous Silicon (a-Si), Copper indium gallium selenide (CIGS) and dye-sensitized solar cell (DSC). Currently, new generations solar cells are being developed, i.e. organic photovoltaic cells (OPV) and concentrated photovoltaics (CPV); both are expected to have a great success in the near future, due to the advances in its fabrication process which enables a reduction of the cost of electricity produced throughout its lifetime.

As Figure 1.9 shows, c-Silicon is the technology with most success and it is expected to maintain its market share at levels of around $80 \%$. Thin-film PV technologies grew strongly last years and it is expected to grow from now on at a lower rate. Emerging technologies such as OPV and CPV are estimated to have around $1 \%$ of the market share by 2017 (Figure 1.9). 


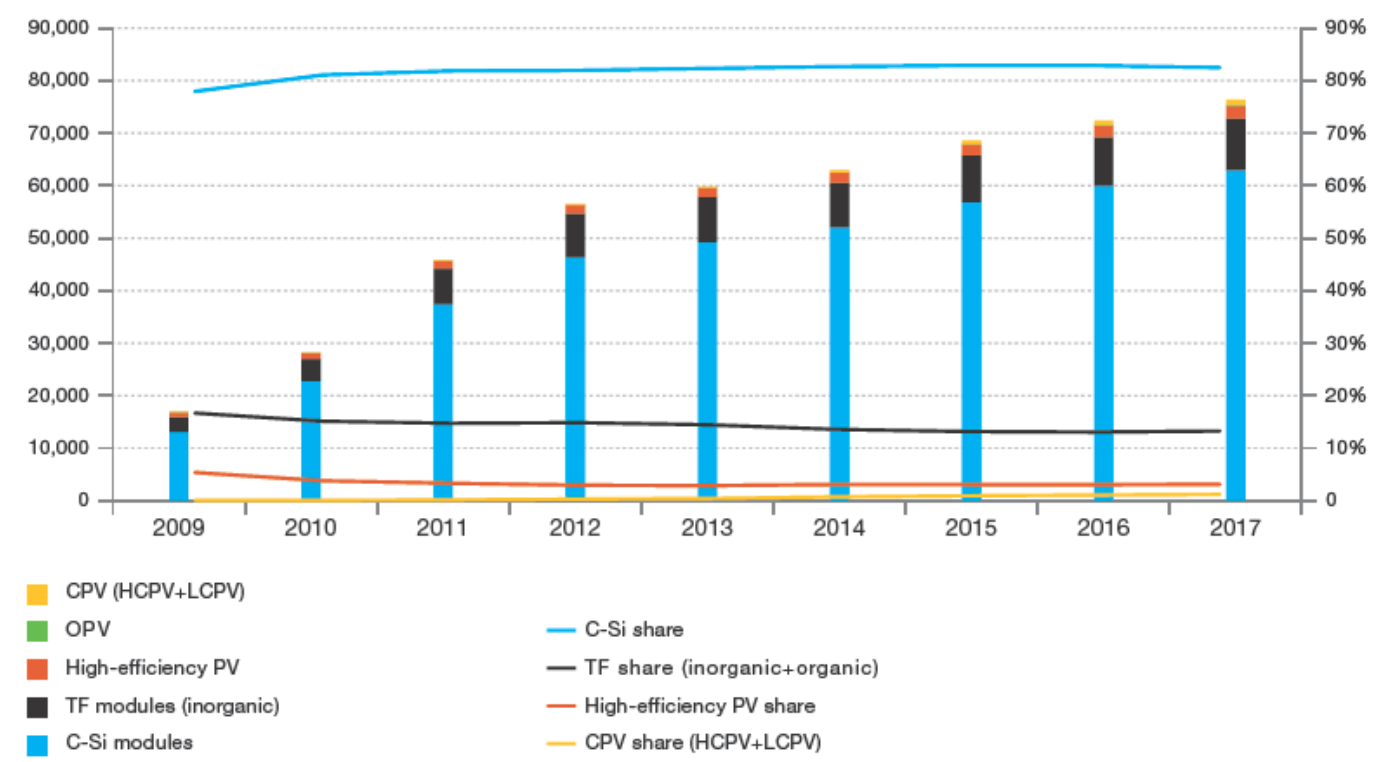

FIGURE 19 PV MODULES PRODUCTION CAPACITY UNTIL 2017 (MW; \%) (EPIA EUROPEAN PHOTOVOLTAIC INDUSTRY ASSOCIATION 2013)

Europe is the continent with most cumulative installed capacity of photovoltaic modules, being more than $70 \mathrm{GW}$ as of 2012 , representing almost $70 \%$ of the world's cumulative PV capacity. China is the second region with most cumulative PV capacity $(8.3 \mathrm{GW})$, followed by USA $(7.8 \mathrm{GW})$ and Japan $(6.9 \mathrm{GW})$. See Figure 1.10. 


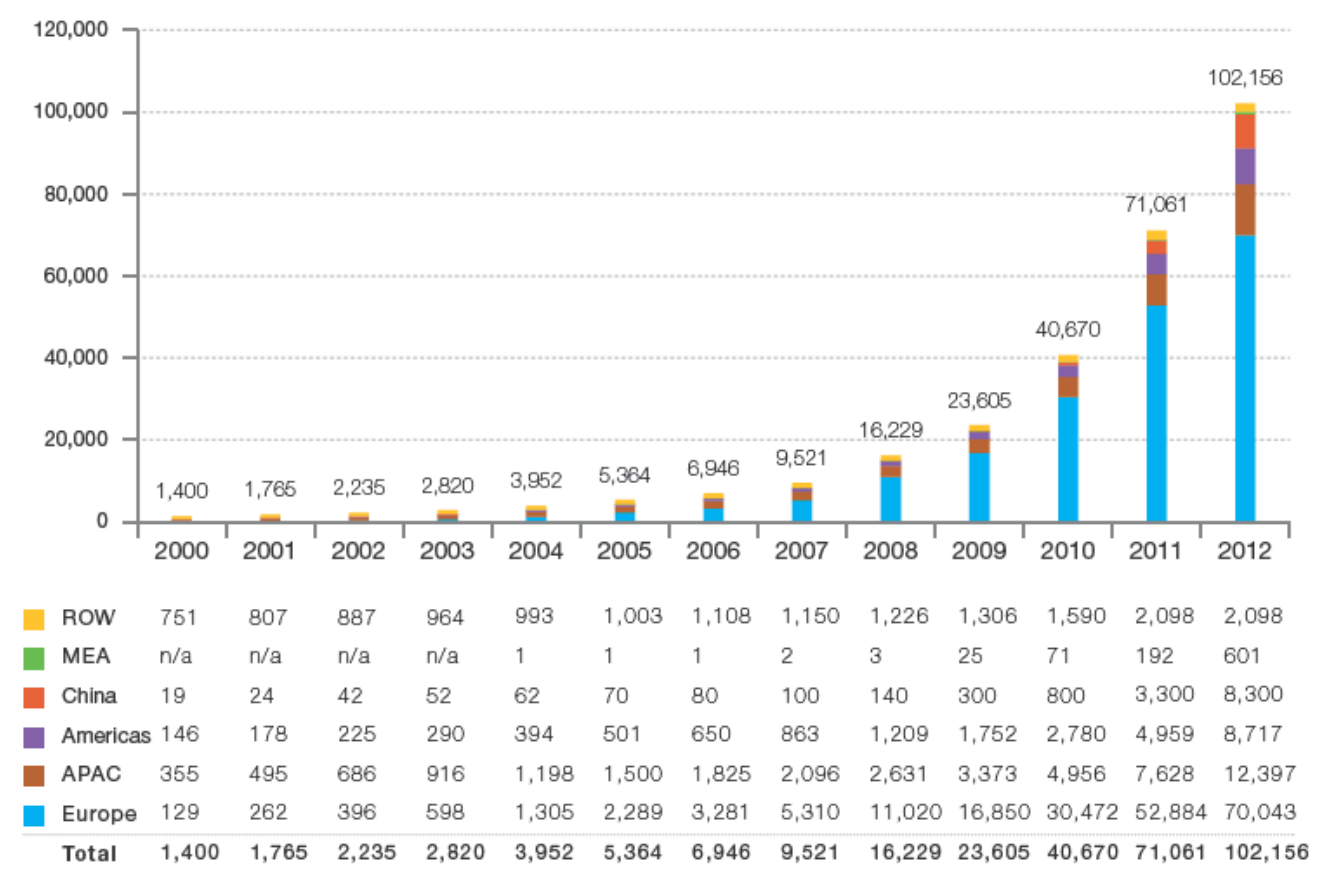

FIGURE 1.10 EVOLUTION OF GLOBAL PV CUMULATIVE INSTALLED CAPACITY 2000-2012 (MW) PHOTOVOLTAIC EVOLUTION

\section{CdTe photovoltaic technology in context}

Photovoltaic (PV) technologies have been highlighted as an ideal source of energy due to its non-polluting performance in the way it produces energy from the Sun, which is a free source of energy, once the facility has been built.

The photovoltaic system studied in this thesis is formed by Cadmium Telluride (CdTe) modules, belonging to a second generation of PV technologies, also known as 'thin-film' technology because the thickness of the solar cells are around a few micrometers (compared with hundreds of micrometers for the conventional crystalline silicon technology). 
Research on thin-film technologies started long time ago in order to save manufacturing material and at the same time maintaining good power conversion efficiency. This goal was achieved with new compounds based on blends of semiconducting materials, such as Cadmium and Tellurium, the so-called CdTe or "cadtel" alloy.

PV technologies are a popular research ground. Each year the PV technology power conversion efficiencies reach a new record. Figure 1.11 shows the best efficiency reached for each kind of PV technology, measured at laboratory, and its evolution during last years. PV technology efficiency is the main feature used for assessment. The higher efficiency they have, the less PV surface will be needed in order to get the same power capacity.

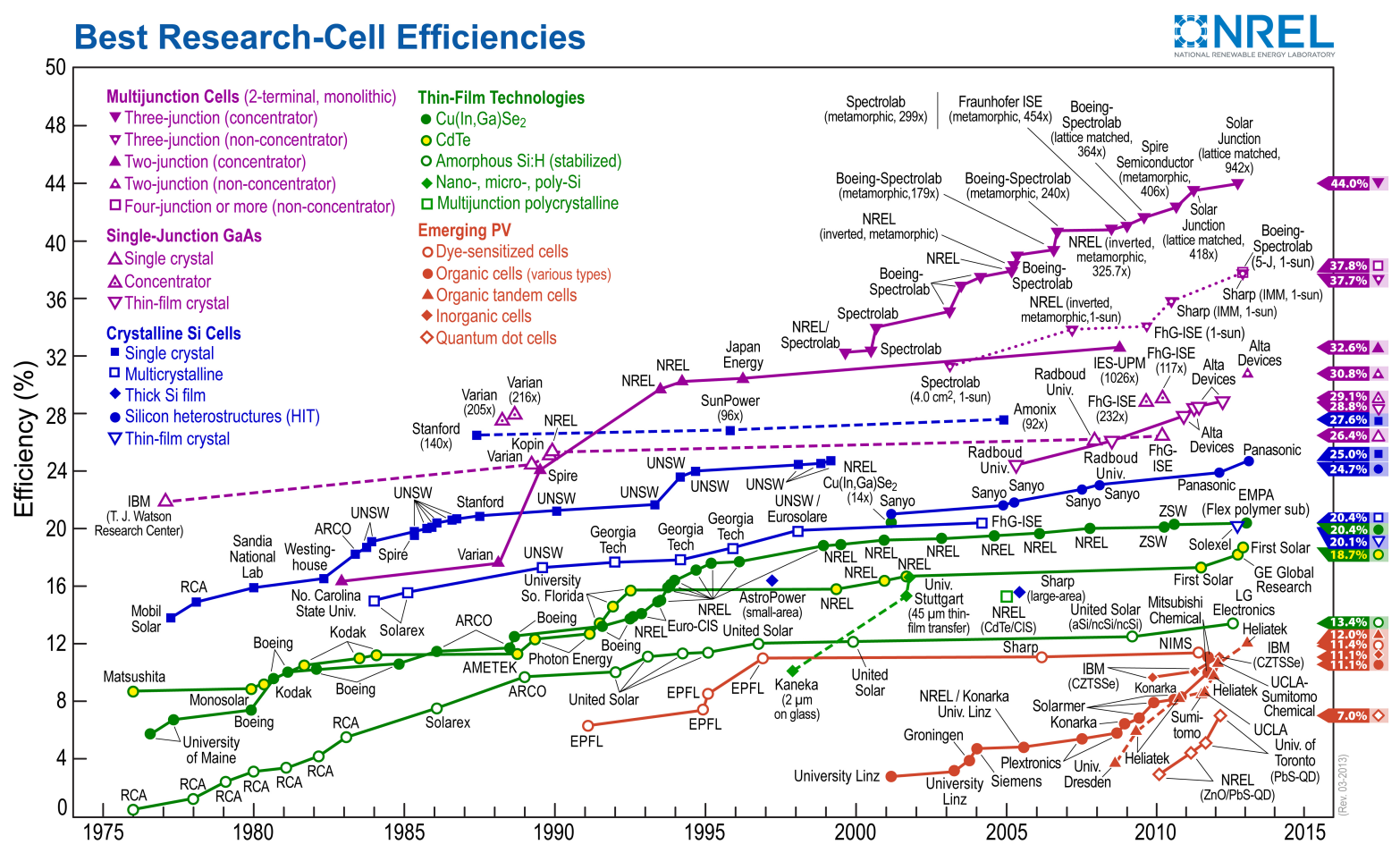

FIGURE 1.11 SOLAR CELL TECHNOLOGY EFFICIENCIES (NATIONAL RENEWABLE ENERGY LABORATORY (NREL))(NATIONAL RENEWABLE ENERGY LABORATORY, USA 2013) 
The main disadvantage of c-Si technology is the costly processing of materials and device fabrication steps, which includes making the very expensive crystalline material with the required purity, despite the abundance of silicon in nature (Razykov T. M. 2011).

CdTe, amorphous and microcrystalline silicon (a-Si), and Copper-IndiumGallium-Selenide (CIGS) mainly form thin-film technologies. The main advantage of such technology is the use of little amount of materials, enabling these technologies to reach a lower market price, and to avoid the very high costs of the silicon wafer. Nevertheless, the materials used in these kinds of technologies are not as cheap as currently hoped for.

A third generation is represented by multiple-junction cells fabricated using alloys of semiconducting materials from groups III and V of the periodic table. Those devices provide efficiencies greater than that of a single-junction solar cell, and actually hold the world-record power conversion efficiencies, over $43 \%$ at very high concentration (418 Suns). This technology is mainly used in satellites, but could be an option if installed on solar trackers.

There are new generation PV technologies emerging that are currently not available on the market. There are two main technologies in this promising group: Organic Photovoltaic Cells (OPV) (Brabec, Sariciftci, and Hummelen 2001) and cells based on nanostructures or the "bulk heterojunction" concept ( $\mathrm{Yu}$ et al. 1995), also known as multiple-junction or "tandem" solar cells.

OPV cells, and within this wide group, polymer solar cells in particular have the advantage over all PV technologies where the possible manufacturing process is very fast and the thermal budget is low since no high temperatures are needed (Espinosa et al. 2012). In this regard, it is expected to be an inexpensive technology. 


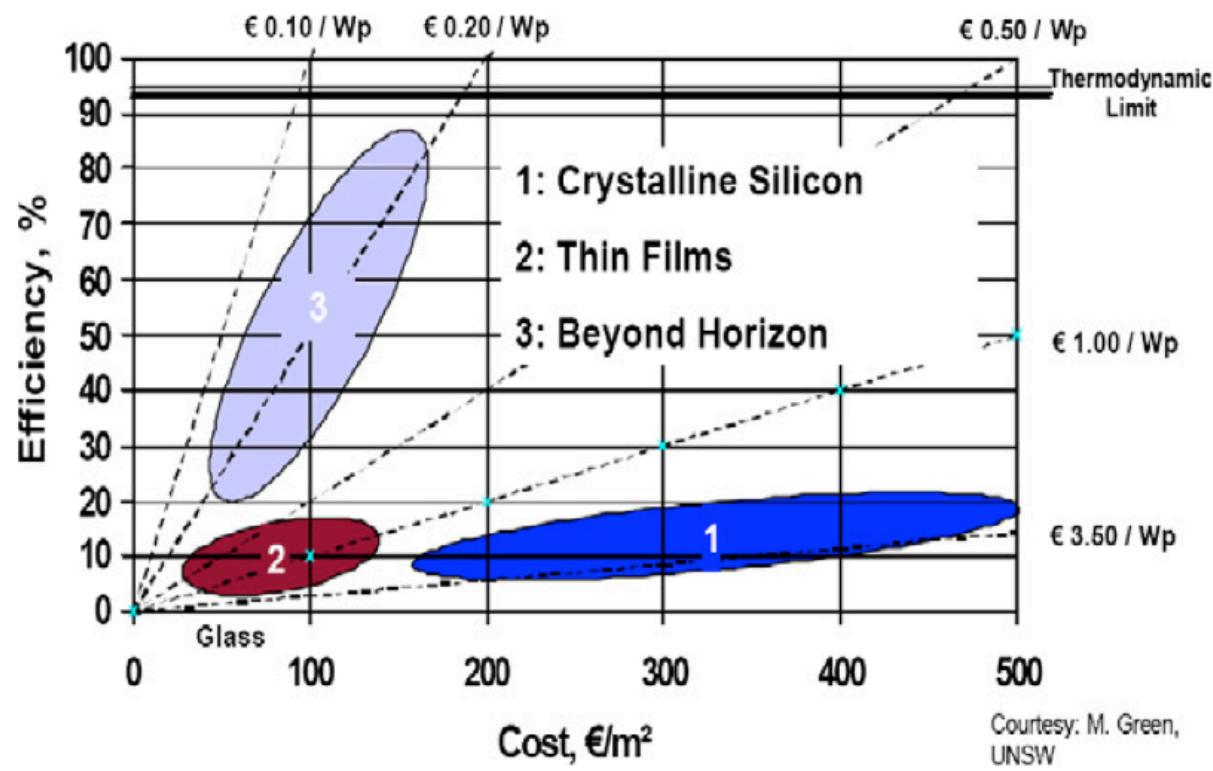

FIGURE 1.12. COST-EFFICIENCY ANALYSIS FOR FIRST-GENERATION (1), SECOND-GENERATION (2) AND THIRD-GENERATION (3) OF PHOTOVOLTAIC TECHNOLOGIES. (GREEN 2001)

\section{Photovoltaic market}

Mono-crystalline silicon (c-Si), polycrystalline silicon (p-Si) and ribbon silicon (r$\mathrm{Si}$ ) form Silicon technology, which has dominated the solar cell market the last 25 years.

During 2011, more than 50 MW of thin-film modules were produced. However, the majority of companies are silicon-based and use either amorphous silicon or an amorphous/microcrystalline silicon structure, followed by companies using $\mathrm{Cu}(\mathrm{In}, \mathrm{Ga})(\mathrm{Se}, \mathrm{S}) 2$ as absorber material for thin-film solar modules, whereas only a few companies use CdTe (PV Status Report, 2012).

c-Si technology is expected to maintain its market share at levels of around $80 \%$. This share is due to the maturity of the technology and the growing capacity in 
Chapter 1 Introduction

China and APAC countries (EPIA European Photovoltaic Industry Association n.d.). Non c-Si PV production capacity during last 4 years and the predicted next 4 years is displayed in Figure 1.13.

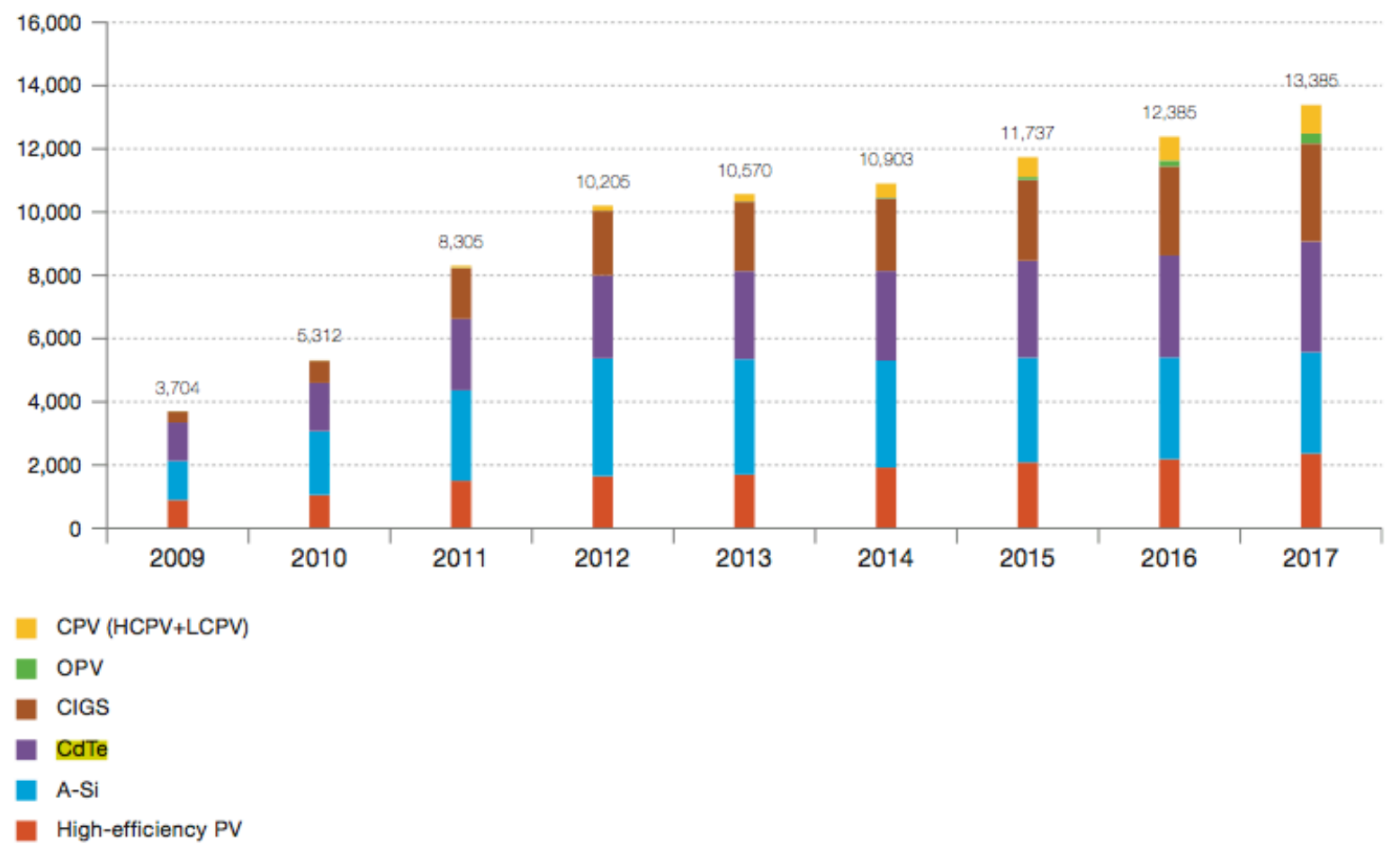

Source: EPIA, IHS Solar, PV Insider and SNE Research

FIGURE 1.13. NON C-SI PV PRODUCTION CAPACITY UNTIL 2017 (MW) (EPIA EUROPEAN PHOTOVOLTAIC INDUSTRY ASSOCIATION N.D.) 


\subsection{Decision-making on sustainable energies}

The last global report of the International Energy Agency (IEA) indicates that 1,577 million people are still lacking access to electricity, mainly in developing countries, where the average electrification rate in rural areas reaches only $56.4 \%$; even with a huge effort in electrification, the increase in population will keep this figure very high in 2030, when still 1,300 million people will live in rural areas without electricity (International Energy Agency IEA, 2010).

According to the International Energy Agency (IEA), the achievement of the Millennium Development Goals (MDGs) is linked to extending access to electricity to over 550 million people by 2015 (IEA, 2004)

Renewable energy technology in general, and photovoltaic technology in particular, can significantly upgrade energy access and thus provide for electricity, lighting, water pumping, and other services in poor rural areas.. At the same time, reduction of fossil fuel consumption can protect the local environment and reduce global green house gases emissions. Besides, fossil fuels generate dependence (buy, transport and consumption, in an continuous cycle) while photovoltaic technology once installed, is self-sustained needing a minimal maintenance.

However, the actual impact of energy provision on poor rural livelihoods have yet to be fully established and questions remain as to how to measure such impact. Furthermore, decisions to increase energy access in developing countries through the expansion of renewable energy systems have taken little or no notice of their global environmental impact, regarding manufacture, transport, and decommissioning. As a result, total $\mathrm{CO}_{2}$ emissions embedded in solar systems have often been overlooked when solar technology is implemented in rural areas of developing countries. 
Photovoltaic technologies have been installed in rural areas are almost entirely silicon made,. However, other PV technologies (described in previous section) could be more suitable than silicon.

Yet, no single study has assessed whether differences among photovoltaic types could have a bearing on poverty reduction and rural livelihoods. There seems to be general consensus that it is desirable to increase energy access to the poor in developing countries, particularly through the use of renewable energy. Nonetheless, decision makers have been unable to calculate the extent to which implementing renewable energy systems would impact the wellbeing of users, affect their local environments, improve economic prospects of poor communities, and contribute towards a low-carbon economy. Furthermore, decisions to provide energy technology to the rural poor have, as a matter of fact, been made mostly on the ground of price, power generation capacity and overlook current information of embedded energy in renewable energy systems.

With the aim of assessing which sustainable energy is the ideal supplying power to rural areas, avoiding harmful impact, multi-criteria decision-support system can assist in calculating the most appropriate set of energy options for providing sufficient power to fulfil local demands that improve livelihoods (Cherni J. 2006).

\subsection{Structure of the thesis}

The structure of the present dissertation is the following:

Chapter 2 explains the sources of data on which this thesis is based. These sources of information are four: literature review (scientific journals and books) and public databases (from Governments, international organizations, etc.); the photovoltaic database developed at our university (real-time data stored in a server from several photovoltaic generators), and socio-economical information 
extracted from a survey in a Cuban rural livelihood. In this way, Chapter 2 describes the methodology, as well as the grid-connected photovoltaic generator where the experimental data have been collected; technical description of both the PV facility and the monitoring system are described in detail.

Then, Chapter 3 describes how the information from PV generator database was applied in computing learning techniques in order to improve the performance of a CdTe grid-connected PV system integrated in a university parking lot; the methodology is to apply computational engineering tools to stored data of the BIPV generator in order to measure its performance and improve its control by gathering and analysing photovoltaic and environmental information using automated computing learning methods.

By applying Life Cycle Assessment methodology, the environmental impact of different case studies of photovoltaic technologies and its potential to climate change mitigation is assessed in Chapters 4 and 5. In Chapter 4 the environmental impacts of the CdTe PV system have been analysed and compared, underlining the environmental benefits of building integration, using the data from monitoring system of real BIPV generator. Chapter 5 extends the analysis to several photovoltaic technologies and shows how environmental impacts of PV systems will depend on the location where the system is manufactured and installed, that is, the geographical dependence of the environmental impacts.

Finally, in Chapter 6, the use of photovoltaic technologies to provide electricity to a rural livelihood is compared with a list of other energy options by a multicriteria decision support software, which has been applied to a case study focused on the energy supply of an isolated rural settlement in Cuba. Its impact into financial, natural, physical, human and social assets are taken into consideration, as an approach to analyse the long-term sustainability of the different energy options. 
Chapter 1 Introduction

The conclusions and proposed future work are presented in Chapter 7.

\subsection{References}

Adam Brown, Simon Müller, and Zuzana Dobrotková

2011 Renewable Energy- Markets and Prospects by Technology. International Energy Agency (IEA).

Alan D. Pasternak

2000 Global Energy Futures and Human Development: A Framework for Analysis,. UCRL-ID-140773.

http://www.llnl.gov/tid/lof/documents/pdf/239193.pdf.

BP Global

2013 Statistical Review of World Energy 2013. http://www.bp.com/en/global/corporate/about-bp/statistical-review-of-worldenergy-2013.html, accessed September 19, 2013.

Cherni J., Dyner I.

2006 Energy Supply for Sustainable Rural Livelihoods. A Multi-criteria Decision-support System. ELSEVIER.

Chu, Steven, and Arun Majumdar

2012 Opportunities and Challenges for a Sustainable Energy Future. Nature 488(7411): 294-303.

EPIA European Photovoltaic Industry Association

2012 Global Market Outlook for Photovoltaics Until 2016. Renewable Energy House. http://www.epia.org/news/publications/.

2013 Global Market Outlook for Photovoltaics 2013-2017. Renewable Energy House. http://www.epia.org/news/publications/. 
European Commision

2012 Europe 2020. http://ec.europa.eu/europe2020/index_en.htm, accessed May 4, 2013.

IEA

2009 Energy Efficiency Indicators for Public Electricity Production from Fossil Fuels. Paris: Organisation for Economic Co-operation and Development. http://www.oecd-ilibrary.org/content/book/9789264061996-en, accessed June 22, 2013.

International Energy Agency

2013aTracking Clean Energy Progress 2013 - IEA Input to the Clean Energy Ministerial. http://www.iea.org/etp/tracking/, accessed September 4, 2013.

2013b Annual Report 2012 - Photovoltaic Power System Programme. http://iea-pvps.org/index.php?id=6\&eID $=$ dam_frontend_push\&docID $=1535$, accessed September 4, 2013.

Van de Kerk, Geurt, and Arthur R. Manuel

2008 A Comprehensive Index for a Sustainable Society: The SSI - the Sustainable Society Index. Ecological Economics 66(2-3): 228-242.

Khalid Malik, Maurice Kugler, Milorad Kovacevic, et al.

2013 Human Development Report 2013. Published for the United Nations Development Programme (UNDP). http://issuu.com/undp/docs/hdr_2013_en, accessed June 29, 2013.

Mulugetta, Yacob, Alison Doig, Simon Dunnett, et al.

2002 Energy for Rural Livelihoods: a Framework for Sustainable Decision Making. London: ITDG.

Ottmar Edenhofer, Ramón Pichs-Madruga, Youba Sokona, et al.

2011 Special Report on Renewable Energy Sources and Climate Change Mitigation. In Renewable Energy Sources and Climate Change Mitigation P. 1075. United Kingdom and New York, NY, USA: Cambridge University Press.

Razykov T. M., Ferekides C.S.

2011 Solar Photovoltaic Electricity: Current Status and Future Prospects. 
Chapter 1 Introduction

ELSEVIER.

Wamukonya, N., ed.

2003 Electricity Reform: Social and Environmental Challenges. UNEP Riso Centre. 


\section{Chapter 2}

\section{METHODOLOGY AND DATA}

\section{Collection}

Synopsis In the course of the studies realized in this dissertation several sources of information have been consulted. Depending on the methodology; theoretical or experimental collections of data were used following a different methodology which is described in detail, specially in the case of the monitored CdTe PV system which provided most of the experimental data. .

In 2009, a Cadmium Telluride $222 \mathrm{~kW}_{\mathrm{p}}$ grid-connected photovoltaic generator was installed at the University of Murcia. Cadmium Telluride (CdTe) modules are an example of the second generation of photovoltaic technologies, also called "thin-film" technology, which is characterized by its low need of material in the manufacturing process. Additionally, CdTe modules are in the fifth segment of photovoltaic market, it has the second position on non c-Si PV production capacity.

A monitoring system was installed, supplying up-to date information about environmental conditions and technical parameters; this information has been in this thesis.

\subsection{Methodology}

In this chapter we describe the different ways of data collection that were carried out during the thesis work. The sources are described below. Each of the case studies presented used data from one or two kind of sources. Since the most important source of experimental data is the CdTe PV system installed and monitored at the university, this data acquisition system is explained in more detail.

In the course of this thesis several studies have been developed. Each one of them has required consulting data from different sources, depending on the practical or 
theoretical character of the research, and sometimes both. Four types of information source can be highlighted:

- Literature review. This primary phase has been carried out in every study. To establish the state of art and to evaluate currently studies developed by other authors is a necessary stage in order to obtain a global context of the problem that is going to be addressed.

- Public databases. The information published by public institutions as International Energy Agency (IEA), Intergovernmental Panel on Climate Change (IPCC), Institute of Energy and Transport-European Commission, United Nations Development Programme (UNDP), public reports from administration of several countries, and private databases as Ecoinvent (Swiss Centre of Life Cycle Inventories), have been used in several studies. These sources of information are reliable and easily accessible.

- Experimental data acquisition. A monitoring system was installed in mid2009 in a CdTe photovoltaic generator at University of Murcia, in southeast Spain, and it has been operating since then. Information from environmental sensors and from PV-generator inverters have been collected in a server every 5 minutes during the past four years, therefore providing a huge database which can be accessed remotely. The next subsection explains all details about the configuration of this monitoring system.

- Survey. A survey was put into practice in a rural settlement in Cuba during the course of RESURL project (Department for International Development, 2004). Real in-situ information from natural, social, economic and human environment was recollected. The questionnaire used in this survey is included in Annex II. 
Literature review was completed in initial phase of all studies. Besides, different data were used for different case studies:

- For the application of learning computing algorithms applied to failure detection and prediction (Chapter 3), data obtained for monitoring system were consulted, as well as public information from PVGIS (European Commision, 2011)

- During the development of Life Cycle Assessment of real PV Generator integrated in parking set, located at University of Murcia, information from the monitoring system installed in it were used, as well as information from public institutions and from Ecoinvent database.

- The study of the geographical dependence of the PV environmental impact required mainly information from public institutions and Governments, and was completed with data from Ecoinvent.

- Finally, the information collected during the survey was applied to SURE software. Improvement in this computing tool required data from public databases as well.

Thus, information constitutes the pillar of the work developed during the studies realized in this thesis. Then, different scientific disciplines were applied to the data in different fields; photovoltaic engineering, computational science and environmental impact analysis:

- Life Cycle Assessment Methodology. The studies showed in Chapter 4 and 5 shows applied LCA to several case studies in order to get its environmental impact.

- Computing science. Two fields of computing science were applied in this thesis. On one hand, computing learning algorithms were applied to information from PV generator (Chapter 3). On the other hand, SUREDSS software tool code was improved and completed (Chapter 6). 
From all kind of data sources explained, data acquisition system required hard work: configuration, implementation of software, monitoring and inspection. In next section the BIPV generator and its monitoring system is explained in detail.

\subsection{Description of the PV generator: $222 \mathrm{kWp}$ CdTe parking integrated grid-connected facility}

A $222 \mathrm{~kW}_{\mathrm{p}}$ CdTe parking integrated grid-connected PV facility, showed in Figure 2.1, was built during late 2008 and beginning of 2009 and finally commissioned in May, 2009, at the University of Murcia, in the South-East of Spain. This facility is located next to Faculty of Computing Science, Faculty of Psychology and the university swimming pool. A montoring system was installed within the PV generator and it started to store operating information on $10^{\text {th }} \mathrm{July,} 2009$.

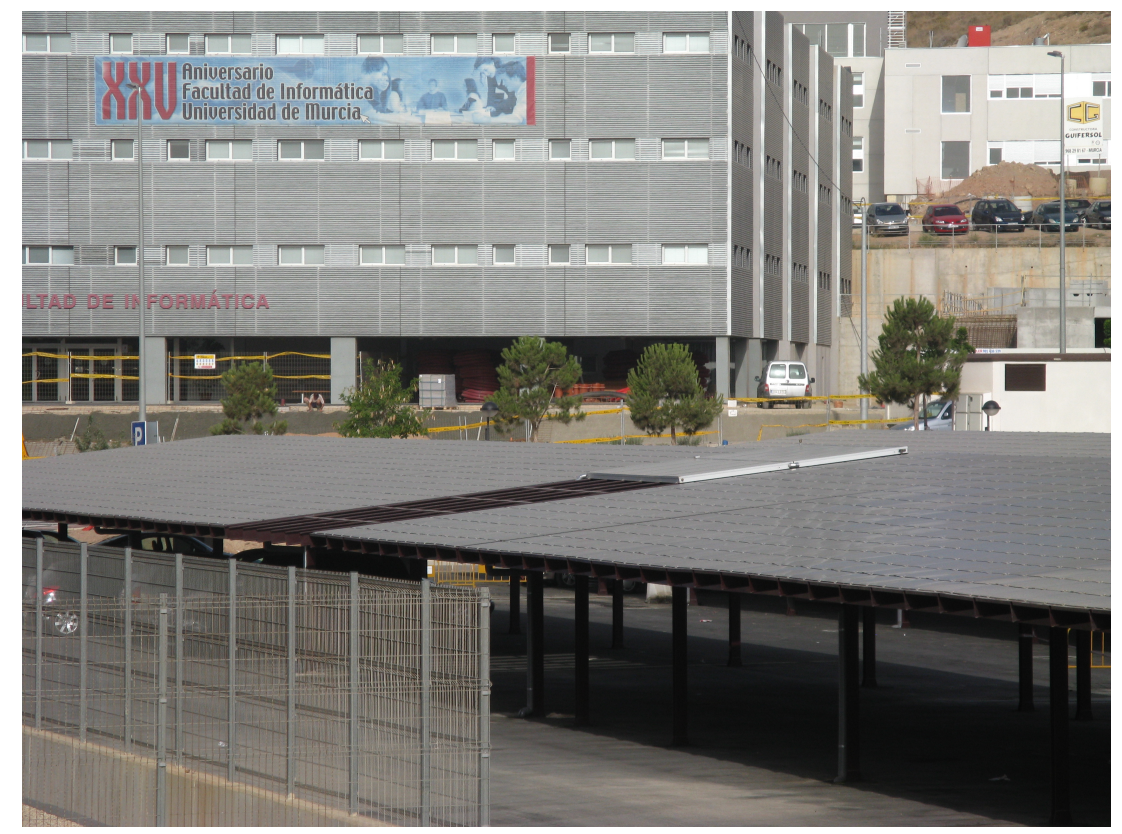

FIGURE 2.1 222KWP CDTE PARKING INTEGRATED GRID-CONNECTED FACILITY 
The main parameters of the system are:

- Latitude $38^{\circ} 01^{\prime} 12^{\prime \prime} \mathrm{N}$

- $7^{\circ}$ tilted

- 3,144 CdTe modules
- Longitude $1^{\circ} 09^{\prime} 56^{\prime \prime} \mathrm{W}$

- $-20^{\circ}$ southeast orientation

- $\quad 2,263.36 \mathrm{~m}^{2}$ surface

- 30 inverters of $7 \mathrm{kVA}$

The facility is oriented $20^{\circ}$ to the East and is tilted $7^{\circ}$ over the horizontal in order to avoid shadows between the three canopies, in which the structure is divided. The limited available surface constrained the design of the PV system to a nonoptimal orientation and tilt angle for the given latitude of the geographical location of the facility.

As can be seen in Table 2.1, the generator is composed of three types of modules with different nominal peak power of $67.5,70$ and $72.5 \mathrm{~W}_{\mathrm{p}}$, respectively, and with modules from First Solar, models FS-267, FS-270 and FS-272 ("First Solar FS Series PV Module," 2011), covering a total PV surface of 2,263 $\mathrm{m}^{2}$, with 25 -years power output transferable warranty of minimum output power.

The modules are divided in 10 groups and 30 subgroups, as Figure 2.2 shows, which are, each of them, connected to an inverter (and therefore we have a total of 30 inverters). The electrical configuration is showed in Figure 2.3. 
LINE 1

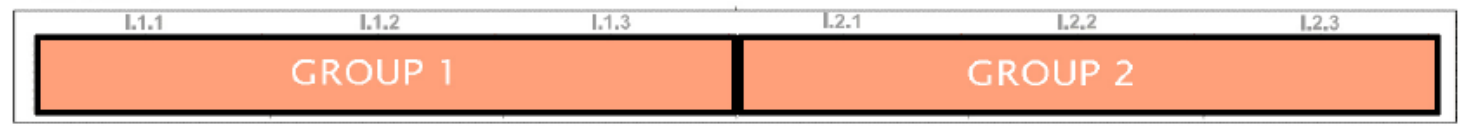

LINE 2

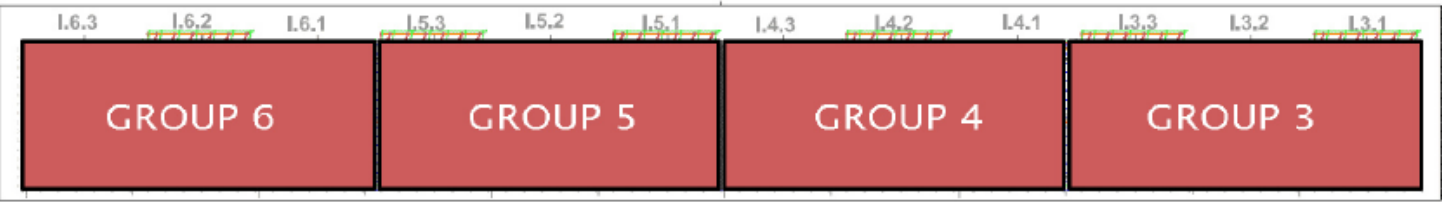

LINE 3

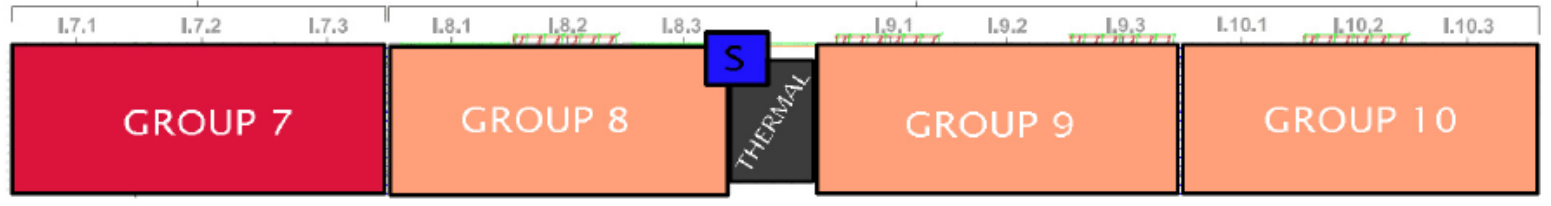

FIGURE 2.2. GROUPS OF PV MODULES FORMING THE PV GENERATOR, GROUP ORGANIZATION AND INVERTER IDENTIFICATION.

\begin{tabular}{ccccccccc} 
Inverter & $\begin{array}{c}\text { Module } \\
\text { type }\end{array}$ & $\begin{array}{c}\text { Serie } \\
\text { modules }\end{array}$ & $\begin{array}{c}\text { Parallel } \\
\text { modules }\end{array}$ & $\begin{array}{c}\text { Vmpp } \\
\text { (V) }\end{array}$ & $\begin{array}{c}\text { Impp } \\
(\mathbf{A})\end{array}$ & $\begin{array}{c}\text { Pmpp } \\
\text { (W) }\end{array}$ & $\begin{array}{c}\text { Area } \\
\left(\mathbf{m}^{2}\right)\end{array}$ & Name \\
\hline 1.1 & FS-270 & 8 & 13 & 536.8 & 13.52 & 7280 & 74.88 & wr7k_023_2000457991 \\
1.2 & FS-270 & 8 & 13 & 536.8 & 13.52 & 7280 & 74.88 & wr7k_023_2000457978 \\
1.3 & FS-270 & 8 & 13 & 536.8 & 13.52 & 7280 & 74.88 & wr7k_023_2000457828 \\
2.1 & FS-270 & 8 & 13 & 536.8 & 13.52 & 7280 & 74.88 & wr7k_023_2000457758 \\
2.2 & FS-270 & 8 & 13 & 536.8 & 13.52 & 7280 & 74.88 & wr7k_023_2000457919 \\
2.3 & FS-270 & 8 & 13 & 536.8 & 13.52 & 7280 & 74.88 & wr7k_023_2000457799 \\
3.1 & FS-272 & 8 & 13 & 543.2 & 13.91 & 7540 & 74.88 & wr7k_023_2000457757 \\
3.2 & FS-272 & 8 & 13 & 543.2 & 13.91 & 7540 & 74.88 & wr7k_023_2000457836 \\
3.3 & FS-272 & 8 & 13 & 543.2 & 13.91 & 7540 & 74.88 & wr7k_023_2000457747 \\
4.1 & FS-272 & 8 & 13 & 543.2 & 13.91 & 7540 & 74.88 & wr7k_023_2000458517 \\
4.2 & FS-272 & 8 & 13 & 543.2 & 13.91 & 7540 & 74.88 & wr7k_023_2000457922 \\
4.3 & FS-272 & 8 & 13 & 543.2 & 13.91 & 7540 & 74.88 & wr7k_023_2000454237
\end{tabular}


Chapter 2 Methodology and Data Collection

\begin{tabular}{|c|c|c|c|c|c|c|c|c|}
\hline Inverter & $\begin{array}{c}\text { Module } \\
\text { type }\end{array}$ & $\begin{array}{c}\text { Serie } \\
\text { modules }\end{array}$ & $\begin{array}{l}\text { Parallel } \\
\text { modules }\end{array}$ & $\begin{array}{l}\text { Vmpp } \\
\text { (V) }\end{array}$ & $\begin{array}{c}\text { Impp } \\
\text { (A) }\end{array}$ & $\begin{array}{c}\text { Pmpp } \\
\text { (W) }\end{array}$ & $\begin{array}{l}\text { Area } \\
\left(\mathrm{m}^{2}\right)\end{array}$ & Name \\
\hline 5.1 & FS-272 & 8 & 13 & 543.2 & 13.91 & 7540 & 74.88 & wr7k_023_2000457764 \\
\hline 5.2 & FS-272 & 8 & 13 & 543.2 & 13.91 & 7540 & 74.88 & wr7k_023_2000457748 \\
\hline 5.3 & FS-272 & 8 & 13 & 543.2 & 13.91 & 7540 & 74.88 & wr7k_023_2000457750 \\
\hline 6.1 & FS-272 & 8 & 13 & 543.2 & 13.91 & 7540 & 74.88 & wr7k_023_2000458131 \\
\hline 6.2 & FS-272 & 8 & 13 & 543.2 & 13.91 & 7540 & 74.88 & wr7k_023_2000458132 \\
\hline 6.3 & FS-272 & 8 & 13 & 543.2 & 13.91 & 7540 & 74.88 & wr7k_023_2000457817 \\
\hline 7.1 & FS-267 & 8 & 13 & 516.8 & 13.65 & 7560 & 80.64 & wr7k_023_2000457928 \\
\hline 7.2 & FS-267 & 8 & 13 & 516.8 & 13.65 & 7560 & 80.64 & wr7k_023_2000458045 \\
\hline 7.3 & FS-267 & 8 & 13 & 516.8 & 13.65 & 7560 & 80.64 & wr7k_023_2000457921 \\
\hline 8.1 & FS-270 & 8 & 13 & 536.8 & 13.52 & 7280 & 74.88 & wr7k_023_2000219910 \\
\hline 8.2 & FS-270 & 8 & 13 & 536.8 & 13.52 & 7280 & 74.88 & wr7k_023_2000355393 \\
\hline 8.3 & FS-270 & 8 & 13 & 536.8 & 13.52 & 7280 & 74.88 & wr7k_023_2000611449 \\
\hline 9.1 & FS-270 & 8 & 13 & 536.8 & 13.52 & 7280 & 74.88 & wr7k_023_2000457749 \\
\hline 9.2 & FS-270 & 8 & 13 & 536.8 & 13.52 & 7280 & 74.88 & wr7k_023_2000457769 \\
\hline 9.3 & FS-270 & 8 & 13 & 536.8 & 13.52 & 7280 & 74.88 & wr7k_023_2000457762 \\
\hline 10.1 & FS-270 & 8 & 13 & 536.8 & 13.52 & 7280 & 74.88 & wr7k_023_2000457997 \\
\hline 10.2 & FS-270 & 8 & 13 & 536.8 & 13.52 & 7280 & 74.88 & wr7k_023_2000457988 \\
\hline 10.3 & FS-270 & 8 & 13 & 536.8 & 13.52 & 7280 & 74.88 & wr7k_023_2000457824 \\
\hline
\end{tabular}

TABLE 2.1 ORGANIZATION AND TECHNICAL SPECIFICATIONS OF THE GROUPS OF MODULES 
Chapter 2 Methodology and Data Collection

\begin{tabular}{llll}
\hline PV module & \multicolumn{3}{c}{ FIRST SOLAR } \\
\hline Model & FS-267 & FS-270 & FS-272 \\
Nominal Power (W) & 67.50 & 70.00 & 72.50 \\
Open circuit voltage (V) & 87.00 & 89.00 & 90.00 \\
Short circuit current (A) & 1.18 & 1.19 & 1.19 \\
Max. power voltage (V) & 64.60 & 67.10 & 67.90 \\
Max. power current (A) & 1.05 & 1.04 & 1.07 \\
Mass (kg) & & 12.00 & \\
Length (cm) & & 120.00 & \\
Width (cm) & & 60.00 &
\end{tabular}

TABLE 2.2. TECHNICAL SPECIFICATIONS OF THE PV MODULES USED AT THE PV-PARKING FACILITY

\begin{tabular}{lc}
\hline Inverter & SMA \\
\hline Model & SMC 7000HV \\
Input voltage, MPP range (V) & $335-560$ \\
Maximum output power (VA) & $7,000.00$ \\
Nominal output power (VA) & $6,650.00$ \\
Maximum output current (A) & 31 \\
Nominal output voltage (A) & $220-240$ \\
Frequency output (Hz) & $50 \pm 1 \%$ \\
European efficiency & $95.3 \%$
\end{tabular}

TABLE 2.3. TECHNICAL SPECIFICATIONS OF THE INVERTERS USED AT THE PV-PARKING FACILITY 
Table 2.2 shows the main parameters of these PV modules. The 30 subgroups of modules are connected to an inverter in the next way: 13 parallel strings of 8 series-connected modules each string, except 3 subgroups of FS-267 modules, which have 14 parallel strings. Each one of these subgroups feeds the grid through an inverter of $7 \mathrm{kVA}$ of capacity. The 30 single-phase inverters are grouped and work in coordination to generate a three-phase AC signal. The model of inverter used at the PV facility is the SMC7000HV(SMA Solar Technology AG, 2012), shown in Table 2.3. The electrical scheme of the facility is shown in Figure 2.3. 


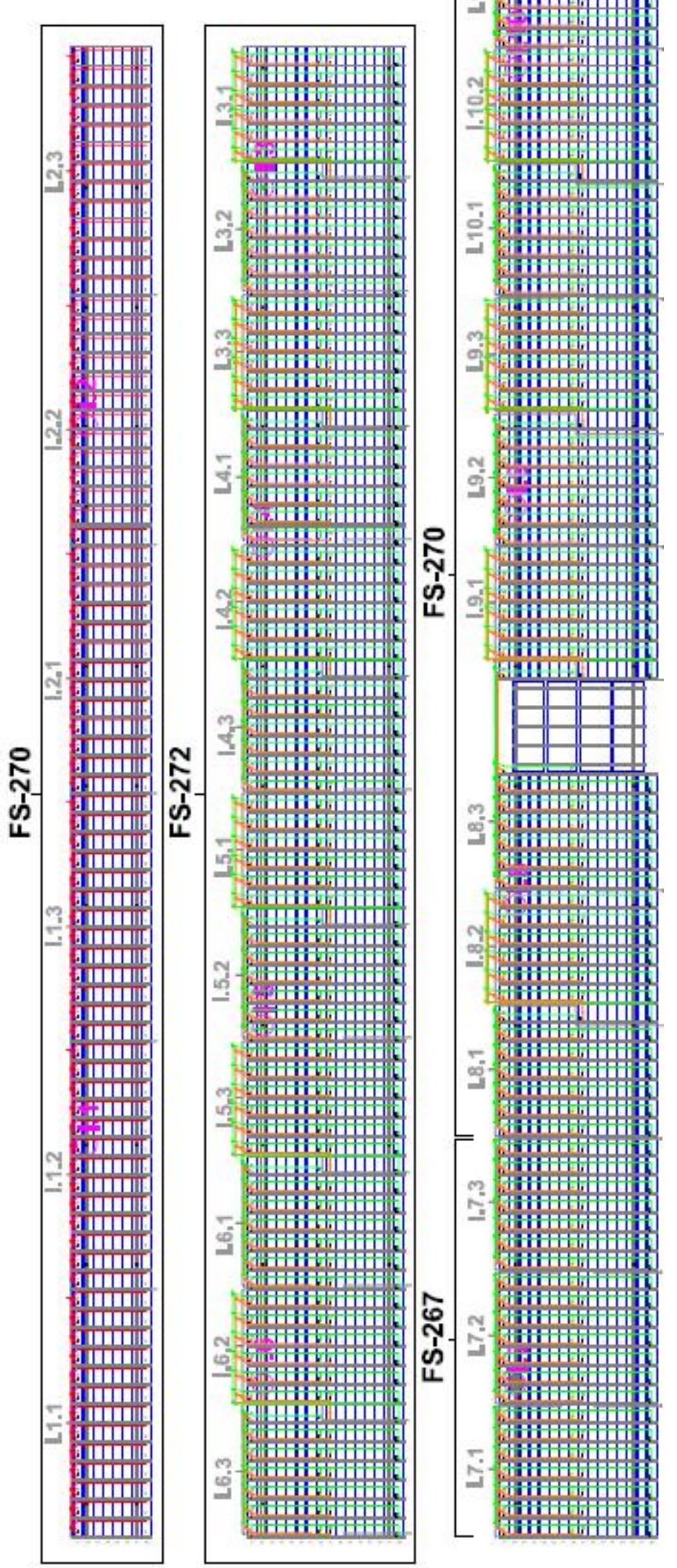

FIGURE 2.3. ELECTRICAL SCHEME OF 222 kWp CdTe PV GENERATOR 


\subsection{Data collection. Monitoring environmental and system parameters.}

As it has been explained in previous section, 3,144 CdTe modules and 30 inverters shape the whole PV generator. Each inverter can send information in a user-defined period of time. In order to record the information provided by the inverters, a monitoring system has been installed; it is divided into three subsystems as shown in Figure 2.4: data acquisition system, permanent data storage and data access.
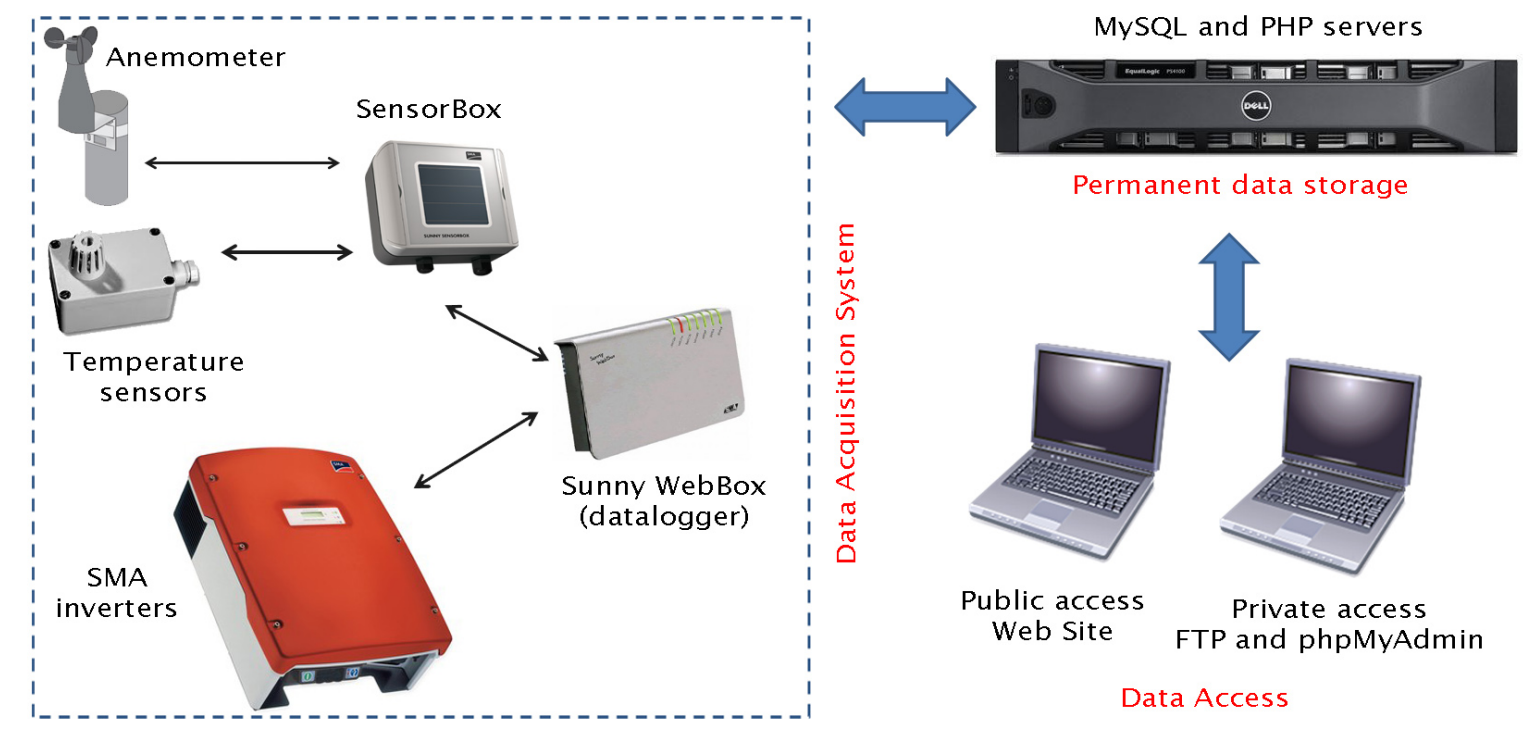

FIGURE 2.4. RELATIONS BETWEEN DATA ACQUISITION SYSTEM, PERMANENT DATA STORAGE AND DATA ACCESS

The aim of the Data Acquisition System is to gather the information from the inverters and environmental sensors.

Inverters use closed communication protocols (SMA-NET and SMA-COM). The manufacturer makes available these protocols, facilitating the task of programming the data-acquisition software. 


\subsubsection{Data Acquisition System}

SMA offers the device "Sunny Sensor Box" (SSB) as monitoring solution. This device monitors the environmental data. It is located on a surface parallel to the photovoltaic modules plane. In our PV system scheme, the SSB is pointed out in the place indicated in Figure 2.2 by the letter " $\mathrm{S}$ ".

The SSB is equipped with an environmental irradiation sensor (that consists on asilicon cell with [0-1500] $\mathrm{W} / \mathrm{m} 2$ range and $+-8 \%$ margin error) and two temperature sensors ("SMA PT100 Ambient Temperature Sensor (SensorBox) Logging - SMA - Accessories - GPC Europe,” 2013), with 2,5m wire longitude: one of them was installed on the modules' opposite side in order to measure the cell temperature and the other one measures the environmental temperature. In addition, an anemometer was installed, providing information about wind speed.

In the same way, SMA offers the device Sunny WebBox (SWB) as data-logger solution. This data-logger stores internally the information that is periodically sent by the inverter and the sensors. The stored information is to be sent at a later stage to a server (our sever is described in next subsection). SWB can be configured in many ways by logging in its Sunny Portal, showed in Figure 2.5, (our Sunny Portal is hosted in the IP 155.54.181.10). The data is automatically sent to this host. Sunny Portal let the user check the connected devices and configure the interval for sending the information to the server. 


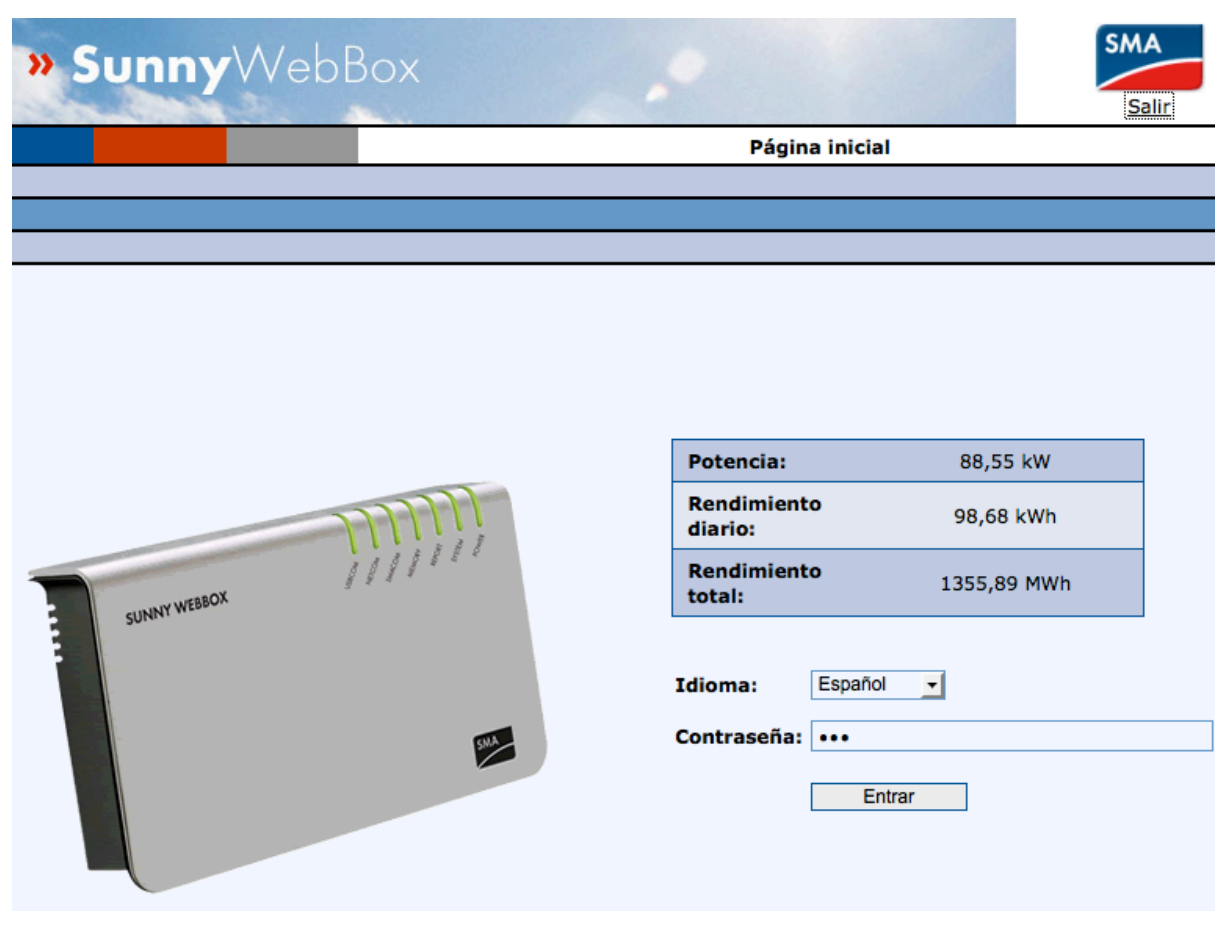

FIGURE 2.5. SMA SUNNY WEB BOX INTERFACE

The data-package shipment was configured for sending all the data every five minutes, from $6 \mathrm{~h}$. in the morning until $22 \mathrm{~h}$. in the night.

The information sent by each one of the 30 SMC7000HV inverters every five minutes is shown in Table 2.4. 


\begin{tabular}{ll} 
Name & Description \\
\cline { 1 - 1 } TimeStamp & Date and time when the information is sent \\
Fac & Total injected energy $(\mathrm{kWh})$ \\
Fehler & Net frequency $(\mathrm{Hz})$ \\
h-On & Total number of hours in service \\
h-Total & Total number of injecting energy hours in service \\
Iac-Ist & Net current (A) \\
Ipv & Direct current (A) \\
Netz-Ein & Total number of connection to net \\
Pac & Delivered CA power (W) \\
Riso & Insulation resistance before net connection \\
Status & Current performance state \\
Uac & Net voltage (V) \\
Upv-Ist & PV input voltage (V) \\
Upv-Soll & Net impedance (Ohm)
\end{tabular}

TABLE 2.4. PARAMETERS SENT BY SMA SMC7000HV INVERTERS. NAME (TAG) AND DESCRIPTION.

This information is encapsulated in each package, together with the environmental data sent by the SSB that send the parameters Table 2.5 shows.

\begin{tabular}{|c|c|}
\hline Name & Description \\
\hline TimeStamp & Date and time \\
\hline IntSollrr & Global irradiation in tilted surface $\left(\mathrm{W} / \mathrm{m}^{2}\right)$ \\
\hline OpTm & Sensor Box Service hours \\
\hline Windvel & Wind speed $(\mathrm{m} / \mathrm{s})$ \\
\hline TmpAmb & Environmental temperature in shadow $\left({ }^{\circ} \mathrm{C}\right)$ \\
\hline TmpMdul & Solar module temperature $\left({ }^{\circ} \mathrm{C}\right)$ \\
\hline
\end{tabular}

TABLE 2.5. PARAMETERS SENT BY SUNNY SENSOR BOX. NAME (TAG) AND DESCRIPTION. 
Chapter 2 Methodology and Data Collection

These parameters are stored in a XML file, which is then compressed into a ZIP file. Several packages are compressed, again, into another ZIP file.

\section{ONE EXAMPLE OF THIS XML FILES IS SHOWN IN}

Figure 2.6. 

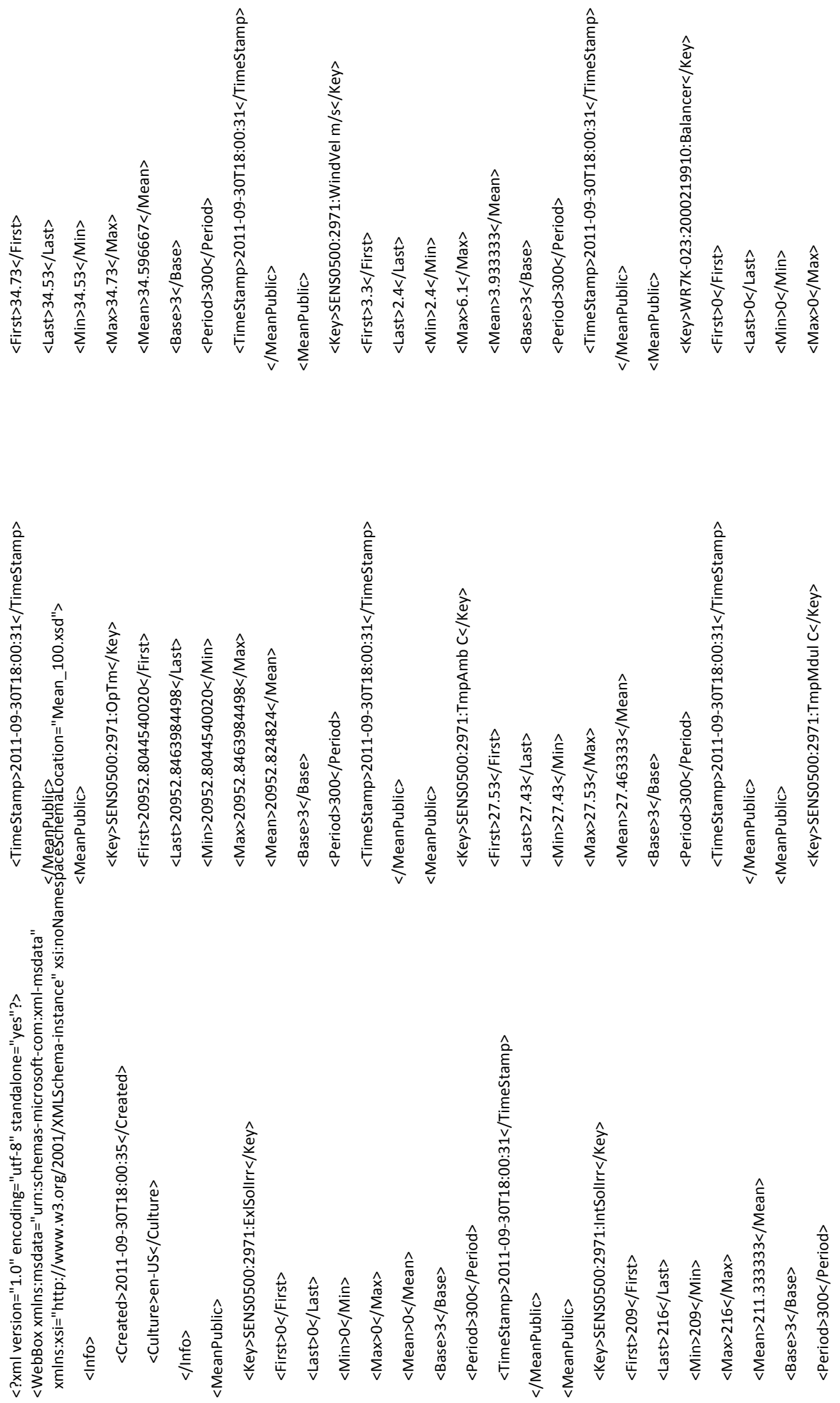


\subsubsection{Permanent Data Storage}

Once the format of the data has been checked, they are sent to the server, which is programmed to process these packages as indicated below.

A new DELL server ("Dell Official Site - The Power To Do More | Dell," 2013) was received on $28^{\text {th }}$ June, 2012. We configured the server by installing Windows Server 2008 (Microsoft, 2013) on a disk partition of 343GB (C:). The received packages are stored in a disk partition of $521 \mathrm{~GB}(\mathrm{~F}:)$. Then, 1TB disk houses the database, and another 1TB disk is used as a backup of the database.

The free application AppServ (“AppServ," 2013) was installed in order to get the next tools at the same time:

- Apache ("Welcome to The Apache Software Foundation!," 2013), that is a web server application,

- PHP ("PHP: Hypertext Preprocessor," 2013) is a server-side scripting language,

- MySQL ("MySQL :: The world's most popular open source database," 2013) is the world's most widely used open-source Relational Database Management System (RDBMS),

- phpMyAdmin ("phpMyAdmin," 2013) is a free software tool written in PHP, intended to handle the administration of MySQL over the Web.

File Transfer Protocol (FTP) was configured using FileZilla tool ("FileZilla," 2013). In order to traduce the ZIP packages, which are received in a folder, into MySQL instructions, three PHP programs are executed simultaneity: 
- “directorio.php". This program unzips each package. The extracted ZIP files are stored in other folder, and at the same time original packages are copied to a backup folder.

- "intermedio.php". This program extracts the ZIP files obtained in "directorio.php". It stores the extracted XML files in other folder and delete the original ZIP files.

- “inversores.php". Finally, this program reads each XML file, and traduces each one into MySQL instructions.

The database was exported from the old server to the new one, keeping the same database configuration. During this process, some occasional time-holes on the database, where information from sensors and inverters were lost, were identified.

There are 30 tables stored at MySQL database, one for each inverter. Names of the tables are written in the right column of Table 2.1. The names of the fields are the same than the inverters send, shown in the first column of Table 2.4. "sens0500_2971" is the name of the table for the information received from each of the sensors, and its fields can be seen in the first column of Table 2.5.

\subsubsection{Data Access}

An informative Web site (UMU-UPCT, 2009) was programmed and made available on-line where users can access to information about the PV gridconnected generator: didactic contents about PV technology and graphical representations of the PV generator behaviour as well. Real time data acquisition (from the PV facility and the environmental parameters) can be monitored by live graphs. 
The database is remotely accessed and administered by the web portal phpMyAdmin. The information used in this work was extracted from MySQL database by SQL instructions.

With this data, we will analyse the performance of the installation, its environmental impact, comparing with another theoretical configurations of the PV system (Chapter 2). We will analyse data, by applying computational learning techniques, to predict malfunctions on the PV generator as well (Chapter 4).

\subsection{Conclusions}

In this chapter the methodology followed in the thesis has been presented. The different kinds of data has used for any case study were described: literature review, data acquisition system, survey and public databases. These sources of information have been consulted during the studies presented in this dissertation.

Our own data acquisition de system, i.e. monitoring system of $222 \mathrm{kWp} \mathrm{CdTe} \mathrm{PV}$ system at University of Murcia, has been explained in detail. This system stores information about performance of the PV generator and about environmental information, so that registers stored since mid-2009 can be used to learn about the PV evolution performance, applying computing learning techniques (Chapter 3) and this information can be used to measure the environmental impact is avoided thanks to its productivity as well (Chapter 4).

\subsection{References}
AppServ
[WWW
Document],
2013.
URL http://www.appservnetwork.com/?newlang=spanish (accessed 4.30.11).
Dell Official Site - The Power To Do More | Dell [WWW Document], 2013. URL http://www.dell.com/ (accessed 9.11.13). 
Department for International Development, 2004. DFID - Research for Development $>$ Renewable Energy for Sustainable Rural Livelihoods (RESURL) [WWW Document]. URL http://r4d.dfid.gov.uk/Project/2979/ (accessed 11.26.12).

European Commision, 2011. Photovoltaic Geographical Information System (PVGIS) [WWW Document]. URL http://re.jrc.ec.europa.eu/pvgis/ (accessed 12.7.11).

FileZilla [WWW Document], 2013. URL https://filezilla-project.org/ (accessed 9.11.13).

First Solar FS Series PV Module [WWW Document], 2011. URL http://www.gehrlicher.com/es/ (accessed 12.7.11).

Microsoft, 2013. Windows Server 2008 [WWW Document]. URL http://technet.microsoft.com/es-ES/windowsserver/bb310558 (accessed 9.6.13).

MySQL :: The world's most popular open source database [WWW Document], 2013. URL http://www.mysql.com/ (accessed 9.6.13).

PHP: Hypertext Preprocessor [WWW Document], 2013. URL http://php.net/ (accessed 9.6.13).

phpMyAdmin [WWW Document], $2013 . \quad$ URL http://www.phpmyadmin.net/home_page/index.php (accessed 9.11.13).

SMA PT100 Ambient Temperature Sensor (SensorBox) - Logging - SMA Accessories - GPC Europe [WWW Document], 2013. URL http://www.gpceurope.com/en/product/sma-pt100-ambient-temperature-sensorsensorbox-80 (accessed 9.11.13).

SMA Solar Technology AG, 2012. SUNNY MINI CENTRAL 7000HV [WWW Document]. SUNNY MINI Cent. 7000HV SMA Sol. Technol. AG. URL http://www.sma.de/en/products/solar-inverters/sunny-mini-central/sunny-minicentral-7000hv.html (accessed 12.7.11).

UMU-UPCT, 2009. http://sustainable-tech.inf.um.es [WWW Document]. URL http://sustainable-tech.inf.um.es/ (accessed 12.2.11).

Welcome to The Apache Software Foundation! [WWW Document], 2013. URL http://www.apache.org/ (accessed 9.6.13). 


\title{
Chapter 3
}

\section{COMPUTATIONAL}

\section{INTELLIGENCE APPLIED TO}

\author{
Photovoltaics
}

Synopsis. Computing learning algorithms have been used on data collected from a photovoltaic system to predict its generation and performance. Nevertheless, this computing approach has mainly centred the efforts in general approximations from weather information. A brief incursion is presented to classify the occurrence of failure during PV performance and to distinguish between different kinds of low-performance states, taken into consideration technical parameters. An initial test tries to guide the beginning of possible behaviours of performance of a group of photovoltaic modules.

\subsection{Introduction. Learning-computing algorithms as a solution to renewables energy control automation}

In previous chapter, $222 \mathrm{kWp}$ PV system at University of Murcia was described. The monitorization system stores technical and environmental information in a database. This information is quite valuable because historical data are a key element in prediction systems.

During recent years the number of large-scale PV system has grown worldwide. In 2010, the photovoltaic industry production more than doubled and reached a world-wide production volume of $23.5 \mathrm{GWp}$ of photovoltaic modules. Business analysts predict that investments in PV technology could double from $€$ 35-40 billion in 2010 to over $€ 70$ billion in 2015, while prices for consumers are 
continuously decreasing at the same time. (Research, Solar Cell Production and Market Implementation of Photovoltaics, 2011)

The complexity in PV system configurations represent an additional problem in maintenance and control operations since a failure in one PV module placed at a big façade is difficult to detect. A quick detection of failures would avoid energy losses due to malfunctions of PV system (Roman et al., 2006).

Up to date, there are several studies that apply the learning-computing algorithm in order to find a solution to renewable energies specific problems.

In (Chaabene et al., 2007) and (Ben Salah et al., 2008) the authors develop a fuzzy decision-making algorithm, based on expert knowledge, in order to decide when to connect devices either to the PVP output or the electric grid to achieve an energy saving during daylight up to $90 \%$ of the PVP generated system. (Sallem et al., 2009) applies fuzzy rules as well, with the aim to extend operation time of the water pump by controlling a switching unit. (Ammar et al., 2010) proposes an energy planning of the estimated photovoltaic generation for the next day. It considers the PVG during the last ten days in order to forecast its behaviour for the following day using a Neuro Fuzzy estimator. (Cirre et al., 2009) uses twolayer hierarchical control strategies, fuzzy logic and physical model-based optimization, to automatically track the operating point despite any disturbances affecting the plant, taking operating constraints into account.

Nevertheless, other lines of research on PV-systems face the solar energy problems from a more general point of view. Increasing attention is being paid to PV systems reliability in recent years due to rapid growth of PV power installation in residential and commercial buildings as well as military bases (Wang et al., 2012). Primary interest for researchers in solar energy is related to 
the design and optimization of solar energy homes, while improving energy efficiency in buildings is a major priority worldwide (Baños et al., 2011). Many studies regard the reliability and risk assessment of large-scale PV systems as a way to bring benefits for both utility companies and customers (Zhang et al., 2013). The discussions are extended to emerging research topics including time varying and ambient-condition-dependent failure rates of critical PV system components (Zhang et al., 2013). (Catelani et al., 2011) noticed that a crucial aspect in PV systems is the cleaning status of the panel surface. They used FMECA (Failure modes effects and criticality analysis) in order to classify the occurrence of failures. The obtained results allow the designer to identify the modification, which must be made in order to improve the RAMS (Reliability, Availability, Maintainability and Safety). Similar is the solution found by (Collins et al., 2009) that uses FMEA (Failure Modes and Effects Analysis) as a technique for systematically identifying, analysing and documenting the possible failure modes within a design and effects of such failure modes on system performance or safety. An hybrid method for six hours in advance solar power prediction was developed by R. Hossain et al. (Hossain et al., 2012).

When data-mining and computing learning algorithms are applied to PV database, wide variety of relations between parameters can be found. This study relays on expert knowledge to study the possible behaviours of PV generation performance when environment conditions change. Several doubts appears about relations between technical parameters can be found with computational tests.

This study focuses on describe a methodology can get a method to control the correct performance of each group of modules that shape a large-scale PV generator, identifying the error occurrence and its most likely possible causes. Mainly, it tries to get an algorithm that controls the performance of group of modules by ignoring environmental information. 


\subsection{Data-mining to find photovoltaic parameters relations}

Data mining is an area of computer science where computer tools are developed in order to find patterns in large data sets. Machine learning methods is a subarea of data mining that focuses on techniques used to find and describe structural patterns as a tool for helping to explain the data and make predictions from it (Witten and Frank, 2005).

The techniques of computational intelligence are today commonly and effectively applied to different problems of the real world. These techniques allow us to perform several tasks with the objective to improve and/or optimize the different problems.

The monitorization system of the CdTe photovoltaic generator, described in Chapter 2, is generating a large database that grows everyday, saving registers about PV performance and its environmental conditions in real time, each 5 minutes since almost three years ago.

The database has by now more than 200,000 registers (16 field attributes) for each inverter that form the PV generator, and more than 200,000 registers (6 field attributes) about environmental information.

The $222 \mathrm{kWp}$ CdTe parking integrated grid-connected facility, can be considered a large-scale photovoltaic system. Fixed shadows, temporal shadows, bad weather or dirty modules are common circumstances that inverters cannot detect. Under these circumstances, group of modules will loss efficiency. Inverters connected to group of modules affected by bad conditions will pour less electricity into the grid than others. It does not exist any mechanism that controls these disparities between same-installation inverters performance. 
With the aim of identify malfunctions on the PV generator, the comparison between groups of modules could be a solution, as well as the comparison between group of modules and the performance of the whole system. Each group of modules is connected to an inverter, which send parameters described in Table 4, Chapter 2. This comparison could check parameters that reflects the performance of the group of modules or possible inverter error:

- Performance Ratio (PR). PR is the relation between the power generated by the modules and the theoretical output power it should produce in specific irradiation conditions. (Defined in EQUATION 3.1, section 3.3.1, page 56). When an inverter has an average PR smaller than the rest, it could indicate a special condition, as fixed shadows, or a potential error. Figure 3.2 shows the number of times each inverter reaches a PR value, namely the frequency of PR for each inverter. For instance, the inverter named "Inverter I.7.2" raises a high PR more often than the rest. Figure 3.1 shows the relation between the PR of the whole PV generator and four groups of modules.

- Output power. If an inverter pours more Pac to the grid than other, it may due to causes that can be explained by the information we have in the database. For example, inverter "Inverter I.2.1" is affected by a shadow that reduces its power production, as Figure 3.3 shows. 
Chapter 3 Computational Intelligence applied to Photovoltaics

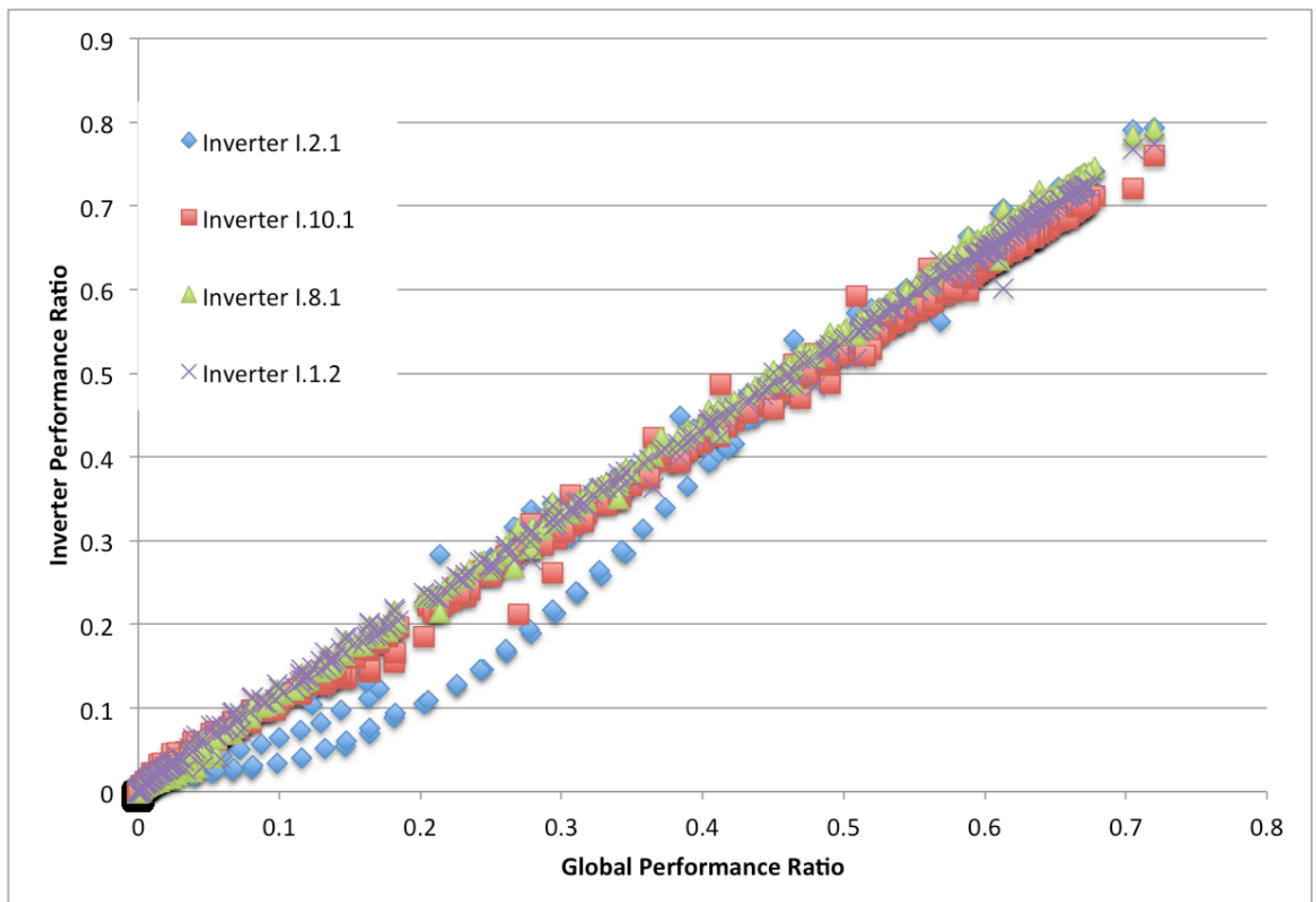

FIGURE 3.1 RELATION BETWEEN PR OF THE WHOLE PV INSTALLATION AND PR OF FOUR GROUP OF MODULES. 


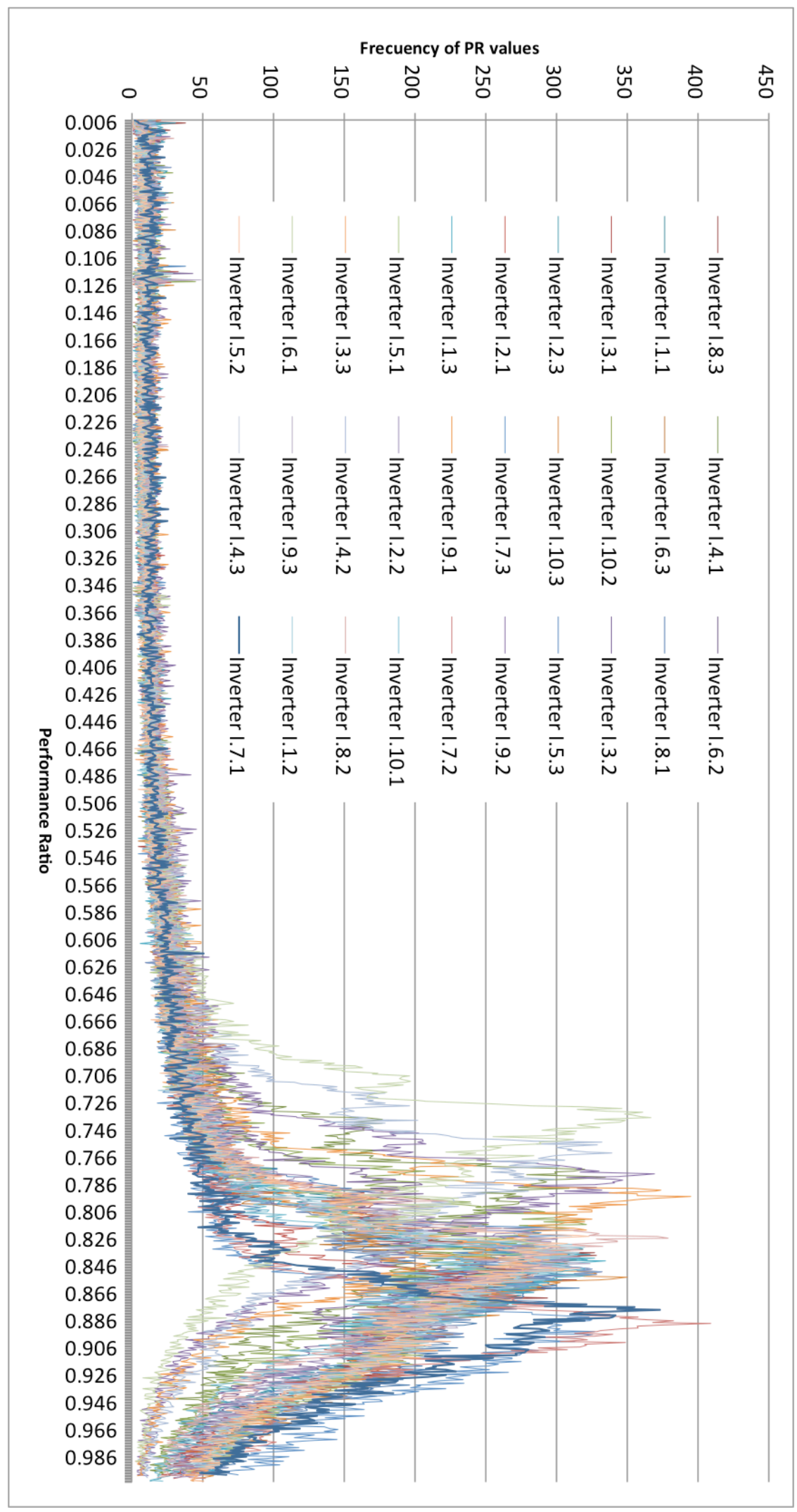

FIGURE 3.2 FRECUENCY OF PERFORMANCE RATIOS OBTAINED FOR EACH INVERTER 


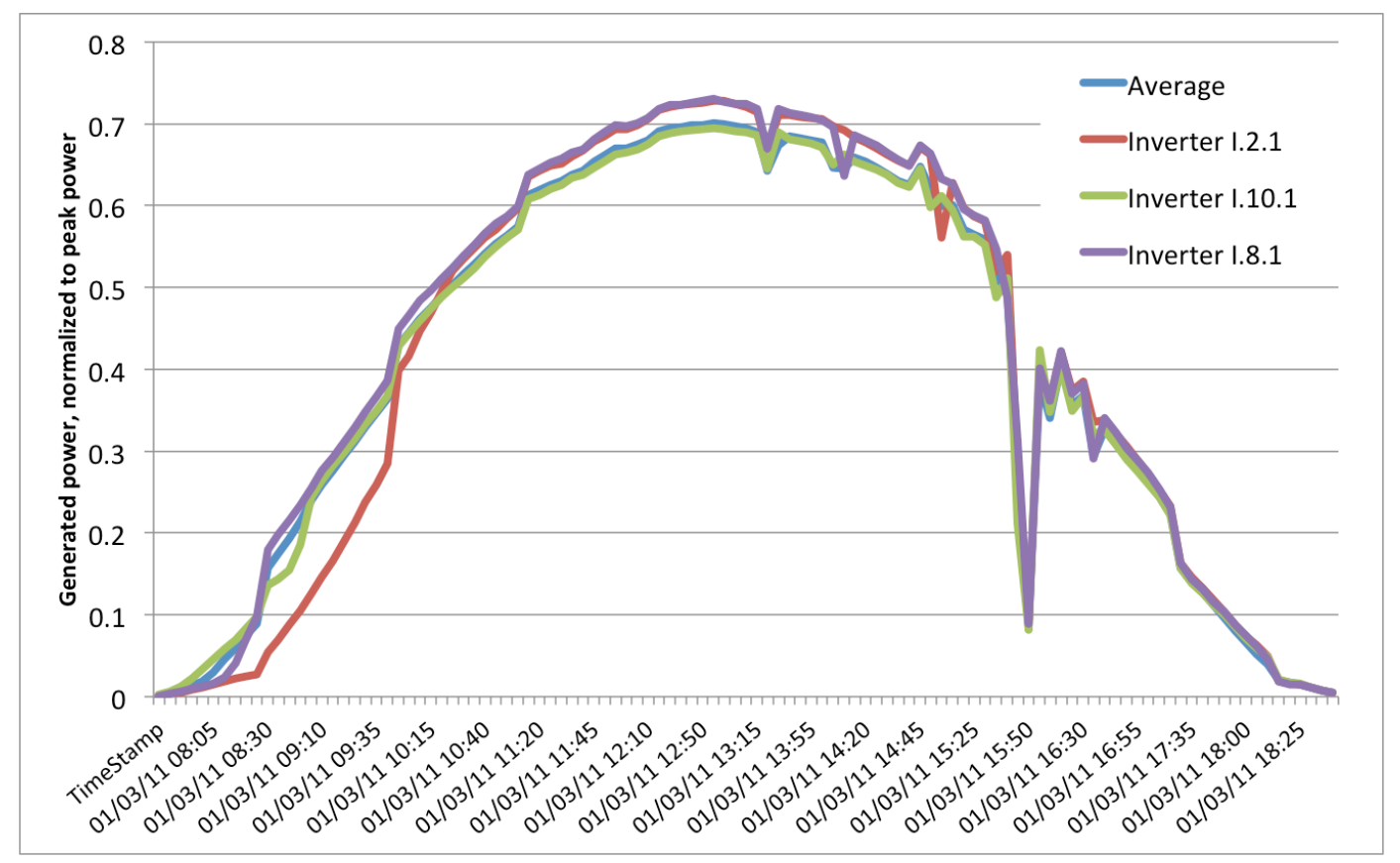

FIGURE 3.3 POWER OUTPUT OF THREE INVERTERS AND THE TOTAL POWER OUTPUT OF THE PV SYSTEM DURING TEN HOURS. A SHADOW AFFECTS INVERTER I.2.1 IN THE MORNING

- Input/output performance. The relation between the input and output power in an inverter is a sign of a possible error in performance. Figure 3.4 shows how shadow affects inverter I.2.1 in its input/output performance.

Data mining tools, and computing learning techniques in particular, can improve the control of performance errors in large-scale PV generators. 
Chapter 3 Computational Intelligence applied to Photovoltaics

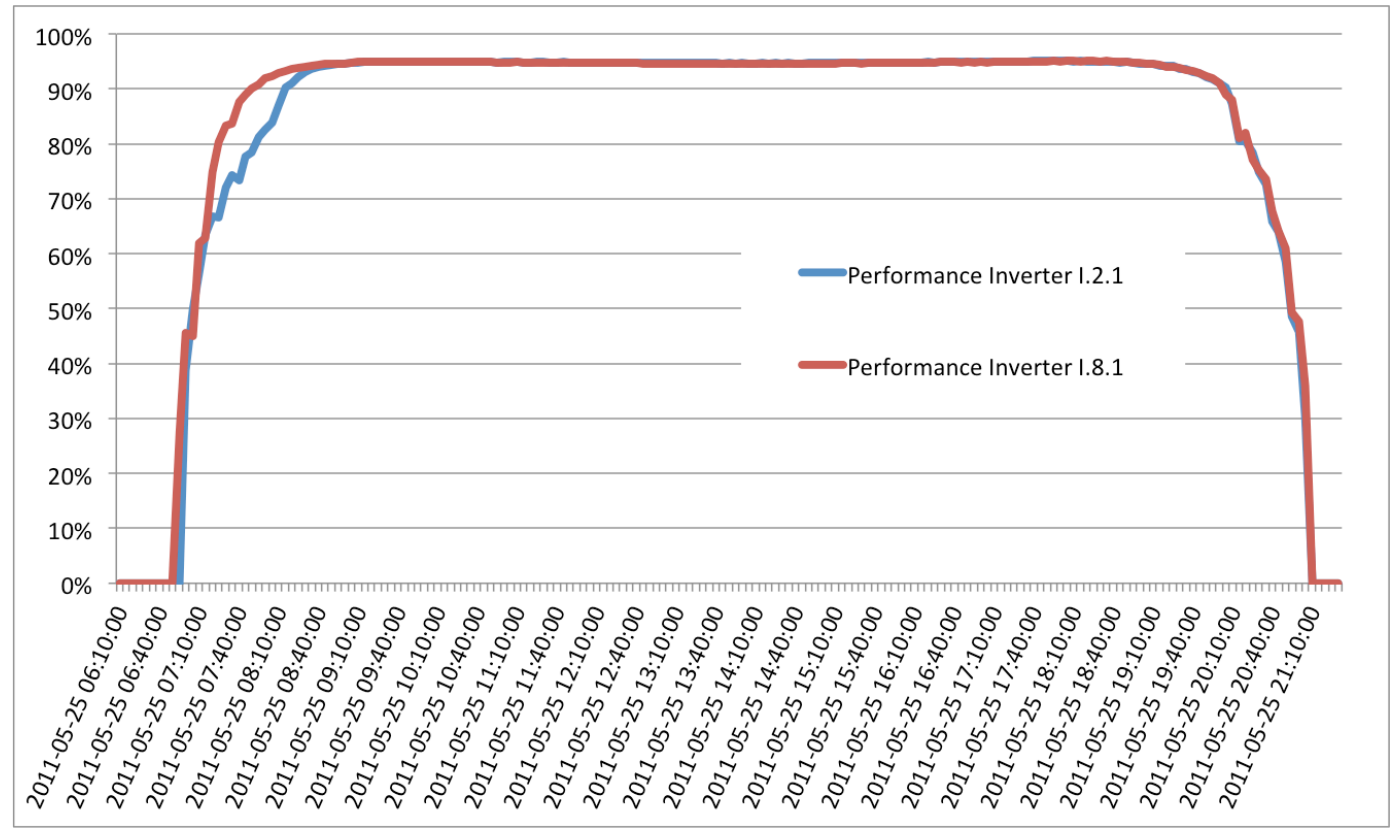

FIGURE 3.4 RELATION BETWEEN INPUT AND OUTPUT POWER INDICATES A POSSIBLE ERROR IN THE INVERTER OR A SHADOW AFFECTING THIS GROUP OF MODULES. INVERTER I.2.1 HAS SMALLER PERFORMANCE.

\subsection{Applying Computational Learning Techniques. Methodology.}

\subsubsection{Getting the data ready}

A necessary and hard first step is data mining. Some of the stored data should not be taken into consideration in the learning computing process, because it is incomplete or wrong.

The criteria to select the date, which will be introduced in learning algorithms, are the following:

- The data sent during the night were not used, 
- selected data does not miss any field. The information sent from inverter and from sensor must be completed,

- irradiation must be greater than zero,

- status inverter parameter must be greater than 0 , because this is the error code,

- just in case, we limited the registers from 6 in the morning until 22 in the night.

From the total of 30 tables with same attributes from different inverters, one was chosen in this study: inverter with name wr7k_023_2000457991. From now it is referred as inverter I.1.1. Technical characteristics can be read at Chapter 2, Table 2.1, and its location is LINE 1- I.1.1, showed in Figure 2.5.

A total of 30550 instances from both inverters fulfil criteria.

From all the fields that compose a register, "Zac" was discarded because its value is not relevant in energy balance. The date and the time were transformed following next equations:

$$
\begin{aligned}
& \text { date }=\text { year } 365+\text { month } 31+\text { day } \\
& \text { time }=\text { hour } 3600+\text { minute } 60+\text { sec }
\end{aligned}
$$

The study of the PV generator behaviour supposes looking for special situations. These situations can be prolonged during time, or can be caused by other previous special situations. With the aim of keep this relations in mind in our search of control algorithms, days before values of key parameters, i.e. Performance Ratio and Power output, are taken into account.

13 new fields was added to each register: 


\begin{tabular}{|c|c|}
\hline Name & Description \\
\hline$P R$ & $\begin{array}{l}\text { Performance Ratio of the group of modules in evaluation, defined in } \\
\text { Equation } 3.1\end{array}$ \\
\hline PRl & 1 day before PR \\
\hline$P R 2$ & 2 days before $P R$ \\
\hline PR3 & 3 days before PR \\
\hline PR4 & 4 days before PR \\
\hline PR5 & 5 days before PR \\
\hline Pacl & 1 day before Pac \\
\hline Pacl & 1 day before Pac \\
\hline Pacl & 1 day before Pac \\
\hline Pacl & 1 day before Pac \\
\hline Pacl & 1 day before Pac \\
\hline$P R_{G}$ & Global PR: PR of the whole PV generator \\
\hline Pvgis $G$ & Average global irradiation in tilted surface $\left(\mathrm{W} / \mathrm{m}^{2}\right)$ \\
\hline Pvgis Gd & Average global irradiation in tilted surface $\left(\mathrm{W} / \mathrm{m}^{2}\right)$ \\
\hline Label & $\begin{array}{l}\text { Describes the state of the modules connected to the inverter }(\mathrm{OK}, \mathrm{M} \text {, } \\
\mathrm{S}, \mathrm{T}, \mathrm{T} 1, \mathrm{~F}, \mathrm{~F} 1)\end{array}$ \\
\hline
\end{tabular}

TABLE 3.1 PARAMETERS ADDED TO EACH REGISTER IN DATABASE

The last field in Table 3.1 ( $\mathrm{Label}$ ) is the state the expert identifies. The mining of the labels is defined in Table 3.2. This attribute is necessary in order to apply the computing learning algorithms, as decision trees, decision rules, linear models, etc. This process was made thanks to expert knowledge, as is explained in next sub-section.

For each register, the PR has been calculated following the Equation 3.1:

$$
\text { EQUATION 3.1 } \quad P R=\frac{P a c}{k \cdot \frac{G}{G_{S T C}}}
$$


with:

Pac $=$ Generated power $\left(\mathrm{kW} / \mathrm{m}^{2}\right)$;

$\mathrm{G}_{\mathrm{STC}}=$ Reference irradiance at Standard Test Conditions $\left(1000 \mathrm{~W} / \mathrm{m}^{2}\right)$;

$\mathrm{G}=$ Irradiance tilted $\alpha=7^{\circ}$ and oriented $\beta=20^{\circ} \mathrm{E}$, measured by irradiation sensor;

$\kappa=$ Peak power of the group of modules connected to the inverter per square meter, $W_{p} / m^{2}$, i.e. 74.88 .

\subsubsection{Expert knowledge}

Looking at each parameter values, an expert labelled each register. The parameters taken into account in expert criteria were defined in Tables 2.4, 2.5 (Chapter 2) and Table 3.1.

Table 3.2 defines the possible states of the group of modules following the labelling process.

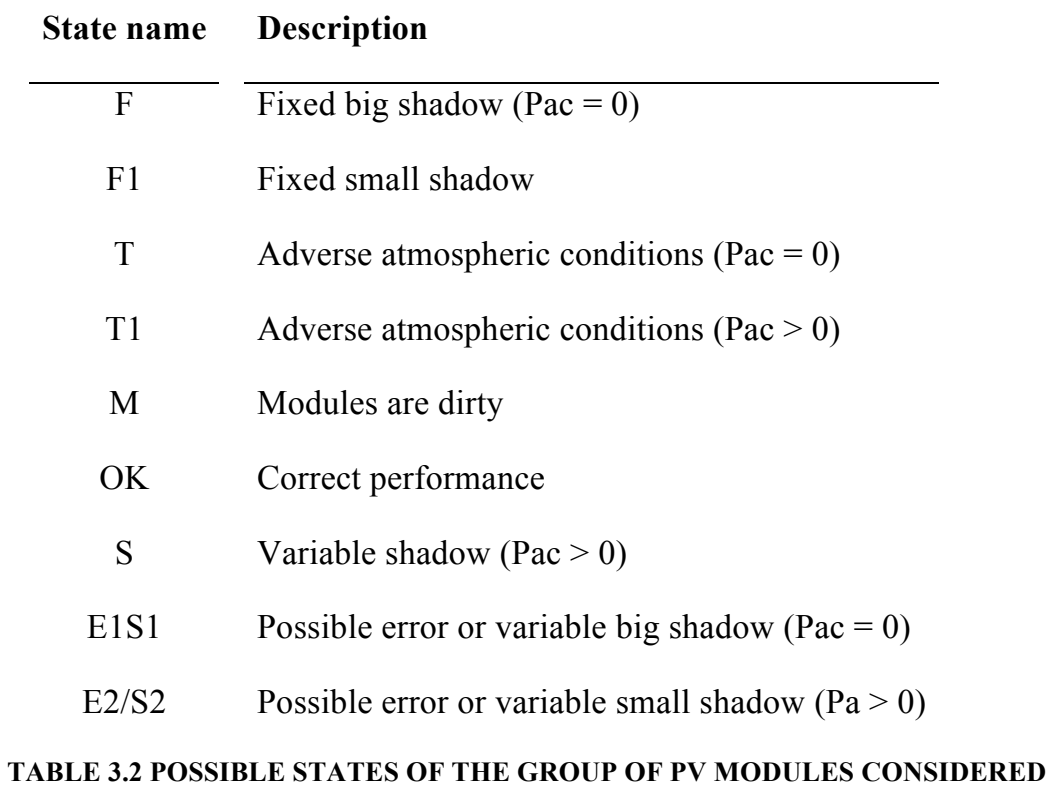




\subsubsection{Applying algorithms}

From the whole intelligent system, we have started analysing the models that are useful to detect and classify the states of the generator. In order to perform this analysis, six computational intelligence techniques, based on decision trees and rules were chosen:

- C4.5. Algorithm used to generate a decision tree.

- Simple Cart. In the construction of decision tree it implements minimal cost-complexity pruning.

- Random Forest. Classification algorithm that construct a multitude of decision trees at training time and outputting the class.

- Ripple-Down Rule learner. Algorithm that generates a default rule first and then exception for the default rule.

- Rule set based on partial decision trees (PART). This algorithm is a separate-and-conquer rule learner. The algorithm producing sets of rules called 'decision lists' which are ordered set of rules.

- Conjunctive Rule. Algorithm that implements a single conjunctive rule learner that can predict for numeric and nominal class labels. A rule consists of antecedents "AND"ed together and the consequent (class value) for the classification/regression. 


\subsection{Results}

\subsubsection{Decision trees}

A dataset of 30550 instances with 35 attributes was labeled thanks to expert knowledge. The set of used labels is: F, E1, T, T1, M, E2/S, F1, S, OK, as was defined in Table 3.2 for labeling process.

To analyze the results obtained in the learning process in terms of prediction accuracy, we use $3 \times 5$-fold cross validation. Therefore, we will show the average of the obtained results during the validation process.

The obtained results applying six techniques indicated before are:

\begin{tabular}{|cccc|}
\hline Interpretable & Method & $\boldsymbol{\mu}$ & $\boldsymbol{\sigma}$ \\
\hline $\boldsymbol{V}$ & $\mathbf{C 4 . 5}$ & 99.969 & 0.009 \\
\hline $\boldsymbol{X}$ & Simple Cart & 99.861 & 0.019 \\
\hline $\boldsymbol{V}$ & Random Forest & 99.961 & 0.015 \\
\hline $\boldsymbol{V}$ & Ripple-Down Rule learner & 99.951 & 0.012 \\
\hline $\boldsymbol{V}$ & PART & 99.948 & 0.012 \\
\hline
\end{tabular}

TABLE 3.3 AVERAGE ACCURACY AND ROOT MEAN SQUARED ERROR OF LEARNING METHODS

In particular, the obtained decision tree (25 leaves and size 749$)$ by $\mathrm{C} 4.5$ at the end of the process is showed in Figure 3.5. This study will focus in C4.5 because it is interpretable and useful for our goals. 


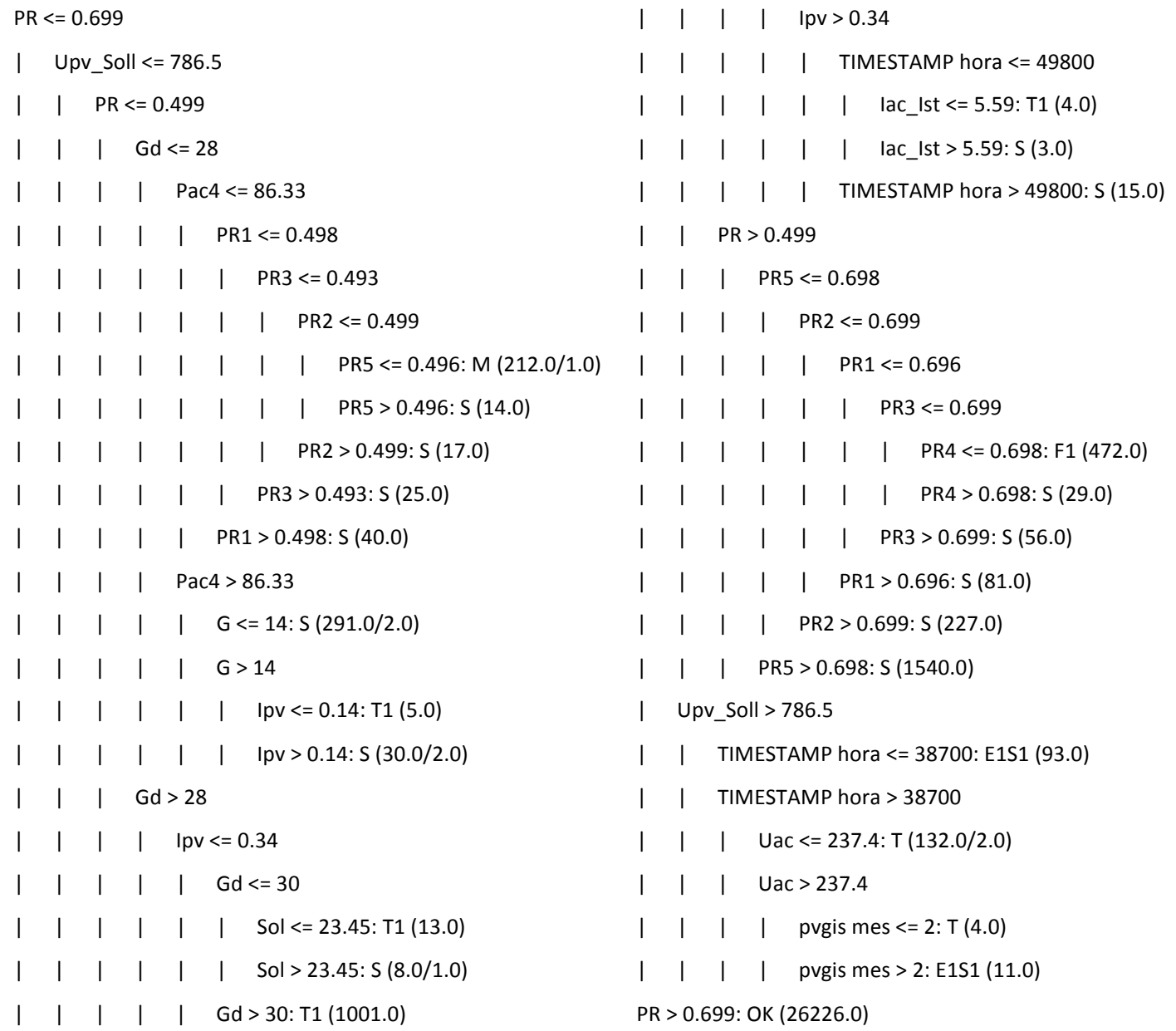

FIGURE 3.5 DECISION TREE OBTAINED IN C4.5 LEARNING METHOD, READING 30550 INSTANCES OF PV GENERATOR INFORMATION 
The obtained results show that the main parameter to decide whether inverter performance is acceptable is the performance ratio (PR). This result has plenty of meaning because a group of modules, whose PR is greater than 0.7 , can be considered to have a correct behavior. Though, when PR is less than 0.7 , from a PV expert point of view, something is obstructing the correct operation of the group of modules.

The branch with the condition "Upv_Soll $>786.5$ " has been considered by the expert system as an error in solution. Resulted tree indicates this branch as error as well, but a little range that is signed as bad atmospheric conditions. Nevertheless, we have taken into consideration all states into this range as an error of the system. Information contained in the database that belongs to this set has attributes with wrong values.

The branch with the condition of diffuse irradiation "Gd $<=28$ " can be explained as well. Diffuse irradiation is low when direct irradiation is high. Gd is a parameter standard, given by PVGIS (European Commision, 2011). So, this comparison indicates that when the average irradiation is high and PR is low, a problem can be affecting the performance of the modules. When days before this finding, the obtained PR is low as well, the tree interprets that modules are dirty or a shadow is affecting the area.

\subsubsection{Managing without environmental information}

Now a new challenge is suggested. The algorithm was trained with no environmental sensor information set.

Monitorization system is not installed in every large-scale installation. Currently, inverters in market are able to send data about input/output power and performance information. Nevertheless, environmental information sent by sensors cannot be found in every PV facility. To tackle the problem of getting a decision tree which does not require environmental information, the same computational intelligence techniques were applied to the same instances of the 
previous study, but changing some attributes in order to avoid the environmental ones.

The considered attributes in this new study are: day, hour, Iac_Ist, Ipv, Pac, Uac, Upv_Ist, Upv_Soll, PR, PR1, PR2, PR3, PR4, PR5, Pac, Pac1, Pac2, Pac3, Pac4, Pac5, PVGIS mes, PVGIS hora, G, Gd, label. These attributes were defined in Table 4Chapter 2, and Table 3.1.

Surprisingly, a very similar decision tree was obtained, as Figure 3.6 shows.
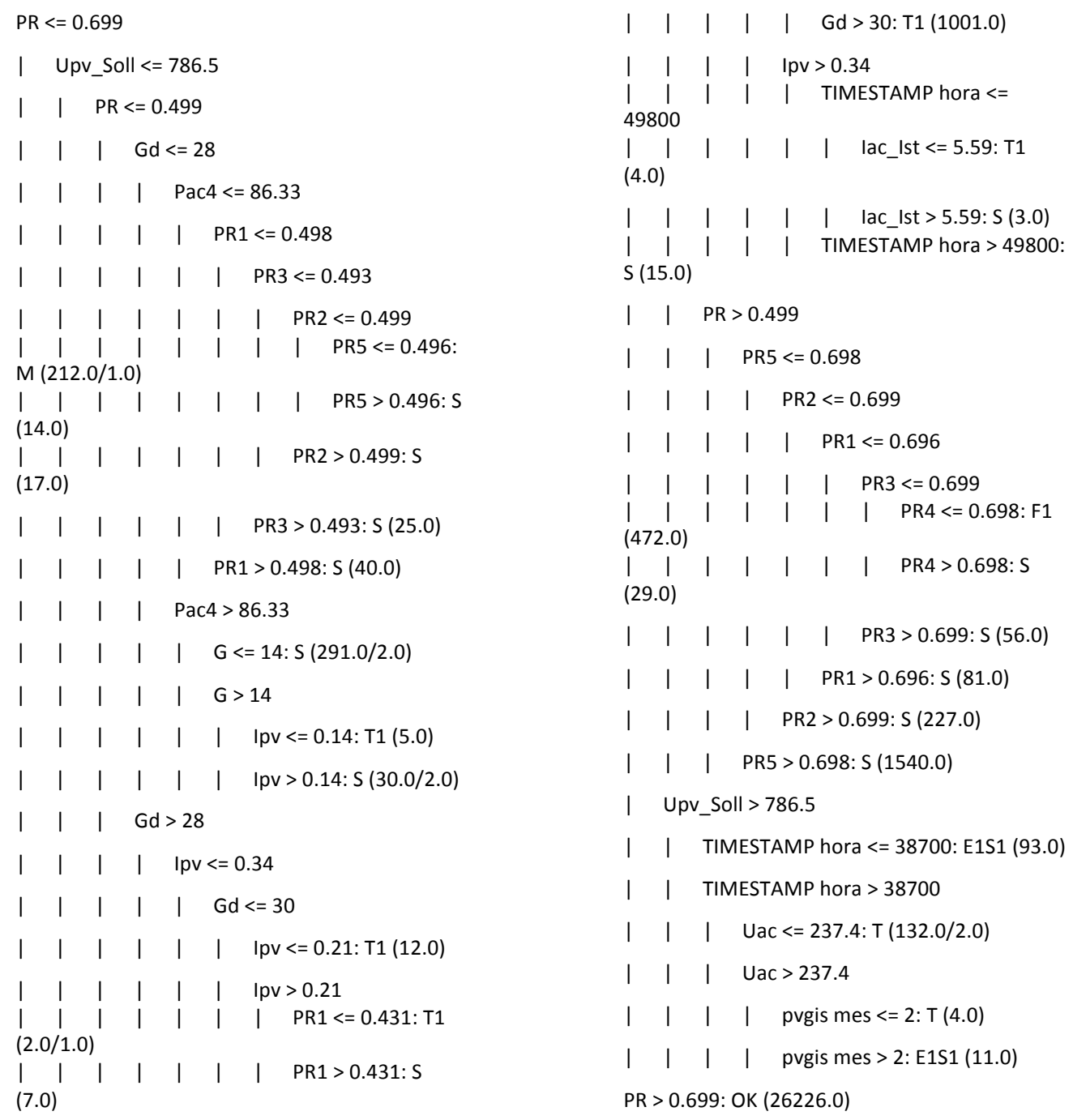

FIGURE 3.6 DECISION TREE OBTAINED IN C4.5 LEARNING METHOD, READING 30550 INSTANCES OF PV GENERATOR, WITHOUT ENVIRONMENTAL SENSOR INFORMATION 
$3 \times 5$ cross-validation were executed in order to validate the obtained decision tree. $99.87 \%$ of the instances were classified correctly $(\boldsymbol{\mu})$, with a root mean squared error $(\boldsymbol{\sigma})$ of 0.019 .

Now it is possible to find the disagreements between obtained decision trees with and without environmental attributes, Figures 3.4 and 3.5 respectively. The decision based on solar irradiation in first tree, Table 3.4 left column, is replaced by rules shown in the right column in the second tree.

\begin{tabular}{|c|c|c|}
\hline Deduced state & Rule using Sol attribute & Rule without Sol attribute \\
\hline \multirow{2}{*}{ T1 } & Sol $<=23.45$ & Ipv $<=0.21$ \\
\cline { 2 - 3 } & & Ipv $>0.21$ and \\
& PR $1<=0.431$ \\
\hline \multirow{2}{*}{ S } & Sol $>23.5$ & Ipv $>0.21$ and \\
& \multicolumn{2}{|c|}{} \\
\hline
\end{tabular}

TABLE 3.4 DISAGREEMENTS FOUND IN DECISION TREES. EQUIVALENT BRANCH WITH AND WITHOUT IRRADIATION ATTRIBUTE

In spite of this found equivalence, only 21 instances of more than 30000 belong to this branch in the tree. If we wanted to dismiss this branch, the error would only increase a $0.0007 \%$. This result shows that insolation parameter is not a deciding parameter when our aim is to predict the state of a studied group of modules.

In the same way that it was found equivalence between this three parameters when decision tree is being modelled, it could be found another relationship between attributes by replacing or omitting some of them.

The results shows that, from the set of information used in this study, it could be possible to get an accurate decision tree, managing without the environmental information, and using the average weather PVGIS data. 


\subsection{Inference phase}

A subset of information from inverter I.1.1 was selected to infer the state of the PV generator using the obtained decision tree without environmental information. During days between 18th and 22th October on 2012, the PV generator suffered from complex weather conditions, as Figure 3.7 shows.

- Day 1 (2012-10-18). Sand storm (special atmospheric conditions)

- Days 2 and 3 (2012-10-19 and 2012-10-20). Modules are dirty due to sand storm day before.

- Day 4 (2012-10-21). It rains.

- Day 5 (2012-10-22). Day is clear and modules are cleaned.

During this period of time irradiance sensor was broken. The performance ratio was re-defined by replacing in Equation 3.1 the parameter or irradiation $G$ by an approximation; the irradiation can be approximated by the multiplication of the output current by a constant parameter " $\lambda$ ", that can be experimentally calculated from stored information, as Equation 3.2 shows. The new performance ratio (PR') is now defined in Equation 3.3.

EQUATION 3.2 $\lambda=\frac{{ }_{{ }^{N}}{ }^{I} P V / G}{N}$

EQUATION 3.3 PR $=\frac{P a c}{k \cdot \frac{I V / \lambda}{G_{S T C}}}$

With: 
Chapter 3 Computational Intelligence applied to Photovoltaics

$\lambda=$ constant factor that defines the relation between irradiation and generated current from group of PV modules

$\mathrm{I}_{\mathrm{PV}=}$ Current generated from PV modules per squared meter

$\mathrm{G}=$ Irradiance tilted $\alpha=7^{\circ}$ and oriented $\beta=20^{\circ} \mathrm{E}$

$\mathrm{N}=$ Number of examples used to calculate the factor average, i.e. 43,820

Pac $=$ Generated power $\left(\mathrm{kW} / \mathrm{m}^{2}\right)$;

$\kappa=$ Peak power of the group of modules connected to the inverter per square $W_{p}$

meter, $m^{2}$, i.e. 74.88 . 


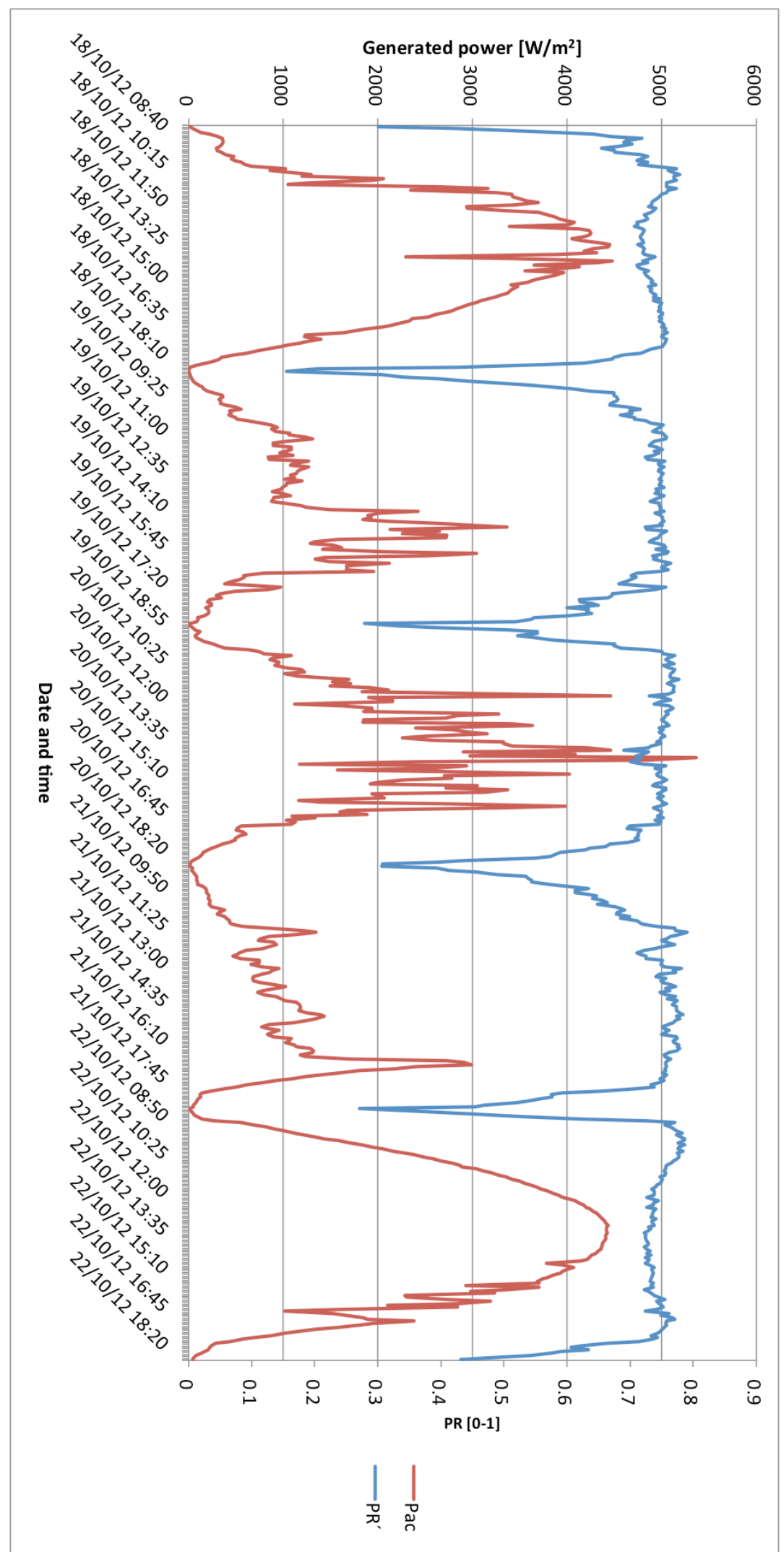

FIGURE 3.7 PERFORMANCE RATIO OF THE WHOLE PV GENERATOR AND OUTPUT POWER OF THE GROUP OF MODULES CONNECTED TO INVERTER I.1.2 DURINT DAYS WITH SPECIAL ATHMOSPHERIC CONDITIONS: STAND-STORM, RAIN AND SUNNY DAY. 
The decision tree showed in Figure 3.6 is used to infer the state of varying weather information set. Figure 3.8 shows the results of the model.

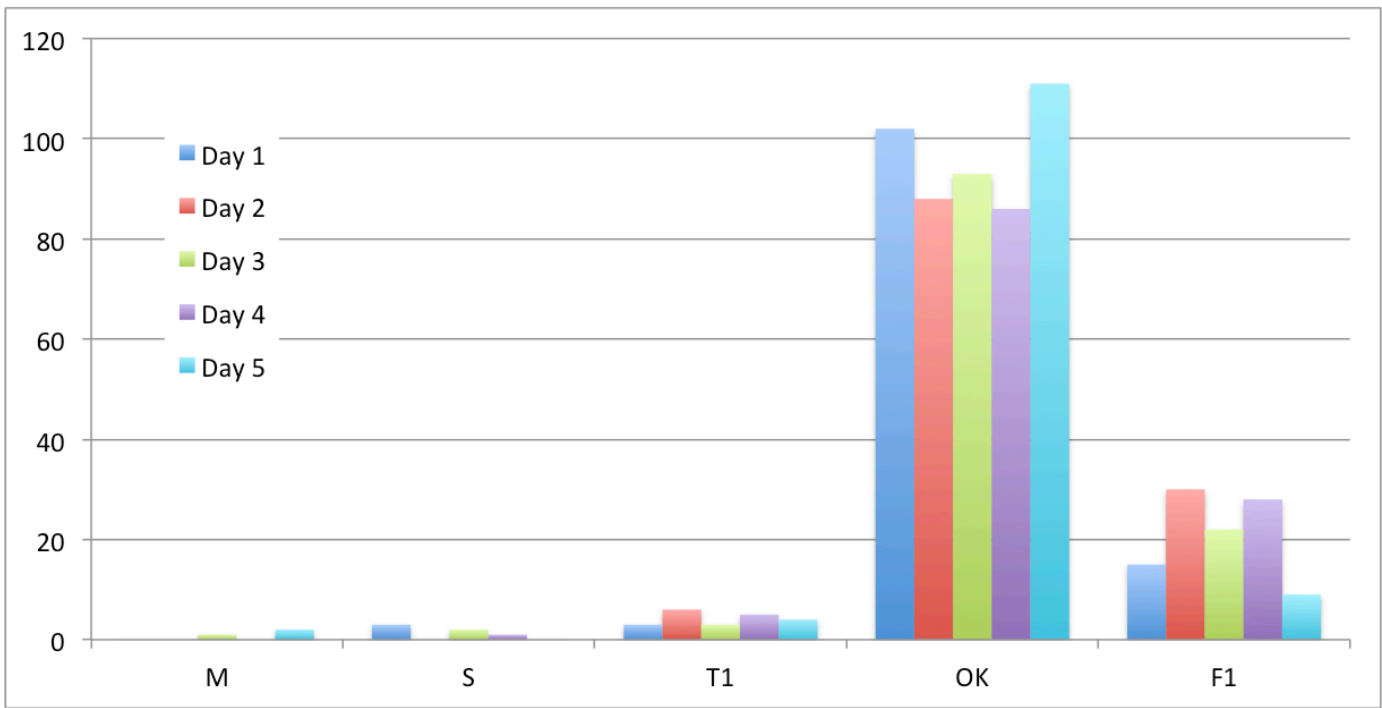

FIGURE 3.8 RESULT OF CLASIFICATION DURING VARYING WEATHER

Results show that a deeper study is needed in order to improve the identification of dirty modules, shadows appearance and special weather circumstances. In spite of the good behaviour of the model when inverter works with high performance ratio, most of the low performance ratio data sets were identified as fixed small shadows (F1), and a low rate as adverse atmospheric conditions. State for "dirty modules" was not identifying correctly.

\subsection{Conclusions}

Computing learning algorithms have been widely used to study and predict solar electricity production and to detect failures or losses due to malfunctions. In this brief study it was searched a methodology to identify the state of PV generator when environmental information is not available. 
A decision tree model was obtained from $\mathrm{C} 4.5$ learning algorithm, which was trained with more than 30,000 instances from inverter technical information and from environmental sensor data set. The training was repeated without environmental sensor and a relation between these trees were identified. Nevertheless, a wider training is needed to get more precise algorithm.

Some of the results are promising since experts have assessed them, but comparison between inverters from the same installation has to be made in order to find other performance parameters can be used to get more accuracy state prediction and to compare and prove results.

This study is an incursion on decision-system design from computational point of view, in order to identify and assess the performance of PV large-scale state. It is a small step to the construction of a hierarchical process to predict states of largescale PV generator is presented. During this study several doubts appear and will be studied in near future.

Future work in small PV system is projected to do in-situ real simulations of shadows, dust, etc. in order to compare the PV modules power output behavior in same time and different conditions. 


\subsection{References}

Ammar, M.B., Chaabene, M., Elhajjaji, A., 2010. Daily energy planning of a household photovoltaic panel. Appl. Energy 87, 2340-2351.

Baños, R., Manzano-Agugliaro, F., Montoya, F.G., Gil, C., Alcayde, A., Gómez, J., 2011. Optimization methods applied to renewable and sustainable energy: A review. Renew. Sustain. Energy Rev. 15, 1753-1766.

Ben Salah, C., Chaabene, M., Ben Ammar, M., 2008. Multi-criteria fuzzy algorithm for energy management of a domestic photovoltaic panel. Renew. Energy 33, 993-1001.

Catelani, M., Ciani, L., Cristaldi, L., Faifer, M., Lazzaroni, M., Rinaldi, P., 2011. FMECA technique on photovoltaic module, in: 2011 IEEE Instrumentation and Measurement Technology Conference (I2MTC). Presented at the 2011 IEEE Instrumentation and Measurement Technology Conference (I2MTC), pp. 1-6.

Chaabene, M., Ammar, M.B., Elhajjaji, A., 2007. Fuzzy approach for optimal energy-management of a domestic photovoltaic panel. Appl. Energy 84, 9921001 .

Cirre, C.M., Berenguel, M., Valenzuela, L., Klempous, R., 2009. Reference governor optimization and control of a distributed solar collector field. Eur. J. Oper. Res. 193, 709-717.

Collins, E., Dvorack, M., Mahn, J., Mundt, M., Quintana, M., 2009. Reliability and availability analysis of a fielded photovoltaic system, in: 2009 34th IEEE Photovoltaic Specialists Conference (PVSC). Presented at the 2009 34th IEEE Photovoltaic Specialists Conference (PVSC), pp. 002316-002321.

European Commision, 2011. Photovoltaic Geographical Information System (PVGIS) [WWW Document]. URL http://re.jrc.ec.europa.eu/pvgis/ (accessed 12.7.11).

Hossain, M.R., Oo, A.M.T., Ali, A.B.M.S., 2012. Hybrid prediction method of solar power using different computational intelligence algorithms, in: Universities Power Engineering Conference (AUPEC), 2012 22nd Australasian. Presented at the Universities Power Engineering Conference (AUPEC), 2012 22nd Australasian, pp. 1-6.

PV STATUS REPORT 2011, 2011., JRC Scientific and Technical Reports. European Commission, DG Joint Research Centre, Institute for Energy, Renewable Energy Unit. 
Roman, E., Alonso, R., Ibanez, P., Elorduizapatarietxe, S., Goitia, D., 2006. Intelligent PV Module for Grid-Connected PV Systems. IEEE Trans. Ind. Electron. 53, 1066-1073.

Sallem, S., Chaabene, M., Kamoun, M.B.A., 2009. Energy management algorithm for an optimum control of a photovoltaic water pumping system. Appl. Energy 86, 2671-2680.

Wang, Y., Zhang, P., Li, W., Kan'an, N.H., 2012. Comparative analysis of the reliability of grid-connected photovoltaic power systems, in: 2012 IEEE Power and Energy Society General Meeting. Presented at the 2012 IEEE Power and Energy Society General Meeting, pp. 1-8.

Witten, I.H., Frank, E., 2005. Data mining: practical machine learning tools and techniques. Morgan Kaufman, Amsterdam; Boston, MA.

Zhang, P., Li, W., Li, S., Wang, Y., Xiao, W., 2013. Reliability assessment of photovoltaic power systems: Review of current status and future perspectives. Appl. Energy 104, 822-833. 
Chapter 3 Computational Intelligence applied to Photovoltaics 


\section{CHAPTER 4}

\section{Life CyCle Assessment}

\section{APPLIED TO PHOTOVOLTAICS}

Synopsis. Life Cycle Assessment is a standardised methodology, which is applied worldwide. Sustainable energy technologies are studied to evaluate its environmental benefits. Following the standard ISO 14040 and 14044 recommendations and using the professional software tool "SimaPro"", LCA was applied to the $222 \mathrm{kWp}$ CdTe PV generator located in Murcia (described in Chapter 2). Environmental impact parameters have been calculated for three different cases: the photovoltaic system integrated as a parking roof (the actual real case) and the case in which the photovoltaic system and the parking are not integrated. Comparisons of selected environmental indicators are discussed in order to evaluate the advantages and disadvantages of each case.

\subsection{Introduction. About Life Cycle Assessment}

Life Cycle Assessment is a methodology that was created in order to analyse and control the Cumulative Energy Demand (CED) and materials in any product or service. This includes the manufacturing process, the use phase and the disposal of a product - its complete life cycle. LCA aims to study material and energy input and output flows, helping to identify which step of the life cycle of a product or service is the most material and/or energy demanding. The origin of these studies was the oil crisis within the USA in the 70s, when oil was the main

1 C PRé Consultants bv, Amersfoort, The Netherlands. All rights reserved. 
source of energy and suddenly turned very expensive due to world political instability.

Initially, the main objective of LCA studies was to provide information, which allowed big manufacturing companies to save resources and energy and therefore reduce the economic cost of the product. Environmental analysis was not the aim of LCA studies at this initial stage. Nevertheless, 30 years after LCA beginning, LCA is now helping companies to measure environmental impact and reduce the carbon footprint of its products.Figure 4.1. The main steps in the life cycle of a product. In LCA methodology we have had to determine the step/s to be analysed. In this project, we have analysed all steps in the life cycle of a PV generator, which was previously described in Chapter 2. This kind of analysis is known as "from the cradle to grave analysis".
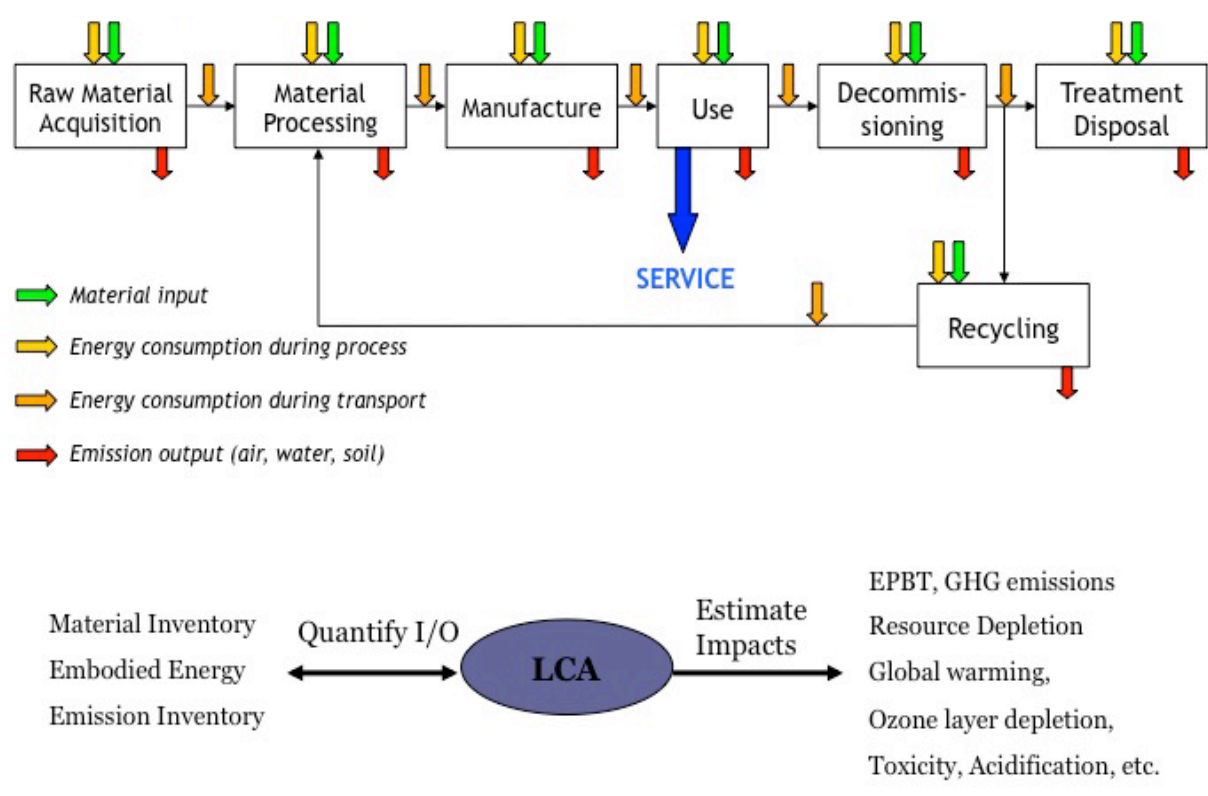

FIGURE 4.1 INPUTS AND OUTPUTS DURING LIFE CYCLE OF A PRODUCT. THE BLOCKS ILLUSTRATE THE MAIN STEPS OF LIFE CYCLE ASSESSMENT.

International Organization for Standardisation (ISO) defines within the series ISO 14040 and ISO 14044 a guideline for conducting an LCA. This guideline 
includes: definition of the goal and scope of the LCA, the life cycle inventory analysis (LCI) phase, the life cycle impact assessment (LCIA) phase, the life cycle interpretation phase, reporting and critical review of the LCA, limitations of the LCA, relationship between the LCA phases, and conditions for use of value choices and optional elements. (Environmental management - Life cycle assessment - Requirements and guidelines, 2006)

\subsubsection{The main phases of an LCA}

As Figure 4.2 shows, ISO 14044 normalizes LCA into four main phases:

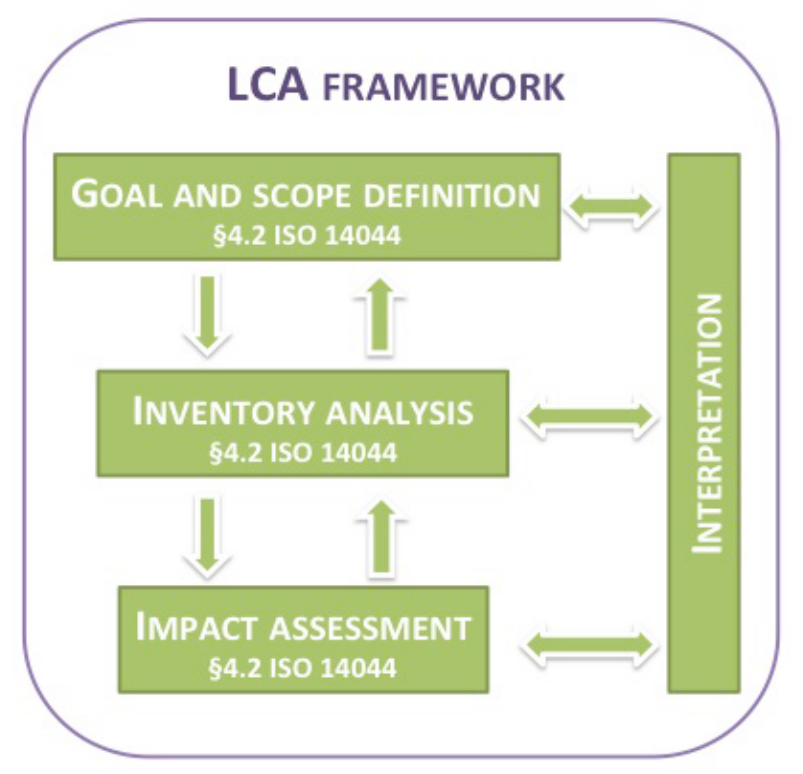

FIGURE 4.2 LCA FRAMEWORK DEFINED BY ISO 14044

- Goal and scope definition

In this first step, the goal must be clearly defined. Defining the goals means defining the application (marketing, improvement of a product, etc.), the purpose (scientific publication, internal report, etc.), the audience (engineers, consumers, politician, etc.) and eventually the aim of doing a critical revision.

Defining the scope implies to determine clearly many features. One of the most important is the functional unit $(F U)$ that determines the primary function quantity 
of the product system, providing a reference to which the inputs and outputs can be related to a well defined quantitative measurement; for example, in photovoltaic technology the functional unit can be ONE module (irrespective of whatever the nominal peak power), or $\mathbf{1 k W p}$ (irrespective of the number of modules required to achieve this peak power), even $\mathbf{1 m}^{\mathbf{2}}$ of modules can be chosen provided that it is clearly indicated in the LCA study. The products and materials needed to complete FU are the reference flow. If it is needed, all information has to be recalculated to match the selected FU, and consequently, the reference flow has to be scaled up or down accordingly. In the next phase, the system boundaries have to be defined, that means, to define the system limits that will be considered; for example, we could study the life cycle of a product from cradle to grave, from cradle to gate, gate to grave or gate to gate (as a single phase production process).

The allocation phase will be needed in order to assign products and sub-products to input and output of a process. This allocation phase can be made following different magnitudes: mass, specific heat, market value, etc.

During goal and scope definition phase the category impact must be specified, before the inventory analysis starts the collection of the relevant data.

\section{- Life cycle inventory}

In this LCA phase an information collection has to be made (energy inputs, material source input, auxiliary inputs, remnants, emissions, etc.). From this information, a Life Cycle Inventory (LCI) table is written. The information has to be validated and related to a unit process. In this process the data is aggregated, and redefining the system boundary is often required. As it was indicated above, all information units have to be transformed to the selected functional unit. LCI is the most time-consuming phase. 


\section{- Life cycle Impact Assessment}

During Life cycle Impact Assessment (LCIA) phase, the input and output flows are classified according to their potential impact, following the impact categories that have been previously selected. Each applied impact assessment methodology will return impact results, although direct comparisons cannot be made across impact categories, since in general each impact category uses a different scale.

\section{- Interpretation}

The final interpretation of the results must be done in order to analyse, in the framework of the evaluation, the results from the LCIA and the impact assessment, and then draw conclusions. The results should be evaluated, according to ISO 14043.

\subsubsection{LCA tools}

ISO 14040 is implemented in SimaPro software. As it was mentioned in Chapter 1, SimaPro helped us to develop an LCA of the PV system. This software was developed by PRéConsultancy Company, founded in 1990 by Mark Goedkoop (PRé Consultants, 2011).

SimaPro let us to develop an LCA by defining the assemblies and subassemblies and selecting the materials and energy input from its database (Swiss Centre for Life Cycle Inventories, 2013). 
Chapter 4 Life Cycle Assessment applied to photovoltaics

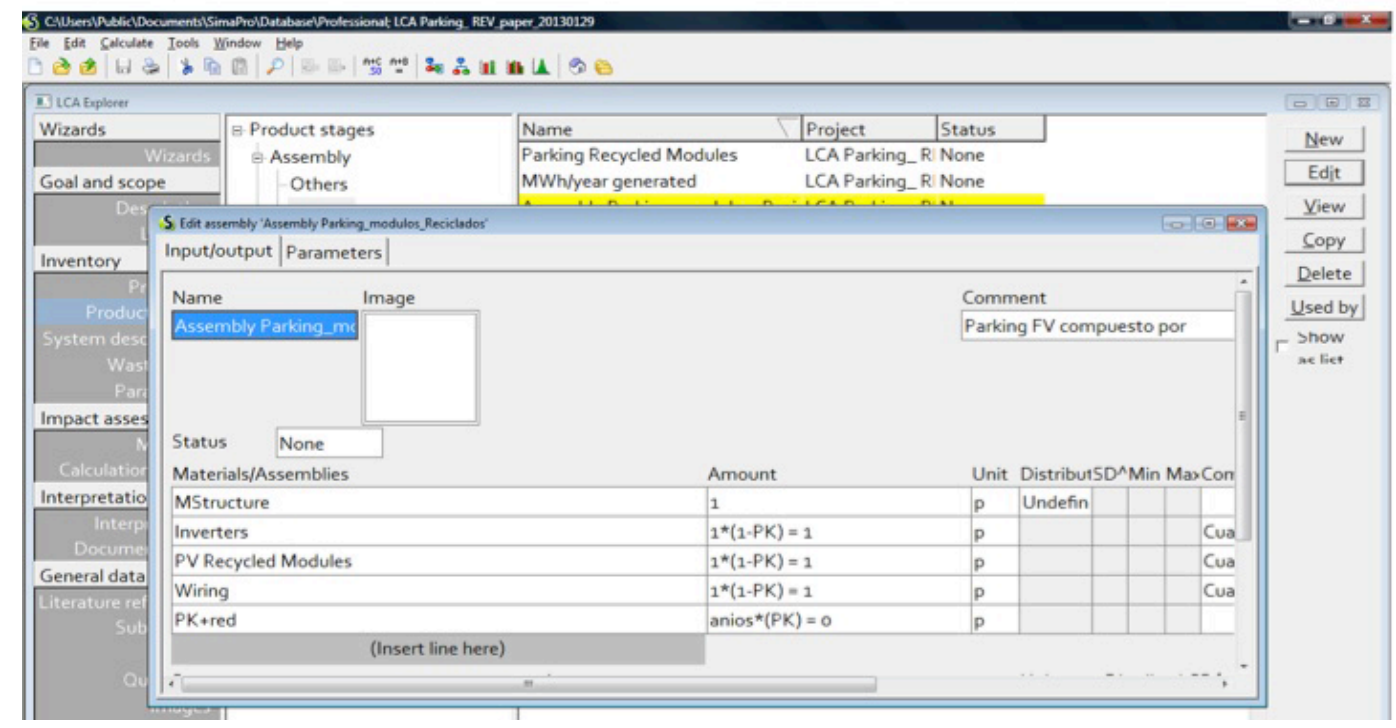

FIGURE 4.3 PARKING ASSEMBLY ON SIMAPRO SOFTWARE: SPECIFING SUBASSEMBLIES OF WHICH THE PARKING IS MADE UP. THE VARIABLE "PK" LET US COMPARE SEVERAL CASES OF ASSEMBLIES, WITH OR WITHOUT SOME SUBASSEMBLIES.

By defining a global variable, this software let us to compare different assemblies: with or without some subassemblies, or with different amount of them.

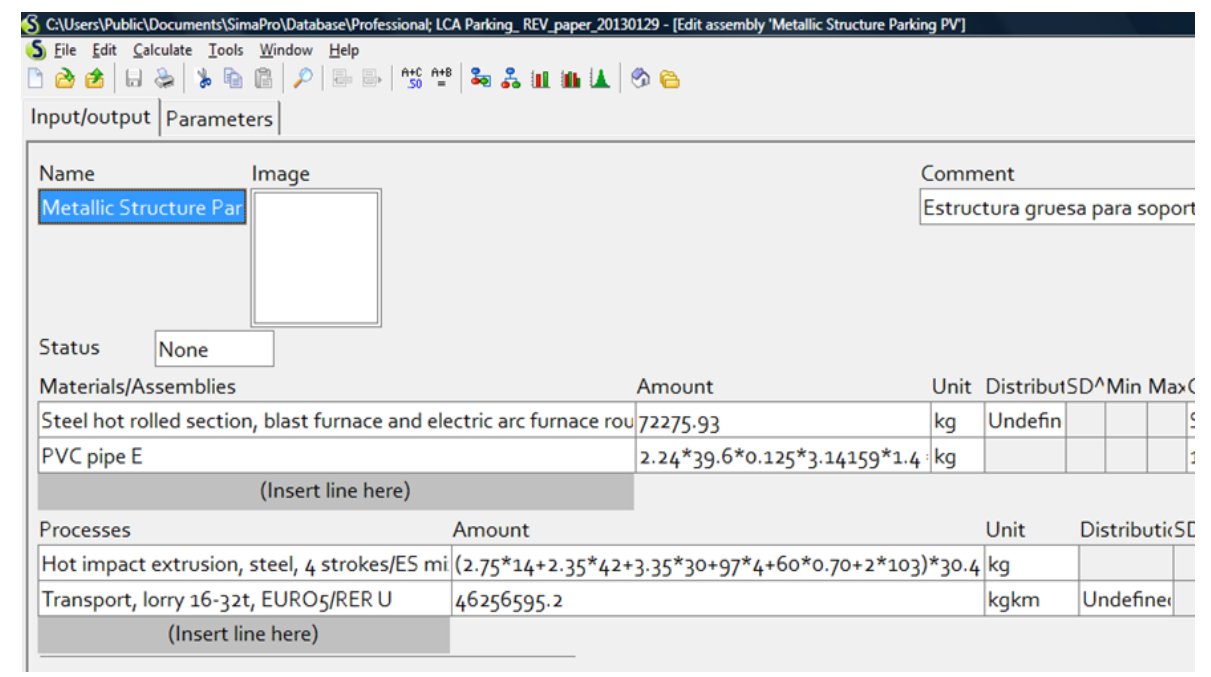

FIGURE 4.4 SPECIFING WITH SIMAPRO A SUBASSEMBLY. THE MATERIALS AND PROCESSES ARE REFERRED TO ECOINVENT DATABASE. 
SimaPro implements the impact assessment methodologies, as Cumulative Energy Demand, Eco-indicator, ReCiPe, Green House Gas Protocol, etc.

If global variables are defined in order to compare assemblies, a direct comparison can be obtained between them, as shown in Figure 4.5.

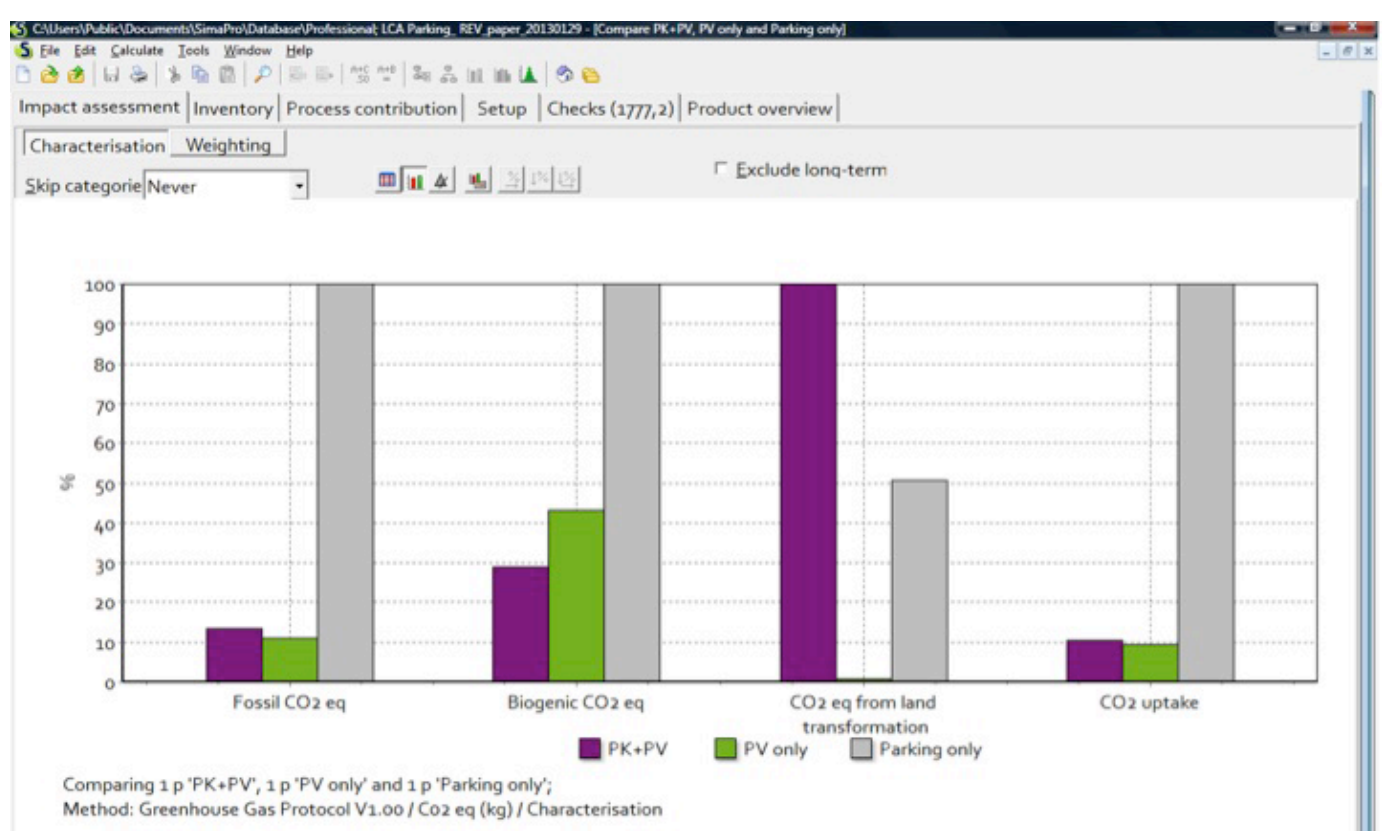

FIGURE 4.5 COMPARING GREEN HOUSE GAS EMISSIONS BETWEEN DIFFERENT ASSEMBLY CONFIGURATIONS

In section 3.2 the features characterising an LCA applied to photovoltaic energy is described. Then, an LCA applied to a real case in Murcia will be developed. With this aim, in section 3.3 the studied case is described, and other two cases to which the system will be compared. Fortunately, we had access to assembling parkingintegrated PV information and a LCIA was performed in detail. We chose as Functional Unit the whole parking in order to compare with other two combinations and get the environmental impacts of each study case. In section 3.4 LCA is applied and the results are shown. Finally, section 3.5 shows the conclusions and the interpretation process, which has been carried out. It is important to emphasize that SimaPro is very useful both to organize all the amount of information required for a standard LCA study, and to access to the 
Swiss EcoInvent database, one of the most complete databases in the world for the analysis of environmental impacts.

\subsection{Life Cycle Assessment applied to photovoltaic technologies}

LCA is widely applied to sustainable energy sources in order to assess the environmental impact of energy generation. In contrast to conventional energy sources that generate pollution, the balance of impacts is always negative. However, in the case of renewable energies, the environmental "benefits" can also be calculated in terms of "avoided" impacts when compared with conventional technologies .

When the goal of an LCA is to assess the environmental impact of a photovoltaic generator, a well-defined functional unit (FU) has to be chosen. The most used FU in photovoltaic technologies is the "installed capacity", (usually $1 \mathrm{Wp}$ ), "generated energy" (1Wh), or "surface" of modules, $\left(1 \mathrm{~m}^{2}\right)$. These units are easily scalable, making possible the comparison between technologies. For a full discussion on this topic, see the articles by Erik Alsema (Alsema, 1998; Alsema and de WildScholten,M.J., 2005; Alsema and Nieuwlaar, 2000).

In a LCA context, the comparison between energy technologies, very often uses Greenhouse Gas emission impact index " $\mathrm{gCO}_{2} / \mathrm{kWh}$ ", that is the $\mathrm{CO}_{2}$ emissions produced per generated kilowatt-hour of energy.

Figure 4.6 shows the amount of $\mathrm{CO}_{2}$ per electrical generated $\mathrm{kWh}$ emitted by each kind of energy technology, including both renewable and fossil fuel technologies. 


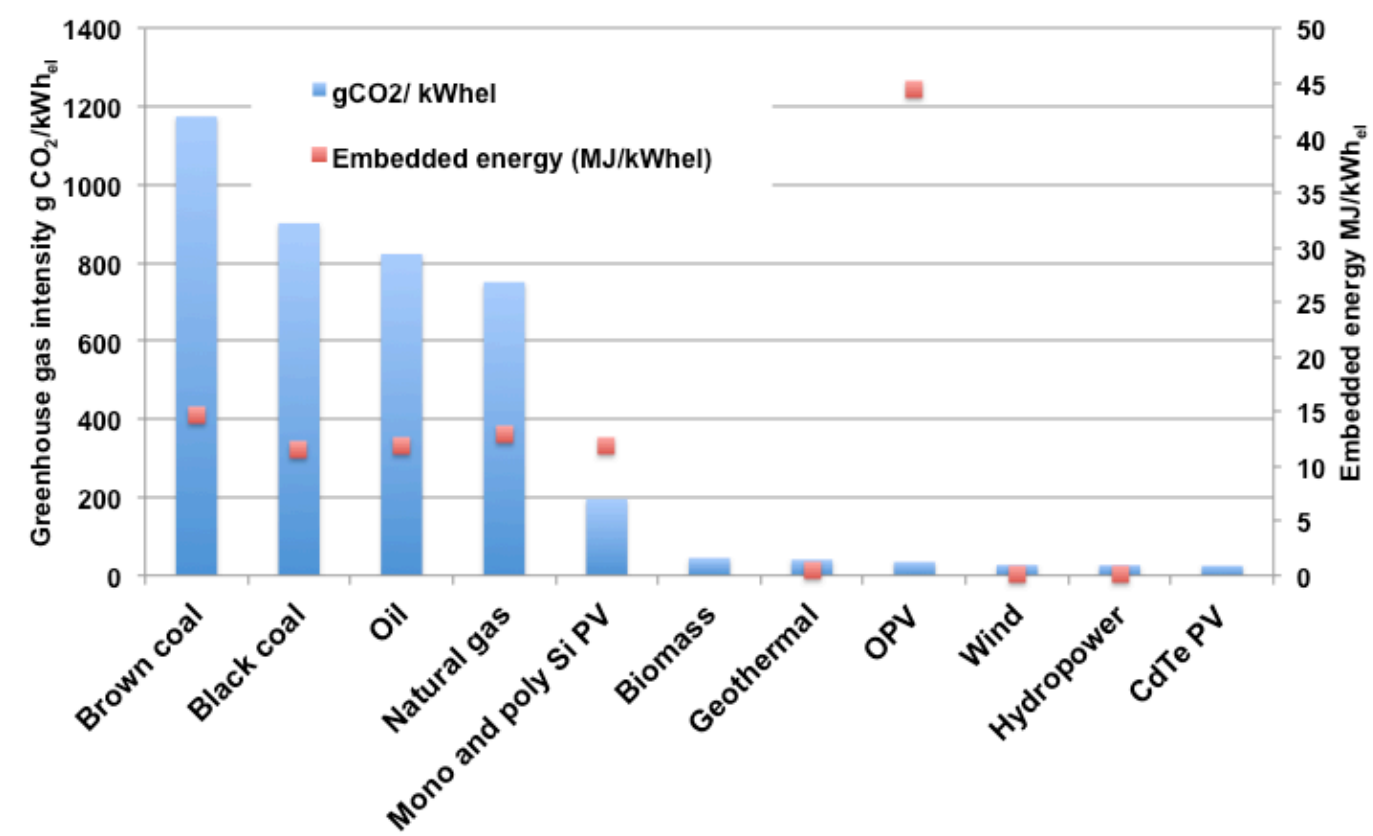

FIGURE 4.6 EMBEDDED ENERGY (MJ/kWh $\left.\mathrm{h}_{\mathrm{ll}}\right)$ AND GLOBAL WARMING POTENTIAL $\left(\mathrm{gCO}_{2} / \mathrm{kWh}_{\mathrm{el}}\right)$ FOR SEVERAL ALTERNATIVE ENERGY TECHNOLOGIES

Cumulative Energy Demand (CED) or Embedded Energy of a product represents $<<$ the direct and indirect energy use throughout the life cycle, including the energy consumed during the extraction, manufacturing and disposal of the raw and auxiliary materials $>>$, (Huijbregts et al., 2006).

CED within a product also illustrates the potential environmental impact. The higher the CED, the greater amount of energy is needed during the manufacturing process of the "functional unit" of a given technology. Using more energy always means the use of limited sources, and, as a result, more environmental impact.

Energy Pay Back Time (EPBT) is one of the parameters most used to compare renewable energies in general, and photovoltaic technologies in particular. This parameter is defined as the number of years that a given photovoltaic system will requires to produce the same amount of energy that was needed to manufacture the same PV system. EPBT is calculated using the total CED as an input, which is then divided by the yearly energy production of the system (Alsema, 1998), as 
Equation 4.1 shows. Similarly, an Energy Return Factor (ERF) is defined as the amount of energy that is produced by a PV system throughout its lifetime for each energy unit embedded in the system (i.e. used to manufacture, install and run the system). Both parameters are related by the lifetime of the system as can be seen in Equations 1 and 2. EPBT and Energy Return Factor (ERF) are mainly used to evaluate the energy balance of energy production systems.

\section{Equation 4.1}

$$
E P B T=\frac{C E D}{E_{G E N}} \quad \quad E R F=\frac{E_{G E N} \cdot L}{C E D}=\frac{L}{E P B T}
$$

CED is the total primary energy input during the PV module life-cycle, $\mathrm{E}_{\mathrm{GEN}}$ is the primary energy generated during a year by the PV system (converted to equivalent primary energy, EPE, according to a $35 \%$ efficiency in the conversion), and $\mathrm{L}$ is the lifetime of the PV system. The EPBT values of several energy sources are written in TABLE 4.1. 
Chapter 4 Life Cycle Assessment applied to photovoltaics

\begin{tabular}{ccc}
\hline Energy source & Technology & EPBT \\
\hline Wind & On land & 0.26 \\
& Offshore & 0.39 \\
\hline & $\begin{array}{c}\text { Silicon Mono and } \\
\text { polycrystalline }\end{array}$ & 1.13 \\
& GaAs PV & $2.36-5$ \\
PV technologies & GaInP/GaAs & $0.73-1.61$ \\
& CdTe & $0.73-1.61$ \\
& CIS & $2.02-2.26$ \\
& Dye sensitized & $0.74-2.1$ \\
& OPV & $0.2-4$ \\
\hline Hydropower & Hybrid & 0.5 \\
\hline Geothermal & & 0.54 \\
\hline Biomass & Gasification & $<5$ \\
\hline & Biomass combustion & $5-10$
\end{tabular}

TABLE 4.1 LISTING OF DIFFERENT RENEWABLE ENERGY TECHNOLOGIES AND THEIR EPBT (IN YEARS), MEASURED IN MJ/KWHEL (ESPINOSA MARTINEZ ET AL., 2012)

\subsection{Description of the alternative study cases}

LCA methodology was applied to the CdTe photovoltaic generator whose electrical and electronic design as well as its monitorization was described in Chapter 2. With the aim of studying advantages or disadvantages of our parkingintegrated system (Case 1 from now), its environmental impact is compared with other two cases or alternatives: the case of a parking-alone (Case 2), and a third one, which is the ground mounted PV-system alone (Case 3). 


\subsubsection{Case 1 (PV\&PK): 222kWp CdTe parking integrated grid-connected facility}

In order to apply LCA methodology, details about the construction of the PV generator is needed, adding information to the description appeared in Chapter 2.

The grid-connected PV facility was built during late 2008 and beginning of 2009 and finally commissioned in May 2009 at the University of Murcia. Figure 4.7 shows the building phases of the installation. The latitude and longitude of the system location are respectively $38^{\circ} 01^{\prime} 12^{\prime \prime} \mathrm{N}$ and $1^{\circ} 09^{\prime} 56^{\prime \prime} \mathrm{W}$. The yearly average of daily irradiation is $5320 \mathrm{Wh} / \mathrm{m} 2$ ("PVGIS home. Photovoltaic Geographical Information System - Interactive Maps," 2011), and it is similar to the average measured by our monitorization system, which is: $4960.17 \mathrm{Wh} / \mathrm{m} 2$ per day. It can be considered as a BIPV system, since the PV modules are frameless and were integrated into the parking structure. All the generated electricity is fed into the grid and it benefits from the Spanish feed-in tariff. The parking structure shown in Figure 4.7D, also integrates a group of solar thermal collectors and a system to harvest rainwater to provide water for irrigation. The facility is $20^{\circ}$ east oriented and it is $7^{\circ}$ tilted over the horizontal, as was indicated before. 


\section{A}

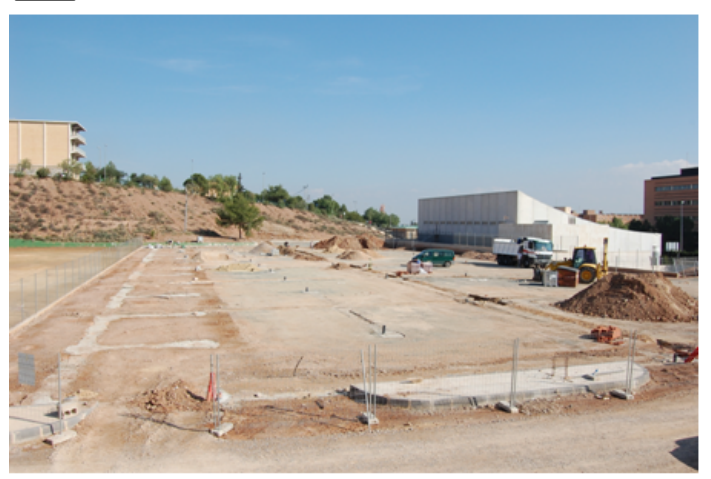

C

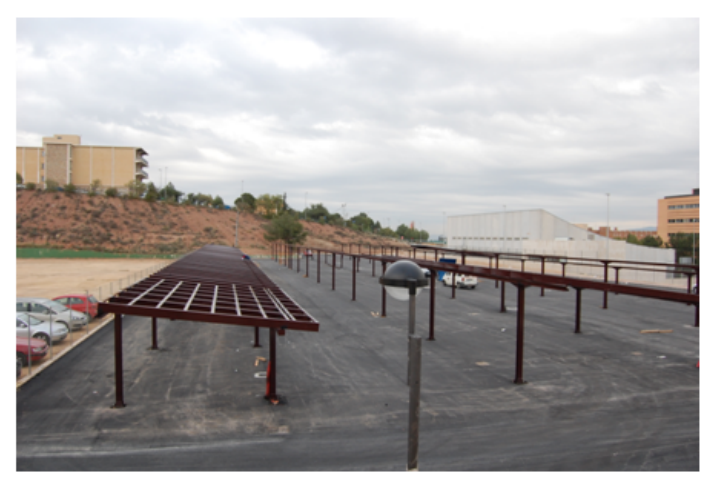

B

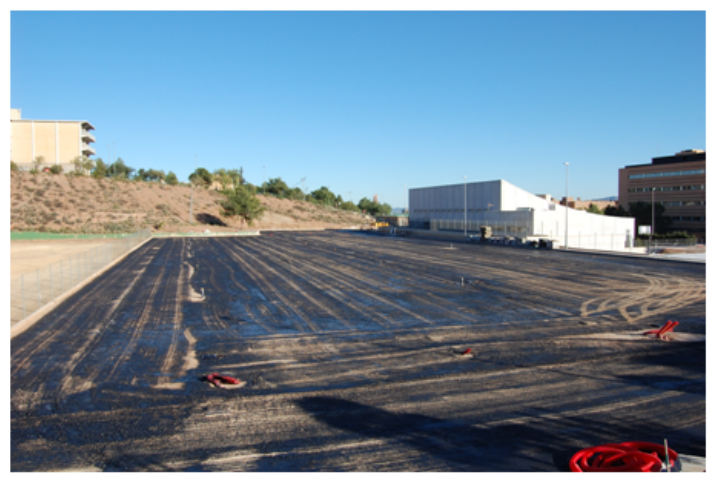

D

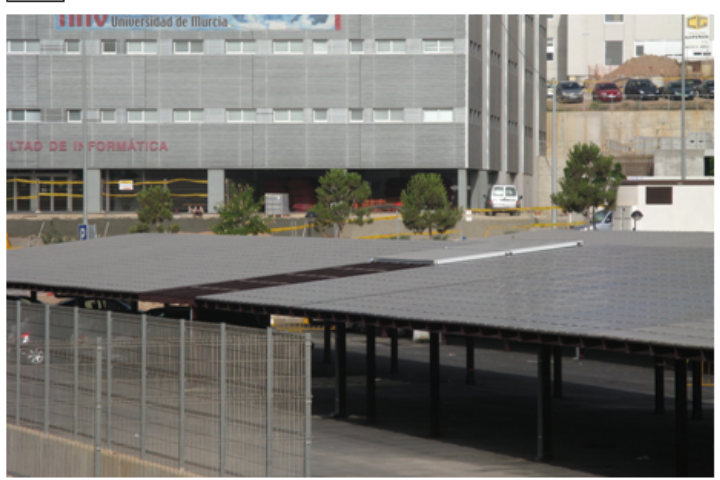

FIGURE 4.7. BUILDING PROCESS OF 222KWP CDTE PARKING FACILITIES: (A) EARTHWORKS, (B) MASTIC ASPHALT, (C) METALIC STRUCTURE ASSEMBLY AND (D) STRUCTURE-INTEGRATED CDTE MODULES PLACEMENT AND FINAL WIRING AND GRID CONNECTION. THE SYSTEM ALSO INCLUDES INFORMATIVE PANNELS ABOUT THE FACILITY FOR TEACHING PURPOSES.

Before the parking was assembled, other construction previously took place: the ground was levelled; rolled and asphalted. Initially, the landscaping (Figure 4.7.A) implies the use of an excavator to level out the land. It turned over 348.75 tons of earth, that was transported $320 \mathrm{~km}$ by truck. In the foundation phase 232.5 $\mathrm{m}^{3}$ of concrete were poured before 21.3 tons of mastic asphalt (Figure 4.7.B) was casted. Subsequently, the structure (made of 72.27 tons of steel hot rolled section, casted by a hot impact extrusion machine) was assembled with a PVC pipe (Figure 4.7.C). Finally, the PV modules were assembled (Figure 4.7.D) together with the required BOS (30 inverters and $305 \mathrm{~m}$ of wire). 
As explained in Chapter 2, the nominal peak-power (installed capacity) of the facility is $222.36 \mathrm{~kW}_{\mathrm{p}}$. The PV generator is made of 3,144 cadmium telluride (CdTe) modules covering a total PV surface of 2,263 $\mathrm{m}^{2}$, with 25 -years power output transferable warranty of minimum output power. The estimated 30 years system lifetime has been also considered for several calculations, since it is recommended by the "Functional guidelines" from the LCA for PV-LCA (V. Fthenakis et al., 2011). Table 1 (Chapter 2) shows the main parameters of these PV modules. Module groups and its technical details are showed in Chapter 2, Table 1. The 30 single-phase inverters are grouped and co-operatively operate to generate a three-phase AC signal.

The model of inverter used at the PV facility is described in Chapter 2, Table 3. The PV system sends information by the monitorization system explained in Chapter 2, section 2.3.

For the sake of clarity, Case 1 , which is the $222 \mathrm{kWp}$ CdTe parking integrated grid-connected facility, will be referred to as PV\&PK from now on.

\subsubsection{Case 2 (PK_ONLY): Same-size parking without PV}

This second alternative option considers the construction of the parking with the same car capacity, but on the assumption that the PV system is not installed on top of it. In this case the structure is lighter $(68 \%)$ than in the PV parking option because although it is made of the same material, i.e. steel, there is no need for the PV module integration on the structure and therefore the frame has less structural resistance requirements.

We have taken into account for the LCA calculation the assembly process of the parking (earthworks, foundation, structure and roofing), the manufacturing of structural parts (steel profiles, metal sheet and gutter) and the transport of all materials. 
Same-size parking without PV from now on will be referred to as PK_ONLY.

\subsubsection{Case 3 (PV_ONLY): 222kWp ground-mounted CdTe grid-connected facility}

This case consists of a hypothetical installation composed by 3,144 CdTe modules placed in a continuous structure line (the simplest one). This is the same number of PV modules as in Case 1, except that in this case they are ground-mounted. The differences in structural framework have been taken into account and simplified as required. This Case 3 does not require asphalt, but it does require structure and landscaping. We have considered the model BASE-FS from the international company Gehrtec ("GEHRTEC BASE-FS, Smart assembly system. www.gehrlicher.com," n.d.) as structure for supporting the modules. The structure could house 5 rows of modules, which means 5x629 modules and 754.8 linear meters. The weight of modules $\left(\right.$ per $\left.\mathrm{m}^{2}\right)$ is $11.6 \mathrm{~kg}$.

The structure would in this case be tilted and oriented with the optimum values for the location (i.e. $30^{\circ}$ South, respectively) in order to maximise the annual production. The type of modules, groups of modules and inverters are considered for comparison to be the same that those of PV parking. We would like to emphasize that although this system is identical in capacity to PV\&PK, the optimum orientation of the modules -for the same irradiation conditions-, will lead therefore to a higher electricity production in this case; this fact will be discussed when comparing the environmental impact of the three considered cases.

The $222 \mathrm{~kW}_{\mathrm{p}}$ ground-mounted CdTe grid-connected facility from now on will be referred to as PV_ONLY.

Hereafter, we are applying the LCA methodology in order to compare the environmental impact of the three cases, its advantages and disadvantages. 


\subsection{Life-cycle assessment applied to the parking- integrated photovoltaic system}

\subsubsection{Goal and scope definition}

The system boundary has been clearly stated and the objectives established in the preceding sections. The aims of this LCA analysis can be summarised as 1) analyse the environmental impact of the photovoltaic parking facility at the University of Murcia, 2) compare this environmental impact with two alternative cases (PK_ONLY and PV_ONLY), and 3) analyse the environmental advantages or disadvantages of having a PV facility integrated on the parking roof.

Once all the required data regarding materials and processes for each scenario have been collected, various methods using SimaPro 7.3 software were applied to assess the environmental impacts as well as the energy costs. The following methods were used:

- Cumulative Energy Demand. Primary energy demand from nonrenewable energy resources (fossil, nuclear and biomass), and from renewable energy resources (biomass, wind, solar, water).

- ReCiPe MidPoint (H). This method is oriented to the measure the environmental damages; organized in several impact categories, for example, land use impact and climate change impact.

- Greenhouse Gas Protocol: indicated for evaluating the impact of Green House Gas emissions. It measures the amount of fossil and biogenic carbon equivalent, just as the $\mathrm{CO}_{2}$ emitted because of land transformation and the $\mathrm{CO}_{2}$ stored in plants and trees.

The Scope Definition section of the LCA standard defines which processes are included in, or excluded from the LCA study. It has been graphically represented in Figure 4.8; this is typically known as system boundary. The energy requirement 
for manufacturing and transportation of materials is taken into account in the study. The life-cycle stages of PV system installation, maintenance and decommissioning were considered as well.
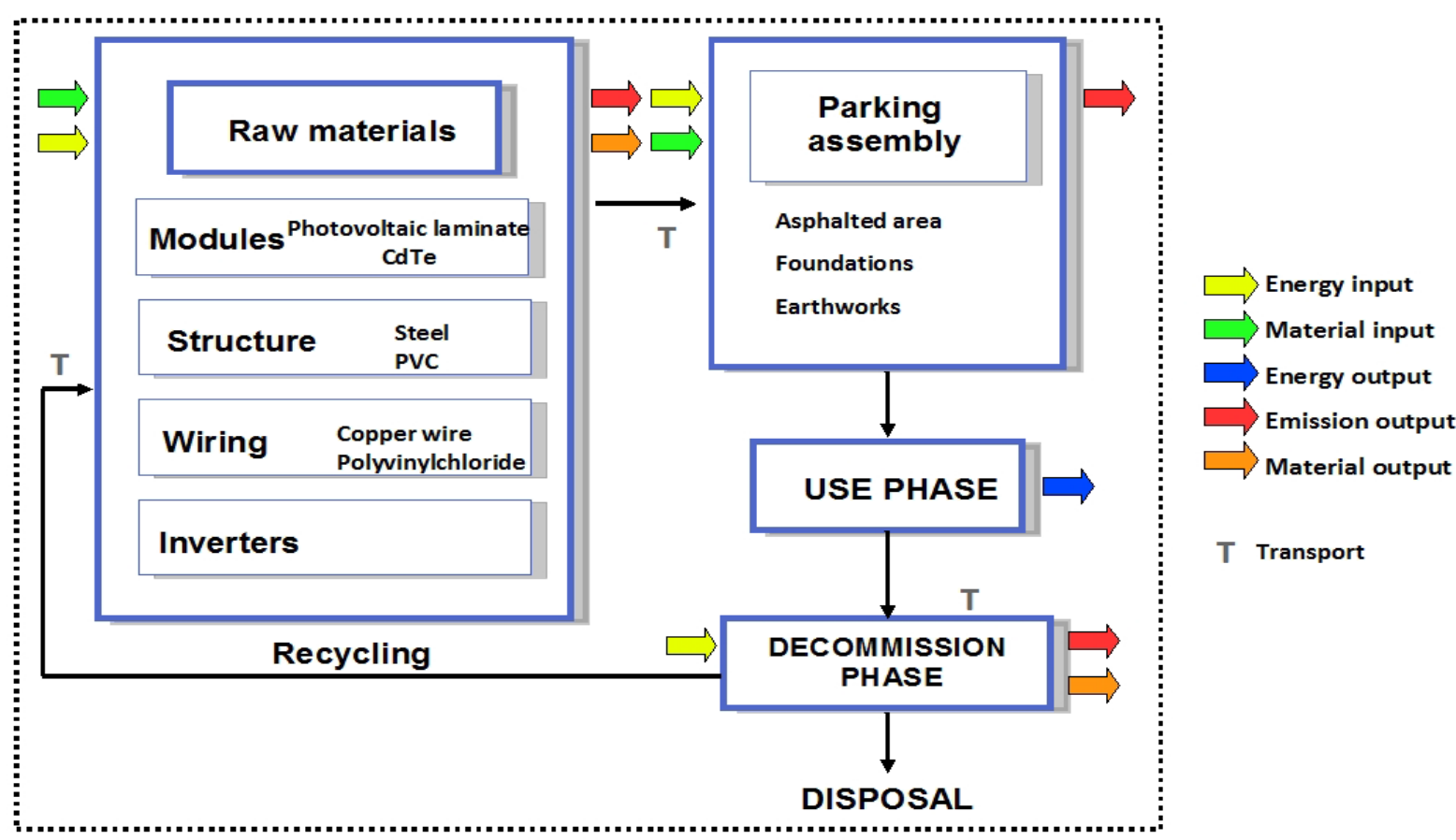

FIGURE 4.8 LIFE-CYCLE STAGES OF THE PARKING CONSTRUCTION, WHERE THE DEFINED SYSTEM BOUNDARIES ARE CIRCLED BY DASHED LINE: RAW MATERIALS EXTRACTION, MANUFACTURING PROCESSES, PARKING ASSEMBLY, USE PHASE AND DECOMMISSION PHASE.

We have considered recycling the copper wire and steel materials in end-of-life phase and transport to recycling plant. The global average recycling rate is estimated to be $95 \%$ and $80 \%$ respectively (European Commission, 2011). With regard to the CdTe modules, the definition of their disposal scenario in Ecoinvent has been used; that is, to be sent to landfill in waste phase because there are no advanced waste treatment processes for any PV types yet (Roes et al., 2009). Nevertheless, if the CdTe modules are partially or totally recycled, the final environmental impacts could be reduced and so the benefits of the generation of renewable electricity increased. According to First Solar ("Cadmium Telluride (CdTe): Proven Thin Film Semiconductor Technology | First Solar. CdTe Facts 
NA FEB 2009," 2012) and PV Cycle Organization (globulebleu.com, n.d.), 90\% of glass and $95 \%$ of CdTe could be recycled, but the details of processing, separation of materials, purification and reuse in the manufacture are not available. We have also performed calculations taking into account this recycling scenario, but only in terms of Life Cycle Inventory (the input materials).

\subsubsection{Functional Unit (FU)}

As it was previously explained, we want to compare the same installation with two alternatives cases. Therefore, it was found more accurate to set as functional unit the complete facility; i.e. a $222 \mathrm{~kW}_{\mathrm{p}}$ PV facility as described in PV\&PK case. Additionally we have also considered $1 \mathrm{kWp}$ as functional unit for same calculations in order to enable easier comparison with existing literature.

\subsubsection{Life-cycle inventory (LCI)}

The inventory analysis is the LCA phase that involves the compilation and quantification of inputs and outputs of a given product system, throughout its lifecycle or for single processes. We have taken into account all material elements of the parking (photovoltaic modules, inverters, wiring and metallic structure), as well as the processes involved in building (transport of materials, foundations, earthworks). For each defined case, the CED will be different depending on the material and processes of each one.

According to the already defined system boundary, we have proceeded to make the following inventories:

- Material inventory: collection of all material flows in the assembly process of the photovoltaic parking, expressed per functional unit.

- Energy inventory: it is the embedded energy or CED in each part of the photovoltaic parking. Part of this energy was consumed in the manufacturing of the input materials and another part was directly used in 
processes (direct process energy). This energy will be also rated per functional unit; that is, the complete PV parking. The Total Equivalent Primary Energy (EPE) is obtained using the Cumulative Energy Demand method in SimaPro, and incorporating data when needed, mainly from the Ecoinvent database. This method converts the different energy inputs to EPE. The photovoltaic modules were made in Germany, so the electricity mix of this country has been taken into consideration for the environmental impact of the energy embedded in the modules. The Spanish electricity mix has been considered for the rest of electrical processes in the different assemblies.

- Emissions inventory: according to the LCA standard, the releases to soil, water and air generated during the entire life-cycle are included in this inventory.

\subsubsection{Life-cycle Impact Assessment}

The Life-cycle Impact Assessment (LCIA) identifies and evaluates the amount and significance of the potential environmental effects arising from the LCI. In order to facilitate this assessment, the inputs and outputs obtained from the LCI are classified and related to some environmental indicators, e.g. Climate change, Ozone depletion, Human toxicity, etc. The choice of these environmental indicators depends on the selected LCIA methodology, and the specific objectives of the study.

As explained in section 3.2 for photovoltaic LCA studies, Energy Pay Back Time (EPBT) and Energy Return Factor (ERF) are typical environmental indicators (see Equation 4.1 and Equation 4.2). In order to calculate these parameters, the generated energy (given by the monitorization system), the embedded energy (obtained by applying Cumulative Energy Demand methodology in SimaPro) and the lifetime of the modules (considered to be the manufacture guarantee -25 yearsand years LCA guide specifies -30 years) are required. 
The yearly energy produced by the PV parking was estimated from the real data collected by the monitoring system between November 2009 and November 2011 . For the Case 3 (PV_ONLY, PV facility on ground), the generated energy was estimated using the main global irradiation for each month in Murcia at the optimized tilted and oriented surface for maximizing annual production and considering the mean performance ratio for each month, the one that was calculated for the PV parking from data acquisition system.

The Green House Gases (GHG) impact assessment is a methodology that measures the greenhouse gas emissions, or carbon footprint, of products and services. This LCA has taken into account the assembly of the parking with roofmounted photovoltaic modules. The generation of $\mathrm{CO}_{2}$ is mainly produced during the manufacturing, transport and assembly phases. Only clean, emissions-free electricity is generated during the use phase. The recycling stages include two materials, which were defined in this way in SimaPro: steel (recycling 80\%) and cooper wire (recycling 95\%). We assume that the rest of materials are deposited into a landfill according to the scenario of Ecoinvent, or as an alternative case, we consider recycling of modules: $90 \%$ glass and 95\% CdTe according to First Solar as mentioned above ("Cadmium Telluride (CdTe): Proven Thin Film Semiconductor Technology | First Solar. CdTe Facts NA FEB 2009,” n.d.).

\subsection{Results and Discussion}

The results have been organized according to the three cases defined previously. We present four sub-sections showing a) the energy, materials and emissions inventories; b) the life-cycle analysis of the three cases, calculating EPBT and ERF indicators; c) Green House Gas emission assessment; and finally, d) comparisons of the three scenarios. 


\subsubsection{Material, energy and emissions inventory}

Table 4.2 shows the CED in input materials, the weight of materials and the released emissions of greenhouse gases, per functional unit, in each scenario of study. All the information used in this analysis comes from reliable sources; that is from the company that built the integrated PV parking and from inverters and PV modules manufacturers. However, for the hypothetical cases (PV_ONLY and PK_ONLY) part of data have been estimated.

\begin{tabular}{ccccccccc}
\hline & PV\&PK & \multicolumn{3}{c}{ PK_ONLY } & \multicolumn{3}{c}{ PV_ONLY } \\
\hline Mass & Energy & $\mathrm{CO}_{2}$ & Mass & Energy & $\mathrm{CO}_{2}$ & Mass & Energy & $\mathrm{CO}_{2}$ \\
$($ ton $)$ & $(\mathrm{GJ})$ & $($ ton $)$ & (ton) & $(\mathrm{GJ})$ & (ton) & (ton) & (GJ) & (ton)
\end{tabular}

\begin{tabular}{|c|c|c|c|c|c|c|c|c|c|}
\hline MATERIALS $^{2}$ & & & & & & & & & \\
\hline Concrete & 0.55 & 287.66 & 38.03 & 0.55 & 287.66 & 38.03 & - & - & - \\
\hline Mastic Asphalt & 21.3 & 150.18 & 4.76 & 21.3 & 150.18 & 4.76 & - & - & - \\
\hline Steel & 72.27 & 844.67 & 81.82 & 36.34 & 424.77 & 41.14 & - & - & - \\
\hline Galvanized steel $^{3}$ & - & - & - & 12.8 & 37.95 & 3.47 & 36.47 & 108.12 & 9.88 \\
\hline Inverter $(x 75)$ & 2.25 & 338.1 & 19.57 & - & - & - & 2.25 & 328.67 & 19.57 \\
\hline $\begin{array}{l}\text { Photovoltaic } \\
\text { laminate CdTe }\end{array}$ & 37.73 & $3,761.08$ & 248.27 & - & - & - & 37.73 & $3,761.08$ & 248.27 \\
\hline Copper wire & 0.55 & 0.9 & 0.04 & - & - & - & 0.55 & 0.9 & 0.04 \\
\hline \multicolumn{10}{|c|}{ ENERGY PROCESSES } \\
\hline $\begin{array}{l}\text { Hot impact } \\
\text { extrusion }\end{array}$ & - & 591 & 33.22 & - & 742.39 & 41.7 & - & 181.81 & 10.21 \\
\hline Transport & - & 295.06 & 17.45 & - & 114.6 & 6.85 & - & 179.86 & 10.56 \\
\hline Total & 134.65 & $6,268.26$ & 443.12 & 70.99 & $1,757.54$ & 135.95 & 77.00 & $4,559.53$ & 298.49 \\
\hline
\end{tabular}

2 It omits some negligible materials: Polyvinylchloride coating wire and Polyvinylchloride pipe.

Considering $90 \%$ of recycled steel [33] 
To quantify the environmental impact of the CED in the different processes, we have considered the Spanish electricity mix as the source to generate the same amount of energy. It comes from several sources: nuclear (7.4\%), coal (11.4\%), fuel oil-gas oil (5.5\%), natural gas $(25.9 \%)$, renewables energies $(33.0 \%)$ (Gobierno de España et al., 2010). When looking at the contributions of the different inputs, as it is shown in Figure 4.9, in case of having parking only (PK_ONLY), the main impact contributor is the metallic structure, while in the option of a PV installation; it would have the lowest value. In the real case (PV\&PK), despite the metallic structure, which represents the largest weight in kilograms over the rest of materials $(53.67 \%)$, the PV modules have the largest share in the $\mathrm{CED}$ and embodied $\mathrm{CO}_{2}$. The modules have the largest energy cost in PV\&PK and PV_ONLY -having both PV installations- embedding 69.78\% and $89.38 \%$ respectively.

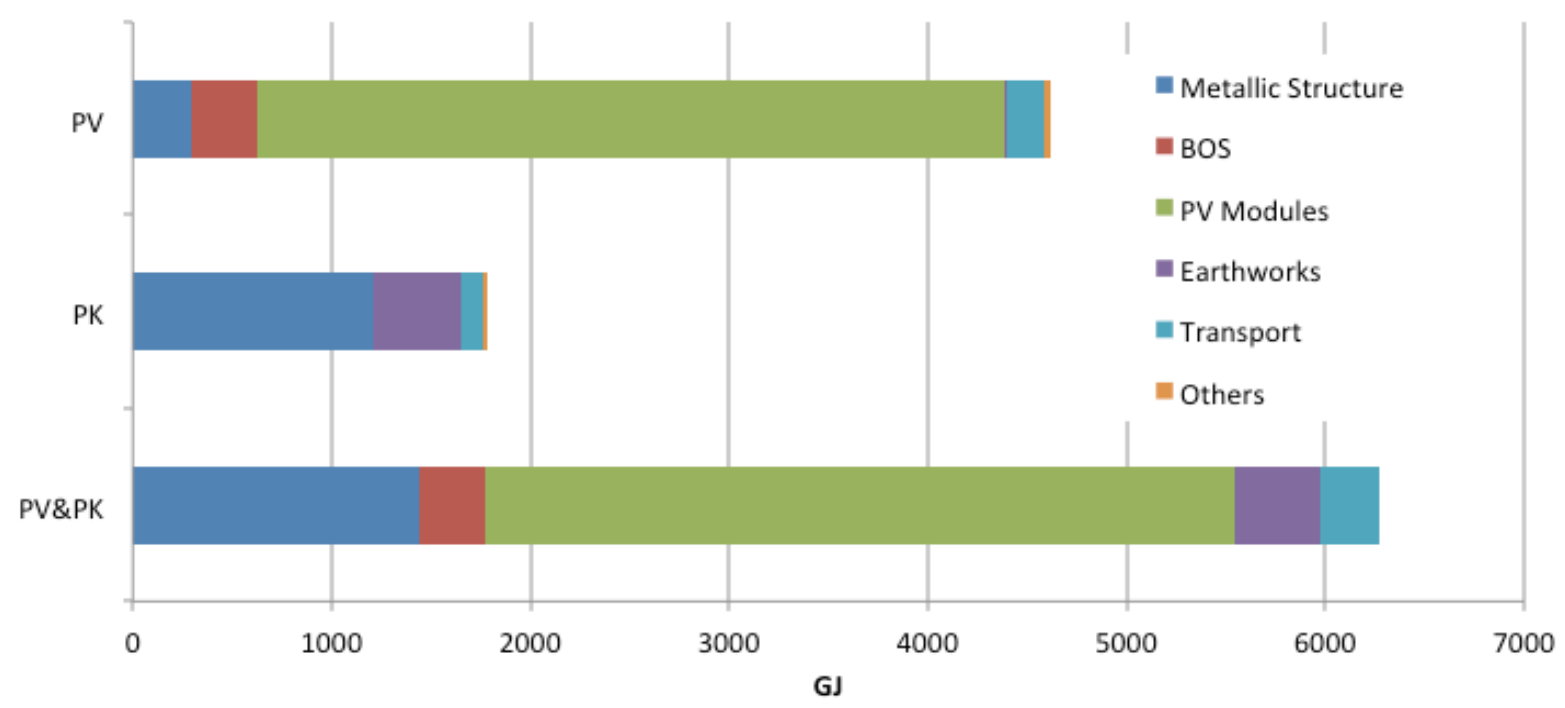

FIGURE 4.9 CED PER FUNCTIONAL UNIT FOR THE FOLLOWING INPUT MATERIALS AND PROCESSES IN GJ EPE UNITS, FOR THE THREE CONFIGURATIONS (PV\&PK, PV_ONLY AND PK_ONLY): METALLIC STRUCTURE, BOS, PV MODULES, EARTHWORKS, TRANSPORT AND OTHER PROCESSES AS EXPLAINED IN THE TEXT. 
Therefore, in terms of the embodied energy or CED, adding PV modules into the parking requires 1.6 times the needed energy for just installing the parking, and 1.8 times the amount of $\mathrm{CO}_{2}$ generated (see Table 4.2). The higher emissions are related to the larger size of the metallic structure, that has to be sturdier, and to the modules, that have the largest impact in all categories. However, there is a clear advantage in integrating the parking and the PV. The integration saves $5.28 \%$ $\mathrm{CO}_{2}$, and only implies $1.3 \%$ more of energetic cost when compared to the addition of PV_ONLY and PK_ONLY. Also, having the PV parking integrated, instead of simply ground-mounted, makes possible the use of the land underneath.

\subsubsection{Life-cycle impact assessment (LCIA)}

To carry out the assessment of the impacts or LCIA, three methods described in section 3.1.1. have been selected and are described in the next sub-sections.

\subsubsection{Energy impact assessment}

The energy pay-back time (EPBT) and the energy return factor (ERF) were defined. The total CED in each scenario is shown in Table 4.4. The energy generated by the PV installation has been calculated by looking up the server database from $10^{\text {th }}$ of June, 2009, to $2^{\text {th }}$ of December, 2011, giving a total of 787.25MWh, which means $328.39 \mathrm{MWh} /$ year. An example of the stored information of the monitorization system is shown in Figure 4.10, where the generated power over the course of a day is displayed for PV\&PK case and illustrates four different environmental conditions. 

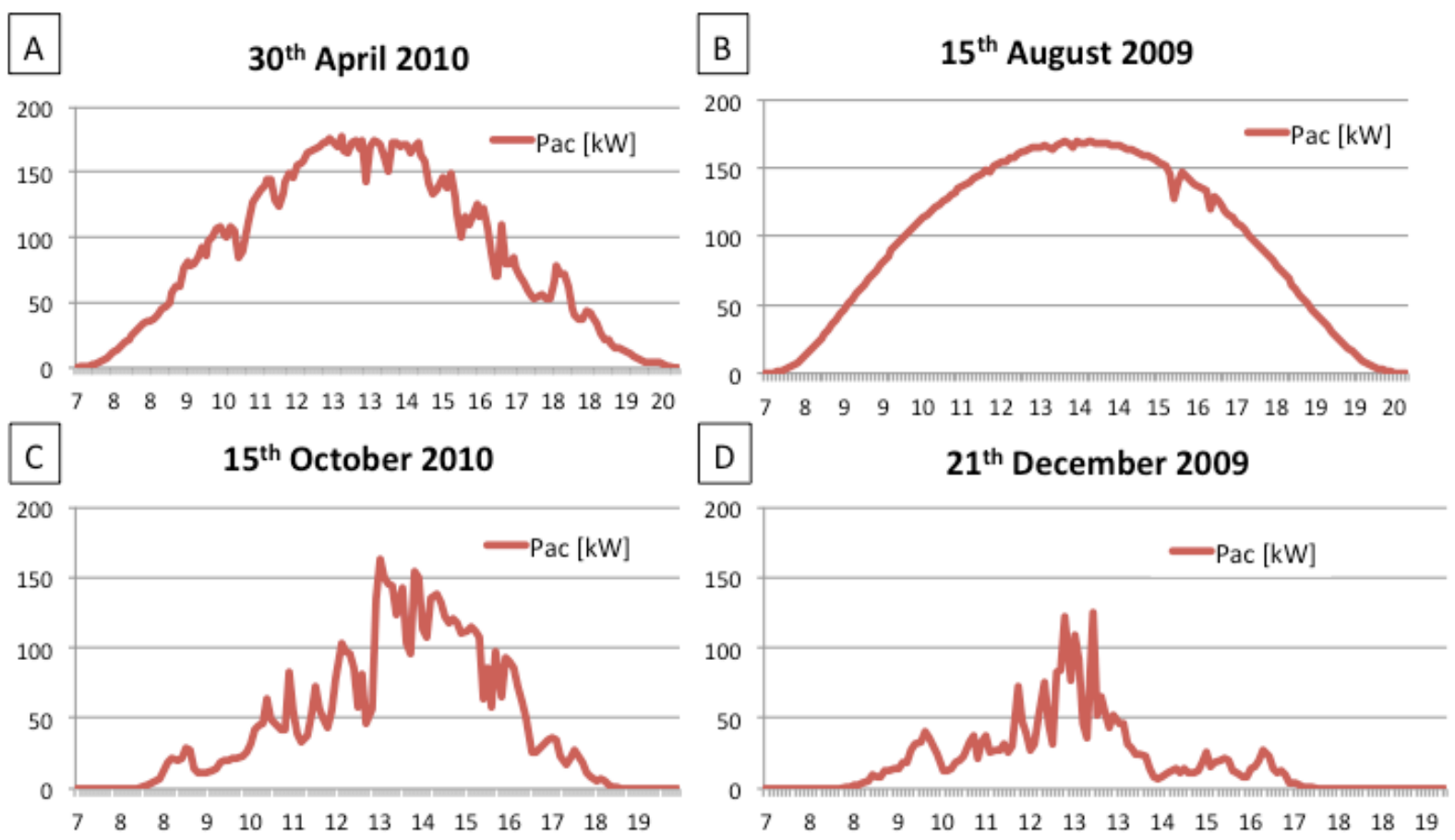

FIGURE 4.10 GENERATED POWER OF THE PHOTOVOLTAIC INSTALLATION ALONG A DAY COVERING THE FOUR SEASONS AND DIFFERENT ENVIRONMENTAL CONDITIONS: (A) $30^{\mathrm{TH}}$ APRIL THE GENERATED ENERGY WAS 1,197.89 KWH, (B) $15^{\mathrm{TH}}$ AUGUST 1,316.42 KWH. IN AUTUMN (C), $15^{\mathrm{TH}}$ OCTOBER, 855.33 KWH AND FINALLY (D) $21^{\mathrm{ST}}$ DECEMBER WAS 247.50 KWH

Using the stored parameters of the PV system, the monthly Performance Ratio $(\mathrm{PR})$ and the Capacity Factor (CF) of the installation have been calculated following Equations 3 and 4:

Equation 3

Equation 4

$$
P R=\frac{\sum_{1}^{N} P a c_{i}}{k \cdot \frac{1}{\sum_{S T C}} G_{i}} \quad C F=\frac{G_{\alpha \beta} \cdot A \cdot P R \cdot \eta_{S T C}}{P_{P} \cdot 8760}
$$


where:

$\mathrm{P}_{\mathrm{ac}}=$ Generated power $\left(\mathrm{kW} / \mathrm{m}^{2}\right)$;

$\mathrm{G}_{\mathrm{STC}}=$ Reference irradiance at Standard Test Conditions $\left(1000 \mathrm{~W} / \mathrm{m}^{2}\right)$;

$\mathrm{G}_{i}=$ Irradiance tilted $\alpha=7^{\circ}$ and oriented $\beta=20^{\circ} \mathrm{E}$;

$\mathrm{G}_{\alpha} \boldsymbol{\beta}=$ Total in-plane solar irradiation $\left(\mathrm{kWh} / \mathrm{m}^{2}\right)$;

$\mathrm{P}_{\mathrm{P}}=$ Peak power, i.e. $222.36 \mathrm{~kW}_{\mathrm{p}}$;

$\mathrm{A}=$ total area of PV modules

$\eta_{\mathrm{STC}}=$ Efficiency of the PV array generator at the Estándar Test Conditions (It has been considered 1)

$\mathrm{K}=$ Peak power of the installation per square meter, ${ }_{p} \mathrm{~m}_{\mathrm{m}}{ }^{2}$, i.e. 98.23 .

Note that the definition of $\mathrm{P}_{\mathrm{ac}}$ above refers to the monthly power obtained from the stored data of generated power, sampled every 5 minutes in the database. Table 4.3 shows the resulting monthly performance ratio for the PV\&PK installation, which has been used later to estimate the generated power of PV_ONLY. The measured irradiation in a sensor $7^{\circ}$ tilted, just as PV\&PK, has been used to calculate the PR.

To estimate the energy that could have been generated by PV_ONLY Equation 5 has been used:

\section{Equation 5}

$E_{g e n}=\frac{G_{b a} \cdot P R \cdot P_{P} \cdot \mathrm{N}}{G_{S T C}}$ 
with:

$\mathrm{PR}=$ Performance ratio of PV\&PK;

$\mathrm{G}_{\mathrm{ba}}=$ Estimated daily average sum of monthly average of daily global irradiation per square meter;

$\mathrm{N}=$ number of days per month;

$\mathrm{G}_{\mathrm{STC}}=$ Reference Irradiance at Standard Test Conditions $\left(1000 \mathrm{~W} / \mathrm{m}^{2}\right)$;

$\mathrm{P}_{\mathrm{P}}=$ Nominal peak power.

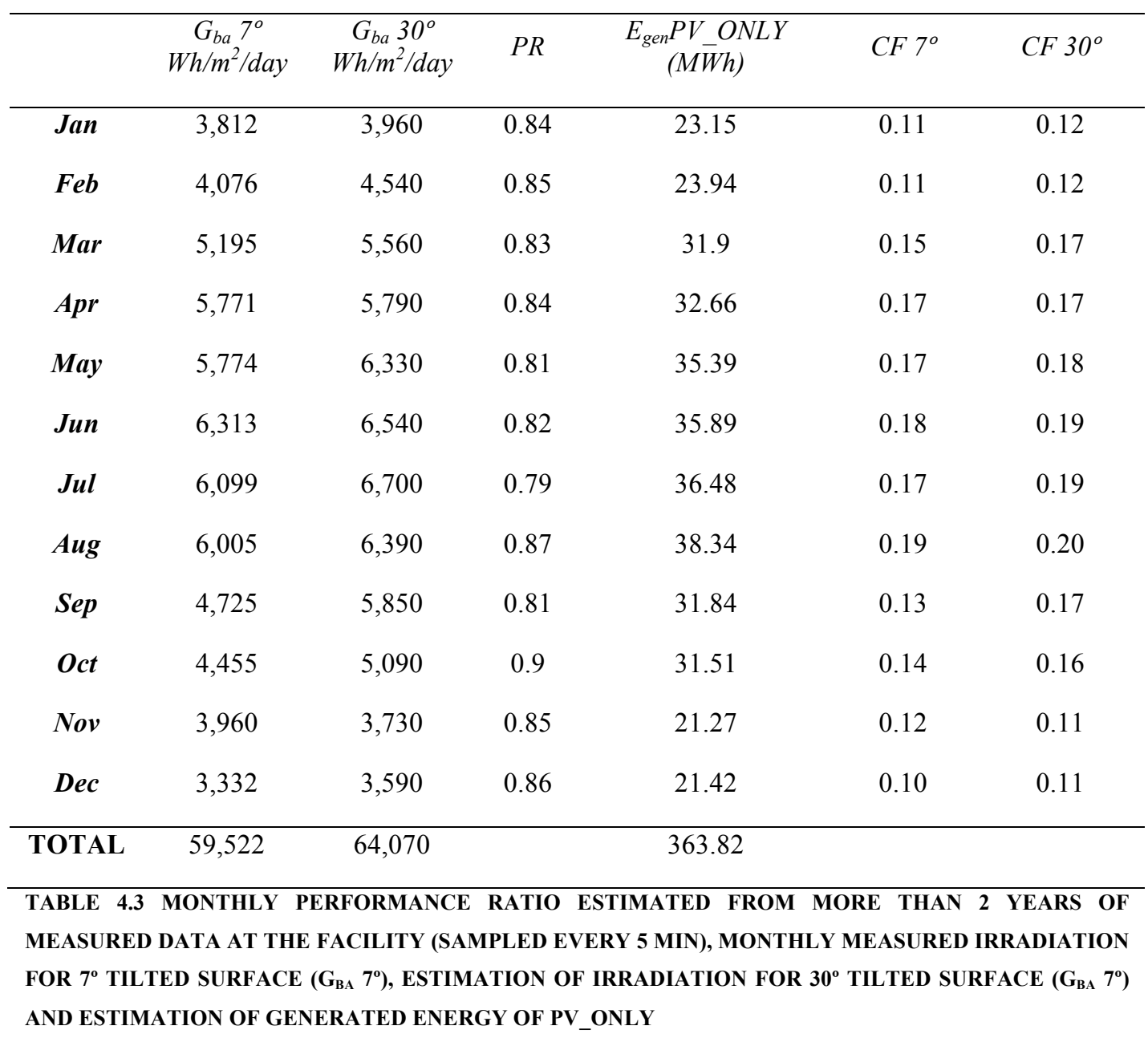


The irradiation used to estimate the generated power of PV_ONLY has been extracted from PVGIS ("PVGIS home. Photovoltaic Geographical Information System - Interactive Maps," 2011) and the performance ratio used is the calculated PR for PV\&PK. As shown in Table 4.3, the energy generated is 363.82 $\mathrm{MWh} /$ year.

The EPBTs for PV\&PK and PV_ONLY are shown in Table 4.4. They are 2.06 and 1.42 respectively. Therefore, the parking with photovoltaic modules has already produced its embodied energy since it started to operate. In order to extrapolate the future electricity production throughout the lifetime of the PV system, a linear loss of efficiency has been included in the calculation; in such a way that for the year 25 of the life system, the power conversion efficiency of the modules is $80 \%$ of the initial efficiency (same assumption for PV\&PK and PV_ONLY). The same trend is applied for calculations that involve 30 years of lifetime.

\begin{tabular}{cc|cccc|cc}
\hline Cases & $\begin{array}{c}\text { Recycled } \\
\text { (CdTe } \\
\text { modules) }\end{array}$ & $\begin{array}{c}\text { EPE } \\
\text { (TJ) }\end{array}$ & $\begin{array}{c}\text { EPBT } \\
\text { (years) }\end{array}$ & ERF & $\begin{array}{c}\text { Embodied CO } \\
\text { (ton eq-CO })\end{array}$ & \multicolumn{2}{|c}{ FU: 1kWp } \\
\hline PV\&PK & No & 6.31 & 2.06 & 12.16 & 444.69 & 29.23 & 2117.85 \\
& Yes & 5.20 & 1.69 & 14.77 & 371.62 & 28.59 & 2005.27 \\
\hline PK_ONLY & & 1.78 & - & - & 136.92 & - & - \\
\hline PV_ONLY & No & 4.61 & 1.42 & 17.56 & 298.49 & 24.10 & 1584.39 \\
& Yes & 3.50 & 1.03 & 24.33 & 226.83 & 22.77 & 1471.82 \\
\hline
\end{tabular}

TABLE 4.4 EPBT, ERF AND EMBODIED $\mathrm{CO}_{2}$ FOR PARKING WITH AND WITHOUT PV, AND PV GROUNDMOUNTED. VALUES FOR THE COMPLETE FACILITY ARE SHOWN IN THE CENTRAL COLUMNS OF THE TABLE. VALUES FOR 1KWP FUNCTIONAL UNIT ARE SHOWN IN THE TWO FINAL COLUMNS ON THE RIGHT HAND SIDE OF THE TABLE.

Assuming that CdTe modules are recycled at the end of its lifetime, the CED for PV\&PK and PV_ONLY cases is a bit shorter than in the first study, being 5.2 and 3.5 TJ. The EPBT in these assumptions are 1.69 and 1.03 years. 
As explained in section 3.1.2, the energy impact of a Functional Unit of $1 \mathrm{~kW}_{\mathrm{p}}$ installation was calculated for recycled and non-recycled modules, as well as for the cases PV\&PK and PV_ONLY. The CED of each assumption having a functional unit of $1 \mathrm{~kW}_{\mathrm{p}}$ are also include in Table 4.4. The recycling of CdTe modules would save potentially between $5 \%$ and $4 \%$ of CED, depending on the alternative cases.

The Capacity Factor of PV\&PK and PV_ONLY cases was calculated, being $14.72 \%$ and $15.84 \%$ respectively, and found to be similar to other studies in southern Europe (Kymakis et al., 2009).

\subsubsection{Green House Gases Impact Assessment}

The results of applying this method to the PV\&PK facility considered for this article are presented in Table 4.4. An estimation of $\mathrm{CO}_{2}$ emissions was also obtained for the three cases during the lifetime of the systems. The total amount of $\mathrm{CO}_{2}$ released for making the PV installation roof-mounted (PV\&PK) was found to be 444.69 equivalent $\mathrm{CO}_{2}$ tons, while for making the parking without $\mathrm{PV}$ (PK_ONLY) were much lower, $136.92 \mathrm{CO}_{2}$ tons. For the third option, the ground-mounted PV installation, emissions amounted to $298.49 \mathrm{CO}_{2}$ tons. If we assume that CdTe modules are recycled at the end of its life, the amount of $\mathrm{CO}_{2}$ released for making the PV\&PK is $371.62 \mathrm{CO}_{2}$ tons, and for PV_ONLY is 226.83 $\mathrm{CO}_{2}$ tons. The carbon footprints have also been calculated for the PV parking and for the PV installation for a functional unit of $1 \mathrm{~kW}_{\mathrm{p}}$, considering (or not) a recycling scenario. The values for all cases are shown in Table 4.4; as expected, in case the CdTe modules were to be recycled, there would be lower $\mathrm{CO}_{2}$ emissions, in particular, between 5\% and 7\% lower.

To find out the $\mathrm{CO}_{2}$ emission factor we have applied the following equation: 
Equation 6

$\mathrm{CO}_{2} \mathrm{EF}\left[\mathrm{gCO}_{2} / k W h_{e l}\right]=\frac{\text { Embodied } C \mathrm{O}_{2}}{E_{\text {gen }}}$

where:

Embodied $\mathrm{CO}_{2}$ is the $\mathrm{CO}_{2}$ calculated from Greenhouse Gas Protocol method defined in section 3.4.1;

$\mathrm{E}_{\mathrm{gen}}=$ Generated energy during module lifetime, i.e. 25 years. The yearly generated energy is $328.39 \mathrm{Wh} /$ year.

To estimate the generated energy for PV\&PK and PV_ONLY during 25 years, a linear $20 \%$ reduction in efficiency throughout its lifetime has been taken into account the yearly reduction of power generation, as indicated above. The total generated energy in its lifetime is estimated to be $7467.89 \mathrm{MWh}$ and 8273.59 MWh respectively for 25 years and 8789.8 MWh, 9738.12 MWh for 30 years lifetime.

The $\mathrm{CO}_{2}$ emission factor is $6.33 \mathrm{gCO}_{2} / \mathrm{kWh}$ for PV\&PK and $4.27 \mathrm{gCO}_{2} / \mathrm{kWh}$ for PV_ONLY. When considering whole lifecycle of CdTe modules, that is 30 years, the $\mathrm{CO}_{2}$ emission factors are $5.38 \mathrm{gCO}_{2} / \mathrm{kWh}$ and $3.63 \mathrm{gCO}_{2} / \mathrm{kWh}$ respectively.

\subsubsection{Additional environmental assessment}

The impact assessment method "ReCiPe Midpoint (H) LCA V1.04/World ReCiPe $\mathrm{H}$ " was used to cover the impact categories shown in Figure 4.11.

The selected methodology has been applied in order to compare the three considered cases (PV\&PK; PK_ONLY; PV_ONLY). A new configuration (PK_25_GRID) has been added in Figure 5 in order to compare the environmental impact that would have been created by the Spanish grid with its actual energy 
Chapter 4 Life Cycle Assessment applied to photovoltaics

mix (Gobierno de España et al., 2010), to produce the same amount of electricity that has been generated by PV\&PK.

The environmental impact of the new case PK_25_GRID has the largest values in all impact categories with the exception of Metal depletion and Urban land occupation; where both PV\&PK and PV_ONLY cause the major impact. As expected, Urban land occupation is one of the main impacts of the PV_ONLY. It is due to the impossibility of using the land that it is situated (Mark Geodkoop et al., 2009). Freshwater eutrophication has the largest value for the three cases. PV\&PK and PV_ONLY cause high impact in Metal depletion category because of the copper, lead and steel that are used to manufacturing CdTe modules and the structure. 
Chapter 4 Life Cycle Assessment applied to photovoltaics

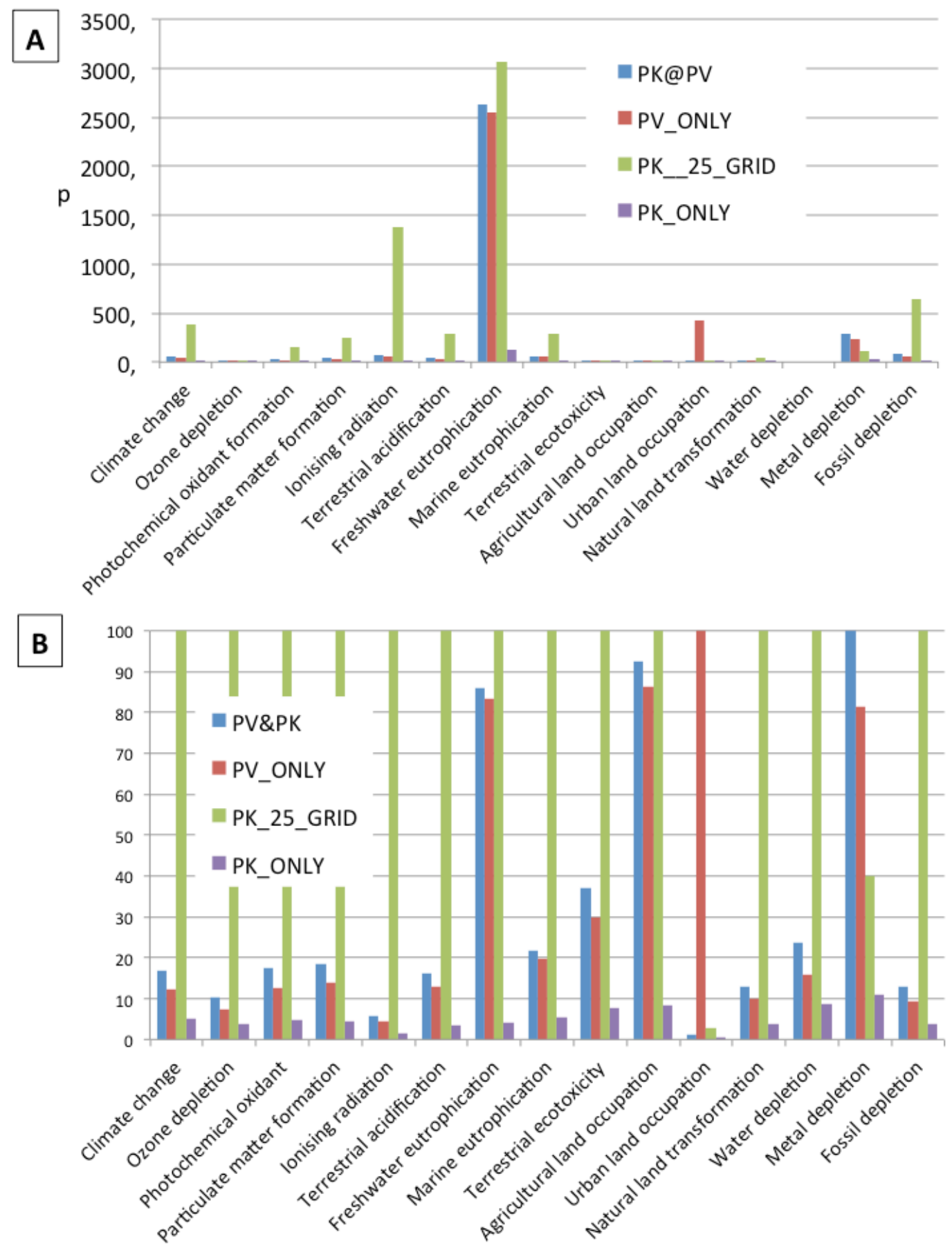

FIGURE 4.11 (A) COMPARISON BETWEEN THE THREE SCENARIOS AND THE ENVIROMENTAL IMPACT BECAUSE OF THE PRODUCTION OF THE SAME AMOUNT OF ENERGY THAN PV\&PK USING RECIPE METHOD. (B) COMPARISON BETWEEN THREE SCENARIOS (PV\&PK, PV_ONLY AND PK_ONLY) USING RECIPE METHOD, WHERE THE COLUMNS HAVE BEEN NORMALIZED TO THE MAXIMUM VALUE IN EACH CASE. 
The unit " $p$ " in Figure 4.11(A) references to the unit of each impact category of ReCiPe method (Mark Geodkoop et al., n.d.). We have omitted three impact categories of ReCiPe method, i.e. Marine ecotoxicity, Freshwater ecotoxicity, and Human toxicity, because of the uncertainty analysis that was developed via Monte Carlo calculations.

Finally, in order to assess the impact of each part of the facilities, we have applied several impact methodologies to PV\&PK, as Figure 4.12 shows, with the result that CdTe modules imply the major environmental impact, ranged between 53\% and $71 \%$. It is followed by the structure and the inverters in all methodologies except for ReCiPe, which scores the inverters with the second environmental weight.

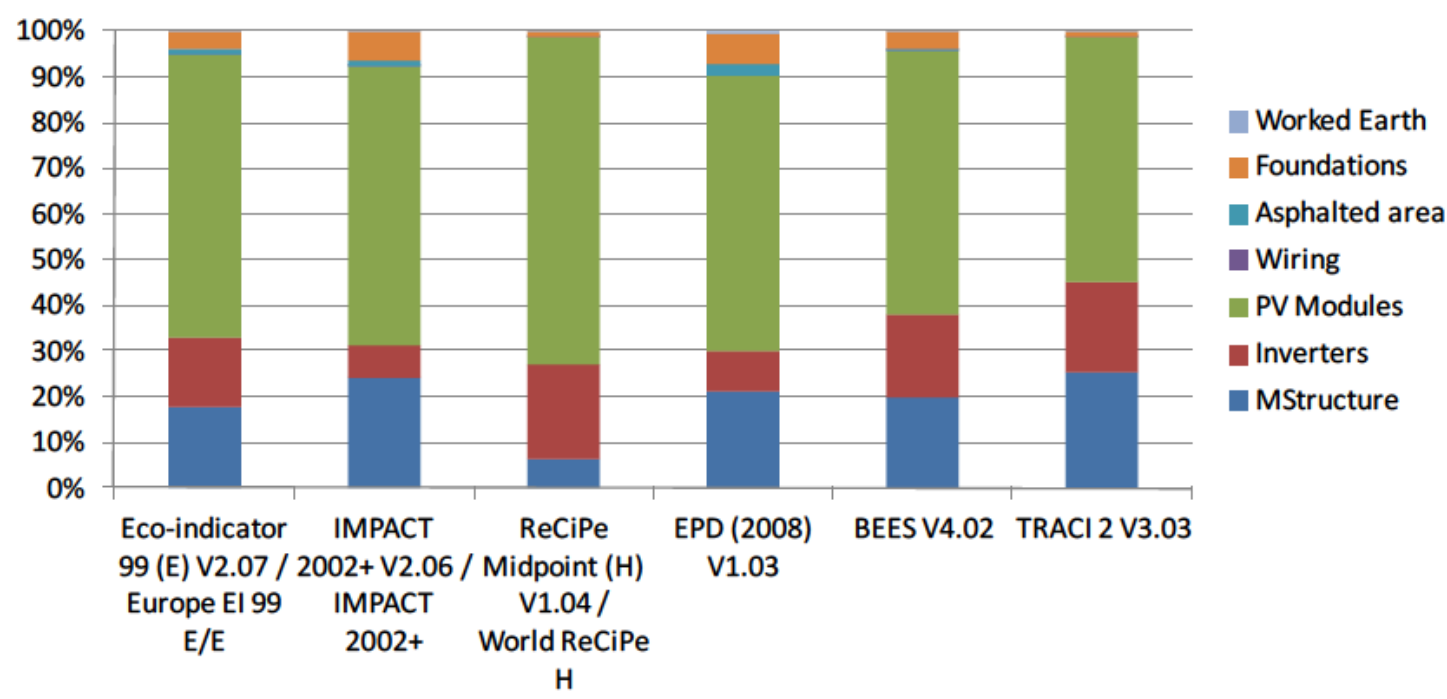

FIGURE 4.12 COMPARISON OF ENVIRONMENTAL METHODOLOGIES AND THE INFLUENCE THEY HAVE IN THE FINAL OUTPUT OF THE ENVIRONMENTAL IMPACT CALCULATION.

Despite recent advances in manufacturing processes of $\mathrm{CdTe}$, this kind of modules have achieved lower environmental impacts and have therefore improved the EPBT (Held and Ilg, 2011), they provide the greatest environmental impact of the facilities. 


\subsection{Conclusions}

A detailed Life-cycle Assessment of a $222 \mathrm{~kW}_{\mathrm{p}} \mathrm{CdTe}$ grid-connected photovoltaic system has been performed in this chapter. It illustrates the application of LCA methodology to the case of photovoltaic technology. The results of this LCA are: the embedded equivalent primary energy of the system is $6.31 \mathrm{TJ}$; taking into account the electricity produced by the system during its initial 2.5 years of life and extrapolating a future electricity production with the same performance ratio and a future linear reduction of $20 \%$ in power conversion efficiency during its 25 years of lifetime. The Energy Pay Back Time of the system is found to be 2.06 years, with an Energy Return Factor of 12.16. Therefore, it has been found the system has already paid back the CED, including future decommissioning and recycling. When a recycling scenario is assumed, and CdTe modules are recycled at the end of their life, the EPBT decreases to 1.69 years and ERF increases to 14.78 .

The system is integrated into a parking lot and the benefits of the building integration have been quantified by comparing the LCA of the PV system with the environmental impact of building them separately, i.e. a parking lot and a PV facility without integration. The integrated system has lower environmental impact than the two separated facilities providing a reduction of $5.28 \%$ in $\mathrm{CO}_{2}$ emissions, and better land use. Additionally, the environmental impact of producing the same amount of electricity than the PV system by the Spanish grid has been calculated; a broad set of parameters allows us to quantify the benefits of building the integrated parking+PV facility from the environmental point of view. An economical analysis (with and without subsidies or feed-in tariffs) is on the way; this future study will then complete the full technical, environmental and economical picture. 
As a summary, in this chapter a real case $222 \mathrm{kWp}$ CdTe parking-integrated PV generator was analysed to find its environmental impacts by using LCA methodology. A reliable environmental impact study has been done, thanks to monitorization system that generates and stores in situ information about performance of the PV generator and environmental conditions. The environmental impacts produced by the PV generator have been calculated such as: avoided $\mathrm{CO}_{2}$ emissions, Energy Pay Back Time (EPBT) and Energy Return Factor (ERF)s. Nevertheless, the amount of avoided CO2 depends on the location where the PV generator is installed because generated energy is higher in places with higher irradiance (also temperature will affect this output, but the dependence is lower). Following the Life Cycle Analysis methodology, in the next Chapter a detailed study about the geographical dependence of PV environmental impact is carried out, with a more general approach taking as a functional unit $1 \mathrm{kWp}$ of several PV technologies

\subsection{References}

Alsema, E., 1998. Energy requirements of thin-film solar cell modules:a review. Renew. Sustain. Energy Rev. 2, 387-415.

Alsema, E.A., de Wild-Scholten,M.J., 2005. Environmental impacts of crystalline silicon photovoltaic module production. Sustain. Dev.

Alsema, E.A., Nieuwlaar, E., 2000. Energy viability of photovoltaic systems. Energy Policy 28, 999-1010.

Cadmium Telluride (CdTe): Proven Thin Film Semiconductor Technology | First Solar. CdTe Facts NA FEB 2009, n.d.

European Commission, 2011. Join Research Centre. Life Cycle Thinking and Assessment [WWW Document]. URL http://lct.jrc.ec.europa.eu/ (accessed 9.20.11).

Environmental management - Life cycle assessment - Requirements and guidelines, 2006. ISO - International Organization for Standardization. ISO Rep. 
140402006.

Espinosa Martinez, N., Hösel, M., Angmo, D., Krebs, F.C., Espinosa Martinez, N., Hösel, M., Angmo, D., Krebs, F.C., 2012. Solar cells with one-day energy payback for the factories of the future. Energy Environ. Sci. 5, 5117-5132.

Gehrlicher Solar, n.d. BASE-FS, Smart assembly system.

globulebleu.com, n.d. Recycling of non-silicon based PV modules - PV CYCLE [WWW Document]. PV CYCLE. URL http://www.pvcycle.org/about/recycling/recycling-of-non-silicon-based-pvmodules/ (accessed 2.1.13).

Gobierno de España, Ministerio de Industria, Turismo y Comercio, Secretaría de Estado de Energía, 2010. La energía en España 2009.

Held, Ilg, R., 2011. Update of environmental indicators and energy payback time of CdTe PV systems in Europe. Prog. Photovoltaics Res. Appl. 19, 614-626.

Hot-Dip Galvanized Steel: Low Environmental Cost Itextbar Sustainable Development \textbar American Galvanizers Association, n.d.

Kymakis, E., Kalykakis, S., Papazoglou, T.M., 2009. Performance analysis of a grid connected photovoltaic park on the island of Crete. Energy Convers. Manag. $50,433-438$.

Mark Geodkoop, Reinout Heijungs, Mark Huijbregts, n.d. ReCiPe 2008 A cycle impact assessment method which comprises harmonised category indicators at the midpoint and the endpoint level.

PRé Consultants, 2011. About SimaPro [WWW Document]. URL www.presustainability.com (accessed 11.18.11).

PVGIS home. Photovoltaic Geographical Information System - Interactive Maps [WWW Document], 2011. URL http://re.jrc.ec.europa.eu/pvgis/ (accessed 12.7.11).

Roes, A.L., Alsema, E.A., Blok, K., Patel, M.K., 2009. Ex-ante environmental and economic evaluation of polymer photovoltaics. Prog. Photovoltaics Res. Appl. 17, 372-393.

Swiss Centre for Life Cycle Inventories, 2013. Ecoinvent Database [WWW Document]. URL http://www.ecoinvent.org/database/ (accessed 9.23.13).

V. Fthenakis, R. Frischknecht, M. Raugei, H.C. Kim, E. Alsema, M. Held, M. de Wild-Scholten, 2011. Methodology Guidelines on Life Cycle Assessment of Photovoltaic Electricity, 2nd edition, IEA PVPS Task 12, International Energy Agency Photovoltaic Power systems Programme. 
Chapter 4 Life Cycle Assessment applied to photovoltaics 


\title{
CHAPTER 5
}

\section{GEOGRAPHICAL DEPENDENCE}

\author{
of Photovoltaic
}

\section{ENVIRONMENTAL IMPACT}

\begin{abstract}
Synopsis. Photovoltaic technologies have the potential to play an important role in climate change mitigation. Technological, geographical and environmental decisions may be made upon a further informed basis. Photovoltaic systems inherently avoid $\mathrm{CO}_{2}$ emissions while running since they replace a share of fossil consumption in the energy mix of the country where they are installed. In this chapter, avoided emissions of $1 \mathrm{~kW}_{\mathrm{p}}$ of several photovoltaic technologies have been calculated: thin-film (CdTe), c-Silicon and Organic polymeric technologies, considering sixteen different geographical locations where the modules could be manufactured and/or installed, respectively. LCA methodology has been applied to $1 \mathrm{~kW}_{\mathrm{p}}$ of different photovoltaic technologies in order to find the optimum geographical combination, manufacturer-installer, that is, a geographical "allocation" that provides the higher avoided $\mathrm{CO}_{2}$ emission per $\mathrm{kW}_{\mathrm{p}}$ of installed PV capacity, and therefore can be considered the greenest decision.
\end{abstract}

\subsection{Introduction. Geographical dependence of the environmental impact of a photovoltaic generator}

Building on LCA methodology applied to photovoltaic technologies (as previously explained in Chapter 4), a study is presented that is designed to assess the environmental impacts of photovoltaic technologies and how it can vary substantially depending on geographical locations. 
During the lifetime of photovoltaic technology, there are stages where the environmental impacts are appreciable: material sources extraction, manufacturing cells and modules, transport and, finally, decommissioning and eventually transport to the recycling plant for the dismantled components of the system.

Impacts onto the soil and air are produced during material extraction and transport, also the consumed energy during manufacturing process will have higher or lower impact depending on the electricity mix of the manufacturing country, creating additional earth and air impacts.

Consumed energy in some countries with cleaner energy mix, like Brazil or Colombia, generates much less environmental impacts than countries with dirtier energy mix, such as Cuba. The impact can be quantified by the level of emissions of green house gasses per kWh of produced electricity, and therefore in Colombia the electricity mix is about $0.087 \mathrm{gCO}_{2}$ per $\mathrm{kWh}$, while Cuba emits $1.012 \mathrm{~kg} \mathrm{CO}_{2}$ per kWh.

An electricity mix is cleaner or dirtier depending on the energy technologies that are being used to produce the electricity. The more sustainable the produced energy; the cleaner its electricity mix will be.

In spite of the environmental impacts that are produced during the production phase, the photovoltaic system does not produce any environmental damage during its use phase. It further avoids environmental damage by the fact that it displaces emissions from non-renewable sources. The produced energy by the PV system will avoid the use of fossil fuel sources to produce energy, that is, it will change the electricity mix of the country.

Nevertheless, the generated energy by the PV system depends on the geographical location where the system is operating. In northern countries, like Denmark or 
Canada, $1 \mathrm{kWp}$ of photovoltaic modules will not produce the same amount of electricity that if $1 \mathrm{kWp}$ of photovoltaic modules installed in Cuba. The annual average Cuban irradiation is 1.77 times higher than Danish irradiation. The more irradiation a place has, more energy a PV system will produce and consequently the EPBT will be lower, ERF higher, and its impact per functional unit on the local electricity mix will be higher.

In this chapter a study about geographical dependences of photovoltaic system performance is carried out. We will present how the location where the PV system is installed affects the global impact indicators: EPBT, ERF and avoided $\mathrm{CO}_{2}$ emissions. These impact indicators are regularly used in LCA studies of sustainable systems, as was described in Chapter 4.

In this regard, the next Section (5.2) describes a LCA methodology applied to $1 \mathrm{kWp}$ of three different photovoltaic technologies, and then its environmental impacts in different geographical locations are compared.

\subsection{Highlighting geographical dependence: LCA applied to $1 \mathrm{kWp}$ PV technologies}

In this section, the LCA methodology was applied in order to quantify the environmental impact of three different PV technologies in a global approach, paying careful attention to the dependence on the geographical locations where the technologies are manufactured and installed. In addition, the main environmental impact parameters arising from different combinations of manufacturing and operation countries are compared. 


\subsubsection{Appling LCA methodology with a global approach}

As previously described, the LCA methodology is a good tool to analyse the environmental impact of products and services; it has been standardized by the International Standards Organization in ISO-14040 series providing guidelines, which recommend four steps in every case study: 1) scoping the study, 2) compilation of the inventories, 3) impact assessment, and 4) interpretation. It has followed the recommended methodology and it is explained in detail the four steps of our analysis illustrating the global approach that has been adopted therein.

\section{- Goal and scope definition}

The aims of this study can be summarized as: 1) to identify the LCA stage where $1 \mathrm{~kW}_{\mathrm{p}}$ of PV-module, considered as the functional unit for the calculation, has the greatest environmental benefit measured in terms of $\mathrm{CO}_{2}$ emissions, 2) to find the dependence between the environmental impact of $1 \mathrm{~kW}, \mathrm{PV}$ and the place where it is manufactured and installed and 3) to compare several types of PV technologies using the same impact indicators.

The considered life cycle covers the manufacturing of the modules, their transport and the installation. We have considered frameless modules and the replacement of the equipment during the PV's lifetime was left aside.

A set of countries has been chosen as they are among the most likely manufacturers and installers (Australia, Brazil, China, Colombia, Cuba, Denmark, Dominican Republic, Germany, India, Italy, Japan, Korea, South Africa, Spain, UK and US). Then, all combinations of these countries as pair manufacturerinstaller have been studied including the transport of the manufactured modules.

\section{- Functional Unit}

The Functional Unit is $1 \mathrm{~kW}_{\mathrm{p}}$ of photovoltaic module for the three technologies under consideration: crystalline silicon (c-Si), thin-film (CdTe) and organic 
polymeric (OPV). The technical specifications of the three generations of photovoltaic modules - listed in Table 5.1 - are representative of the technologies: the power conversion efficiency, weight and lifetime have been taken from industrial reports (FC Krebs, 2013; First Solar, 2011; SHARP, 2013) and the embedded energy calculations from literature review or our own previous calculations (Fthenakis and Alsema, 2006; Kato K. et al., 2001; Knapp and Jester, 2001; Mohr et al., 2007; Raugei et al., 2007). For c-Si modules, a representative efficiency is about $18 \%$ and $14 \%$ for CdTe modules; their lifetime has been considered to be 25 years in all cases. Since OPV has still a lower lifetime, we have considered replacement in the calculation of the embedded energy (Espinosa et al., 2011). Finally the performance ratio (PR) for the installed systems has been considered as 0.8 , which is a number well accepted in the literature and is representative of most technologies. The motivation to choose the same value for all the technologies is to avoid a cross-talking with other parameters of the calculation, although PR values for well established technologies are usually higher than for emerging technologies.

\begin{tabular}{lcccccc}
\hline PV & Efficiency & $\begin{array}{c}\text { Embedded } \\
\text { Energy } \\
(\%)\end{array}$ & $\begin{array}{c}\text { Weight } \\
\left(\mathrm{GJ} / \mathrm{kW}_{\mathrm{p}}\right)\end{array}$ & $\begin{array}{c}\text { Lifetime } \\
\left(\mathrm{kg} / \mathrm{m}^{2}\right)\end{array}$ & $\begin{array}{c}\text { Manufacturing } \\
\text { Energy } \\
(\text { years })\end{array}$ & $\begin{array}{c}\text { PR } \\
\left(\mathrm{MJ} / \mathrm{m}^{2}\right)\end{array}$ \\
\hline $\mathrm{c}-\mathrm{Si}$ & 18 & 27.35 & $12.26^{\mathrm{a}}$ & 25 & $4952.2^{\mathrm{b}, \mathrm{c}}$ & 0.8 \\
Thin-film & 14 & $15.7^{\mathrm{d}}$ & $11.6^{\mathrm{e}}$ & 25 & $1760.7^{\mathrm{f}, \mathrm{gh}}$ & 0.8 \\
$(\mathrm{CdTe})$ & & & & & \\
OPV & $5^{\mathrm{i}}$ & $7.6^{\mathrm{i}}$ & $0.3^{\mathrm{j}}$ & 25 & $368.5^{\mathrm{i}}$ & 0.8
\end{tabular}

TABLE 5.1 TECHNICAL SPECIFICATION OF THE PV MODULES CONSIDERED AS REPRESENTATIVE OF THE CORRESPONDING TECHNOLOGIES.

\footnotetext{
${ }^{\text {a }}$ (SHARP solar electricity, 2013)

${ }^{\mathrm{b}}$ (Fthenakis and Alsema, 2006)

${ }^{\mathrm{c}}$ (Knapp and Jester, 2001)
} 
Chapter 5 Geographical dependence of environmental impacts

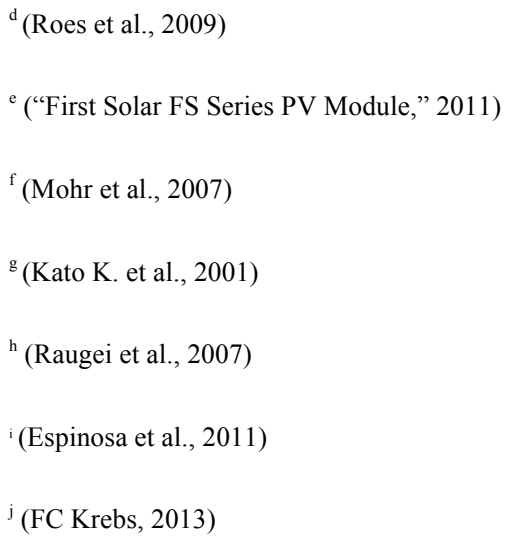

\section{- Impact Indicators}

Energy Pay Back Time (EPBT) and Energy Return Factor (ERF), as was defined in Equations 1 and 2 in Chapter 4, Section 4.2, are typical environmental impact indicators for photovoltaic LCA studies. EPBT is the number of years the PV system requires to run in order to deliver the energy embedded in the system. ERF indicates the total amount of energy produced throughout its lifetime per unit of invested energy, that is the numbers of times the invested energy that will be recovered by the system. The main different between the LCA that was applied in Chapter 3 and this LCA, is the theoretical aspect of the second one. The studied PV generator includes a monitorization system that provides information about the produced energy in real time, but the study that is presented here focuses on $1 \mathrm{kWp}$ of different technologies, and the generated energy was estimated. In order to calculate the embedded energy and the generated energy for a given photovoltaic system, we apply Equation 5.1 and Equation 5.2.

\section{Equation 5.1}

$E_{G E N}=P R * L T * P_{p} * I r r$

\section{Equation 5.2}

$E_{\mathrm{EMB}}=S * k W h / m^{2}$ 
Where:

$E_{E M B}$ : Manufacturing Energy per functional unit of PV system

PR: Performance Ratio

$L T:$ Lifetime

$P_{p}$ : Power peak

Irr: Irradiation

The emissions of $\mathrm{CO}_{2}$ avoided by $1 \mathrm{~kW}_{\mathrm{p}}$ of PV system are defined here as the $\mathrm{CO}_{2}$ avoided by replacing the electricity mix of the country minus the emissions caused by the manufacturing of the modules and its transport from the manufacturing location to the installation (and therefore servicing) location (Equation 3).

Equation 5.3

$\mathrm{CO}_{2 \text { Manufacture }}=S * E_{m} *\left[\mathrm{CO}_{2} / \mathrm{kWh} h_{P E}\right]$

Equation 5.4

$\mathrm{CO}_{2 \text { Use }}=E_{\mathrm{GEN}} *\left[\mathrm{CO}_{2} / \mathrm{kWh}\right]$

Equation 5.5

$\mathrm{CO}_{2 \text { Transport }}=\mathrm{CO}_{2 \text { lorry }}+\mathrm{CO}_{2 \text { ship }}$

Equation 5.6

$\mathrm{CO}_{2}$ Avoided $=\mathrm{CO}_{2}$ Use $_{2}-\mathrm{CO}_{2 \text { Manufacture }}-\mathrm{CO}_{2}$ Transport

where: 
$\left[\mathrm{CO}_{2} / \mathrm{kWh} h_{P E}\right]: \mathrm{CO}_{2}$ emissions per kilowatt per hour from total primary energy supply,

$\left[\mathrm{CO}_{2} / \mathrm{kWh}\right] \frac{\mathrm{CO}_{\mathbf{2}}}{\mathbf{k W h}}: \mathrm{CO}_{2}$ emissions per $\mathrm{kWh}$ from electricity generation

$S:$ PV surface

$E_{G E N}$ : Energy delivered by functional unit of PV system

$E_{m}$ : Manufacturing energy

\subsubsection{Results: EPBT, ERF and avoided emissions}

We present three subsections showing 1) the EPBT and the ERF, defined in Equations 1 and 2, for the functional unit defined above; 2) the avoided $\mathrm{CO}_{2}$ emissions for each technology and its geographical dependence; and finally, 3) the LCA methodology which has been applied to the 2011 PV market, where avoided and emitted $\mathrm{CO}_{2}$ emissions have been calculated taking into account manufacturing and installing PV information for the 2011 market.

- LCA Results: Energy Pay Back Time and Energy Return Factor

Table 5.2 shows the EPBT and the ERF as result of installing PV modules on the targeted countries, shown in the first column. These parameters are independent of the geographical location of the manufacturing country (since the amount of embedded energy will not be affected assuming that the manufacturing process is the same in the different countries); on the other hand, the location where the 
system is installed will have, as expected, a strong impact on both parameters, since the energy delivered by the system throughout its lifetime is dependent on the level of irradiation on the particular location, and therefore the energy generated by $1 \mathrm{~kW}_{\mathrm{p}}$ of $\mathrm{PV}$ depends on the irradiation where it is located. The generated energy defined in Equation 1 depends on the PV technology and the irradiation of the installation place; the higher irradiation provides the lower EPBT.

\begin{tabular}{|c|c|c|c|c|c|c|}
\hline \multirow[b]{2}{*}{ Country } & \multicolumn{3}{|c|}{ EPBT (years) } & \multicolumn{3}{|c|}{ ERF } \\
\hline & c-Si & CdTe & OPV & c-Si & CdTe & OPV \\
\hline Denmark & 3.25 & 1.48 & 0.87 & 7.70 & 16.84 & 28.73 \\
\hline Germany & 3.21 & 1.47 & 0.86 & 7.78 & 17.01 & 29.03 \\
\hline UK & 3.05 & 1.40 & 0.82 & 8.19 & 17.91 & 30.56 \\
\hline USA East & 2.79 & 1.27 & 0.75 & 8.97 & 19.63 & 33.50 \\
\hline Korea & 2.57 & 1.17 & 0.69 & 9.74 & 21.31 & 36.37 \\
\hline Japan & 2.28 & 1.04 & 0.61 & 10.97 & 24.00 & 40.95 \\
\hline China East & 2.16 & 0.99 & 0.58 & 11.59 & 25.35 & 43.27 \\
\hline Spain & 2.09 & 0.96 & 0.56 & 11.96 & 26.17 & 44.66 \\
\hline Italy & 1.92 & 0.88 & 0.52 & 12.99 & 28.42 & 48.50 \\
\hline Colombia & 1.90 & 0.87 & 0.51 & 13.14 & 28.76 & 49.07 \\
\hline Cuba & 1.83 & 0.84 & 0.49 & 13.65 & 29.85 & 50.94 \\
\hline Dominican Republic & 1.67 & 0.76 & 0.45 & 15.01 & 32.84 & 56.04 \\
\hline India & 1.67 & 0.76 & 0.45 & 15.01 & 32.84 & 56.04 \\
\hline Brazil & 1.63 & 0.75 & 0.44 & 15.33 & 33.53 & 57.22 \\
\hline South Africa & 1.58 & 0.72 & 0.42 & 15.83 & 34.63 & 59.09 \\
\hline China West & 1.53 & 0.70 & 0.41 & 16.30 & 35.66 & 60.85 \\
\hline Australia & 1.52 & 0.69 & 0.41 & 16.45 & 35.99 & 61.41 \\
\hline USA West & 1.34 & 0.61 & 0.36 & 18.69 & 40.89 & 69.78 \\
\hline
\end{tabular}


Chapter 5 Geographical dependence of environmental impacts

\section{- LCA Results: Avoided $\mathrm{CO}_{2}$ emissions}

The electricity mix of a country reveals the mixture of sources, both renewable and non-renewable of the energy supply that provides the generated electricity. For example, in Brazil, this share is mainly $74 \%$ Hydro, $6.8 \%$ Natural gas, $4.7 \%$ Biomass and $2.7 \%$ Nuclear. The amount of emissions of $\mathrm{CO}_{2}$ due to the electricity generation depends strongly, on the percentage of fossil fuel contribution to the energy mix. The electricity produced by the PV system is meant to replace the electricity generated by the original sources comprised in the energy mix of a given country. We can establish an amount of avoided $\mathrm{CO}_{2}$ emissions per $1 \mathrm{~kW}_{\mathrm{p}}$ of installed PV capacity, which will be then strongly dependent on the energy mix of the country of installation under consideration. We have calculated the avoided emissions for the three PV technologies in several installation countries when the manufacturing took place in different countries. This dependence is plotted in Figure 5.1 for the case in which the system was manufactured in China. The impact of PV manufacturing amounts to less than $10 \%$ of the total avoided $\mathrm{CO}_{2}$. First, the differences of PV technologies remain very similar, no matter the country of installation. Not surprisingly, the avoided emissions are lower in those countries with a cleaner energy mix. 
Chapter 5 Geographical dependence of environmental impacts

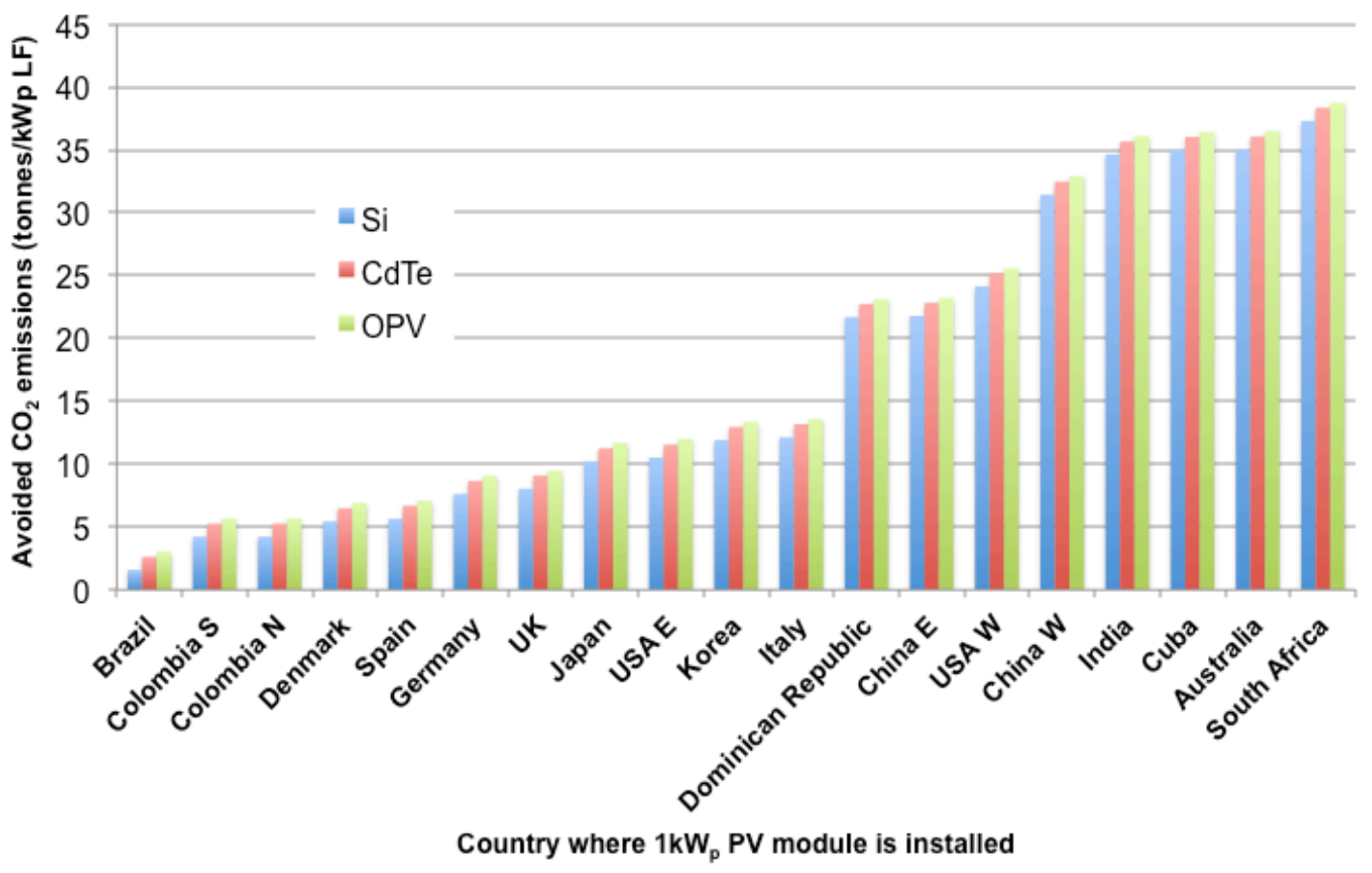

FIGURE 5.1 DEPENDENCE OF THE AVOIDED EMISSIONS ON THE INSTALLATION PLACE FOR 1 kWp THROUGHOUT THE LIFETIME (LF) OF THREE DIFFERENT PV TECHNOLOGIES: C-SI, CDTE AND OPV, ASSUMING THEIR MANUFACTURING HAS TAKEN PLACE IN CHINA (RESULTS FOR OTHER MANUFACTURING COUNTRIES ARE INCLUDED IN THE ANNEX).

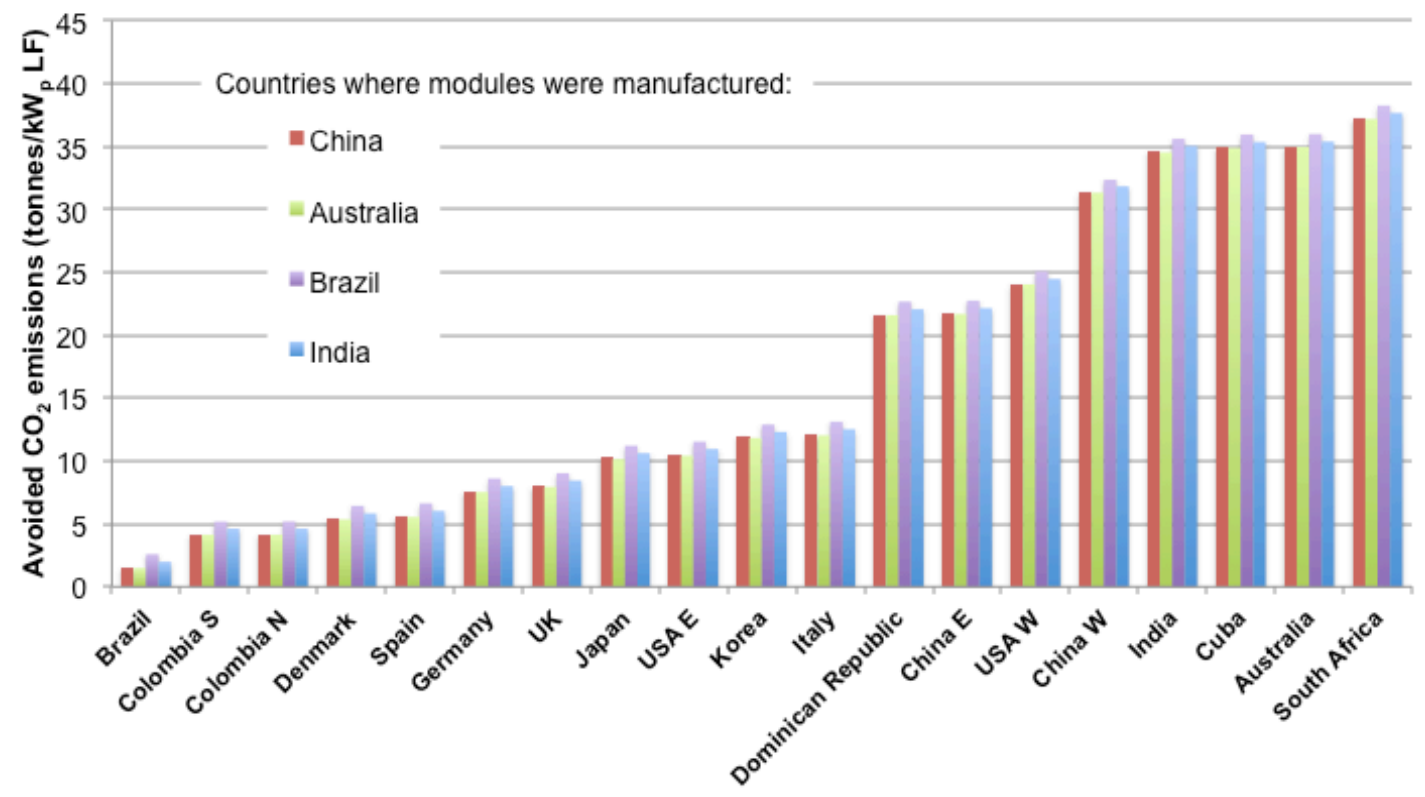

Country where $1 \mathrm{~kW}_{\mathrm{p}}$ PV module is installed 
FIGURE 5.2 DEPENDENCE OF THE AVOIDED $\mathrm{CO}_{2}$ EMISSIONS ON THE INSTALLATION LOCATION OF 1 kWp SI-PV, WHEN THE MANUFACTURE HAS TAKEN PLACE IN CHINA, AUSTRALIA, BRAZIL OR INDIA.

In particular for c-Si technology, the dependence between the avoided emissions and the place where the PV-module is manufactured is very small, while the dependence of these avoided emissions on the place where the PV-module is installed is very high (see Figure 5.2). The manufacturing of the PV-module emits between $1 \%$ and $37 \%$ of the total amount of $\mathrm{CO}_{2}$ avoided emissions during PV lifetime, except for Colombia (49\%) and Brazil (136\%). Installing $1 \mathrm{~kW}_{\mathrm{p}}$ of c-Si module in Brazil isn't environmentally beneficial when this PV system has been manufactured in China, Australia or Cuba, because the emissions of $\mathrm{CO}_{2}$ during the manufacture are higher than the total avoided $\mathrm{CO}_{2}$ during PV lifetime. This is mainly due to the very clean energy mix that is providing electricity in Brazil, which is the cleanest of the world, emitting only $87 \mathrm{~g} \mathrm{CO}_{2}$ per $\mathrm{kWh}$ of electricity generated. Regarding the transport of the modules, this implies a small share of embedded emissions and in all cases is below $6 \%$ of the total amount of avoided $\mathrm{CO}_{2}$ during PV lifetime. A full list of data can be found in the Annex.

The avoided $\mathrm{CO}_{2}$ emissions of a given PV technology during its operation time are strongly correlated to the irradiation on the installation place. The $\mathrm{CO}_{2}$ emissions per $\mathrm{kWh}$ of electricity generation considering the energy mix and the irradiation of a given location are shown in Figure 5.3 using a coloured mapping.

Same dots can be included in this coloured map, which indicates a given combination of energy mix and irradiation that determine the avoided emission of a particular location. Top right corner defines the energy mix-irradiation combination which delivers the highest potential for avoided emissions per $\mathrm{kW}_{\mathrm{p}}$ peak of installed capacity. Similarly, the bottom-left combination defines the combination for which the potential to avoid emission is strongly reduced. 


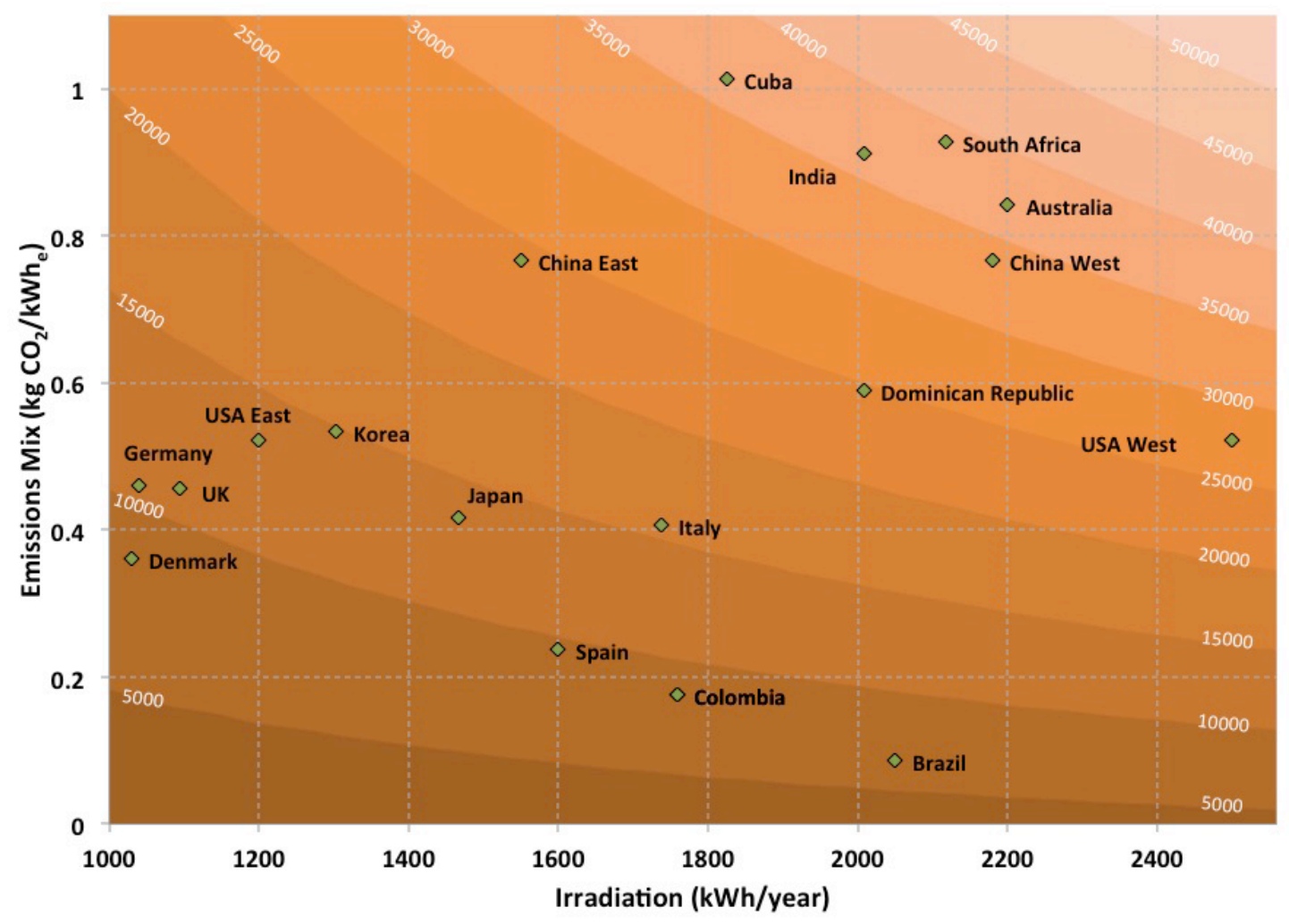

FIGURE 5.3 RELATION BETWEEN THE AMOUNTS OF AVOIDED $\mathrm{CO}_{2}$ BY $1 \mathrm{~kW}_{\mathrm{P}}$ OF MANUFACTURED IN CHINA DURING ITS OPERATIONAL LIFETIME (IN tons/kW $W_{\mathrm{P}}$, INDICATED IN SMALL WHITE NUMBERS AT THE LEVEL CURVES) AND THE PLACE WHERE IT IS INSTALLED, SHOWING THE BALANCE BETWEEN IRRADIATION AND $\mathrm{CO}_{2}$ EMISSIONS PER kWh FROM ELECTRICITY GENERATION.

When we plot the selected countries on the continuous landscape delivered by the colour code we can superimpose the position of the countries (the corresponding figures of avoided emissions are also shown in Table 5.3). As we can see in Figure 5.3, three groups of countries can be selected depending on the $\mathrm{CO}_{2}$ that could be avoided by installing $1 \mathrm{~kW}_{\mathrm{p}}$ of PV module. Avoided $\mathrm{CO}_{2}$ emissions ranging between 35 and 40 tons characterize a first group formed by: South Africa, Australia, Cuba, India and China West. This first group is ideal for installing PV system, because of the high irradiation and the high $\mathrm{CO}_{2}$ emissions in their electricity productions will maximize the avoided emissions. This group of countries coincides with the countries which have most $\mathrm{CO}_{2}$ reduction 
Chapter 5 Geographical dependence of environmental impacts

potential, as found by Kawajiri et al. (Kawajiri and Genchi, 2012; Kawajiri et al., 2011).

USA West, China East and Dominican Republic are included in a second group, whose irradiation and electricity mixes allow avoiding between 25 and 30 tons of $\mathrm{CO}_{2}$ during $1 \mathrm{~kW}$ pV lifetime. The rest of the considered countries could avoid emissions below 15 tonnes of $\mathrm{CO}_{2}$, due to a lower irradiation or to a clean energy mix, being Brazil the location which will avoid less emissions per $1 \mathrm{kWp}$ of installed PV capacity as commented above. This representation is a static view for a $1 \mathrm{kWp}$ functional unit of installed capacity. We are aware that if PV systems are installed in a country, the energy mix will change progressively (becoming cleaner) therefore changing its vertical position (downwards) in the mapping in Figure 5.3. In the same way, countries could (and probably will) meet their future energy demand consuming more fossil fuels moving upwards in the vertical position. A dynamical study including time evolution will be required to have a time projection of total avoided emissions.

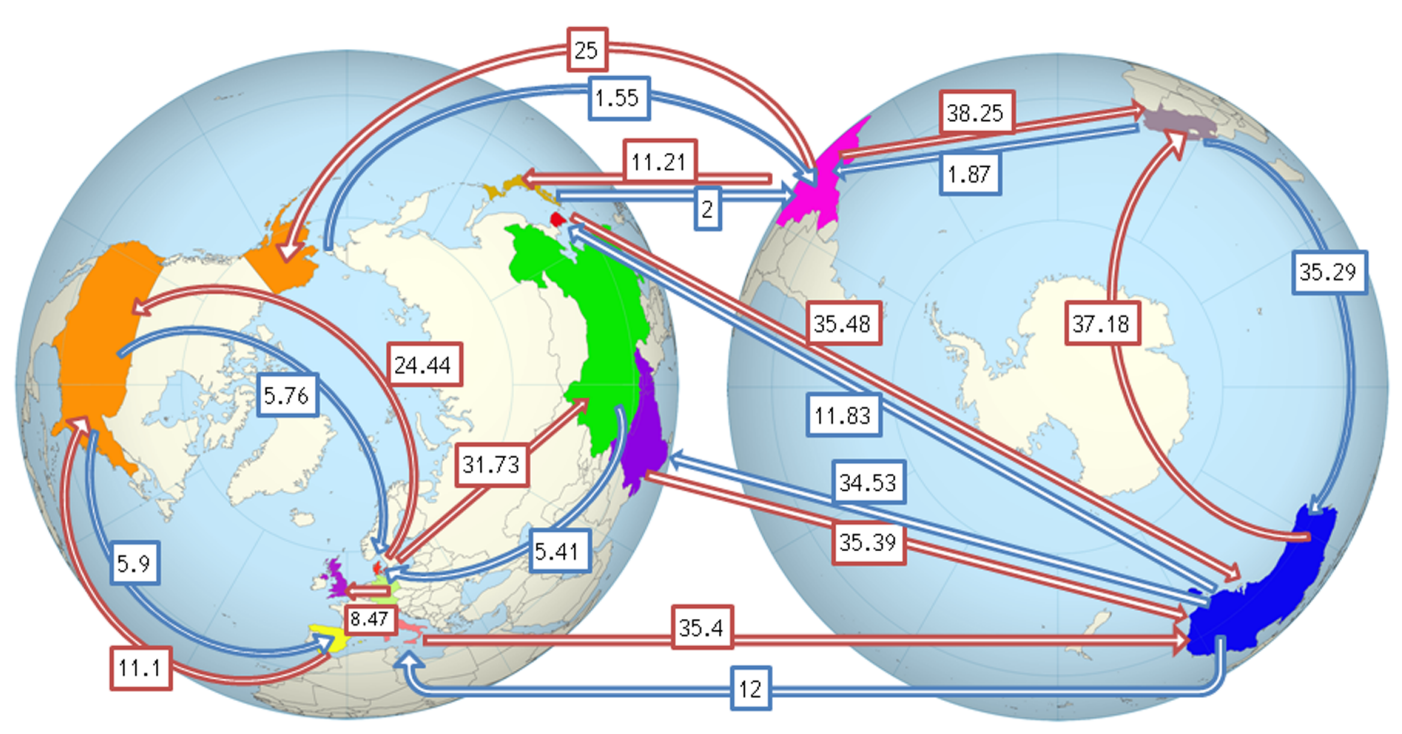


Chapter 5 Geographical dependence of environmental impacts

FIGURE 5.4 THE NUMBER IN THE ARROWS INDICATES THE AVOIDED $\mathrm{CO}_{2}$ EMISSIONS (TONS PER KW $_{\mathrm{P}}$ OF INSTALLED PV CAPACITY THROUGHOUT LIFETIME OF THE PV SYSTEM) FOR A GIVEN COMBINATION OF LOCATIONS: ORIGIN OF ARROW IS THE MANUFACTURING PLACE AND END OF ARROW IS THE INSTALLATION OF THE FACILITY.

The geographical dependence is therefore critical for the environmental impact in terms of $\mathrm{CO}_{2}$ emissions. The optimum selection of these two locations (manufacturing and installation) may save up to 20 times more tons of $\mathrm{CO}_{2}$, as Figure 5.4 shows.

\begin{tabular}{|c|c|c|c|c|}
\hline Country & PV Market $\left(\mathrm{MW}_{\mathrm{p}}\right)^{\mathrm{a}}$ & $\begin{array}{c}\text { Irradiation } \\
\left(\mathrm{kWh} / \mathrm{m}^{2} / \text { year }\right)\end{array}$ & $\begin{array}{l}\mathrm{kg} \mathrm{CO} 2 / \mathrm{kWh} / \text { year from } \\
\text { electricity generation }\end{array}$ & $\begin{array}{c}\mathrm{kg} \mathrm{CO} 2 / \mathrm{kWh} / \text { year from } \\
\text { primary energy }\end{array}$ \\
\hline Australia & 774 & 2200 & 0.841 & 0.264 \\
\hline Austria & 80 & 930 & 0.188 & \\
\hline Belgium & 974 & 930 & 0.22 & \\
\hline Brazil & 5 & 2050 & 0.087 & 0.126 \\
\hline Bulgaria & 100 & 1163 & 0.579 & \\
\hline Canada & 364 & 1163 & 0.186 & \\
\hline China East & 2200 & 1550 & 0.766 & 0.253 \\
\hline China West & 2200 & 2180 & 0.766 & 0.253 \\
\hline Colombia & 0 & 1758 & 0.176 & 0.162 \\
\hline Cuba & 0 & 1825 & 1.012 & 0.235 \\
\hline Cyprus & 3 & 1628 & 0.702 & \\
\hline Czech Republic & 6 & 1104 & 0.589 & \\
\hline Denmark & 10 & 1029 & 0.36 & 0.210 \\
\hline $\begin{array}{l}\text { Dominican } \\
\text { Republic }\end{array}$ & 0 & 2008 & 0.589 & 0.191 \\
\hline Estonia & 0.1 & 1172 & 1.014 & \\
\hline Findland & 1 & 814 & 0.229 & \\
\hline France & 1671 & 1245 & 0.079 & \\
\hline
\end{tabular}


Chapter 5 Geographical dependence of environmental impacts

\begin{tabular}{|c|c|c|c|c|}
\hline Country & PV Market $\left(\mathrm{MW}_{\mathrm{p}}\right)^{\mathrm{a}}$ & $\begin{array}{c}\text { Irradiation } \\
\left(\mathrm{kWh} / \mathrm{m}^{2} / \text { year }\right)\end{array}$ & $\begin{array}{l}\mathrm{kg} \mathrm{CO} 2 / \mathrm{kWh} / \text { year from } \\
\text { electricity generation }\end{array}$ & $\begin{array}{c}\mathrm{kg} \mathrm{CO} 2 / \mathrm{kWh} / \text { year from } \\
\text { primary energy }\end{array}$ \\
\hline Germany & 7485 & 1040 & 0.461 & 0.200 \\
\hline Greece & 426 & 1800 & 0.718 & \\
\hline Hungary & 3 & 930 & 0.317 & \\
\hline India & 300 & 2008 & 0.912 & 0.202 \\
\hline Ireland & 3 & 956 & 0.458 & \\
\hline Israel & 130 & 2093 & 0.689 & \\
\hline Italy & 9284 & 1737 & 0.406 & 0.201 \\
\hline Japan & 1296 & 1467 & 0.416 & 0.198 \\
\hline Korea & 92 & 1303 & 0.533 & 0.194 \\
\hline Latvia & 0.2 & 1170 & 0.227 & \\
\hline Lithuania & 0.1 & 1164 & 0.548 & \\
\hline Luxembourg & 5 & 930 & 0.41 & \\
\hline Malaysia & 0 & 1628 & 0.727 & 0.219 \\
\hline Malta & 10 & 1861 & 0.872 & \\
\hline Mexico & 10 & 1861 & 0.455 & \\
\hline Netherlands & 20 & 930 & 0.415 & \\
\hline Norway & 0 & 814 & 0.017 & \\
\hline Poland & 1 & 930 & 0.781 & \\
\hline Portugal & 33 & 465 & 0.255 & \\
\hline Romania & 2 & 1163 & 0.499 & \\
\hline Slovakia & 321 & 1095 & 0.197 & \\
\hline Slovenia & 46 & 1233 & 0.325 & \\
\hline South Africa & 1 & 2117 & 0.927 & 0.218 \\
\hline Spain & 372 & 1600 & 0.238 & 0.181 \\
\hline Sweden & 3 & 814 & 0.03 & \\
\hline Switzerland & 105 & 930 & 0.027 & \\
\hline Taiwan & 70 & 1628 & 0.768 & 0.213 \\
\hline
\end{tabular}


Chapter 5 Geographical dependence of environmental impacts

\begin{tabular}{|c|c|c|c|c|}
\hline & & Irradiation & & \\
\hline Country & PV Market $\left(\mathrm{MW}_{\mathrm{p}}\right)^{\mathrm{a}}$ & $\left(\mathrm{kWh} / \mathrm{m}^{2} /\right.$ year $)$ & $\begin{array}{l}\mathrm{kg} \mathrm{CO} 2 / \mathrm{kWh} / \text { year from } \\
\text { electricity generation }{ }^{\mathrm{b}}\end{array}$ & $\begin{array}{c}\mathrm{kg} \mathrm{CO} 2 / \mathrm{kWh} / \text { year from } \\
\text { primary energy }\end{array}$ \\
\hline Turkey & 5 & 1628 & 0.46 & \\
\hline Ukraine & 188 & 1153 & 0.419 & \\
\hline United Kingdom & 784 & 1095 & 0.457 & 0.205 \\
\hline USA East & 1855 & 1200 & 0.522 & 0.208 \\
\hline USA West & 1855 & 2500 & 0.522 & 0.208 \\
\hline $\begin{array}{c}\text { Total installed } P V \\
\text { capacity }\end{array}$ & $33.1 \mathrm{GW}_{\mathrm{p}}$ & & & \\
\hline
\end{tabular}

TABLE 5.3 $\mathrm{MW}_{\mathrm{P}}$ PV INSTALLED WORLDWIDE IN 2011, IRRADIATION, $\mathrm{kg} \mathrm{CO}_{2}$ PER $\mathrm{kWh}$ FROM ELECTRICITY GENERATION AND $\mathrm{CO}_{2}$ FROM ELECTRICITY GENERATION OF EACH COUNTRY CONSIDERED IN THE STUDY. NOTE THAT THE VALUES IN LAST COLUMN (kg $\mathrm{CO}_{2}$ RELATED TO ENERGY MIX) ONLY APPEAR IN MANUFACTURING COUNTRIES.

${ }^{a}$ (EPIA European Photovoltaic Industry Association, 2012)

${ }^{\mathrm{b}}$ (International Energy Agency, 2012)

- LCA Results: 2011 PV market

In order to have a snapshot of the actual situation regarding PV deployment and its potential for climate change mitigation via avoided $\mathrm{CO}_{2}$ emissions, the LCA methodology described in section 5.4.1 has been applied to the real $2011 \mathrm{PV}$ market (EPIA, 2012; Photon International, 2012). This approach will allow us to find the $\mathrm{CO}_{2}$ tons that were released because of the PV manufacturing in 2011 as well as the avoided $\mathrm{CO}_{2}$ emissions thanks to the installed PV during the same year.

In 2011, $37.2 \mathrm{GW}_{\mathrm{p}}$ of photovoltaic modules were manufactured. Monocrystalline and polycrystalline silicon materials covered $87 \%$ of PV market while thin-film 
Chapter 5 Geographical dependence of environmental impacts

PV rate was 13\%. European cumulative installed capacity from 2008 until 2011 has increased fivefold. China manufactured close to $60 \%$ of the PV modules during 2011 (Photon International, 2012), meaning $21 \mathrm{GW}_{\mathrm{p}}$ manufactured PV modules and implying more than 38 Megatons of $\mathrm{CO}_{2}$ emissions, followed by Taiwan that manufactured $4 \mathrm{GW}_{\mathrm{p}}$. The information about the shares of the 2011 PV market is showed in Table 5.4.

\begin{tabular}{lcr}
\hline Country & \% Manufacture & MW $_{\mathbf{p}}$ \\
\hline China & 57.3 & 21312.3 \\
Taiwan & 11 & 4081.3 \\
Germany & 6.7 & 2508.3 \\
Japan & 6.9 & 2564 \\
Rest of Asia & 3.8 & 1410.3 \\
Malaysia & 5.8 & 2172.8 \\
USA & 3 & 1120.5 \\
Rest of Europe & 2.3 & 845.6 \\
South Korea & 2.9 & 1095 \\
Africa y Middle East & 0.2 & 75 \\
\hline \multicolumn{2}{c}{ TOTAL MANUFACTURED PV } \\
\hline
\end{tabular}

TABLE 5.4 MANUFACTURING COUNTRIES IN 2011 AND ITS MANUFACTURED CAPACITY.

Figure 5.5 shows the $\mathrm{CO}_{2}$ emissions by country in 2011 due to $\mathrm{PV}$ manufacture according to data shown in Table 5.3. For the calculation we have assumed that each country produces the same share of PV technologies: $87 \%$ of c-Silicon and $13 \%$ of thin-film, which is the global market share. According to this, 61 megatons of $\mathrm{CO}_{2}$ were generated worldwide in 2011 due to the production of cSilicon and thin-film PV modules. 
Chapter 5 Geographical dependence of environmental impacts

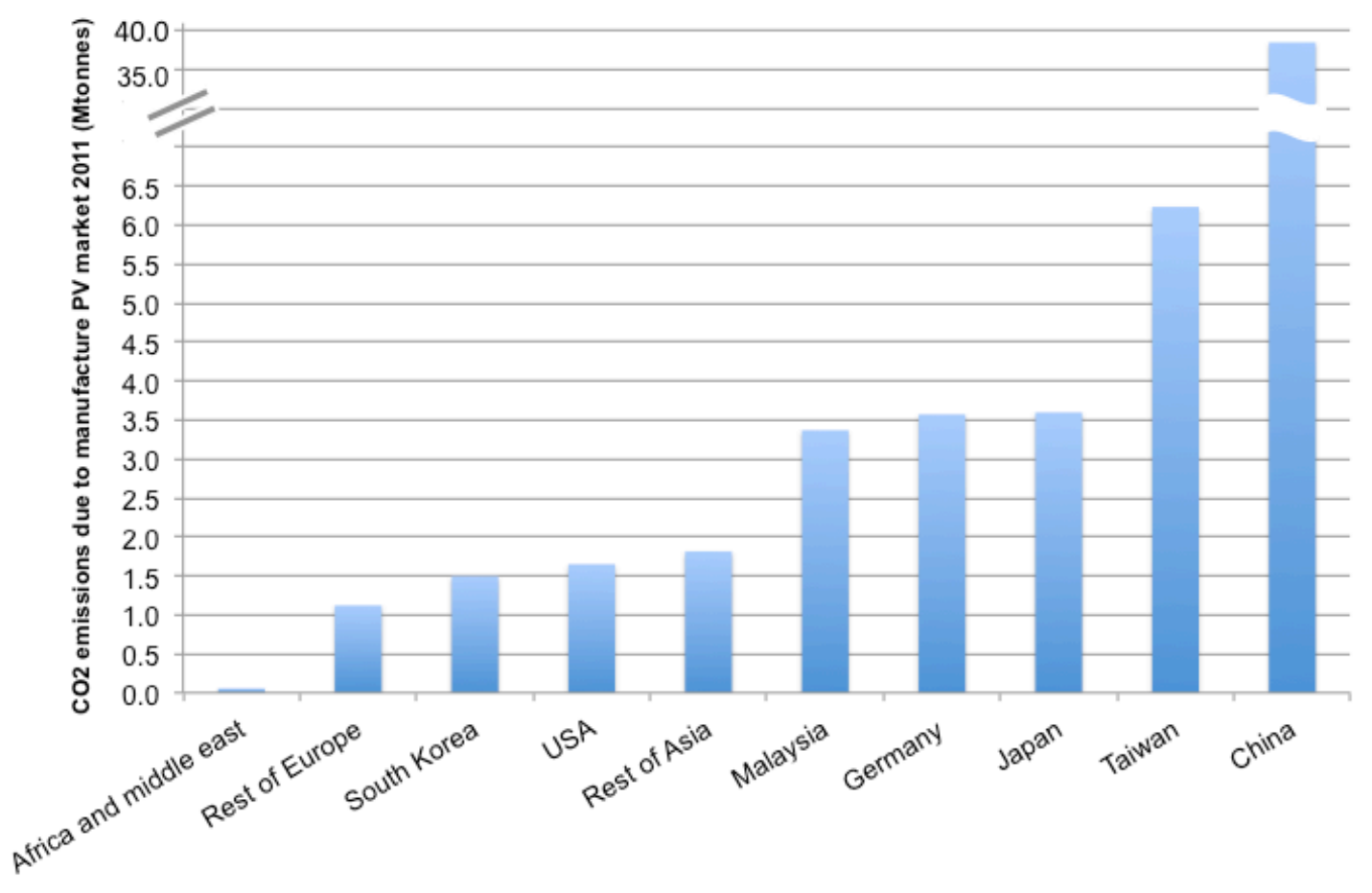

FIGURE 5.5 TONS OF EMITTED $\mathrm{CO}_{2}$ DUE TO THE MANUFACTURING OF C-SI AND THIN-FILM SOLAR CELLS IN 2011(EPIA, 2012). FOR EACH COUNTRY, THE GLOBAL MARKET SHARE OF TECHNOLOGY HAS BEEN ASSUMED.

Supposing all 2011 PV market would have consisted of the same kind of technology; c-Si, CdTe or OPV, the emitted $\mathrm{CO}_{2}$ would be $65.8,30.76$ and 17.63 megatons, respectively. If all manufactured PV capacity in 2011 worldwide would be only made of c-Si, the amount of $\mathrm{CO}_{2}$ would be four times higher, and two times higher if PV would be made of CdTe, with respect to OPV, as Figure 5.6 shows. This relationship holds for all countries. 
Chapter 5 Geographical dependence of environmental impacts

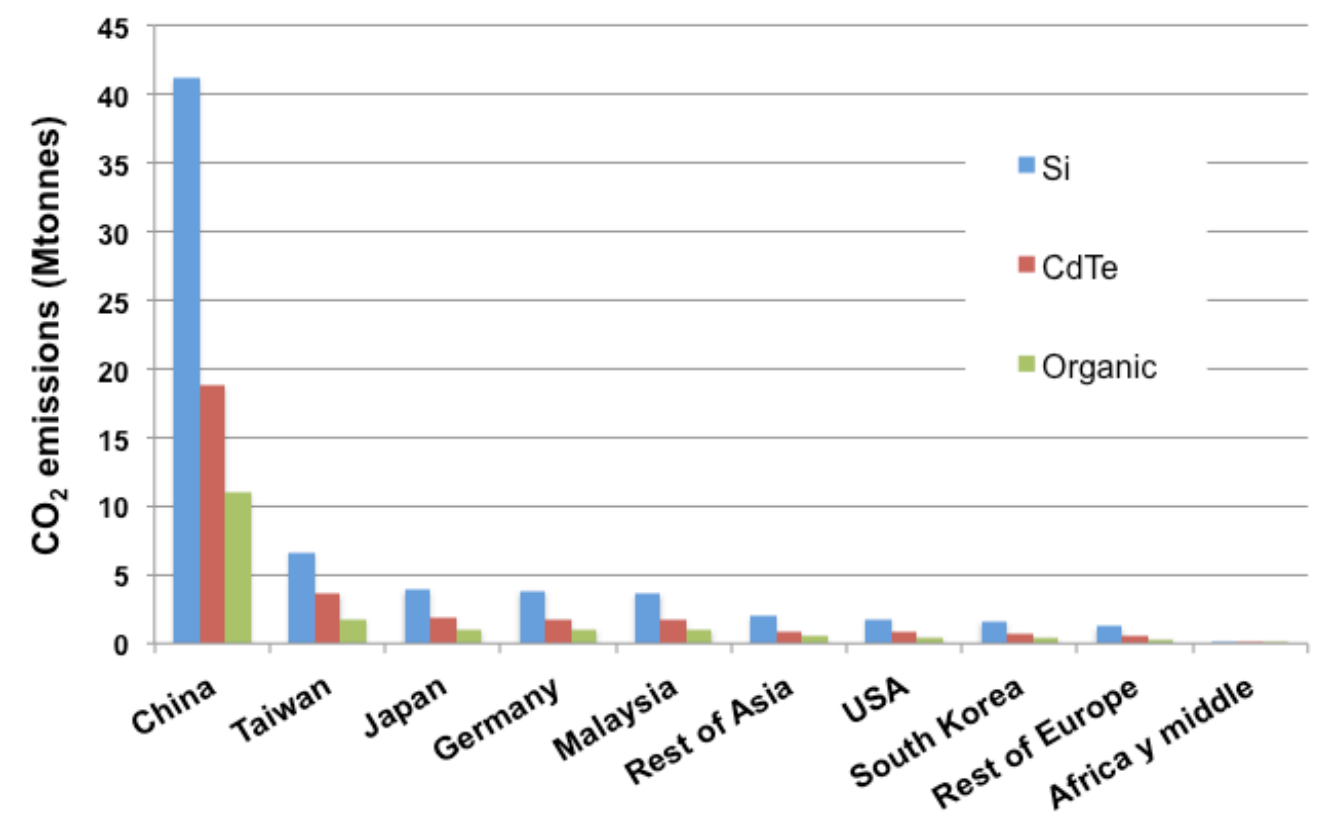

FIGURE 5.6 EMISSIONS OF $\mathrm{CO}_{2}$ BY COUNTRY IN MEGATONS, SUPPOSING ALL PV CAPACITY WOULD HAVE BEEN MADE OF THE SAME PV TECHNOLOGY: C-SI OR THIN-FILM OR OPV (FOLLOWING VALUES OF THE MARKET IN 2011).

On the other hand, during 2011, $33 \mathrm{GW}_{\mathrm{p}}$ of PV were installed worldwide. Italy was the country where most PV modules were installed, followed by Germany, China and USA. Figure 5.7 shows the avoided emissions during the first year after installation, considering the energetic mix and the irradiation of each country.

In 2011, the total avoided megatons of $\mathrm{CO}_{2}$, thanks to the operation of PV modules were installed during this year, is estimated to be 14.03 megatons, and during its lifetime this amount will be about 399.14 megatons. The net amount of avoided $\mathrm{CO}_{2}$ emissions in 2011, that is the avoided $\mathrm{CO}_{2}$ minus emissions due to the manufacturing, is -47.21 megatons after the first year of operation, that is the $\mathrm{CO}_{2}$ in the atmosphere has increased as a result of the PV manufacture, but during the installed PV systems lifetime 337.9 megatons of $\mathrm{CO}_{2}$ will be avoided. This result emphasizes the need of a dynamical approach to analyse in detail the time 
dependence of the net balance of $\mathrm{CO}_{2}$ emissions throughout the lifetime of the PV systems.

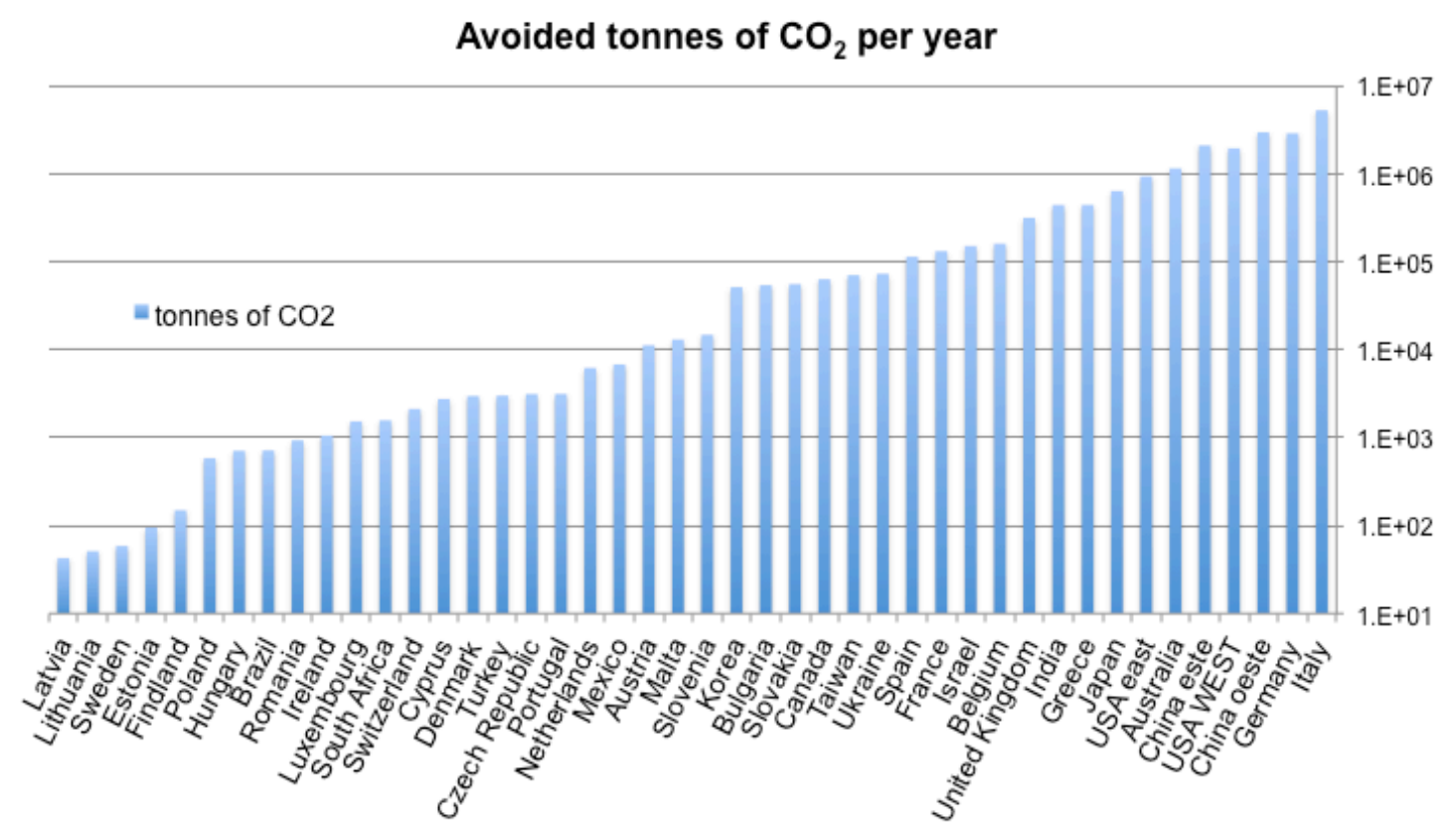

FIGURE 5.7 TONS OF AVOIDED $\mathrm{CO}_{2}$ EMISSIONS OF EACH COUNTRY, DUE TO ALL INSTALLED PV MODULES IN 2011, DURING ITS FIRST YEAR.

Let's consider now that all PV modules manufactured in $2011(87 \% \mathrm{Si}, 13 \%$ thin film as mentioned above) would be installed at the same location; the avoided $\mathrm{CO}_{2}$ emissions during the first year for each country is shown in Figure 5.8, this graph indicates clearly what would be the best place for installing PV, in order to save the greatest amount of $\mathrm{CO}_{2}$. South Africa would be the best place for installing PV, followed by the countries that belong to the first group of the Figure 5.3 mapping, which are those that reflect the larger $\mathrm{CO}_{2}$ savings. This group of optimal locations is followed by the countries from the second group of Figure 5.3, and so on. The real amount of avoided emission during the first year, 14.03 megatons could have been increased to 51.95, almost a four-fold increase had the optimal location been chosen for the installation. 


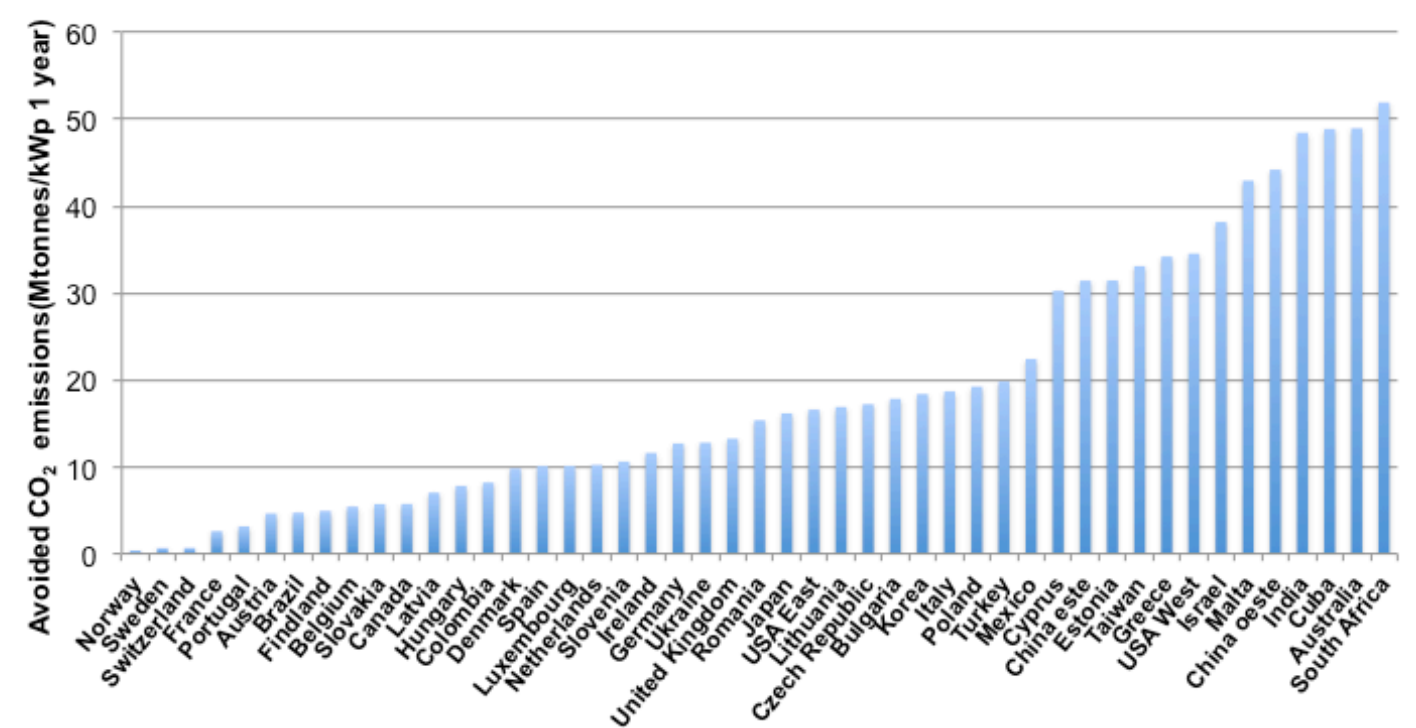

FIGURE 5.8 GEOGRAPHICAL DEPENDENCE OF AVOIDED $\mathrm{CO}_{2}$ IF ALL THE PV CAPACITY WOULD HAVE BEEN INSTALLED IN THE SAME COUNTRY AND WOULD HAVE BEEN RUNNING FOR ONE YEAR.

\subsection{Conclusions}

A detailed life cycle analysis methodology with a global approach has been applied to obtain the geographical dependence of the PV technology potential for climate change mitigation.

A strong geographical dependence on the installation location is obtained for the amount of avoided emissions; this dependence is given by a balance between the energy mix and the solar irradiation for a given location. On the other hand, the geographical dependence on the manufacturing location is smaller: only a variation of $16 \%$ is obtained (except Brazil and Colombia, with a variation of $42 \%$ and $20 \%$ respectively). The impact of transport between manufacturing and installation locations was not significant, amounting to $6 \%$ of total embedded $\mathrm{CO}_{2}$ for the worst case. As a consequence, there exists an optimal location for the installation of a PV system if we want to maximize its impact on climate change 
mitigation: South Africa; this country is included in a first group which also comprises Australia, Cuba, India, West China and then followed by other countries which show a variety of impacts. As has been illustrated by the application of the LCA methodology for the 2011 global PV market, a four-fold increase in avoided $\mathrm{CO}_{2}$ emissions could have been obtained if all installed PV in 2011 throughout the world would have been installed in a single optimum country (South Africa). This is obviously an unrealistic scenario but it shows the potential benefits of a more global approach to PV policy and market regulations.

\subsection{References}

EPIA European Photovoltaic Industry Association, n.d. Global Market Outlook for Photovoltaics until 2016. Renewable Energy House.

Espinosa, N., García-Valverde, R., Urbina, A., Krebs, F.C., 2011. A life cycle analysis of polymer solar cell modules prepared using roll-to-roll methods under ambient conditions. Sol. Energy Mater. Sol. Cells 95, 1293-1302.

FC Krebs, n.d. Personal communication.

First Solar FS Series PV Module [WWW Document], 2011. URL http://www.gehrlicher.com/es/ (accessed 12.7.11).

Fthenakis, V., Alsema, E., 2006. Photovoltaics energy payback times, greenhouse gas emissions and external costs: 2004-early 2005 status. Prog. Photovoltaics Res. Appl. 14, 275-280.

International Energy Agency, 2012. $\mathrm{CO}_{2}$ Emissions from Fuel Combustion HIGHLIGHTS.

Kato K., Hibino T., Komoto K., Ihara S., Yamamoto S., Fujihara H., 2001. A lifecycle analysis on thin-film CdS/CdTe PV modules. Sol. Energy Mater. Sol. Cells 67, 279-287.

Kawajiri, K., Genchi, Y., 2012. The Right Place for the Right Job in the Photovoltaic Life Cycle. Environ. Sci. Technol. 46, 7415-7421. 
Chapter 5 Geographical dependence of environmental impacts

Kawajiri, K., Oozeki, T., Genchi, Y., 2011. Effect of Temperature on PV Potential in the World. Environ. Sci. Technol. 45, 9030-9035.

Knapp, K., Jester, T., 2001. Empirical investigation of the energy payback time for photovoltaic modules. Sol. Energy 71, 165-172.

Mohr, N.J., Schermer, J.J., Huijbregts, M. a. J., Meijer, A., Reijnders, L., 2007. Life cycle assessment of thin-film GaAs and GaInP/GaAs solar modules. Prog. Photovoltaics Res. Appl. 15, 163-179.

Photon International, 2012.

Raugei, M., Bargigli, S., Ulgiati, S., 2007. Life cycle assessment and energy payback time of advanced photovoltaic modules: CdTe and CIS compared to poly-Si. Energy 32, 1310-1318.

Roes, A.L., Alsema, E.A., Blok, K., Patel, M.K., 2009. Ex-ante environmental and economic evaluation of polymer photovoltaics. Prog. Photovoltaics Res. Appl. 17, 372-393.

SHARP solar electricity, n.d. ND-224U1F Multi-purpose 224 Watt module from the world's trusted source for solar. 


\section{CHAPTER 6}

\section{BEYOND TECHNICAL}

\section{SUSTAINABILITY: A GLOBAL}

\section{APPROACH TO PV SYSTEMS}

Synopsis. A different information technology approach to energy supply is SURE-DSS, a multicriteria approach and software tool that supports decision makers to select optimum energy solutions in rural areas of the developing world. SURE assesses several renewable and non renewable energy technologies; evaluates social, human, natural, physical and financial assets owned by rural populations, and chooses which energy technology arrangements could maximize the benefits on each of those five assets. The global environmental impact of these energy solutions has however, not been calculated before. With a special focus on photovoltaic technology, this chapter employs the data discussed in Chapters 4 and 5 to add global impact calculations to the current capabilities of SURE-DSS. The global analysis enables assessing precisely different technologies of same energy source. In this case, photovoltaic technologies have been assessed, including its geographical dependence. The software has been modified to add this new capability to the SURE-DSS software.

\subsection{Introduction.}

Energy supply is necessary to meet the needs of rural poor in developing countries in order to provide basic services such as water pumping, lighting, refrigeration, etc, all of which has a beneficial impact on the human development of the community. In the developing world, it is often uneconomic, and sometimes even technically and geographically unfeasible to extend the national grid to very isolated areas; the only economically viable solution might well be decentralized electricity generation, particularly renewable energy technology (REN21, 2011). 
With the aim to provide energy to isolated rural settlements, the selection of the ideal energy technology should carry out a comparative mitigation analysis between different energy options, including renewable or non-renewable, in order to make an optimum selection. Taking into account the end-users demand of electricity as well as their opinion about the priorities for its consumption is key for an effective and sustainable energy provision.

The impact of photovoltaic stand-alone systems on rural livelihoods can be remarkable. Electricity from PV can extend the day by enabling light-hours that can be used for increasing productive reading, entertainment and other activities; powering small-scale tools, and pumping drinking or irrigation water-. The Human Development Index measures the wealth of a nation (United Nations Development Programme, 2013). It is apparent that the HDI significantly improves by the delivery of the first kilowatt-hour supply. The benefit accrued from a small amount of electricity in poorest communities where there is no access to modern energy can be enormous (Chaurey et al., 2004; Mulugetta et al., 2002; United Nations Development Programme UNDP, 1999).

However, while modern energy provision may facilitate development, it may also have a negative impact on the local environment or drain scarce financial resources, all of which could be mitigated if a technology solution were selected more carefully (Judith A. Cherni and Nicole Kalas, 2010). Appropriate energy solutions should aim to match technology with communities' priorities, needs and their available resources and be sustainable over time. 


\subsection{Decision software tools that assist electrification}

Decision-help software tools, such as LEAP (Stockholm Environment Institute SEI, 2013), HOMER (Peter Lilienthal et al., 2013), PVSyst (André Mermoud et al., 2013) and SURE (Henao et al., 2012) have been developed during the last years in order to provide decision makers with a support tool in order to make decision about energy supply technologies and address the problem of lack of energy sources in isolated settlements, as well as choose the best energy option in efficiency and economic terms. We propose to add into SURE software the global environmental impact, as discussed in Chapter 5, including the results of LCA studies on energy technologies.

- LEAP can be used to track energy consumption, production and resource extraction in all sectors of an economy, as well as to account for both energy sector and non-energy sector greenhouse gas (GHG) emission sources and sinks.

- HOMER models both conventional and renewable energy technologies. It simplifies the task of designing distributed generation systems and compares the cost and feasibility of different configurations.

- PVSsyst take into account meteo data to get an estimation of production for an installation (by sizing and hourly simulation) and focuses almost exclusively on technical data

- SURE-DSS is a multi-criteria modelling tool that recognizes five types of livelihoods resources or capitals: physical, financial, natural, social and human, and arrive to optimum energy solutions, taking into account the impacts onto five capitals or assets. 
This chapter discusses the application of the new capability to evaluate the global environmental impact of photovoltaic technologies, following LCA methodology to the SURE-DSS, it can be named as a global environmental impact evaluation of the PV technology considered for the rural electrification. The software was tested using existing original information on a rural case study in Cuba. This chapter draws on current work in progress by the research project RESURL III (Renewable Energy for Sustainable Rural Livelihoods, UK Department for International Development 2004 (Henao et al., 2012; Judith A. Cherni and Nicole Kalas, 2010; Judith A. Cherni et al., 2013a, 2013b)

\subsubsection{SURE-DSS}

The Sustainable Rural Energy Decision-Support System (SURE-DSS) was developed to address many of the gaps that were highlighted in 6.1 (see Cherni et al., 2007). SURE approach recognizes that communities not only have needs but also own five types of resources or capitals. These are physical capital (e.g., infrastructure such as houses, roads, schools), financial capital (e.g., wages, savings, access to credit); natural capital (e.g., water, land, wind, sun irradiance, organic waste, landscape); social capital (e.g. networks, social or political affiliation), and human capital (e.g., education, health, skills, literacy.). SUREDSS assumes that a resource baseline supplies some energy to the community is studied. The baseline serves as a reference to available - often insufficient energy access in the rural area. An underlying tenet of the system is that any addition of energy supply will have an impact on all and each one of the five capitals; and livelihood is graphically represented in a pentagon. 
To arrive to optimum energy solutions, quantitative and qualitative information about candidate energy technologies is employed. This information is stored in an Energy Matrix and its function is to describe the natural source as well as the efficiency of each energy option. Although this multi-criteria system has amply fulfilled its purpose to match local priorities with appropriate technological solutions (as explained in Section 6.2.2), it is possible to sharpen the selection process if information about the potential for climate change mitigation of the different energy supply options is taken into consideration. However, the climate change mitigation potential of energy technology for rural areas may vary not only between different options but also within a same 'generic' technology: In the case of solar, available technologies have different features and information about its mitigation potential could be crucial to make policy, investment and aid decisions.

SURE-DSS has been dubbed the most far-reaching tool for comprehensive assessment of energy access and lined up with the most credible approaches to link development to renewable energy, by matching technology, assets and needs, producing information that is essential for advancing sustainable rural livelihood (Brent and Kruger, 2009). From a sustainable development perspective, the framework is perceived to pace the way forward to a sustainable future as it facilitates increased complexity (Brent and Kruger, 2009). To further enlighten the way to sustainable, low carbon outlook, the capacity to assess greenhouse gas mitigation is now comprised in SURE.

\subsubsection{Information technology for rural areas: the SURE-DSS}

SURE tool simulates the effect of the supply of additional energy in relation to available assets. The capitals are used as indicators of the existing and final conditions of the community before and after the new energy system is deployed. 
The five criteria for analysis correspond to the following capitals: physical (e.g., with infrastructure indicators such as houses, roads, schools); financial (e.g., wages, savings, cost of the system, access to credit); natural (resources such as water, land, wind, sun irradiance, but also the environmental impact on this natural resources, landscape impact is also taken into account); social (e.g. networks, social and political organizations...) and human (education, health, skills, literacy). Recognition of the availability or lack of these resources provides an indication of the living conditions, information necessary to build a baseline, for future improvement. It then compares the evolution and trade-offs when the different energy solutions are analysed.

Equation 6.1 calculates the overall resources found in a community:

EQUATION 6.1 $\quad C_{j}\left(A_{i}\right)=\frac{1}{1+e^{\alpha_{j} X_{j}\left(A_{i}\right)}}$,

where $C_{j}\left(A_{i}\right)$ represents the impact of the $i$ th energy alternative $\left(A_{i}, i=1, \ldots, n\right)$ on asset $j, j=1,2, \ldots, 5$, (1 indicates Physical, 2 Financial, 3 Natural, 4 Social and 5 Human assets); $C_{j}\left(A_{i}\right)$ takes values in the interval $(0,1)$, and indicates how the energy option $i$ impacts capital $j$ (" 0 " is for the strongest negative effect of the energy alternative $i$ on asset $j$, and " 1 " indicates the largest positive effect on the asset); $X_{j}$ represents the set of factors that compose each asset $j$ (e.g., for natural capital, the factors refer to water, air, landscape, flora and fauna); $X_{j}\left(A_{i}\right)$ represents the effects of the i-th energy alternative on the factors of the corresponding asset $j$. Finally, $\boldsymbol{\alpha}_{j}$ is an arithmetic mean function that normalizes, in a common interval for all assets $[-b, b]$, the effects of the i-th energy option across all assets, so that it can be compared. Then, $b$ is the largest absolute value that covers all assets' scores, which is used to standardise the $C_{j}$ function. 
The multi-criteria model SURE seeks optimization by minimizing the gap between the maximum possible value for a livelihoods capital (i.e., 1) and the real value that such capital may achieve if energy were supplied by any specific technology. The optimization takes into account, in addition to the information collated in the Energy Matrix, priorities and needs of prospective users. Users' views contributed to determine the weights that decision-makers give to various indicators to reach a more representative and participatory output. An appropriate energy selection is thus reached and a forecast of impact on livelihoods criteria is obtained. Technical and non-technical information has been brought together to obtain a balanced outcome that considers both, initial and resulting values for each of the five capitals (for details, see Cherni et al., 2007; Henao et al., 2012).

The software tool, after introducing all information about the community, its environment, and the impact on the five capitals of different energy supply options, shows the results in a pentagon. This figure reflects the improvements that can be made in each capital thanks to the supply of each considered energy source. (See Figure 6.1 for an example of different user's interface screens of the software tool). 


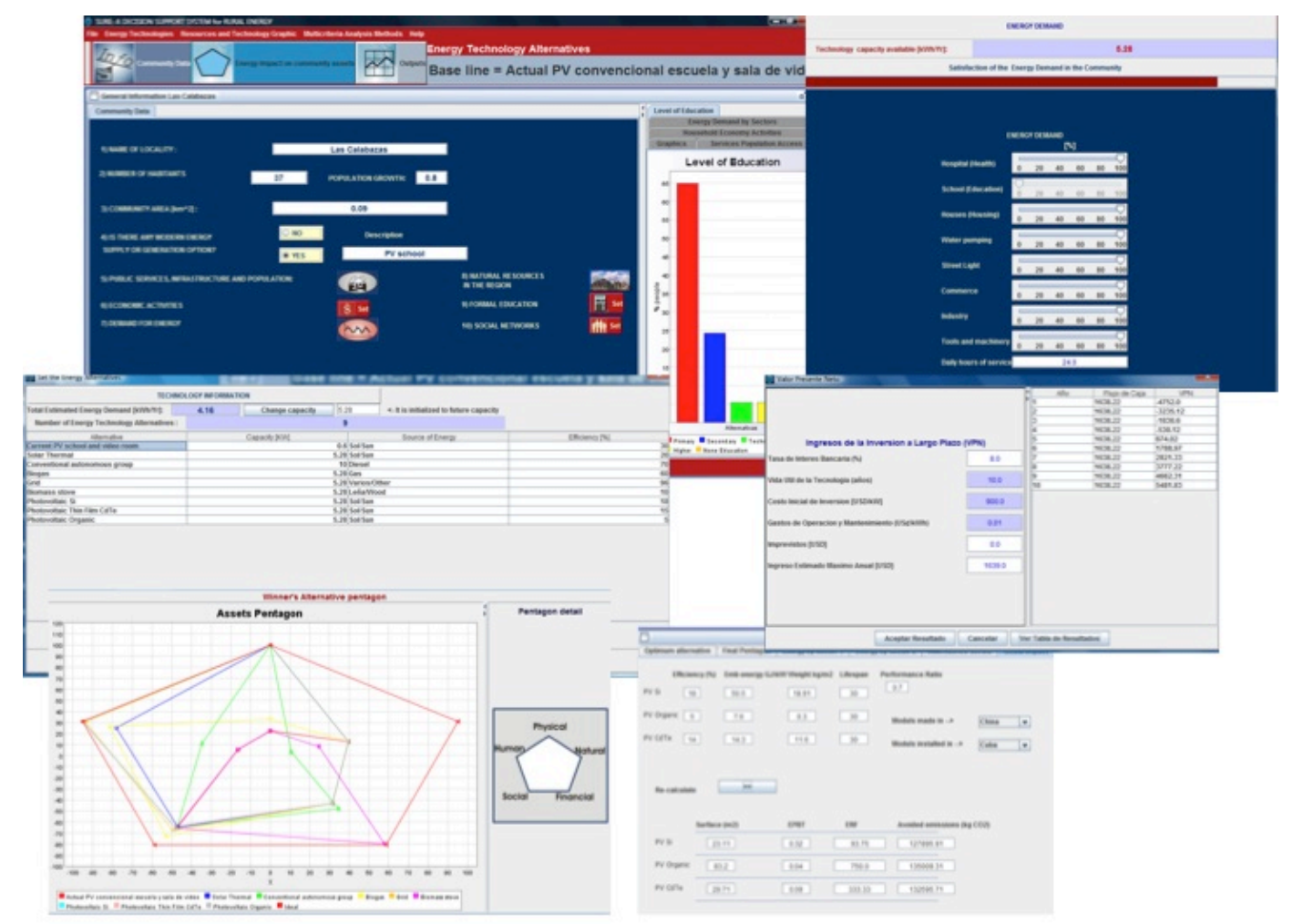

FIGURE 6.1 WINDOWS THAT ILLUSTRATE THE USER INTERFACE OF SURE SOFTWARE.

\subsubsection{Adding global environmental impact to SURE}

The analysis of impact on sustainable rural livelihoods of energy technology for developing countries can be enhanced by the adding a "global environmental impact" approach as proposed in the previous section. The data used to calculate this impact for each PV technology are collected from databases and from our own calculations as described in the previous chapters. 
New interface windows were added to SURE in order to show the global impacts. Input parameters needed to operate this new capability, which can be modified by user, are: efficiency of the modules (\%), embedded energy (in terms of needed energy (GJ) in manufacture per $\mathrm{kW}$ of module capacity), weight ( $\mathrm{kg}$ per $\mathrm{m}^{2}$ of module), lifetime (years), Performance Ratio ( 0.8 by default), country where the modules are made and country where the modules are installed (Cuba, China, Spain, Denmark, United Kingdom, Colombia, Dominican Republic). A literature review and database access related to PV technologies was carried out (see Table 6.1) to provide a "default" set of data for SURE, starting from this "default" values, the SURE user can introduce his own set of data or modify just a few parameters. The "default" considered parameters, for photovoltaic technologies are an average of the published available data, they are shown in Table 6.2. Those data, together with the LCA approach applied to PV technologies described in Chapter 3, and the application of simple equations to scale the functional unit results up to the installed capacity of the PV solution for the rural livelihood provides the "global environmental impact" information to the decision-makers. 
Chapter 6 Beyond Technical Sustainability: a global approach to PV system

\begin{tabular}{|c|c|c|c|c|c|c|}
\hline & \multicolumn{2}{|l|}{ PV Technology } & $\begin{array}{l}\text { Efficiency } \\
(\%)\end{array}$ & $\begin{array}{l}\text { Cost } \\
(€ / W p \text { for } \\
200 \mathrm{MWp})\end{array}$ & $\begin{array}{l}\text { EPBT } \\
\text { (Years) }\end{array}$ & $\begin{array}{l}\mathbf{E}_{\mathrm{emb}} \\
(\mathrm{GJ} / \mathrm{kWp})\end{array}$ \\
\hline \multirow{7}{*}{ 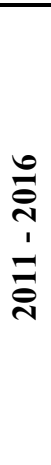 } & \multirow{2}{*}{ Silicon } & Poly & $>17$ & \multirow{2}{*}{$-005-17$} & \multirow{2}{*}{2} & \multirow{2}{*}{45 to 56} \\
\hline & & Mono & $>19$ & & & \\
\hline & \multirow{2}{*}{ Thin-film silicon } & $\begin{array}{l}\text { Glass } \\
\text { substrate }\end{array}$ & $>11$ & $<0.7$ & \multirow{2}{*}{1.13} & \multirow{2}{*}{17} \\
\hline & & $\begin{array}{l}\text { Flexible } \\
\text { substrate }\end{array}$ & $>10$ & $<0.6$ & & \\
\hline & \multicolumn{2}{|l|}{ Thin-film CIGS } & 15 & $<0.7$ & 2.2 & $27.7-39.4$ \\
\hline & \multicolumn{2}{|l|}{ Thin-gilm CdTe } & 14 & $<0.6$ & 1.25 & $\begin{array}{l}7.6 \\
10.2-17.5 \\
21.9\end{array}$ \\
\hline & \multicolumn{2}{|l|}{ Organic } & 5 & 1 & 1.35 & 7.6 \\
\hline
\end{tabular}

\begin{tabular}{|c|c|c|c|c|c|}
\hline \multirow{7}{*}{ 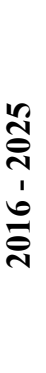 } & \multirow{2}{*}{ Silicon } & Poly & $>19$ & \multirow{2}{*}{$2.5-2.2$} & \multirow{2}{*}{$1-1.5$} \\
\hline & & Mono & $>21$ & & \\
\hline & \multirow{2}{*}{ Thin-film silicon } & $\begin{array}{l}\text { Glass } \\
\text { substrate }\end{array}$ & $>14$ & $\begin{array}{l}<0.5 \quad \text { (for } \\
500 \mathrm{MWp})\end{array}$ & \\
\hline & & $\begin{array}{l}\text { Flexible } \\
\text { substrate }\end{array}$ & $>13$ & $\begin{array}{l}<0.4 \quad \text { (for } \\
500 \mathrm{MWp})\end{array}$ & \\
\hline & \multicolumn{2}{|l|}{ Thin-film CIGS } & $16-17$ & $<0.5$ & \\
\hline & \multicolumn{2}{|l|}{ Thin-gilm CdTe } & 16 & $<0.4$ & 1.25 \\
\hline & \multicolumn{2}{|l|}{ Organic } & 10 & $0.5-0.6$ & $<0.5$ \\
\hline
\end{tabular}

TABLE 6.1 CURRENT AND PROJECTED TECHNICAL, FINANCIAL AND LIFE-CYCLE INDICATORS FOR CRISTALLINE SILICON, THIN-FILM AND ORGANIC BULK HETEROJUNCTION PHOTOVOLTAIC TECHNOLOGIES. SOURCES (ALSEMA, 2000; EUROPEAN PHOTOVOLTAIC TECHNOLOGY PLATFORM, 2007; JUNGBLUTH, 2005; KATO ET AL., 2001; KNAPP AND JESTER, 2001; KRAUTER AND RÜTHER, 2004; RAUGEI ET AL., 2007)

\begin{tabular}{|c|c|c|c|c|}
\hline PV technology & Efficiency (\%) & $\begin{array}{c}\text { Embedded } \\
\text { Energy } \\
(\mathbf{G J} / \mathbf{k W})\end{array}$ & $\begin{array}{c}\text { Weight } \\
(\mathbf{k g} / \mathbf{m} 2)\end{array}$ & $\begin{array}{c}\text { LIFETIME } \\
\text { (years) }\end{array}$ \\
\hline $\boldsymbol{c}$-Si & 18 & 50.5 & 18.91 & 30 \\
\hline Organic & 5 & 7.6 & 0.3 & 30 \\
\hline $\boldsymbol{C d T e}$ & 14 & 14.3 & 11.6 & 30 \\
\hline TABLE $\quad \mathbf{6 . 2}$ INPUT-PARAMETERS IN & PHOTOVOLTAIC & GLOBAL IMPACT & INTERFACE,
\end{tabular}
FUNCTIONALITY ADDED TO SURE-DSS SOFTWARE 
The outputs in new "Global impact" interface are the global indicators: surface required, Energy Pay Back Time, Energy Return Factors and $\mathrm{CO}_{2}$ avoided emissions. The equations applied to get these indicators are described in Chapter 4, Equations 4.1 - 4.2 and in Chapter 5, Equations 5.1 - 5.6.

The environmental impact of the deployment of a photovoltaic technology will also depend on the distance that the system needs to be transported from the manufacturing site to the deployment site. The distances and the emmissions associated to each means of tranport per $\mathrm{km}$ (and per weight of transported material) are reflected in the Tables of Annex II.

\subsection{Case study: Las Calabazas, Cuba}

\subsubsection{Data collection and analysis of community baseline}

A field work was carried out in Cuba. As part of the methodology described above, a SURE household questionnaire was applied to each home in Las Calabazas (see Annex II for a detailed description of the questionnaire). It recorded information essential to build the community's baseline on access to financial, social, human, natural and physical resources. The questionnaire also identified resident's livelihoods priorities and the energy demands of the community. Additionally, secondary sources of information were employed to assess availability of local natural resources, and calculate embedded global energy and $\mathrm{CO}_{2}$ emissions of prospective installations of solar energy in the Las Calabazas.

The multi-criteria character of SURE-DSS and the flexibility in its Energy Matrix (see section 6.2) facilitated the incorporation of three types of PV technologies, 
representative of the three most important technologies of potential use in rural electrification: crystalline silicon, a representative of thin film $(\mathrm{CdTe})$ and a representative of new emerging low cost technologies (organic polymeric PV).

The application of SURE, including the "global impact" capability analysis was tested for a rural community in Cuba, Las Calabazas, in the municipality of Manicaragua $^{1}$, in the province of Cienfuegos. The physical characteristics of Las Calabazas match the national definition of isolated dispersed rural community. A survey of the local population was undertaken by the members of the RESURL project (Cherni et al., work in progress). It was found that, at the time of the study, the settlement comprised 37 inhabitants, with 12 houses scattered over an extended territory of $0.09 \mathrm{Km}^{2}$.

The closest township is indeed Manicaragua, $20 \mathrm{~km}$ away, with administrative municipal responsibility for Las Calabazas. Guinía is a larger town and it is located $3 \mathrm{~km}$ away. The locality of Manicaragua is found in the mountains range of Guamuhay, at the Escambray Sierra, in the south-centre of the island. Highest peaks reach 1,200 m (San Juan peak) and $931 \mathrm{~m}$ (Potrerillo peak) - both enclosed in a National Park.

The findings from the SURE-DSS survey indicate that the financial resource in this remote dispersed community is low. The main income originates in growing coffee plantations and some forestry management. Las Calabazas represents a deprived community with high unemployment, especially among women. Interviews with local authorities revealed that there were no plans to increase

\footnotetext{
${ }^{1}$ Manicaragua is located in Villa Clara province, having 73,370 habitants, an area of $1,063 \mathrm{Km}^{2}$ and population density of $69.0 \mathrm{hab} / \mathrm{Km}^{2}$.
} 
current capabilities, increase awareness about environmental issues, or undertake more sustainable management approach to forestry was found.

The physical resources were relatively few: the local infrastructure consisted of a primary school building, a small video room that was used for communal activities, and a stall. Two system solar panels were used, one deployed on the roof of the video room and the other on the roof of the one room-school building.

Furthermore, there was a communal warehouse or leisure facilities that did not count with any source of electricity. The main access road connecting to the closest main town of Guinía was found to be in bad condition.

In terms of natural resources, water sources availability is limited. The main resource relevant to produce energy is solar radiation. Persistent drought has affected the farming production, and caused impoverishment and desertification of land.

Human capital however showed high indicators (if compared to other rural areas of developing countries) A large proportion of the residents completed primary school $64.8 \%$; a quarter of the total population $(24.3 \%)$ attended secondary school; and $5 \%$ had some type of technical training, with women having the lowest attainment in professional skills. This educational profile is quite similar to other rural communities of Villa Clara province. Human capital is high compared to other isolated oriental rural communities in oriental region of the country.

All recollected information was used in SURE-DSS to find the energy technology that may provide Las Calabazas electricity demanding. The list of supply options, proposed by SURE, is shown in Table 6.3. 


\begin{tabular}{|l|c|c|}
\hline Technology options names & Capacity $(\mathbf{k W})$ & Efficiency \\
\hline Current energy supply & 0.6 & 30.0 \\
\hline Solar Thermic & 4.38 & 20.0 \\
\hline Diesel generator & 10.0 & 70.0 \\
\hline Biogas & 4.38 & 60.0 \\
\hline Grid & 4.38 & 96.0 \\
\hline Biomass oven & 4.38 & 10.0 \\
\hline Silicon photovoltaic & 4.38 & 18.0 \\
\hline Thin-film photovoltaic & 4.38 & 13.16 \\
\hline Organic photovoltaic & 0.0 & 5.0 \\
\hline
\end{tabular}

TABLE 6.3 SUPPLY OPTIONS CONSIDERED IN SURE BY DEFAULT AND ITS TECHNICAL PARAMETERS

\subsubsection{Results: providing solar electricity to the community}

As discussed above, the present study focuses on the three variations of PV technologies, i.e., crystalline Silicone, thin film CdTe and organic PV. The process of technology optimization compared diesel generation, grid-connection, biogas, biomass stove, three types of photovoltaic, and the current electricity provision source in Las Calabazas (i.e, solar thermal, and two silicon solar panels).

The results produced by SURE-DSS indicate that the most appropriate solution would be connection of Las Calabazas to the national grid - which is found $4 \mathrm{Km}$ away. A very close second option is, though, solar energy. The advantage of this particular study is, however, that the system was able to score each type of photovoltaic individually. That is, while it is still possible to carry out optimization analysis using generic solar technology option (i.e., the silicon type, as discussed above) - an enriched result was obtained because the 'solar option' 
could be further qualified in three different solar technologies. The solar technologies compared very well in relation to the other technologies options for improving energy supply in Las Calabazas. Furthermore, the three solar energy variations, silicon, thin film and organic, clustered together, with ratings very similar to those obtained for grid connection between 100 and 95). The following, third best solution was won by biogas, but it was definitely distant from the three solar technologies cluster (with 65) (Figure 6.3).

SURE-DSS modelled the expected livelihoods impact that the various energy options, including the three variations of PV technologies (3), would exercise on each, financial, natural, physical, social and human, resources available in Las Calabazas. The measurements were achieved in values 0 to 1 but the figures had been normalized, 0 to 100 ( 0 is lowest, 100 highest impact, in order to compare the alternatives (see Figure 6.2).

The physical asset would be best improved if the isolated community were connected to the national grid. Yet, the impact of the second most recommended technology, i.e., solar, was strikingly positive by eliminating the dependency on buying fossil fuels (although expenses would be incurred in batteries). The lifetime of the PV modules matches well the lifetime of the electrification project (although battery replacement is required), the new installations add to the existing infrastructure, i.e., the community physical asset, which is distributed among households.

The use of solar technologies would cause that the "natural" asset would be strongly benefited. Photovoltaic approaches have the lowest environmental impact on the local area; all other alternatives have higher impact on the natural asset, although impact on landscape may be significant and lack of maintenance of batteries may lead to leaks of toxic compounds. 
PV installations would have a considerable effect on the existing human assets in Las Calabazas. Any of the three varieties of PV could improve both access to health and education and also residents technical skills, for people learn how to use the PV systems. Increasing technical local capacity could also enhance social capital, e.g., availability of light at nights could enable more social cohesion and willingness to participate in social networks, an important feature of Cuban society.

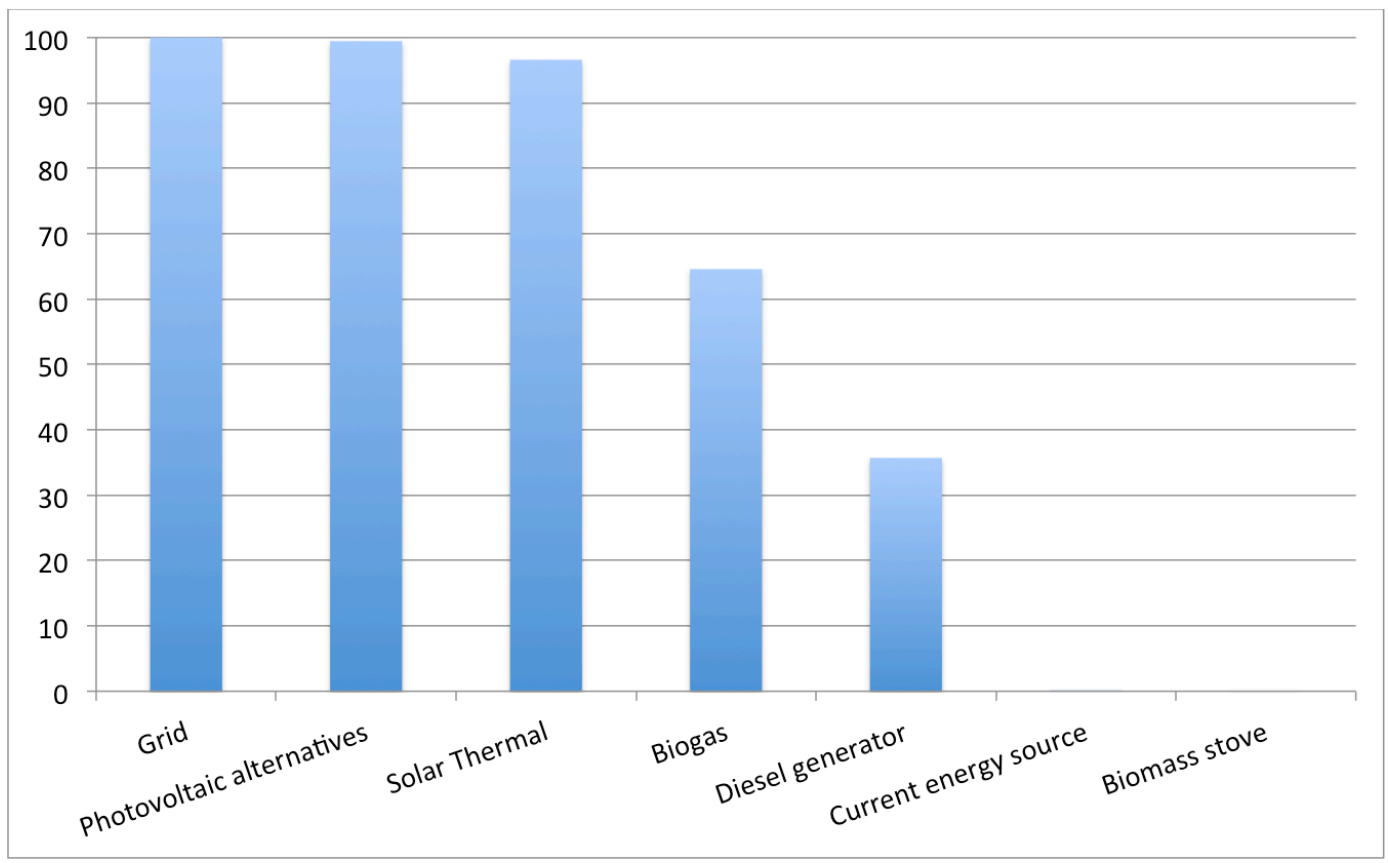

FIGURE 6.2 ENERGY OPTIONS, AS PER SURE-DSS, FOR LAS CALABAZAS, CUBA 


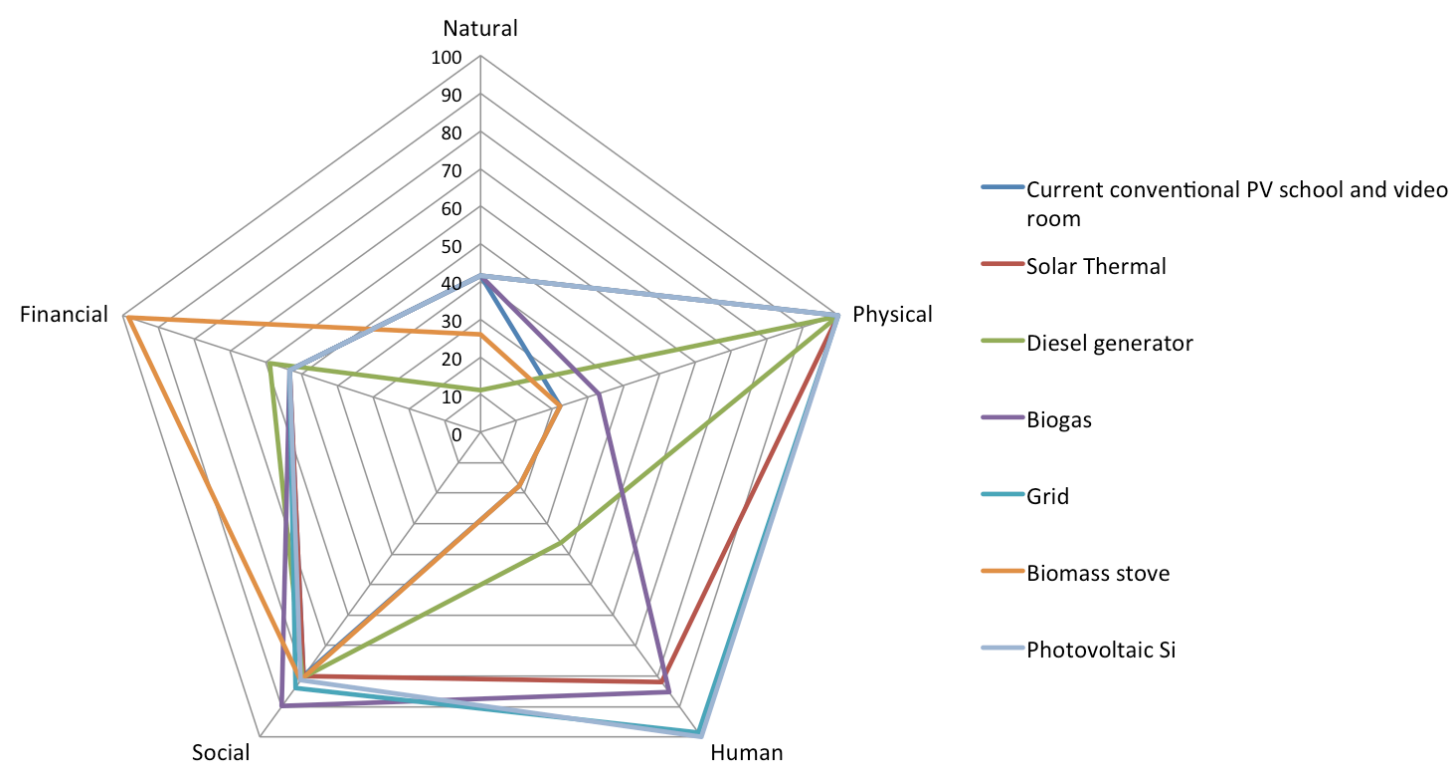

FIGURE 6.3 IMPACT OF MODELLED ENERGY TECHNOLOGIES, INCLUDING THREE PHOTOVOLTAIC TYPES, ON THE LIVELIHOODS ASSETS OF LAS CALABAZAS, CUBA

Should PV technology be installed, it could also bring about few negative impacts on the financial resources of the community, (see Figure 6.3). The investment cost per unit of installed capacity is particularly high, and construction and operation of solar systems generate only few employment opportunities. A significant policy factor is that the Cuban government pays the upfront capital related to any national grid extension. The community is therefore exempted from using financial resources - savings, salary or loans - and therefore the financial resource becomes positively impacted if grid extension were chosen. While the policy principle to enable electrification through the support of the government is correct, the same policy, if not properly qualified, could well work against the financial logic of expanding PV - or, for this matter, any other renewable energy technology - in Cuba. Significantly, Las Calabazas sits just at the boundary of what would be cost effective to extend the national grid. If the distance from the 
community to the grid were longer than $4 \mathrm{~km}$, the output that SURE would have delivered would have been different and definitely in favour of solar technology, i.e., any of the PV clustered options.

On the other hand, global impacts of different PV technologies were found, as Figure 6.4 shows. The Energy Pay Back Time (EPBT) of organic photovoltaic is the lowest; requiring only four months to produce the energy was used in its manufacture. Nevertheless, its surface requirement is the biggest due to its low efficiency. CdTe requires more surface than c-Silicon, but the EPBT is lowest and the $\mathrm{CO}_{2}$ avoided emissions are greater. The final decision about which photovoltaic technology choose will depend on the community priority and resources. The amount of avoided $\mathrm{CO}_{2}$ emissions change when other manufacturing country is selected, nevertheless the relation between them are the same; being organic PV the major $\mathrm{CO}_{2}$ saving. Denmark is the country with most saving $\mathrm{CO}_{2}$ emissions when PV modules are manufacture there. 


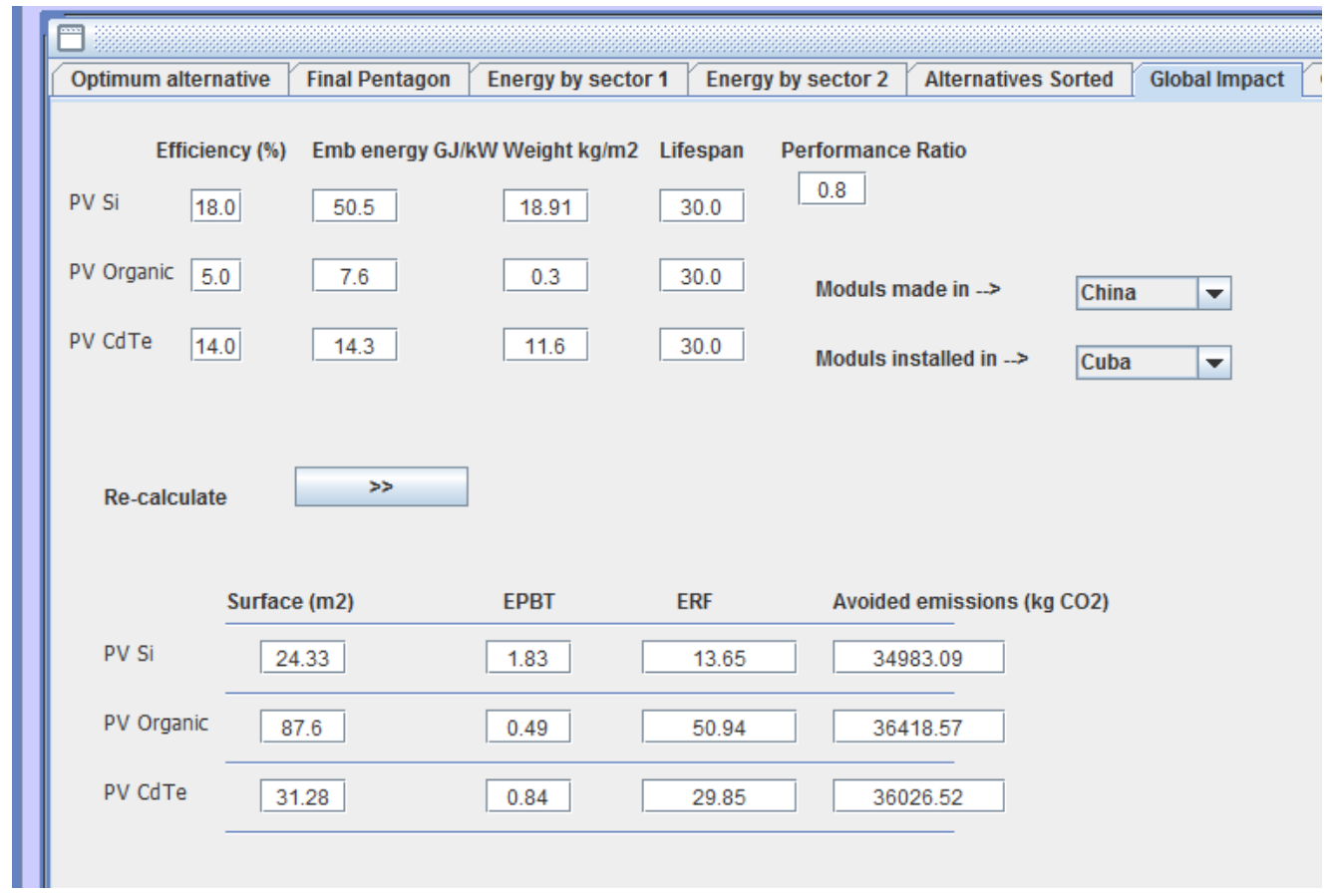

FIGURE 6.4 GLOBAL IMPACTS RESULTS ON PHOTOVOLTAIC TECHNOLOGIES AND ITS GEOGRAPHICAL DEPENDENCE.

\subsection{Conclusions}

When the objective is not just to supply energy to rural poor communities in developing countries, but to also improve their livelihoods and mitigate global $\mathrm{CO}_{2}$ emissions, the selection of appropriate energy source is more complicated. The SURE-DSS tool was designed to address these concerns: the SURE tool has the advantage that selecting energy technologies is just the beginning of the process of increasing energy access. Its optimization capability builds on the capacity to also calculate how livelihoods may be improved and less global environmental damage caused by the choice of technology. This study demonstrates that appropriate and effective renewable energy technology can address these two apparent conflictive objectives and that to reach an optimum choice, mitigation analysis was crucial. 
The multi-criteria decision support tool (SURE-DSS) was tested for the Las Calabazas in Cuba.

It ascertained that, although connection to the national grid emerges as the first most suitable technical solution, solar energy technology is a most realistic and cleaner option for this small remote and scattered community. Providing that the energy mix in Cuba emits a significant amount of equivalent $\mathrm{CO}_{2}$ emissions, grid extension to Las Calabazas cannot benefit the global environment - in fact, the impact is negative in terms of emissions.

With a focus on photovoltaic, while most modelling studies and tools refer to a generic solar technology, SURE-DSS has also the capacity to differentiate among three types of solar technologies, crystalline sillicone, thin film and organic solar. The differentiating criteria used here are rooted in life-cycle analysis, i.e., manufacturing materials, embedded energy, related $\mathrm{CO} 2$ emissions, energy paidback time and energy return factor.

The livelihoods impact analysis indicated that any one of the three PV technologies would equally provide for the community's demands and therefore were clustered nearby in Figure 6.2.

The SURE-DSS mitigation analysis provided the insight needed to select the most appropriate option to contribute to low carbon society. Whereas livelihoods analysis considers local conditions and priorities, global parameters were used to undertake the enriching mitigation analysis.

It was through the mitigation analysis that clear and more precise differences could be spotted among the three solar options, e.g., Energy Pay Back Time ranging from 1.86 years for Si-PV to 0.5 years for organic PV, or Energy Return Factor from 16 to 60 respectively. It is only when local sustainable livelihoods 
assessment is complemented with global mitigation impact that different potentials of solar technologies for climate change mitigation is realized. The software SURE-DSS makes that the choice of an optimum solution is more informed. It enables to ascertain local livelihoods improvement of the rural poor in developing countries as well as defining the global mitigation impact of the same technology.

\subsection{References}

Alsema, E.A., 2000. Energy pay-back time and CO2 emissions of PV systems. Prog. Photovolt. Res. Appl. 8, 17-25.

André Mermoud, Michel Villoz, Julien Rosener, Sylvain Pepoli, 2013. PVSYST Photovoltaic Software [WWW Document]. URL http://www.pvsyst.com/en/ (accessed 10.18.13).

Chaurey, A., Ranganathan, M., Mohanty, P., 2004. Electricity access for geographically disadvantaged rural communities - technology and policy insights. Energy Policy 32, 1693-1705.

European Photovoltaic Technology Platform, 2007. A Strategic Research Agenda for Photovoltaic Solar Energy Technology. European Communites, Belgium.

Henao, F., Cherni, J.A., Jaramillo, P., Dyner, I., 2012. A multicriteria approach to sustainable energy supply for the rural poor. Eur. J. Oper. Res. 218, 801-809.

Judith A. Cherni, Antonio Urbina, Raul F. Olalde, Lucía Serrano-Luján, Felipe Henao, 2013a. Mitigation capacity of renewable energy for rural livelihoods - the case of photovoltaics. Work Prog.

Judith A. Cherni, Nicole Kalas, 2010. A Multi-criteria Decision-Support Approach to Sustainable Rural Energy in Developing Countries, in: Jain, L.C., Lim, C.P. (Eds.), Handbook on Decision Making, Intelligent Systems Reference Library. Springer Berlin Heidelberg, pp. 143-162.

Judith A. Cherni, Raul Olalde Font, Antonio Urbina, Lucía Serrano-Luján, Felipe Henao, 2013b. Photovoltaic technologies for rural livelihoods and the global 
environment - A multi-criteria system. Presented at the EUK2013, Proceedings of the EuropeanUnion/Korea2013 Conference on Science and Innovation, Brighton, United Kingdom.

Jungbluth, N., 2005. Life cycle assessment of crystalline photovoltaics in the Swiss ecoinvent database. Prog. Photovolt. Res. Appl. 13, 429-446.

Kato, K., Hibino, T., Komoto, K., Ihara, S., Yamamoto, S., Fujihara, H., 2001. A life-cycle analysis on thin-film CdS/CdTe PV modules. Sol. Energy Mater. Sol. Cells 67, 279-287.

Knapp, K., Jester, T., 2001. Empirical investigation of the energy payback time for photovoltaic modules. Sol. Energy 71, 165-172.

Krauter, S., Rüther, R., 2004. Considerations for the calculation of greenhouse gas reduction by photovoltaic solar energy. Renew. Energy 29, 345-355.

Mulugetta, Y., Doig, A., Dunnett, S., Jackson, T., Khennas, S., Rai, K., 2002. Energy for rural livelihoods. ITDG, London.

Peter Lilienthal, Marilyn Walker, Jack Sinclair, Ed Sanders, 2013. HOMER Energy - Hybrid Renewable and Distributed Power Design Support [WWW Document]. URL http://homerenergy.com/ (accessed 10.18.13).

Raugei, M., Bargigli, S., Ulgiati, S., 2007. Life cycle assessment and energy payback time of advanced photovoltaic modules: CdTe and CIS compared to poly-Si. Energy 32, 1310-1318.

REN21, 2011. Renewables 2011: Global Status Report. Paris.

Stockholm Environment Institute SEI, 2013. LEAP: Long-range Energy Alternatives Planning System [WWW Document]. URL http://seius.org/software/leap (accessed 10.17.13).

United Nations Development Programme, 2013. Human Development Reports (HDR) [WWW Document]. URL http://hdr.undp.org/en/ (accessed 11.28.12).

United Nations Development Programme UNDP, 1999. Energy as a Tool for Sustainable Development; For ACP Countries. 


\section{Chapter 7}

\section{CONCLUSIONS}

Photovoltaic technologies are an important tool to mitigate climate change. An appropriate methodology is needed in order to assess PV environmental impacts and therefore to provide a qualitative assessment in each case about the real impact of solar electricity on climate change mitigation. This thesis dissertation focuses on the development of such methodology and its application to specific issues in different levels: grid-connected building integrated systems, rural electrification systems and its global environmental impacts.

Different data sets were used during the development of the studies: literature review, experimental data acquisition system (monitoring system), public access to data bases, and field survey using a questionnaire. These ways of gathering information have been applied to different case studies.

This chapter presents the conclusions of the thesis:

- LCA of PV technologies as proof of their sustainability. BIPV advantages.

Photovoltaic technologies have an EPBT in ranges between few months and up to 3 years depending on the technology and the performance of the system. Thus, 1 $\mathrm{kWp}$ of CdTe building integrated was studied in this thesis and an EPBT of 2.06 years was obtained, while organic PV modules are being developing (it is not in market yet) has an EPBT of 0.8 years.

The embedded energy has been improved last years and it is being improved in current developed research worldwide. The conclusions of all studies in this line are the same: photovoltaic technology is a sustainable energy whose initial 
economic and energy investment worth in an energetic and sustainable way. LCA methodology enables us to quantify the environmental impact of a real PV generator, taking into account all energy and material invested in it. The BIPV system has been studied and is highlighted its configuration to avoid land-use impacts when is compared with ground-mounted PV configuration. $222 \mathrm{kWp}$ CdTe grid-connected parking integrated PV generator was studied, and its environmental impacts were compared to same-sizing ground-mounted configuration. The results indicated that, in spite of EPBT of real case is greater than ground-mounted, 2.06 and 1.42 years respectively, less environmental impacts were found in BIPV design.

- Monitoring of PV generators to control its performance

Storing information from PV generators enables the assessment of its real performance, and consequently the global environmental benefits that can be quantified as avoided $\mathrm{CO}_{2}$ emissions. Besides, each PV installation possesses a particular inverter model, PV modules type, dimensions, etc. Up to now, learning computing algorithms and fuzzy algorithms have been used to predict weather conditions, helping the prediction of PV generation from meteorological data. Nevertheless the control and performance prediction can be studied in less general way, paying attention to local PV technical parameters in real time as they are generated and monitored. This new approach helps controlling and predicting errors in inverters and PV modules. Environmental and technical parameters have been measured during last four years, and they have been stored in a database, where error-detection algorithms are being applied. These learning techniques let us to improve PV generator performance and control and have shown the capability to detect and classify failures or malfunctioning of parts of the PV system 
- Political strategies based on geographical dependence of PV technologies

Study about the dependence of environmental indicators; i.e. EPBT, ERF and amount of avoided $\mathrm{CO}_{2}$ emissions, results crucial to choose the less polluting route manufacturing-country and country where $P V$ will be installed. Looking at current market, these kind of environmental parameters are not taking into consideration, but the main guide is economical factors.

Countries with very clean electricity mix, as Brazil and Colombia, stand out as ideal manufacturing PV countries, while countries with high yearly average irradiation and dirty electricity mix are highlighted as ideal places where install PV generators, as South Africa, Australia, Cuba, India and West China.

- Sustainable energy to supply isolated livelihoods

SURE-DSS is useful software to assess energy technologies. SURE-DSS was applied to evaluate the best electricity option to supply the demand of a rural livelihood in Cuba, which resulted in the best renewable alternative in order to bring about less environmental damage, but taking into account other four assets apart of natural: financial, physical, human and social. Global environmental impact of three PV technologies and its geographical dependence were added to SURE, facilitating the decision on choose the PV technology less polluting, less surface-demanding or an average of both.

\section{Summary of conclusions}

The main achievement of this thesis has been to establish a methodology based on computing tools and data gathering from different sources, which combines 
analysis of technical, environmental and socio-economical data and enables to evaluate the potential for climate change mitigation of photovoltaic systems. The methodology goes beyond standard Life Cycle Analysis including a multidisciplinary approach that aims to evaluate the sustainability of the photovoltaic systems. The methodology has been tested in different case studies, such as the analysis of the environmental impact of photovoltaic real installation at Murcia, measuring the environmental advantages of BIPV configuration; the study the geographical dependence of the environmental impact of $1 \mathrm{kWp}$ of three PV technologies; i.e. organic, c-Si and CdTe (thin-film) emphasizing that the selection of an optimal combination of geographical location where the modules are manufactured and where the modules are installed can vary the environmental impact up to a factor of 20 , resulting in several tones of avoided $\mathrm{CO}_{2}$; and finally evaluating PV technology as an electricity supply option for isolated rural settlement in Cuba.

\section{Future work}

During the last decade, photovoltaic markets have grown in countries where policy and economic strategy has supported these technologies and had provided the resources needed to this purpose. Nevertheless, the result of this study has discovered that the best combination of geographical locations of manufacturinginstalled countries matching, whose $\mathrm{CO}_{2}$ avoided emissions are optimal, are quite different to the real market (as it has been in 2012). A deeper analysis will be made in order to study $\mathrm{CO}_{2}$ projected emissions during time, associated to manufacture and transport of PV modules, and its balance with avoided emissions due to generated energy. This analysis will show the evolution of energy mix of each country which installs a significant capacity of PV technology in its electricity grid. Comparison between PV technologies should be made as well to 
complement previous mentioned study. This evolution will also provide a varying (in time) LCA analysis for each technology and the long term solutions that have the maximum potential for climate change mitigation.

BIPV systems are highlighted as cleaner configuration than ground-mounted. New building integrated PV configuration can be studied to enhance its performance and to optimize the integration, i.e. greenhouse solar PV and industrial building integrated PV systems.

Monitored PV systems has let study in detail the performance of a real PV generator. Information (different sets of parameters, with or without meteorological data) from PV generators can be used to control and predict its performance and behaviour in real time. A deeper study can be made to develop a methodology to get this real time prediction of the performance for next hours and even days, including the detection and classification of failures or malfunctioning of components of the system. These algorithms would be presented as a userfriendly software application.

Multi-criteria decision software SURE-DSS recommends photovoltaic as best option of energy source for energy isolated settlement in Cuba. Methodologies applied in other studies on this thesis could be applied as well in Cuba if real PV generator was installed. Monitoring system could store information and computing techniques could be applied as well. In this way, the SURE-DSS recommendation as the optimum energy solution for the community could be assessed in the field including the long-term sustainability of the systems. Application of SURE-DSS to other geographical locations is also a future work. 
Chapter 7 Conclusions 
ANNEX I 


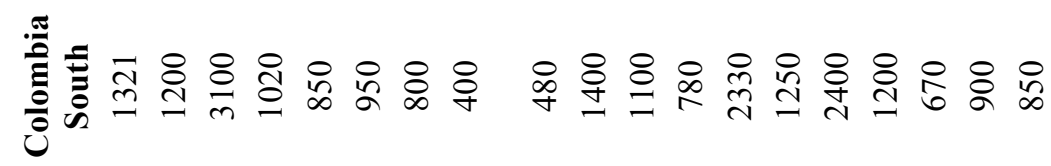

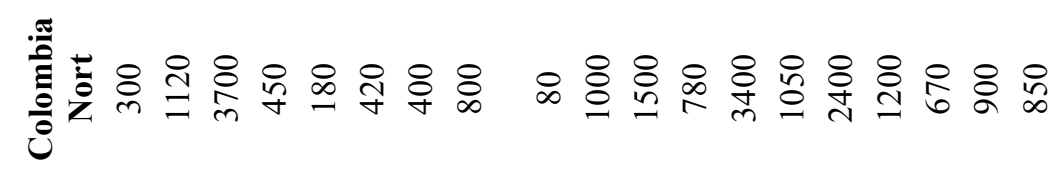

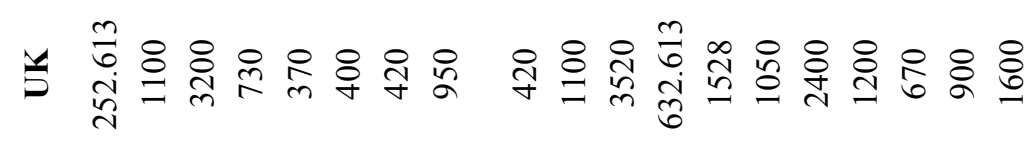

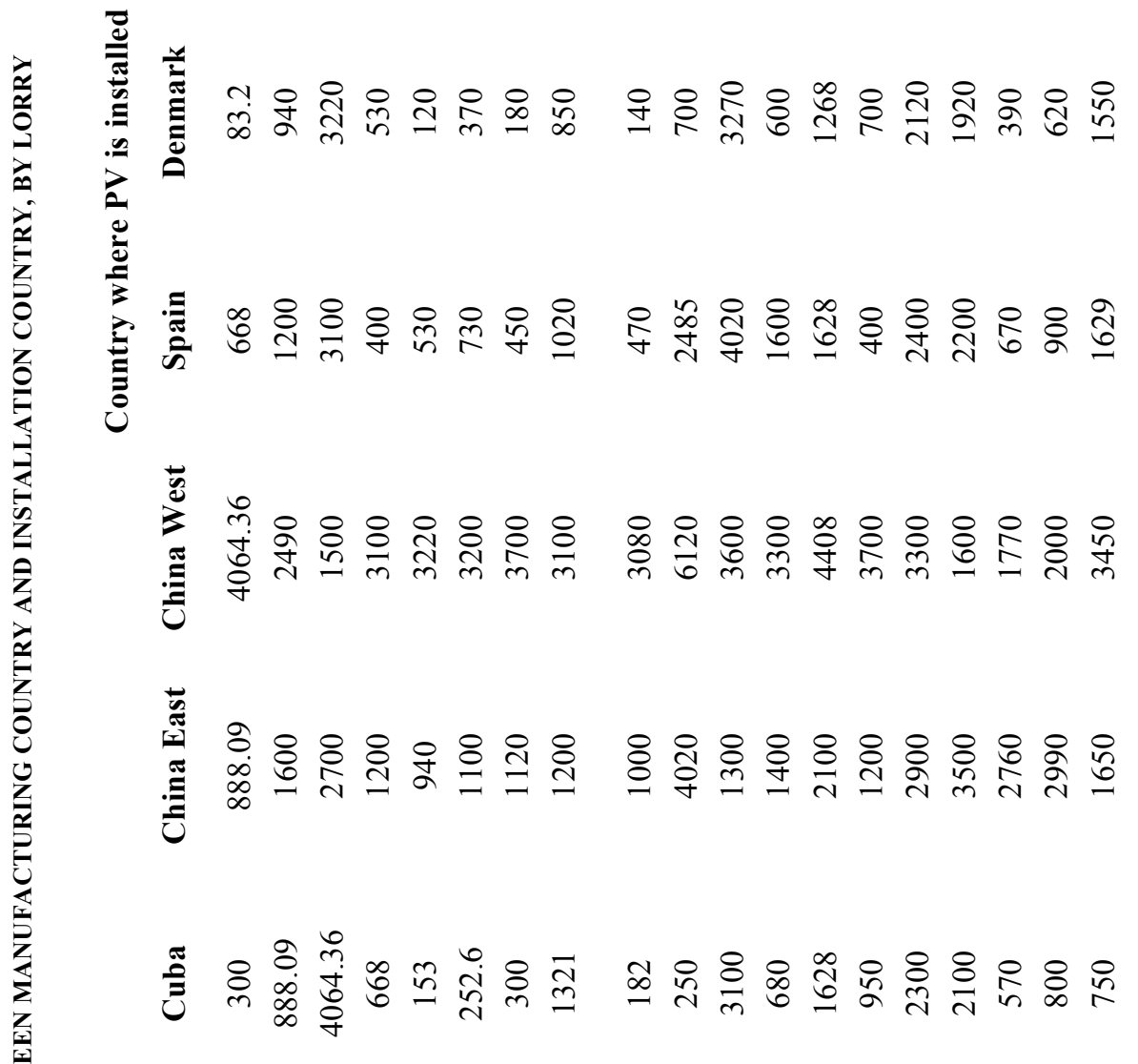

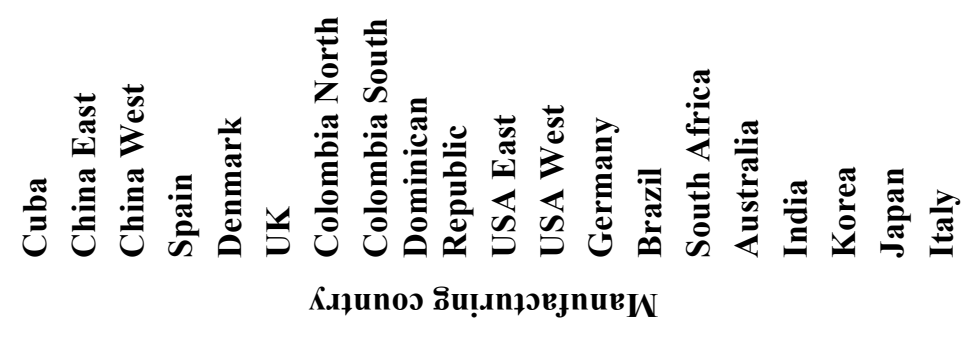




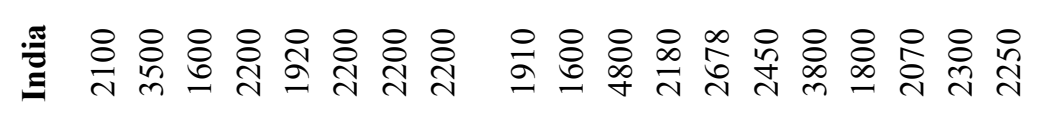

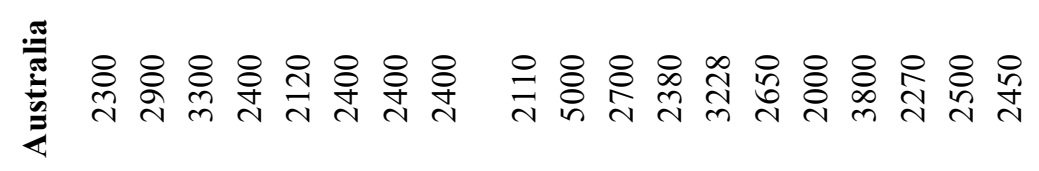

童

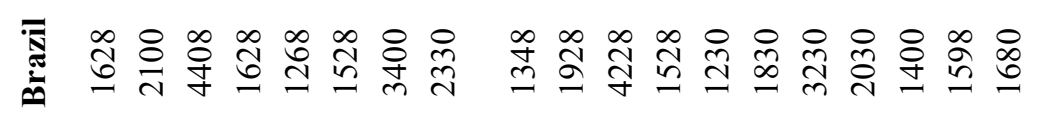

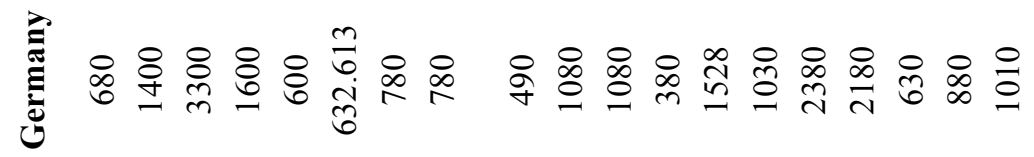

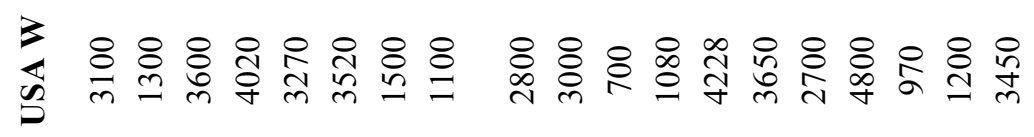

ธุ

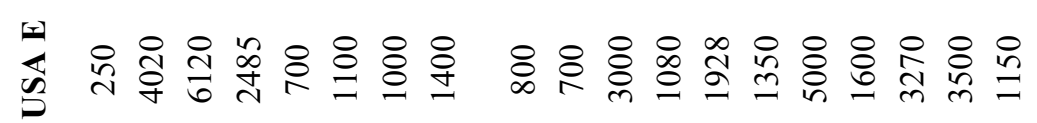

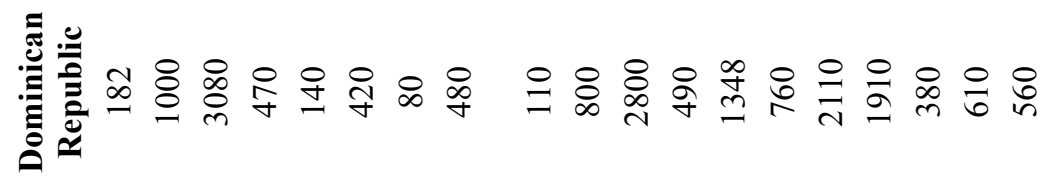

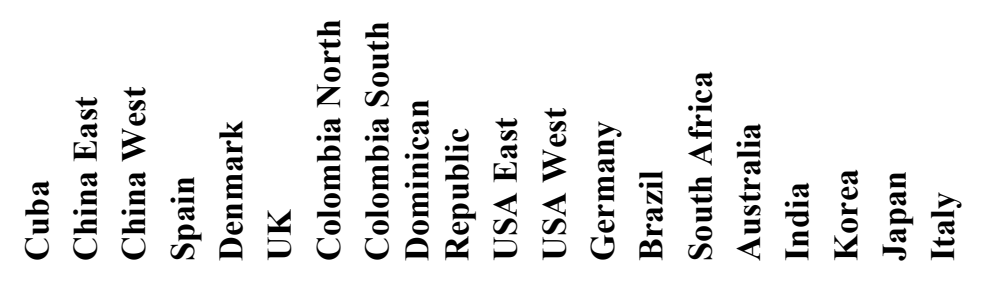

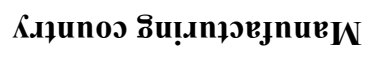


TABLE C KILOMETERS BETWEEN MANUFACTURING COUNTRY AND INSTALLATION COUNTRY, BY LORRY

\begin{tabular}{|c|c|c|c|}
\hline & \multicolumn{3}{|c|}{ Country where PV is installed } \\
\hline & Korea & Japan & Italy \\
\hline Cuba & 570 & 800 & 750 \\
\hline China East & 2760 & 2990 & 1650 \\
\hline China West & 1770 & 2000 & 3450 \\
\hline Spain & 670 & 900 & 1629 \\
\hline Denmark & 390 & 620 & 1550 \\
\hline $\mathbf{U K}$ & 670 & 900 & 1600 \\
\hline Colombia North & 670 & 900 & 850 \\
\hline $\begin{array}{l}\text { Colombia South } \\
\text { Dominican }\end{array}$ & 670 & 900 & 850 \\
\hline Republic & 380 & 610 & 560 \\
\hline USA East & 3270 & 3500 & 1150 \\
\hline USA West & 970 & 1200 & 3450 \\
\hline Germany & 630 & 880 & 1010 \\
\hline Brazil & 1428 & 1598 & 1680 \\
\hline South Africa & 920 & 1050 & 1100 \\
\hline Australia & 2270 & 2500 & 2450 \\
\hline India & 2070 & 2300 & 2250 \\
\hline Korea & 270 & 770 & 710 \\
\hline Japan & 770 & 500 & 950 \\
\hline Italy & 710 & 950 & 450 \\
\hline
\end{tabular}




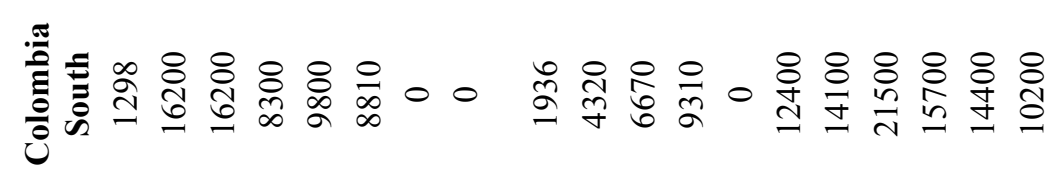

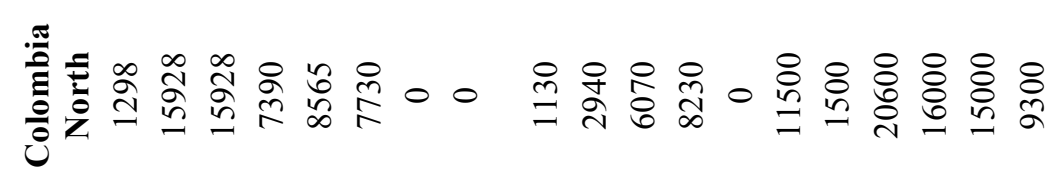

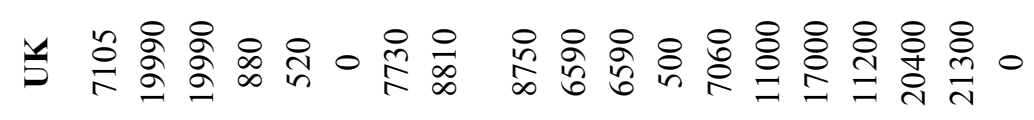

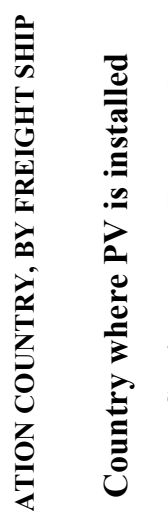

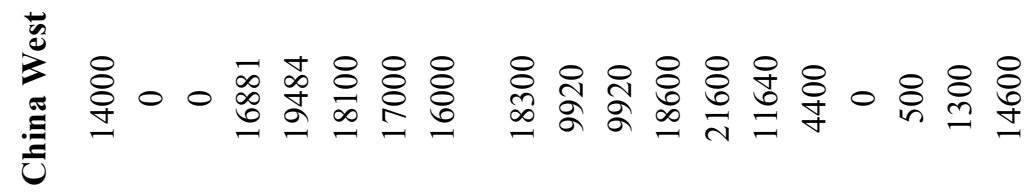

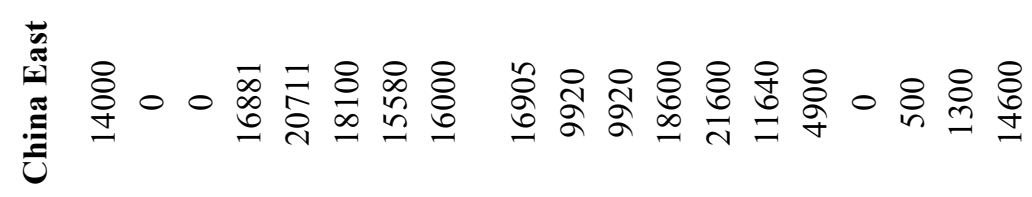

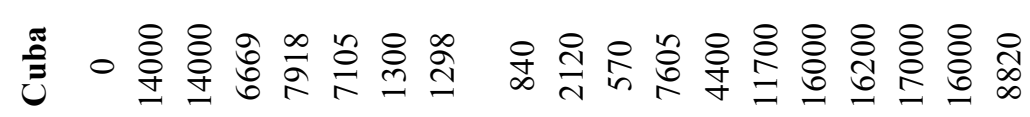

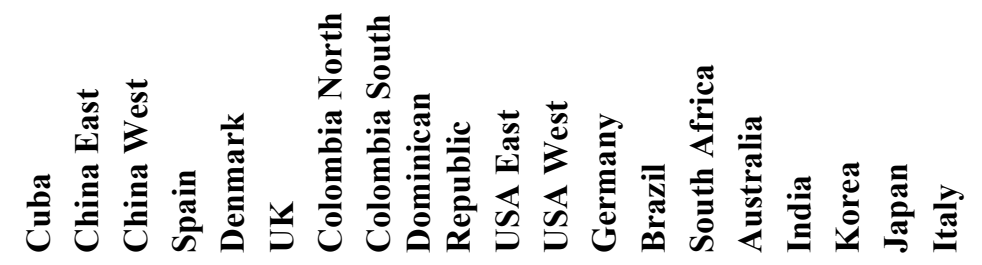

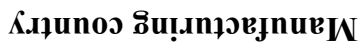




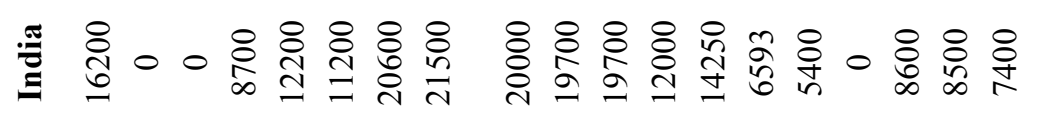

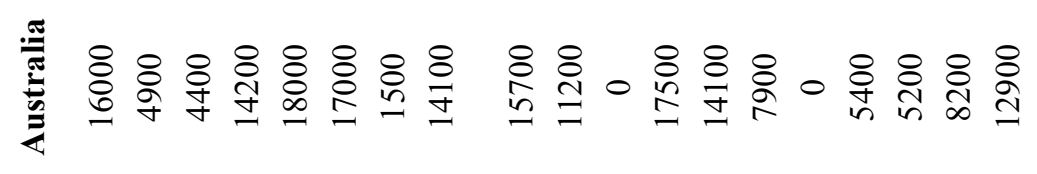

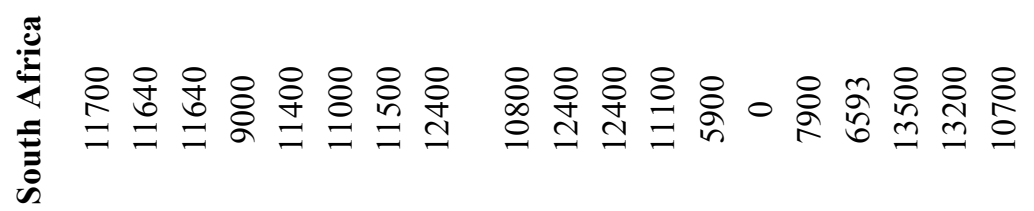

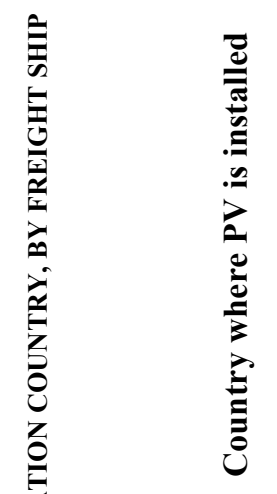

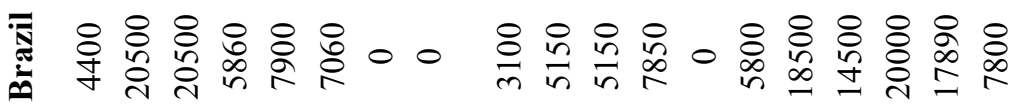

Uे

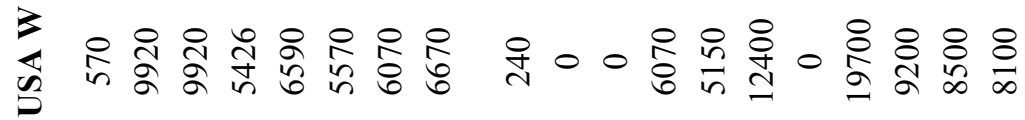

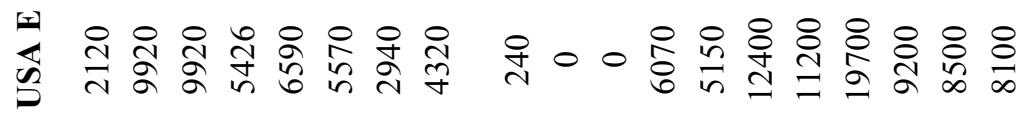

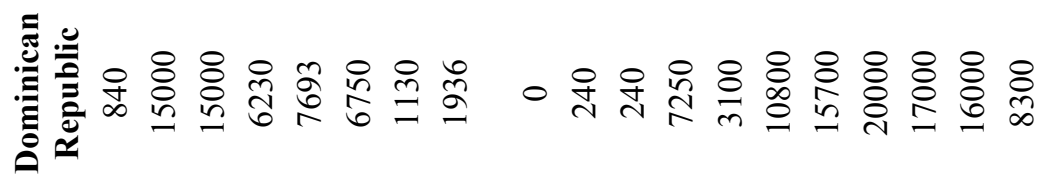

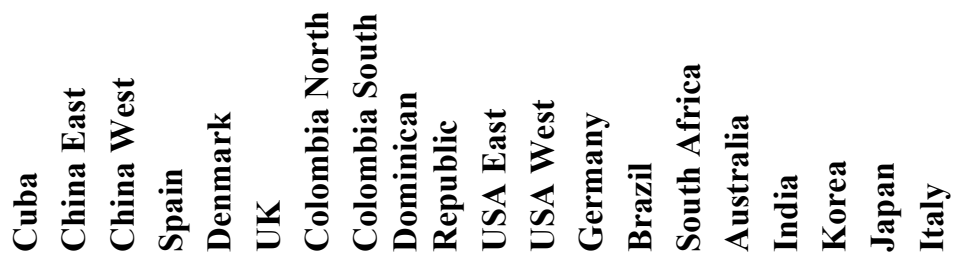

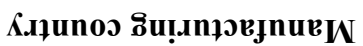


TABLE F KILOMETERS BETWEEN MANUFACTURING COUNTRY AND INSTALLATION COUNTRY, BY FREIGHT SHIP

Country where PV is installed

$\begin{array}{lccc} & \text { Korea } & \text { Japan } & \text { Italy } \\ \text { Cuba } & 17000 & 16000 & 8820 \\ \text { China East } & 500 & 1300 & 14600 \\ \text { China West } & 500 & 1300 & 14600 \\ \text { Spain } & 17800 & 19000 & 0 \\ \text { Denmark } & 21500 & 22400 & 0 \\ \text { UK } & 20400 & 21300 & 0 \\ \text { Colombia North } & 16000 & 15000 & 9300 \\ \text { Colombia South } & 15700 & 14400 & 10200 \\ \text { Dominican } & 17000 & 16000 & 8300 \\ \text { Republic } & 9200 & 8500 & 8100 \\ \text { USA East } & 9200 & 8500 & 8100 \\ \text { USA West } & 21000 & 22300 & 0 \\ \text { Germany } & 20240 & 17890 & 7800 \\ \text { Brazil } & 13000 & 13200 & 10700 \\ \text { South Africa } & 8300 & 8200 & 12900 \\ \text { Australia } & 8600 & 8500 & 7400 \\ \text { India } & 0 & 330 & 16500 \\ \text { Korea } & 330 & 0 & 16700 \\ \text { Japan } & 16500 & 16700 & 0 \\ \text { Italy } & & & \end{array}$

TABLE G INVESTED ENERGY IN $1 \mathrm{~kW}_{\mathrm{P}}$ OF PV MODULES MANUFACTURE

$\begin{array}{cc}\text { PV technology } & \text { Energy } \boldsymbol{k W h} \\ \text { Si } & 2674.81 \\ \text { Organic } & 716.51 \\ \text { CdTe } & 1222.68\end{array}$


TABLE H GENERATED ENERGY DURING LIFETIME OF $1 \mathrm{~kW}_{\mathrm{P}}$ OF PV, $\mathrm{CO}_{2}$ AVOIDED EMISSIONS DUE TO ITS PERFORMANCE AND $\mathrm{CO}_{2}$ EMITTED EMISSIONS DUE TO ITS MANUFACTURE. GEOGRAPHICAL DEPENDENCE OF MANUFACTURE PLACE AND PV TECHNOLOGY

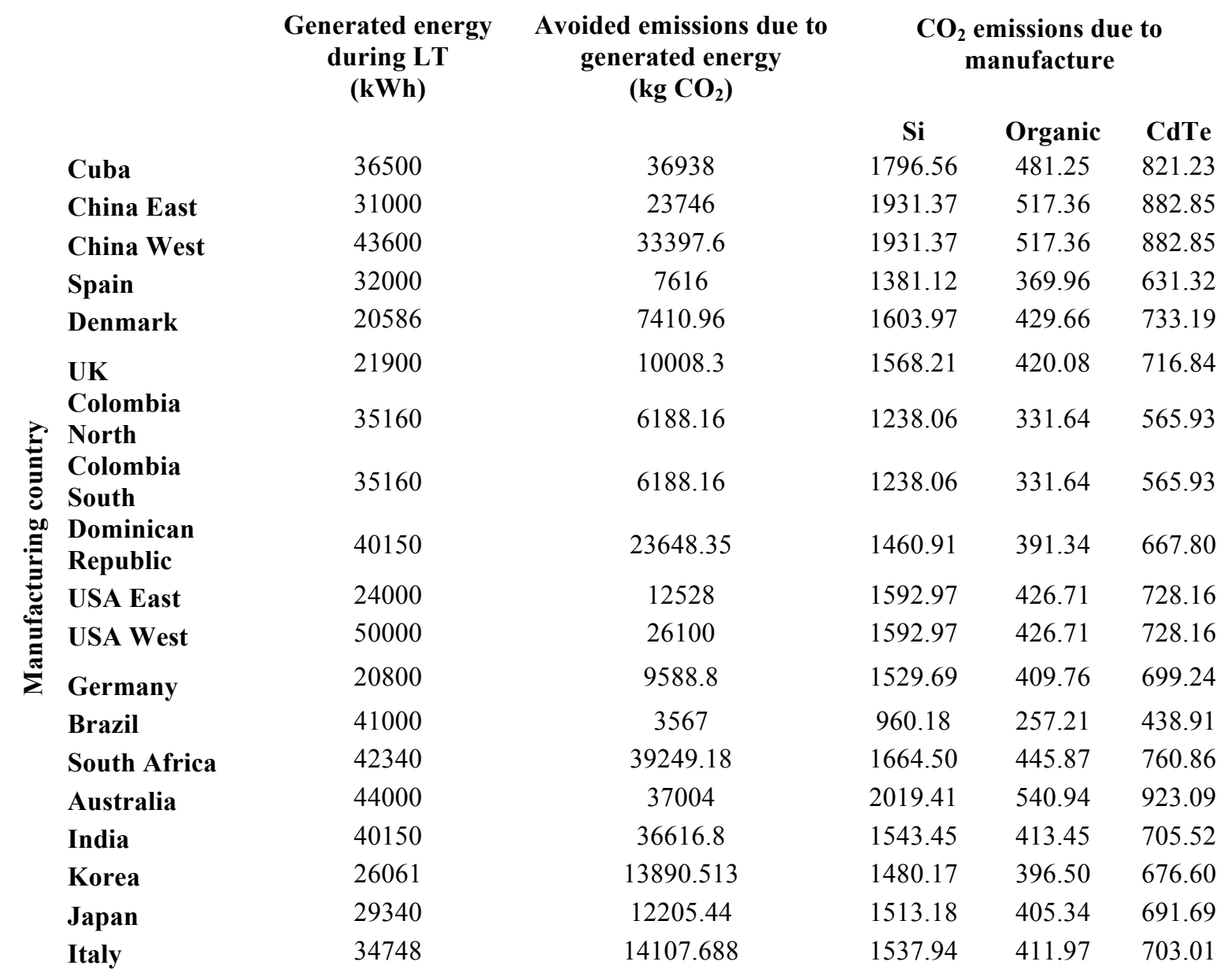


\& $\curvearrowleft$ ஸे

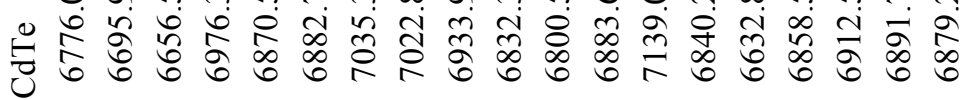

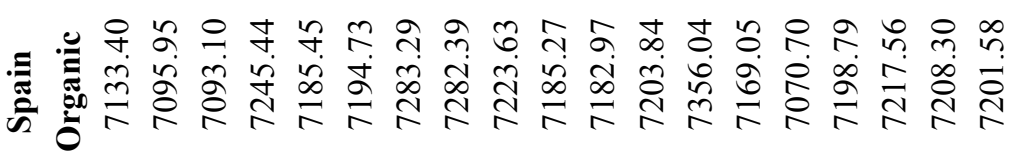

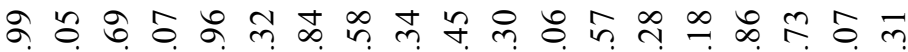

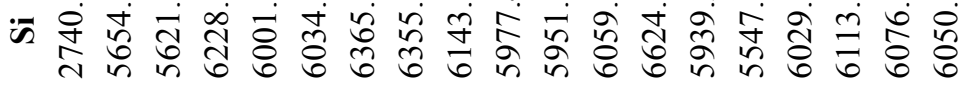
。

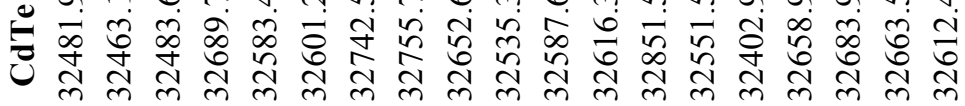

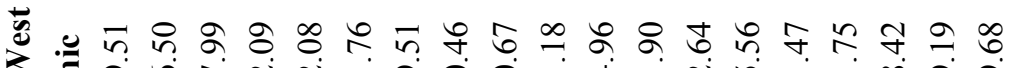

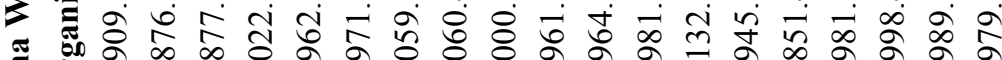

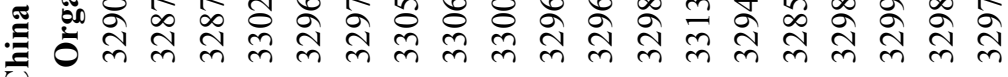
से $\infty$ \%

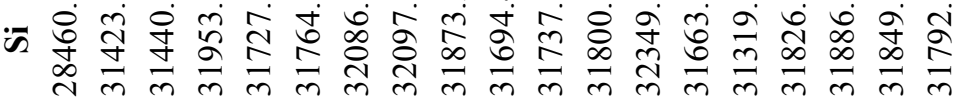
ㅎำ

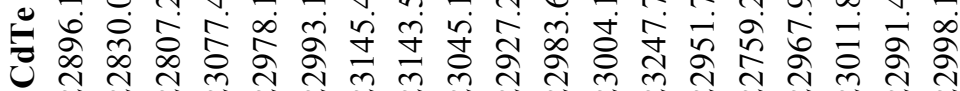
ปै ปิ

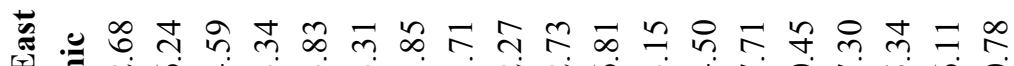
㐘

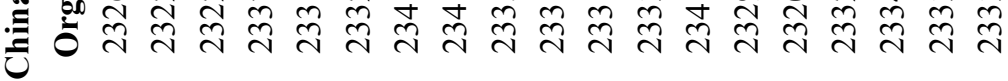

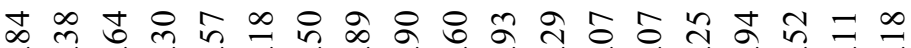
क

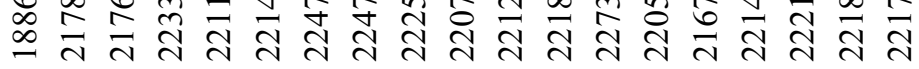
-

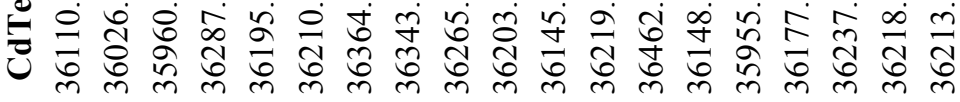

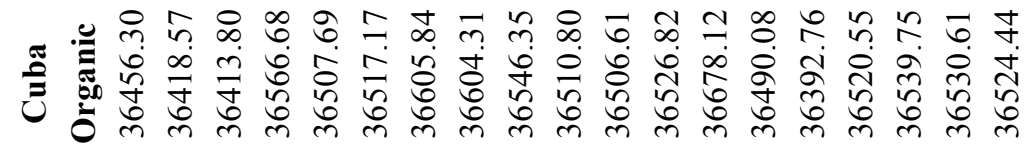

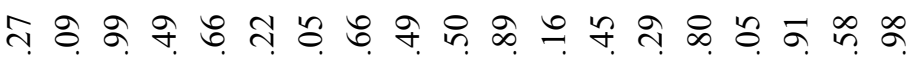

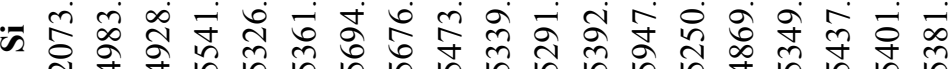

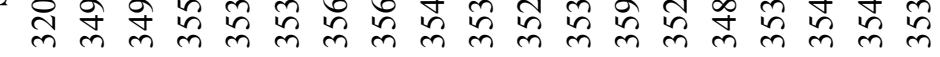

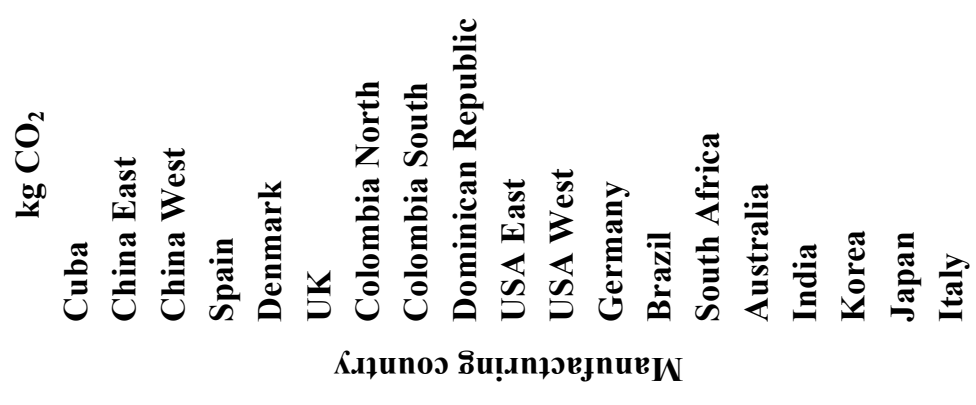




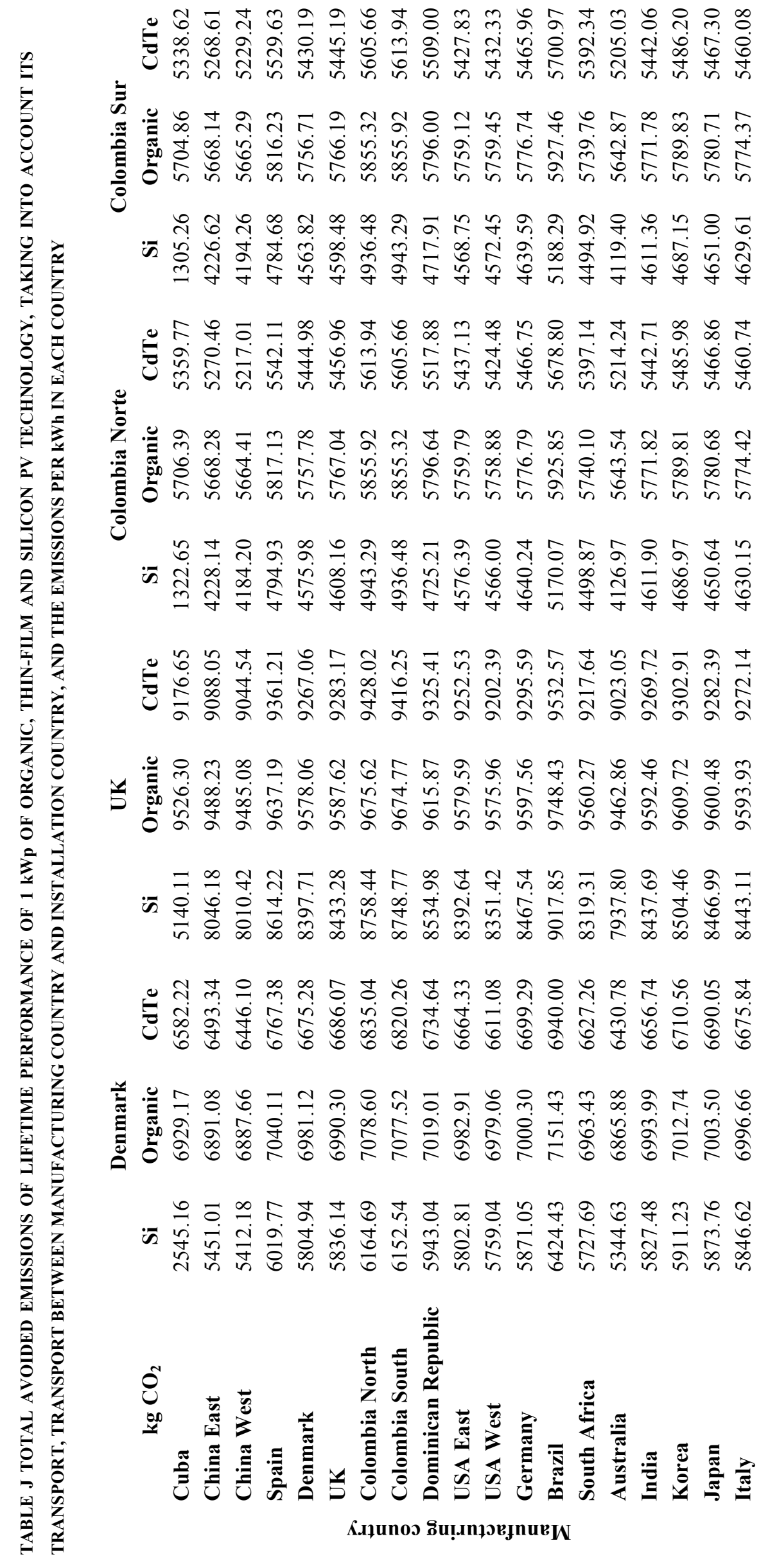




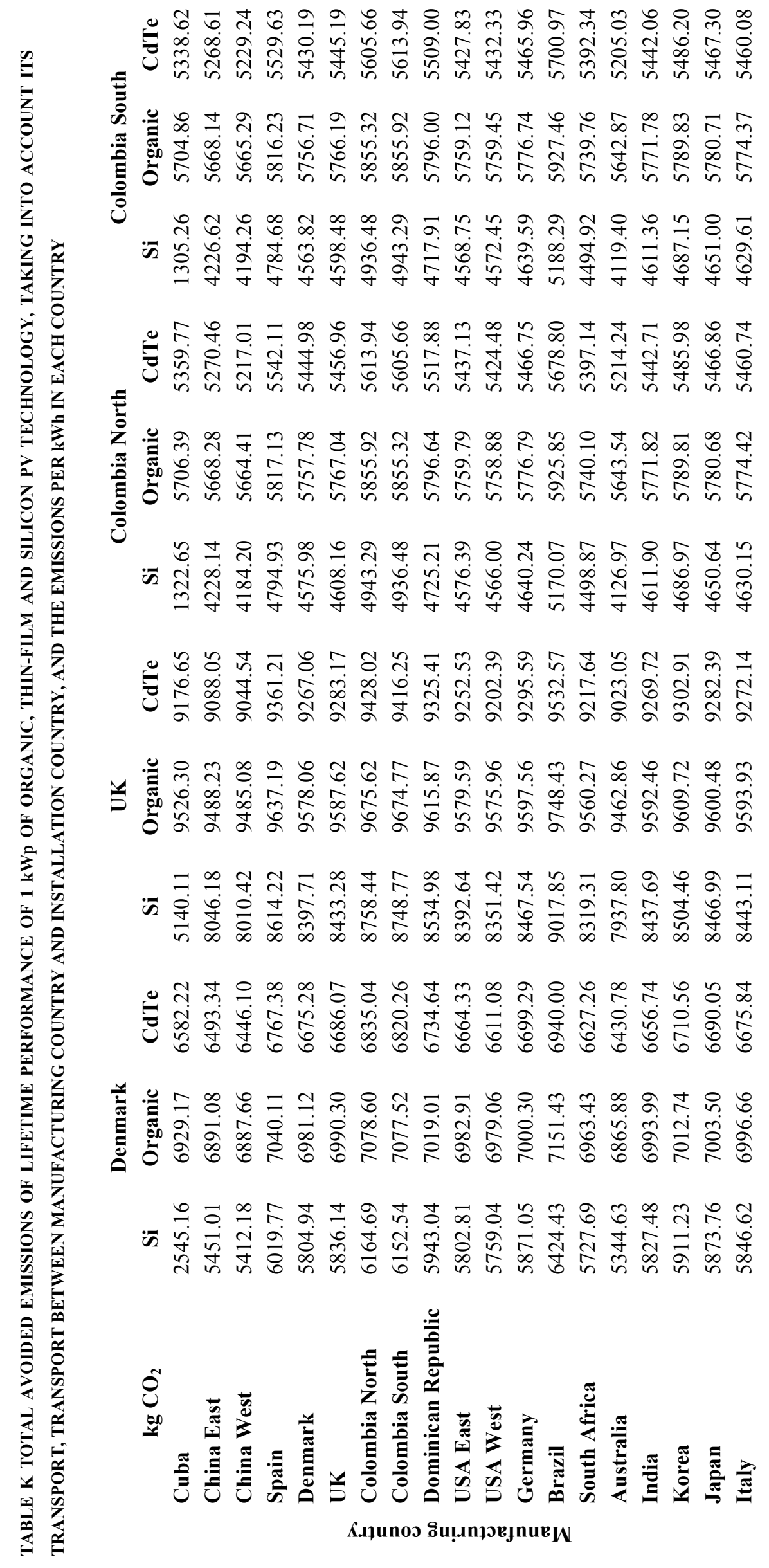


๙ุ

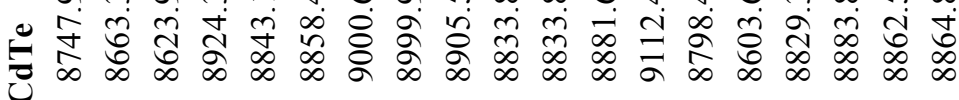

药

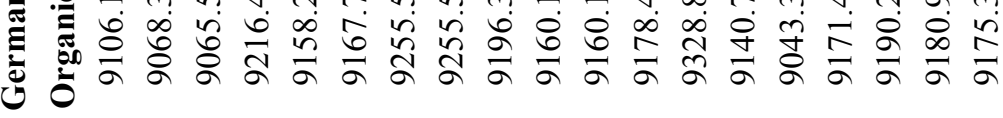

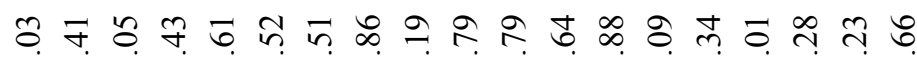

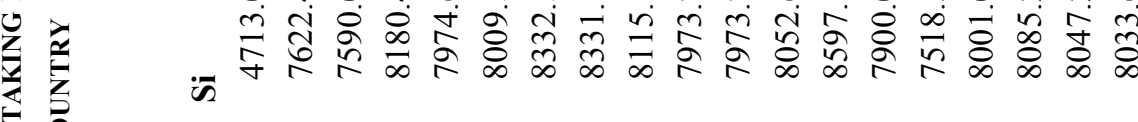

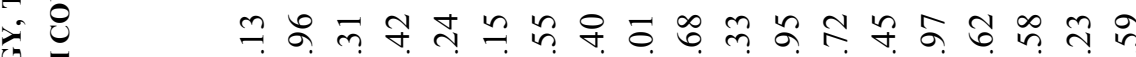

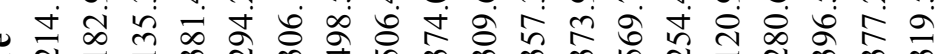

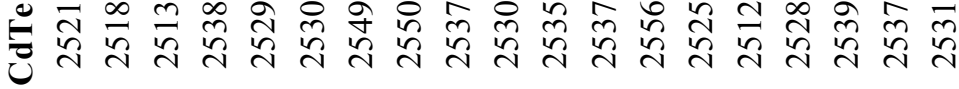

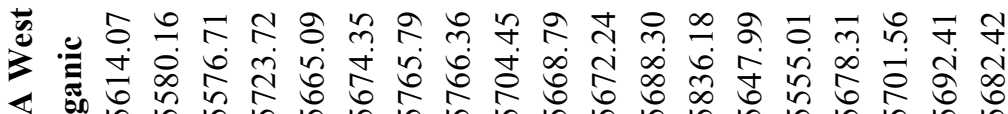

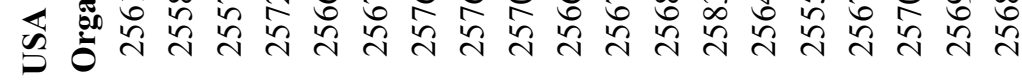
ปุ

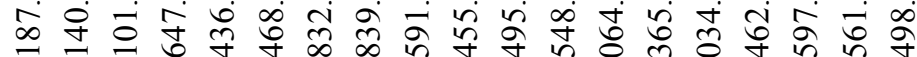

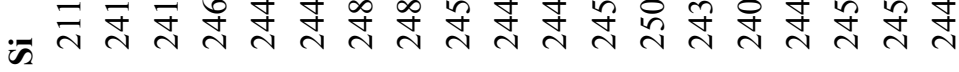

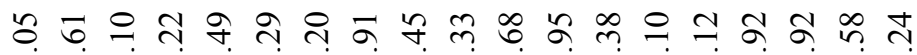
已

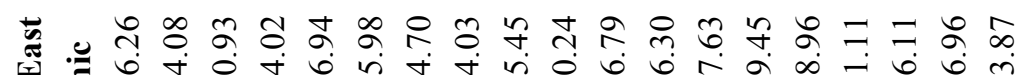
ษ

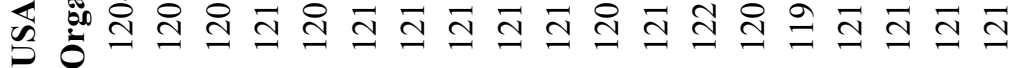

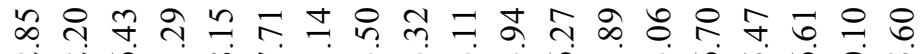

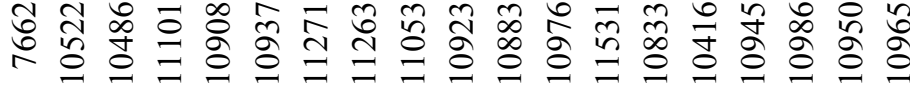
कs

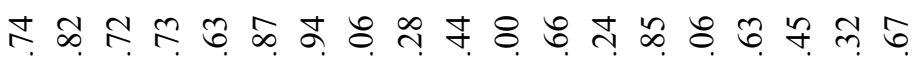

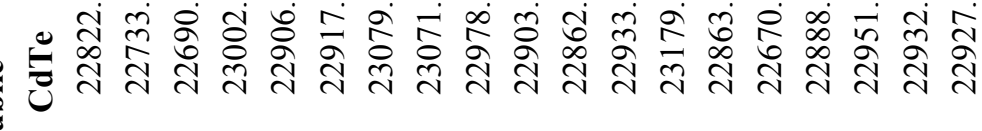
言,

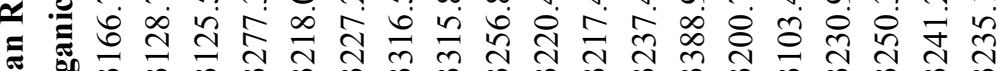
可

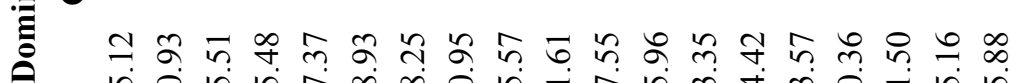

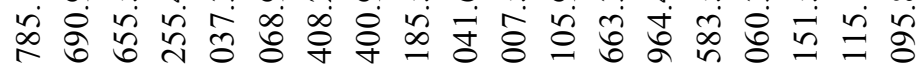
$\pi^{\infty} \bar{\lambda}$ ปे

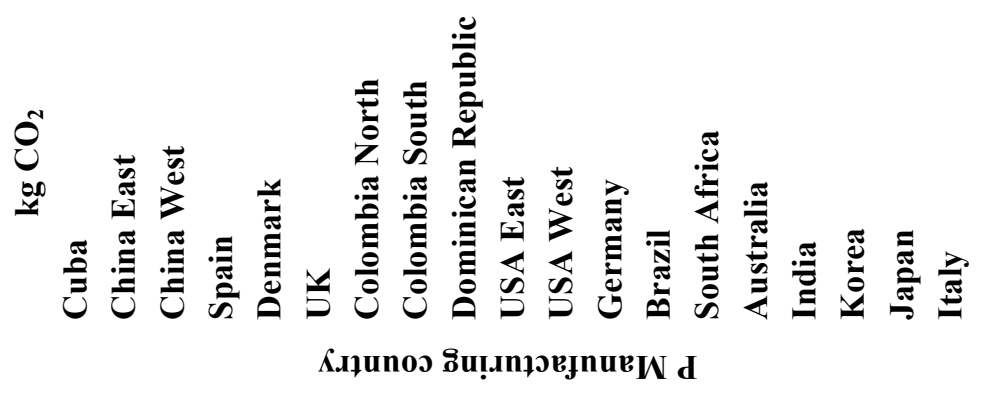




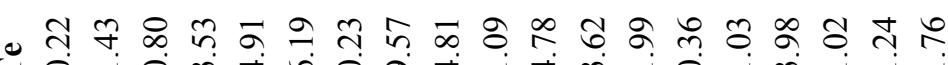

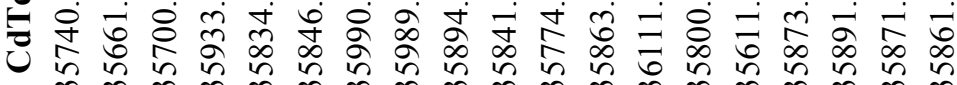
.

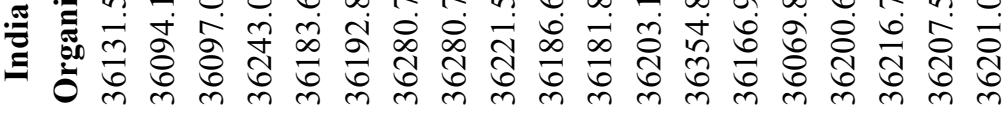

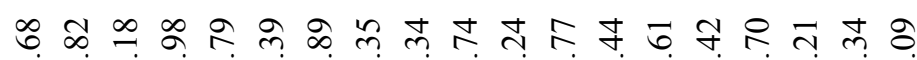

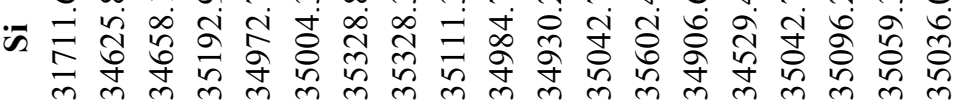

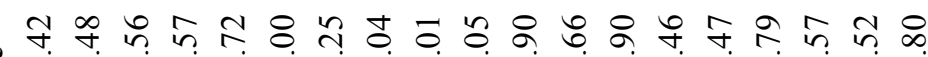

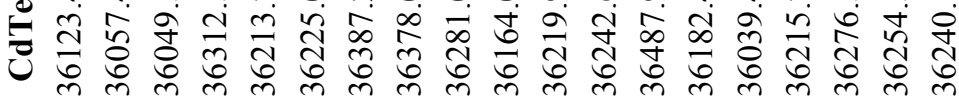
ஊ ๆ

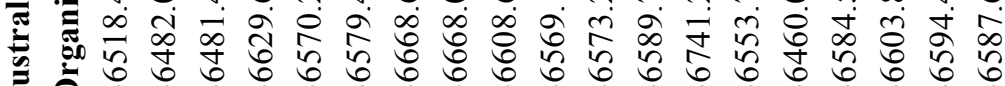

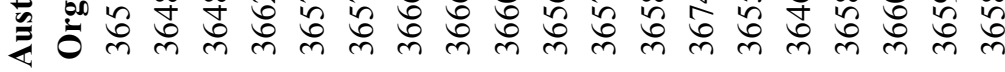

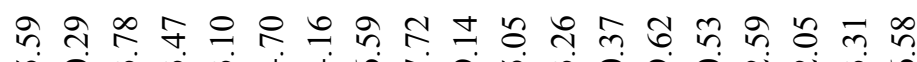
क

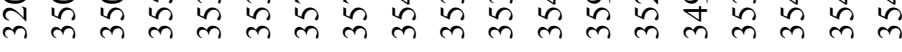

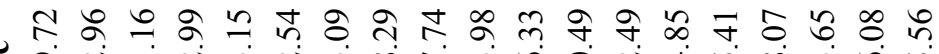

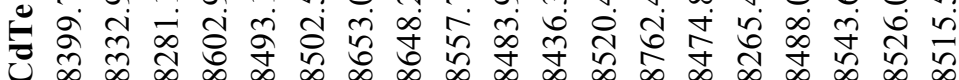

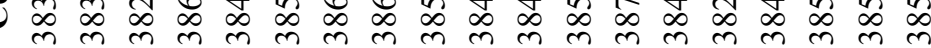

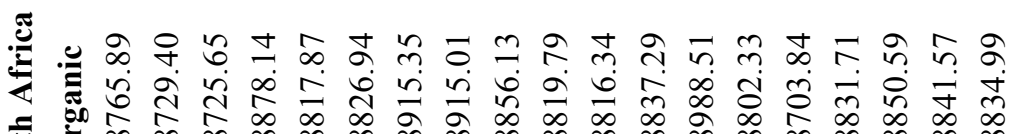

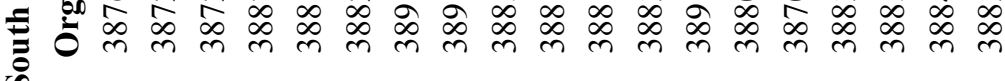

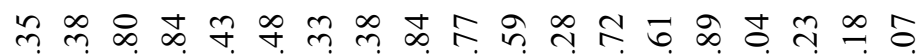

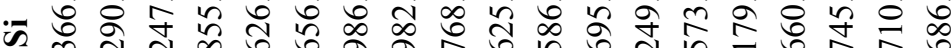

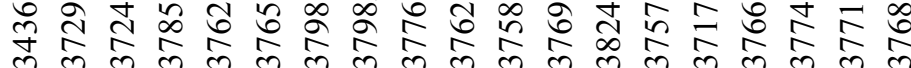
అ

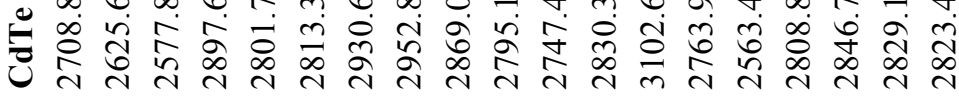

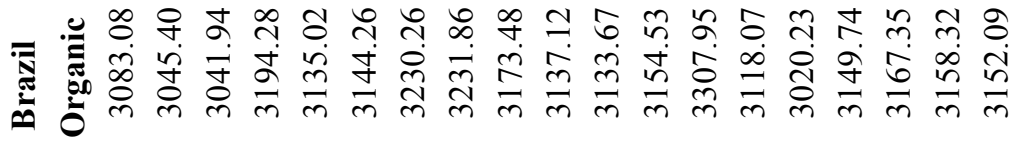

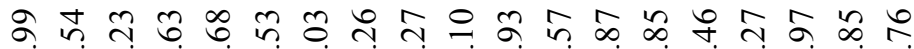

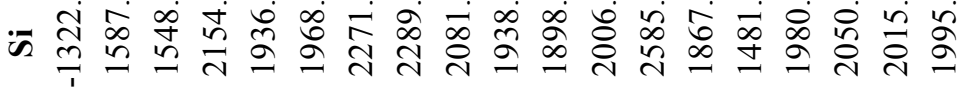

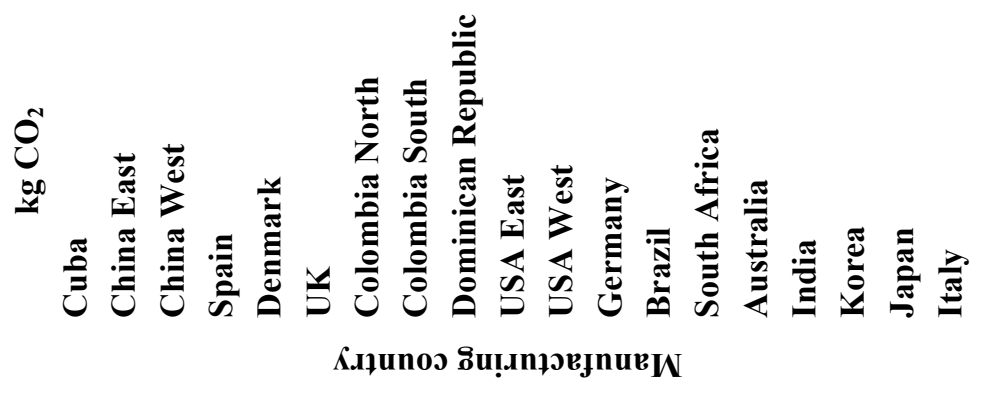


舟 $\infty$ o

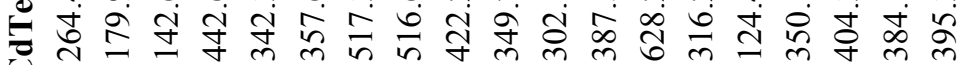

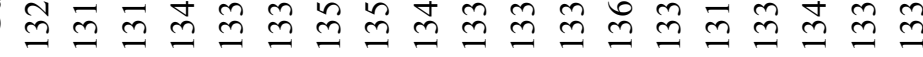

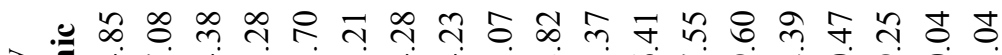

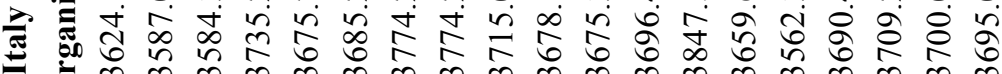

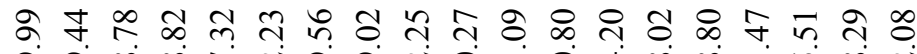

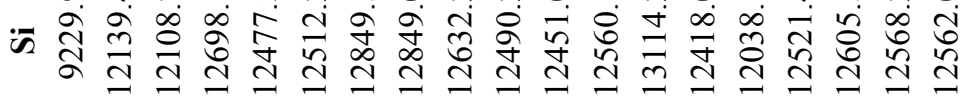

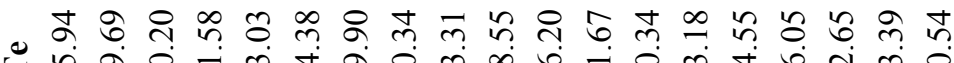

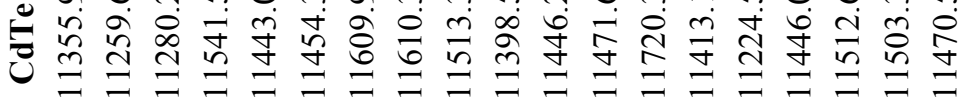

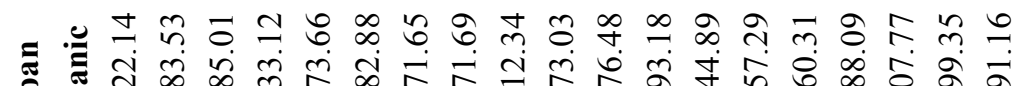
芫

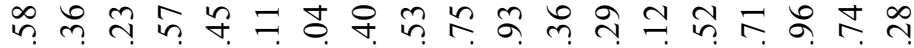
的䒕 ๑

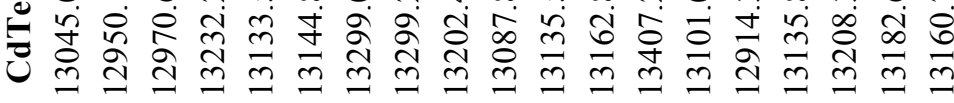
๑

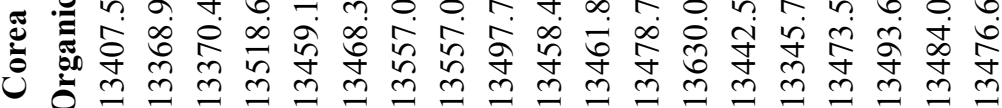
โล

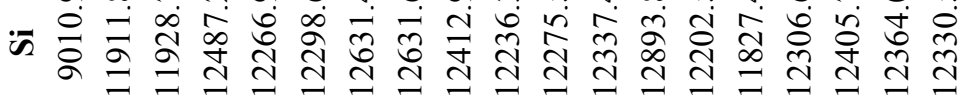

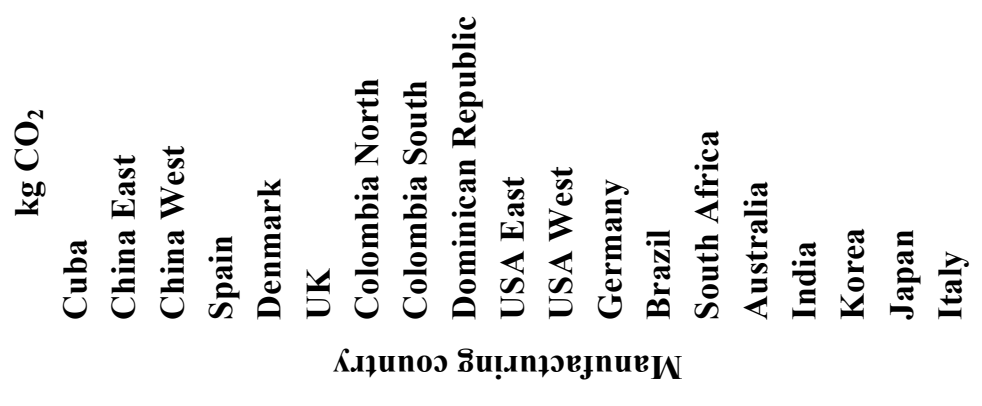


 
ANNEX II 



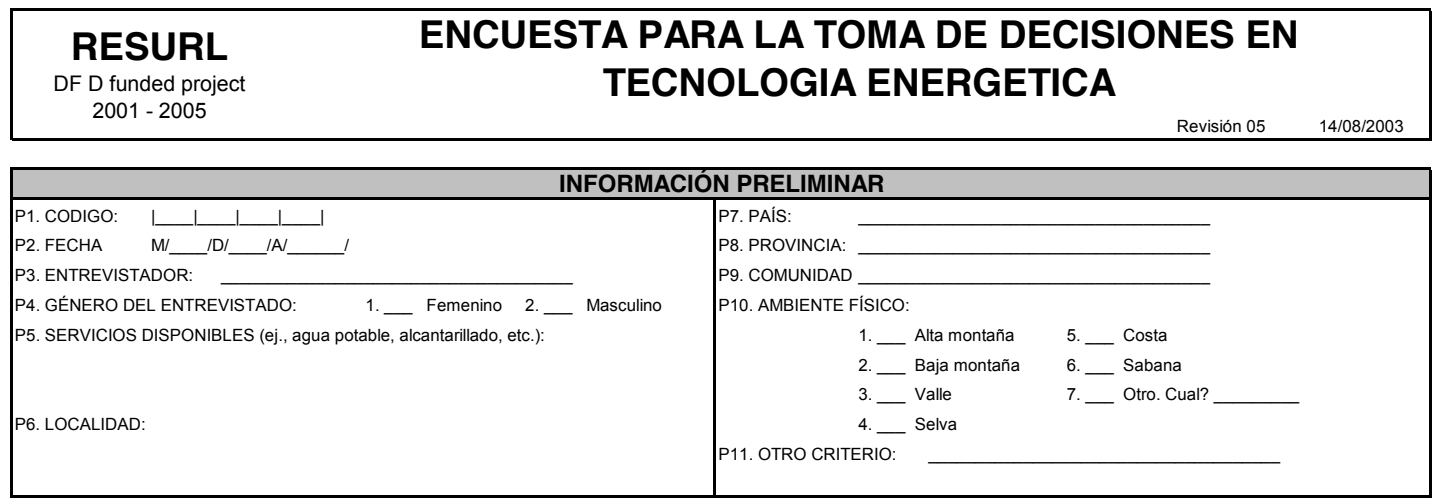

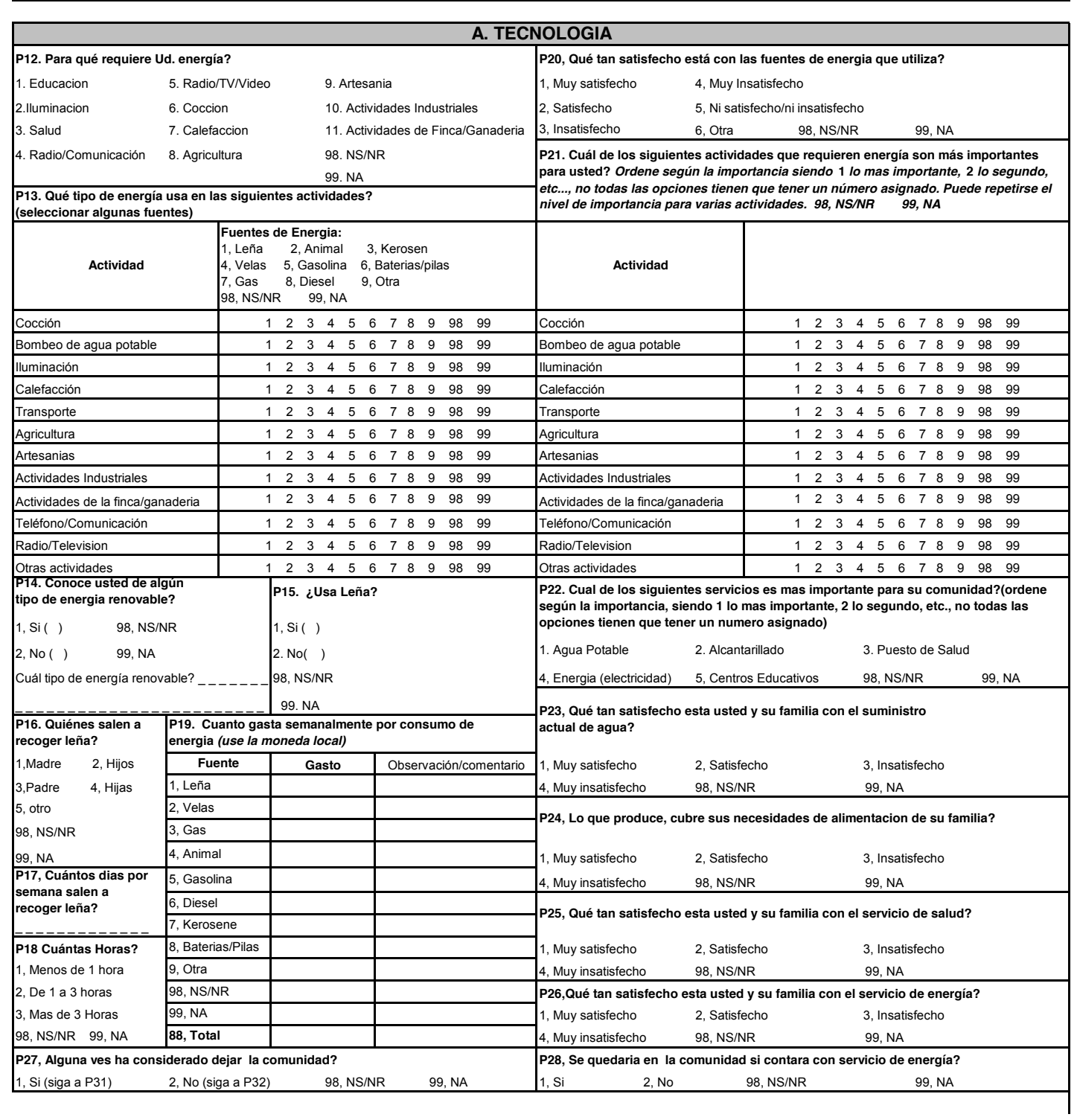


B. ASPECTOS MEDIO - AMBIENTALES

\begin{tabular}{|c|c|c|c|}
\hline \multirow{2}{*}{\multicolumn{2}{|c|}{$\begin{array}{l}\text { P29, Qué opina si usase algunos de los recursos siguientes para } \\
\text { producir energia? (referirse al recurso que existe en la zona) }\end{array}$}} & \multicolumn{2}{|c|}{ P31. Para qué usaria la leña entonces? } \\
\hline & & \multicolumn{2}{|c|}{ 1, Calefacción 2, Fogon al aire libre (fogata, hornos, caramicas) } \\
\hline 1, El Rio & & $98, \mathrm{NS} / \mathrm{NR}$ & $99, \mathrm{NA}$ \\
\hline 2, El Bosque & 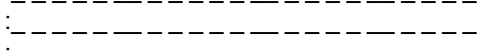 & \multirow{2}{*}{\multicolumn{2}{|c|}{$\begin{array}{l}\text { P32, Qué cambios en la naturaleza se han producido en su zona? } \\
\text { (ejemplo: llueve mas, mas arboles, menos fertilidad, etc.) }\end{array}$}} \\
\hline 3, El Lago & $:---------------------$ & & \\
\hline $\begin{array}{l}4, \text { La Cascada } \\
5, \text { La Tierra }\end{array}$ & :-ー-ー-ー---ー-ーー---ー-ー- & \multicolumn{2}{|c|}{$\begin{array}{r}--1- \\
-\end{array}-$} \\
\hline $\begin{array}{l}\text { 5, La Tierra } \\
\text { 6, La Montaña }\end{array}$ & --- & \multirow{2}{*}{\multicolumn{2}{|c|}{$\begin{array}{l}\text { P33, Se ha afectado la salud de alguno de los miembros de su familia } \\
\text { por el uso de los combustibles }\end{array}$}} \\
\hline $\begin{array}{l}\text { 7, Otro elemento especial } \\
98, N S / N R\end{array}$ & $:_{----}$ & & \\
\hline $99, \mathrm{NA}$ & & \multirow{2}{*}{$\begin{array}{l}\text { 1, Si Que tipo de enfermedad } \\
2, \text { No }\end{array}$} & \\
\hline \multicolumn{2}{|r|}{ si tuviera Kerosene o Gas? } & & --- \\
\hline I, $\mathrm{Si}$ & $98, \mathrm{NS} / \mathrm{NR}$ & $98, \mathrm{NS} / \mathrm{NR}$ & \\
\hline
\end{tabular}

\section{ASPECTOS SOCIO - ECONOMICOS}

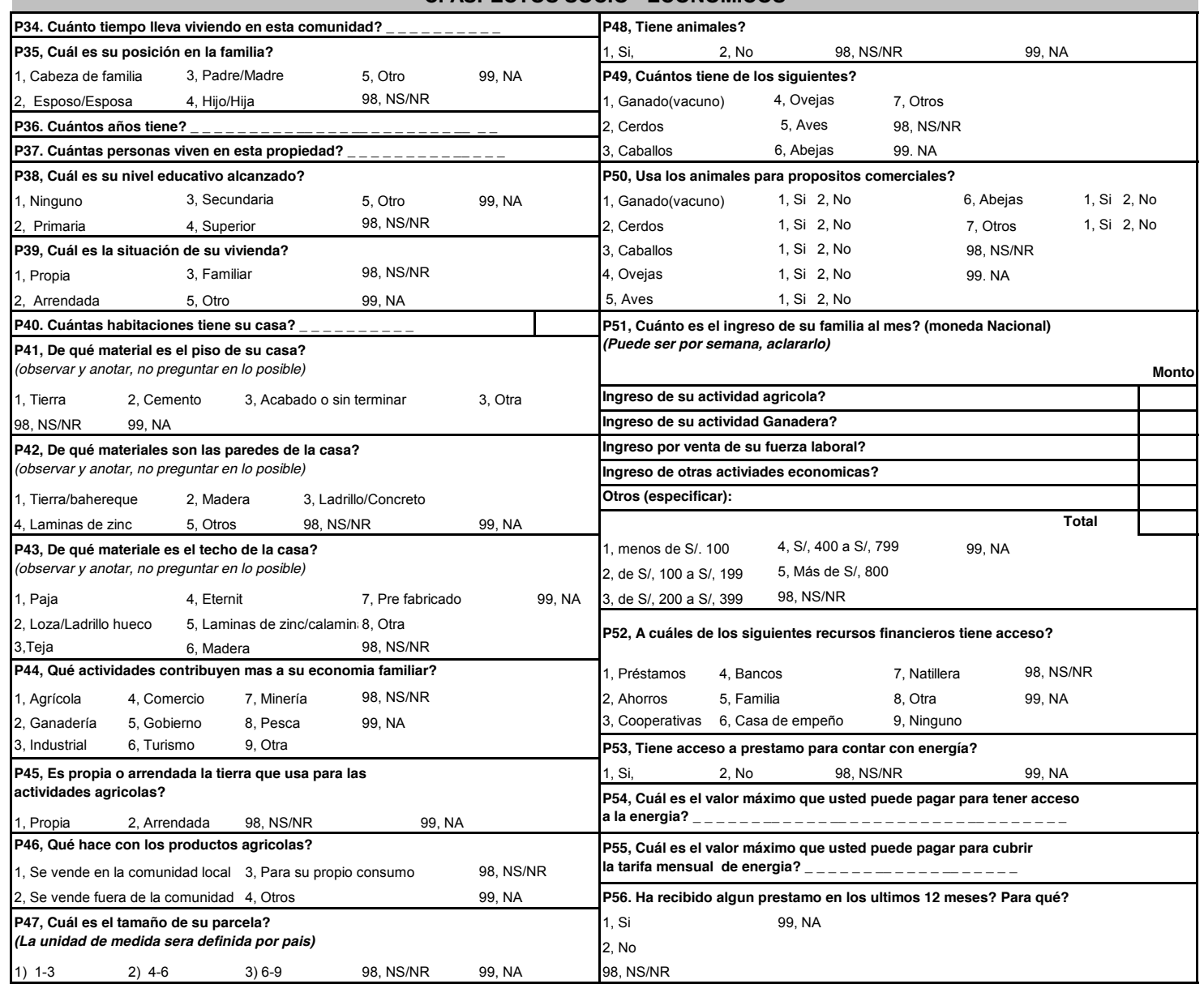




\section{ASPECTOS DE ORGANIZACIÓN}

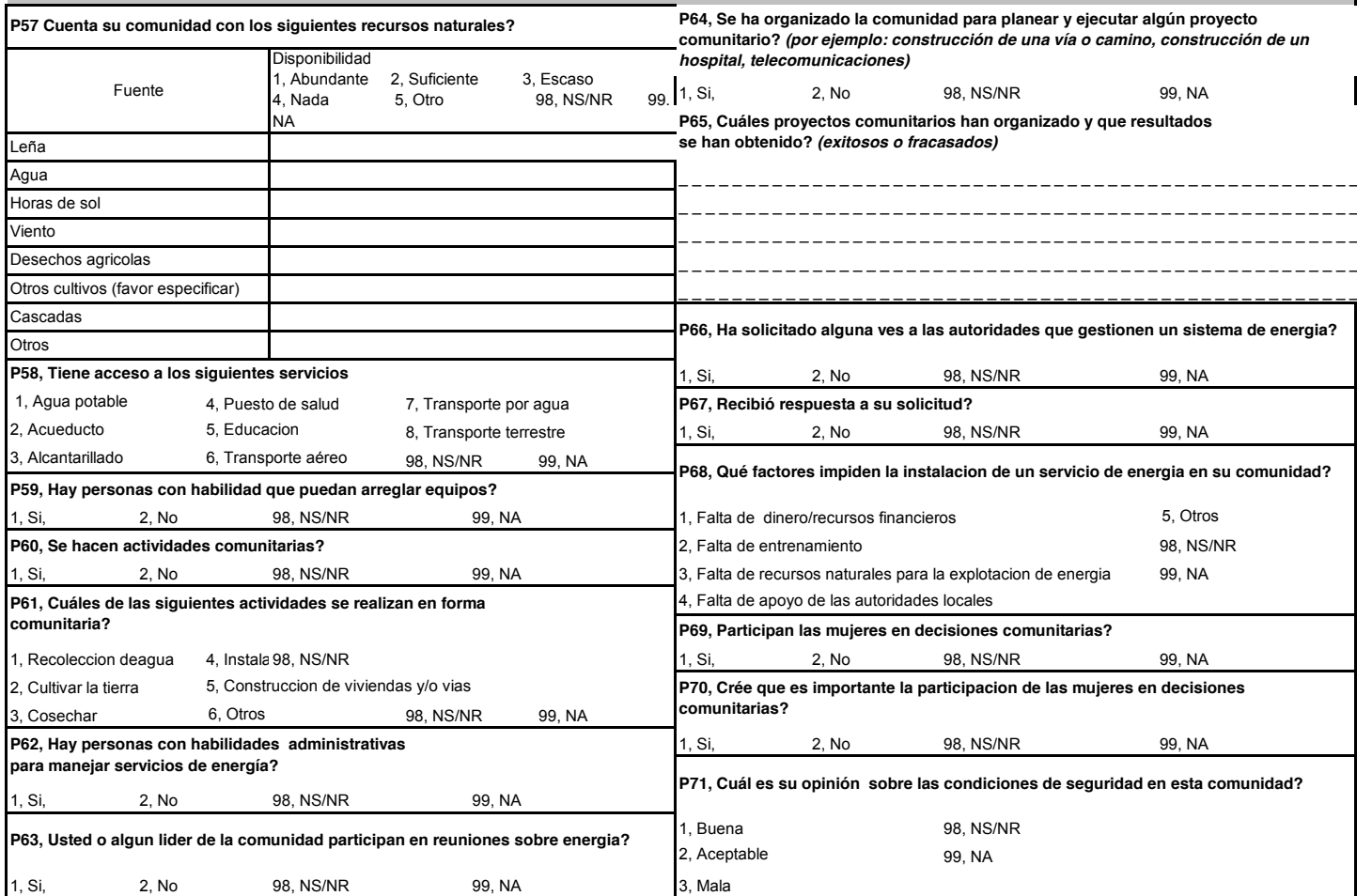

